\title{
Combustion in Homogeneous Charge Compression Ignition Engines: Experiments and Detailed Chemical Kinetic Simulations
}

Daniel L. Flowers

Ph.D Dissertation

U.S. Department of Energy

June 7, 2002

Lawrence

Livermore

National

Laboratory 


\section{DISCLAIMER}

This document was prepared as an account of work sponsored by an agency of the United States Government. Neither the United States Government nor the University of California nor any of their employees, makes any warranty, express or implied, or assumes any legal liability or responsibility for the accuracy, completeness, or usefulness of any information, apparatus, product, or process disclosed, or represents that its use would not infringe privately owned rights. Reference herein to any specific commercial product, process, or service by trade name, trademark, manufacturer, or otherwise, does not necessarily constitute or imply its endorsement, recommendation, or favoring by the United States Government or the University of California. The views and opinions of authors expressed herein do not necessarily state or reflect those of the United States Government or the University of California, and shall not be used for advertising or product endorsement purposes.

This work was performed under the auspices of the U. S. Department of Energy by the University of California, Lawrence Livermore National Laboratory under Contract No. W-7405-Eng-48.

This report has been reproduced directly from the best available copy.

Available electronically at http://www.doe.gov/bridge

Available for a processing fee to U.S. Department of Energy

and its contractors in paper from

U.S. Department of Energy

Office of Scientific and Technical Information

P.O. Box 62

Oak Ridge, TN 37831-0062

Telephone: (865) 576-8401

Facsimile: (865) 576-5728

E-mail: reports@adonis.osti.gov

Available for the sale to the public from

U.S. Department of Commerce

National Technical Information Service

5285 Port Royal Road

Springfield, VA 22161

Telephone: (800) 553-6847

Facsimile: (703) 605-6900

E-mail: orders@ntis.fedworld.gov

Online ordering: http://www.ntis.gov/ordering.htm

OR

Lawrence Livermore National Laboratory

Technical Information Department's Digital Library

http:/ / www.llnl.gov/tid/Library.html 


\title{
Combustion in Homogeneous Charge Compression Ignition Engines: Experiments and Detailed Chemical Kinetic Simulations
}

\author{
By
}

DANIEL LEE FLOWERS

B.S. (University of California, Davis) 1996

M.S. (University of California, Davis) 1997

\section{DISSERTATION}

Submitted in partial satisfaction of the requirements for the degree of

DOCTOR OF PHILOSOPHY

in

Engineering

in the

OFFICE OF GRADUATE STUDIES

of the

UNIVERSITY OF CALIFORNIA

DAVIS

Approved:

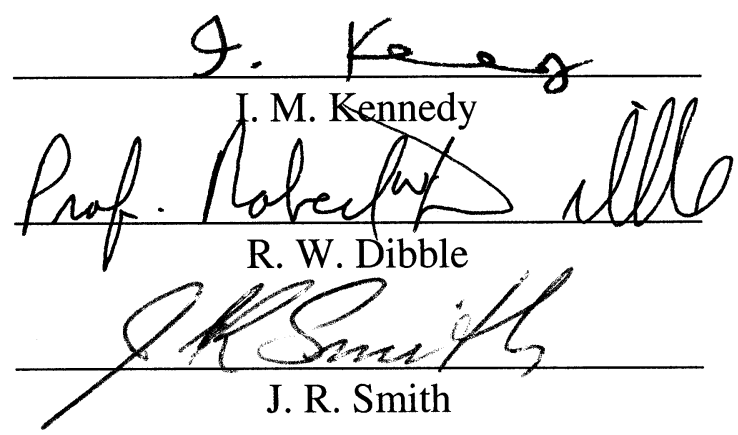

Committee in Charge 



\section{$\underline{\text { Abstract }}$}

Homogeneous charge compression ignition (HCCI) engines are being considered as an alternative to diesel engines. The HCCI concept involves premixing fuel and air prior to induction into the cylinder (as is done in current spark-ignition engine) then igniting the fuel-air mixture through the compression process (as is done in current diesel engines). The combustion occurring in an HCCI engine is fundamentally different from a spark-ignition or Diesel engine in that the heat release occurs as a global autoignition process, as opposed to the turbulent flame propagation or mixing controlled combustion used in current engines. The advantage of this global autoignition is that the temperatures within the cylinder are uniformly low, yielding very low emissions of oxides of nitrogen $\left(\mathrm{NO}_{\mathrm{x}}\right.$, the chief precursors to photochemical smog). The inherent features of HCCI combustion allows for design of engines with efficiency comparable to, or potentially higher than, diesel engines.

While HCCI engines have great potential, several technical barriers exist which currently prevent widespread commercialization of this technology. The most significant challenge is that the combustion timing cannot be controlled by typical in-cylinder means. Means of controlling combustion have been demonstrated, but a robust control methodology that is applicable to the entire range of operation has yet to be developed. This research focuses on understanding basic characteristics of controlling and operating HCCI engines. Experiments and detailed chemical kinetic simulations have been applied to the characterize some of the fundamental operational and design characteristics of HCCI engines. Experiments have been conducted on single and multi-cylinder engines to investigate general features of how combustion timing affects the performance and 
emissions of HCCI engines. Single-zone modeling has been used to characterize and compare the implementation of different control strategies. Multi-zone modeling has been applied to investigate combustion chamber design with respect to increasing efficiency and reducing emissions in HCCI engines. 


\section{Contents}

1. Introduction

2. Modeling of the HCCI engine combustion process

2.1 The fixed mass, variable volume reactor 2.1.1 Derivation of Governing Equations

2.1.2 Heat transfer sub-model

2.2 Single-zone modeling of HCCI combustion

2.3 Multi-zone modeling of HCCI combustion

2.3.1 Formulation of the governing equations

2.3.2 Coupling a CFD Solver with the multi-model for prediction of precombustion temperature histories

2.3.3 Determining zonal mass distributions for the multi-zone solver

3. HCCI Engine Simulations

3.1 Single-Zone Simulation Results

3.1.1 Effect of Fuel Composition on Combustion Timing

3.1.2 Control Methods for HCCI Engines

3.1.2.1 Dimethyl-Ether Additive Control

3.1.2.2 Inlet heating Control

\subsubsection{EGR Control}

3.1.2.4 Overall Discussion of Control Methods

3.2 Multi-zone Modeling of HCCI in VW TDI Engine Geometry

3.2.1 Comparison to Experimental Combustion Data

3.2.2 Effect of Geometry

3.2.3 Effect of Swirl

4. HCCI Combustion Experiments

4.1 Single-Cylinder HCCI Experiments

4.1.1 Experimental Setup

4.1.2 Single-Cylinder Experimental Results

4.1.3 Single-Zone Simulation of CFR Operating Conditions

4.2 Multi-Cylinder Experiments

4.2.1 Experimental Setup

4.2.2 Multi-Cylinder Engine Test Results

4.2.2.1 Overall Performance

4.2.2.2 Cylinder-by-Cylinder Operation

5. Conclusions and Discussion

References

Appendix A Definition and Calculation of Residual Gas Fraction 
- iv - 


\section{Acknowledgement}

Many wise and wonderful individuals have guided and supported me in the pursuit of this degree, Salvador Aceves, Bob Dibble, and Ray Smith being foremost among them.

Salvador has a keen intellect and an easygoing manner; he is always approachable and insightful. Dibble's court jester and carnival barker manner belies his scientific expertise and business sense, as well as his strong work ethic. Ray is uniquely able to delve into detailed technical issues and still maintain a vision of the larger scope; he never ceases to amaze me with his knowledge about seemingly every area of physical sciences. I am especially grateful to these three for their invaluable contributions to my education during the course of this research.

I wish to express my gratitude to Ian Kennedy, my research advisor at UC Davis, who supported this work and provided assiduous review of this dissertation. I need to thank my LLNL colleagues, Charlie Westbrook, Bill Pitz, Henry Curran, and Joel Martinez along with the UC Berkeley graduate students Michael Au, Jim Girard, and John Torres for their substantive contributions to this work. The Department of Energy Office of Transportation Technologies should also be acknowledged for supporting HCCI research in general, along with this specific research program at LLNL. Thanks to other LLNL individuals who have provided administrative, financial, and moral support for the degree program: Jens Mahler, Satish Kulkarni, Rich Couch, Rose McCallen, Harry Brandt, and Kathy Zobel. Last (but surely not least) I want to thank Helen Magann for her always expeditious, adept, and diligent administrative support. 
- vi - 


\section{Introduction}

The Homogeneous Charge Compression Ignition (HCCI) engine concept has lately become a subject of great interest to engine researchers. The driving force for this interest is the necessity to develop power systems that are highly efficient with little environmental impact. Current piston engine have technological hurdles that may limit opportunities to simultaneously achieve high efficiency and low emissions. The Diesel engine is well known for its high efficiency - due to high compression ratios and no need for throttling. But the highly stratified combustion in Diesel engines results in two major pollutants: oxides of nitrogen $\left(\mathrm{NO}_{\mathrm{x}}\right)$ and soot. The spark-ignited engine, using conventional hydrocarbon fuels, is able to operate with very low emissions when a 3way catalyst is employed. A practical $\mathrm{NO}_{\mathrm{x}}$ reducing catalyst for Diesel engines has yet to demonstrated for diesel engines. Efficiency in spark-ignition engines is limited by low compression ratio (due to knock limits) and the need for throttling to achieve a wide range in load.

It may be possible to make great strides in improving the performance and emissions of conventional engines, but it may also be possible that a radically different approach could sidestep the limitations of current technologies. The HCCI concept has the potential to meet the need for a high efficiency and low emissions engine. While the HCCI concept has great promise, there are still many technical barriers that currently prevent practical implementation. This research seeks to provide guidance in overcoming those barriers by using experimental and analytical means to investigate the fundamental characteristics of the HCCI combustion process. 
While HCCI was identified as a distinct combustion phenomenon about 20 years ago, earlier engines existed that fit the HCCI description. For example a recent article in the popular press refers to a 1950's era Lohmann bicycle motor that operates with no spark plug and no fuel injector [1]. The fuel and air was externally controlled and a hand-lever was used to actuate a screw that varied the compression ratio. A recent paper by Hilter et al. found evidence that in the 1900-1920 timeframe "'Oil vaporizing engines" were operated that also fit the HCCI description [2]. The inherent simplicity of an engine that does not require an in-cylinder fuel injector or spark plug would suggest that this concept would have been attempted during early engine development.

The initial papers of what might be considered the modern era of HCCI research recognized the basic characteristics of HCCI that have been validated many times since then: HCCI ignition occurs at many points simultaneously, with no requirement for flame propagation $[3,4]$. These studies were conducted in two stroke engines with high levels of recycled or trapped residual gas. Combustion was described as very smooth, with very low cyclic variations. Noguchi et al. also conducted a spectroscopic study of HCCI combustion and spark ignition combustion in the same engine [3]. In sparkignited operation the authors observed that the radicals appeared in a spatially distinct sequence throughout the combustion chamber. On the other hand, in HCCI combustion the radicals appear in the same temporal sequence throughout the combustion chamber. In other words, at some point in the combustion chamber of an engine undergoing conventional SI combustion, a certain time history of radicals can be observed. When moving to another point across the combustion chamber, the same or similar time history of radicals can be observed, but the radical time histories have different phasing 
in the cycle. This phasing difference exists because conventional SI engine combustion occurs due to propagation of a front in the combustion chamber. In the HCCI combustion process the radical time history observed is phased the same at different locations in the combustion chamber - thus combustion occurs at many points throughout the combustion chamber simultaneously, not subject to propagation of a front. Onishi et al. used Schlieren photography to visualize the combustion process in an engine operating in spark-ignited and HCCI modes [4]. The Schlieren imaging showed very distinct flame propagation during spark-ignited operation and no apparent flame propagation during HCCI operation. More recent studies using optical methodologies have resulted in similar findings [5-7].

Since this early work $[3,4]$, two-stroke engines with HCCI operation over part of their load range have been developed to the point of commercialization for motorcycles $[8,9]$. HCCI motorcycle engines have higher fuel economy, lower emissions and smoother combustion than 2-stroke spark-ignited engines. However, hydrocarbon (HC) and carbon monoxide emissions (CO) out of the HCCI engine are still very high compared with the current automotive emissions standards. An improved version of the engine has been recently evaluated, which shows improvements in fuel economy and emissions [10].

In 1983, Najt and Foster performed HCCI experiment with a four-stroke engine [11]. They also analyzed the process, considering that HCCI is controlled by chemical kinetics, with negligible influence from physical effects (turbulence, mixing). Najt and Foster used a simplified chemical kinetics model to predict heat release as a function of pressure, temperature, and species concentration in the cylinder. 
In 1989, Thring studied four-stroke, Diesel fueled, HCCI operation with control by varying the intake temperature and EGR fraction over a range of equivalence ratio [12]. The Diesel fueled HCCI engine achieved lower indicated specific fuel consumption than a conventional Diesel engine, although the energy needed for intake preheating was not accounted for in this assessment. Ryan and Callahan performed a more comprehensive study of HCCI with Diesel fuel looking at operation at different compression ratios [13]. Diesel appears poorly suited to HCCI because of the difficulty of evaporating Diesel fuel coupled with its propensity for autoignition. The intake charge must be preheated to nearly $200{ }^{\circ} \mathrm{C}$ to evaporate fuel in the intake manifold, but the compression ratio will have to be held to 6 or $8: 1$ in order to avoid severely advanced combustion.

Attempts have been made to overcome the problems of HCCI with Diesel fuel. Suzuki et al. looked at premixing some of the fuel in the intake and then direct-injecting the balance [14]. The main result was that $\mathrm{NO}_{\mathrm{x}}$ and soot decreased as more fuel was premixed, reaching a minimum when the fuel was fully premixed. The UNIBUS scheme of early injection of diesel fuel showed low $\mathrm{NO}_{\mathrm{x}}$ and soot relative to a diesel engine [15]. Unfortunately, better mixing of fuel and air required the injection timing to be advanced well ahead of top dead center. On the other hand, to get more ideal combustion timing (TDC or later) the injection had to be moved closer to TDC, essentially returning the engine to conventional Diesel mixing controlled combustion.

Takeda et al. investigated early injection of Diesel fuel using a novel staged injection scheme [16]. In this study a longer time between injection and ignition ("ignition delay") was achieved, and timing at or after TDC could be achieved with 60- 
70 crank angle degrees (CAD)of mixing time. The major difference between the two early injection papers may be the compression ratio - the UNIBUS [15] tests were conducted with 19:1 compression ratio engine while the Tekada et al. tests were conducted with a 16:1 compression ratio engine. Many investigations based on the early Diesel fuel injection are reported in the literature [17-24]. One of the major challenges of these schemes is that the early injection schemes are successful only at low load. Thus far, attempts to run at higher loads result in poor mixing and thus the combustion process becomes more like conventional diesel combustion.

Kimura et al. showed another method of handling Diesel fuel in a small displacement engine by using an HCCI-like mode (named the "MK" system by the authors) [25, 26]. A ramped fuel injection is performed at or after TDC allowing for some premixing of fuel and air prior to ignition. This work has demonstrated efficient, low $\mathrm{NO}_{\mathrm{x}}$ operation, but only under low-load conditions. Engines with small displacement per cylinder have unique challenges relative to larger displacement engines because of the heat transfer effect due to the typically higher ratio of combustion chamber surface area to volume, i.e. surface to volume ratio.

Many fuels have been studied for their performance in HCCI engines. Iida used a dual mode (spark-ignited/HCCI) two-stroke engine to investigate gasoline, methane, propane, methanol, ethanol, and dimethyl-ether [27]. The HCCI operation was conducted in a naturally aspirated engine with high levels of trapped residual gas ; the equivalence ratio was in a range of $0.7-1.2$, a regime where both flame propagation and HCCI could possibly be achieved. The high equivalence ratio was necessitated by the low 6:1 compression ratio of the engine. HCCI operation could not be achieved with 
methane and propane, and could be achieved with varying degrees of success with the other fuels. Gasoline, methanol and ethanol could be operated at low load in HCCI mode, but transition to spark ignition was necessary to achieve higher load. DimethylEther (DME) could only be operated in HCCI mode. At higher load or equivalence ratio severe knock would occur.

Thring and Leet looked at using early direct-injection of natural gas in what they called "Stratified Charge Glowplug Ignition (SCGI)." [28] The authors suggested that the ignition process might be similar to HCCI in that the natural gas was injected very early in the cycle and thus could be relatively well mixed by the time combustion begins. By utilizing a glowplug, ignition could be sustained down to very low equivalence ratio $(\phi<0.35)$. It can be debated whether this is truly a simultaneous multipoint autoignition process or simply a "hot-spot" initiated flame propagation process like the hot-tube ignition engines used in the 1890s-1910s. This concept showed cycleto-cycle variability, which runs counter to typical HCCI engines that typically manifest almost no cycle-to-cycle variation. This may suggest that turbulence and mixing may have a strong influence in the SCGI combustion process.

Researchers at the Lund Institute in Sweden have done a great deal of experimental work in four-stroke, single-cylinder, HCCI combustion [6, 7, 29-35]. Both naturally aspirated and supercharged operation have been studied using natural gas, isooctane and ethanol [35]. Moderate to high loads were achieved in this study: 14 bar imep for natural gas, 12 bar imep for ethanol and 10 bar imep for isooctane. $\mathrm{NO}_{\mathrm{x}}$ was very low over the entire operating range, but $\mathrm{HC}$ and $\mathrm{CO}$ emissions high. Another study looked at the same fuels in naturally aspirated mode but with variable EGR [34]. This 
work showed that increasing EGR for each of these fuels could further reduce $\mathrm{NO}_{\mathrm{x}}, \mathrm{HC}$ and $\mathrm{CO}$ emissions.

Recently the Lund group has operated a six-cylinder engine (in this case 1.95 L/cylinder) in HCCI mode [31]. The combustion process was adjusted using variable intake temperature and a dual-fuel configuration that allowed for variation of the fuel blend's autoignition characteristics (e.g. octane number). Engine speed was also varied. Brake Mean Effective Pressure (BMEP) between 1.5 and 6 bar was achieved and brake thermal efficiency ranged between 26 and 43\%. $\mathrm{NO}_{\mathrm{x}}$ emissions of under $20 \mathrm{mg} / \mathrm{kWh}$ were achieved up to 5 bar BMEP, but rose rapidly at higher load (up to 250-450 mg/kWh. A typical Diesel has much higher $\mathrm{NO}_{\mathrm{x}}$ emissions, on the order of 4000 $\mathrm{mg} / \mathrm{kW}-\mathrm{h})$.

A description of the HCCI process has gained acceptance: HCCI has been described as controlled by chemical kinetics, with little effect of turbulence. Gasses in the crevices and boundary layers are too cold to react completely, and result in HC and $\mathrm{CO}$ emissions. Combustion at homogeneous, low equivalence ratio ("lean") conditions, results in modest temperature combustion products, containing very low concentrations of $\mathrm{NO}_{\mathrm{x}}$ and particulate matter.

If this description holds, that the ignition process in HCCI engines is dominated by chemical kinetics, then the process should be very accurately modeled if accurate chemical kinetic mechanisms are used. Fortuitously, researchers have been working to develop and validate detailed chemical kinetic mechanisms for autoignition of hydrocarbon fuels [36-41]. 
Najt and Foster recognized the dominance of chemistry in this process and utilized a simplified chemistry model [11]. This model gave an average energy release rate that was well-correlated experimental data. This crude model was useful in predicting trends in the experimental data. There was relatively little modeling work in HCCI until the late 1990's when single-zone, well stirred reactor type models utilizing full detailed chemical kinetic mechanisms were implemented [35, 42, 43]. These singlezone simulations assume that everything within the combustion chamber is at uniform temperature, pressure and composition. Single-zone models typically do a good job predicting start of combustion and $\mathrm{NO}_{\mathrm{x}}$ emissions, but tend to overpredict indicated mean effective pressure (IMEP, essentially work normalize by engine displacement and engine speed), and peak cylinder pressure and severely underpredict burn duration, HC and $\mathrm{CO}$ emissions. The limitation of the single-zone model is that the cooler boundary layer and crevice regions are not accounted for. In the single-zone simulation either all fuel will react to completion or nothing will react. In a real engine the hottest core gasses will react first, compressing the boundary layer fluid and causing that to react. Also some of the mixture near walls and in crevices will not be hot enough to react in a real engine. Single-zone models have utility in predicting overall HCCI engine performance trends in response to variations in operating conditions or fuel properties.

This single-zone work emphasizes the need to capture the spatial variations of temperature within the combustion chamber. An innovative scheme, developed by Aceves et al., takes advantage of the lack of coupling between fluid mechanics and the ignition process in HCCI engines [44, 45]. This method uses a computational fluid dynamics code to predict the temperature-time history as a function of spatial location in 
the charge prior to ignition. A multi-zone kinetic code is used with a handful of computational zones to provide resolution of the different temperature regions within the combustion chamber. Validation studies comparing HCCI experiments and simulations using various fuels and engine geometries show excellent agreement in imep, peak cylinder pressure, and burn duration as well as good agreement in $\mathrm{HC}$ and $\mathrm{CO}$ emissions. In addition to these integrated cycle quantities, the instantaneous pressure and rate of heat release were matched very closely over the entire engine cycle. This methodology can be applied as a design tool to specifically address combustion chamber optimization.

Other multidimensional or multi-zone modeling simulations of HCCI combustion have been performed with varying degrees of success. Maigaard et al. used a stochastic reactor model, essentially a one spatial dimensional pdf-transport model with full chemistry, to simulate HCCI combustion [46]. The limitation of this model is that it is not directly coupled to the combustion chamber geometry; the boundary layer profile at some point during the compression stroke is specified. This method has been shown to capture the combustion process well, but the initial conditions can be tuned so that the results match the desired results. Other multi zone models have been developed. Fiveland and Assanis proposed a two-zone model to attempt to account for boundary layer and crevice effects [47]. A two-zone method may enhance system analysis type studies, but does not have enough resolution to be useful for combustion chamber design studies. In papers by Easley et al. [48] and Noda and Foster [49] multi-zone models of the HCCI combustion process have been developed using the Woschni correlation for heat transfer [50]. These models have utility for qualitative exploration of HCCI 
combustion, but the use of an empirical correlation for heat transfer limits the generality of the models.

Some researchers have suggested that turbulence must be accounted for in simulation of the combustion process in HCCI engines [51, 52]. This kind of analysis makes sense for early the early injection schemes, in which the mixture may not be truly homogeneous during ignition $[24,53]$. These simulations suffer from the fact that they are indistinguishable from simulations of conventional Diesel combustion, which have not yet been proven to be a reliable predictive tool.

Kong et al. applied applied KIVA-3V to simulations of HCCI combustion and concluded that a turbulence factor must be accounted for in the chemical reaction rates $[51,52]$. This seems to contradict the Aceves et al. papers that found excellent agreement with experiment when the effect of turbulence on reaction rates was neglected $[44,45]$. It may be that the Kong et al. work has a fundamental flaw in oversimplifying the chemical kinetics [51]. Although the authors utilized full kinetic mechanisms to determine time constants for the combustion process, they assumed that all reactions have the same chemical kinetic time constant. This time constant was based on the conversion rate of fuel. The autoignition process is so sensitive to small changes in individual species that this assumption likely misses key details in the combustion process. In order to match experimental data, an additional empirical tuning parameter was added to the experimental data to adjust the chemical timescale by a factor related to the turbulence scale. This tuning parameter is probably necessary to overcome incorrect chemical rates, not to account for turbulence effects. 
Multi-zone analysis of HCCI combustion for both propane and natural gas has given insight into the ignition process [44, 45]. The decomposition of hydrogen peroxide $\left(\mathrm{H}_{2} \mathrm{O}_{2}\right)$ "triggers" the ignition. $\mathrm{H}_{2} \mathrm{O}_{2}$ accumulates due to low temperature reactions during the compression stroke. At temperatures in the range of 1050-1100K the $\mathrm{H}_{2} \mathrm{O}_{2}$ decomposes rapidly into two hydroxyl $(\mathrm{OH})$ radicals, forming an enormous pool of $\mathrm{OH}$ radicals. This pool of radicals sets in motion a very effective chain branching sequence that rapidly consumes the fuel. $\mathrm{HC}$ and $\mathrm{CO}$ emissions are due to the coupling of between the chemistry and the in-cylinder temperature distribution. In regions of lower temperature, an insufficient population of $\mathrm{OH}$ radicals is produced, resulting in incomplete or very little conversion of the fuel contributing to high $\mathrm{CO}$ and HC emissions

Despite our physical understanding, a solution to the problems of operating a four-stroke engine in HCCI mode remains a challenge. The control issue appears to be most important. A general HCCI engine control strategy has not been identified, even for single-cylinder engines. Multi-cylinder operation provides an added level of complexity to the HCCI engine control problem, because each cylinder may need independent control. Single-zone detailed kinetic modeling has been demonstrated to be very useful for analysis of control strategies $[43,47,54,55]$. Some control systems that have been proposed are variable valve timing, variable compression ratio, thermal control, exhaust gas recirculation (EGR) control, and variable fuel composition control.

Fully variable valve-timing results appear promising for HCCI control [56, 57]. Variable valve actuation could effectively vary the engine compression ratio and be used to retain necessary residual gas to control timing. Residual gasses provide a readily 
available source of heat that can be used to adjust the temperature time history of the inducted mixture. Inexpensive, durable valve systems that allow for the precision timing adjustments that would be needed are not currently available. $\mathrm{B}$ - fuel control systems can be readily implemented $[58,59]$. In these systems, blending two fuels with different autoignition characteristics controls ignition timing. This kind of system works effectively to control timing over a small range, but would likely need to be coupled with another type of system (EGR or intake preheating) to obtain wide load range control. Also, these systems are somewhat impractical for production engines because of the system and infrastructure requirements imposed by requiring two fuels.

It is apparent that many efforts have been applied to development of HCCI engines. Most of the research performed has been experimental in nature and has typically looked at very specific implementation issues. The literature currently lacks a fundamental study of the basic characteristics of controlling and operating HCCI engines. The research reported in this Thesis aims to remedy this deficiency.

The application of experiments and detailed chemical kinetic simulations to the characterization of some of the fundamental operational and design characteristics of HCCI engines has been studied. Experiments have been conducted on single and multicylinder engines to investigate general features of how combustion timing affects the performance and emissions of HCCI engines. Single-zone modeling has been used to characterize and compare the implementation of different control strategies. Multi-zone modeling has been applied to investigate combustion chamber design with respect to increasing efficiency and reducing emissions in HCCI engines. 


\section{Modeling of the HCCI engine combustion process}

The key assumption in simulation of HCCI is that the combustion process is controlled solely by chemical kinetics. In other words, turbulent mixing does not affect the chemical reactions and heat release process during the main chemical heat release process. The justification for this assumption is that the combustion in HCCI engines is a global autoignition process, i.e. ignition occurs simultaneously at many points throughout the combustion chamber. Thus, the chemical reactions that yield the main heat release occur so rapidly that the turbulent mixing does not have time to influence combustion. Note that this assumption applies to truly homogeneous charge engines and may not be correct for engines that seek to use stratification to control start of ignition or burn duration.

The basis for the assumption that chemistry does not influence the heat release process comes from the fundamental nature of HCCI combustion. The Damköhler number, the ratio of turbulent time scales to chemical timescales, is considered to be a measure of the regime of combustion. Large Damköhler (>>1) number means that turbulent mixing is the rate-limiting process and therefore, in premixed flame propagation, the mixture at the flame front reacts almost instantly once mixing occurs. Small Damköhler number means that chemistry is the rate-limiting process and the relatively fast mixing causes the bulk mixture to have uniform composition during reaction. The chemistry that occurs in $\mathrm{HCCI}$ autoignition is identical to what occurs in a flame front - the key difference is that in the flame the cold mixture is brought up to an autoignition temperature by diffusion of radicals and heat into unreacted mixture. In 
HCCI the entire mixture is brought up to temperature at once by the compression process.

Prior to reaching the autoignition temperature the chemistry is slow and the regime is a very low Damkolher number "distributed reaction type regime." Once a sufficient radical pool is formed and the chain reactions begin to occur that result in the main heat release the chemistry accelerates to very fast. Since, during heat release, the bulk of the combustion chamber reacts simultaneously on very fast timescales (order of a few microseconds), the turbulent scales (order 1-10 milliseconds) are two slow to affect the heat release process.

If turbulence does not play a significant role in the heat release process, the modeling can be greatly simplified. The fluid flow can be decoupled from the turbulence and still yield accurate predictions. Two approaches are taken in the simulation of HCCI combustion: single zone and multi-zone methodologies. The term "zone" for the chemistry simulation refers to a computational domain with uniform temperature, pressure, and composition. Solving the time dependent response of this chemically reacting system involves solving a very stiff non-linear system of first order ordinary differential equations (ODEs). For each zone, the number of equations that must be solved is equal to the number of species, $\mathrm{S}$, plus one additional equation to account for the system thermodynamics, or $(\mathrm{S}+1)$. As the number of zones, $\mathrm{N}_{\text {zones }}$, increases, the solution time increases roughly by the number of equations squared, or $\left[\mathrm{N}_{\text {zones }}(\mathrm{S}+1)\right]^{2}$. Thus the computational time requirement increases significantly with increasing numbers of species and increasing numbers of zones. 
The single zone modeling approach treats the combustion chamber as a uniform temperature reactor and does not account for variations in temperature throughout the combustion chamber. This approach can be considered to be representative of the "core" of the combustion chamber gas mixture. The core is the hottest region of gas, surrounded by the thermal boundary layer. The highest temperature region is where the autoignition first initiates, so the core dictates the combustion timing in HCCI engines. Trends in work output, efficiency, and $\mathrm{NO}_{\mathrm{x}}$ emissions can be determined by analysis of the core zone, so single zone simulations can yield information on combustion timing control. The main advantage of the single zone modeling is that trends in combustion timing and performance can be determined with the minimum computational effort. The limitation of single zone modeling is that it does not account for the distribution in temperature throughout the combustion chamber. Temperature variations in the combustion chamber must be accounted for to capture boundary layer and crevice effects such as hydrocarbon and carbon monoxide emissions.

To account for variations in temperature throughout the combustion chamber, a multi-zone modeling methodology has been developed. This method couples a computational fluid dynamics solver with the multi-zone chemical kinetics solver in a novel way that requires only a handful of zones to solve the chemistry while hundreds of thousands of zones are used to solve the fluid flow. Although computationally more expensive than the single-zone model, the multi-zone method provides detailed information on distributed processes within the combustion chamber. 


\subsection{The fixed mass, variable volume reactor}

The system of equations that is solved in both the single and multi- zone HCCI combustion models is based on a fixed mass, variable volume reactor. Heat transfer can occur through the boundary of the reactor to the surroundings and work occurs at the boundary due to pressure-volume interaction.

\subsubsection{Derivation of Governing Equations}

The following assumptions are made in the derivation of the system:

1. The reactor has a fixed mass

2. All species are ideal gasses

3. Kinetic and potential energy are neglected

4. Temperature is uniform throughout the reactor

5. Work interactions consist of P-dV work at the boundary

The first law of thermodynamics for this system is:

$$
\delta Q-\delta W=d U
$$

As stated in assumption 5 above, the work is defined as $\delta W=P d V$. Taking time derivatives of eq. 2.1:

$$
\dot{Q}-P \frac{d V}{d t}=\frac{d U}{d t}
$$

The internal energy, $U$ is defined below with $n_{k}$ the number of moles of species $\mathrm{k}$ and $\bar{u}_{k}$ the molar specific internal energy of species $\mathrm{k}$, with $\mathrm{S}$ total species 


$$
U=\sum_{k=1}^{S} n_{k} \bar{u}_{k}
$$

and so,

$$
\frac{d U}{d t}=\sum_{k=1}^{S} \frac{d n_{k}}{d t} \bar{u}_{k}+\sum_{k=1}^{S} n_{k} \frac{d \bar{u}_{k}}{d t}
$$

The first sum on the right-hand side is related to the chemical reaction rates,

$$
\frac{d n_{k}}{d t}=V \dot{\omega}_{k}
$$

where $\dot{\omega}_{k}$ is the chemical production rate that can be extracted from codes like HCT [60] or CHEMKIN [61]. The second sum on the right hand side of eq. 2.4 is related to the specific heat and rate of change of temperature,

$$
\frac{d \bar{u}_{k}}{d t}=\frac{d \bar{u}_{k}}{d T} \frac{d T}{d t}=\bar{C}_{V, k} \frac{d T}{d t}
$$

Substituting back into eq. 2.2

$$
\dot{Q}-P \frac{d V}{d t}=V \sum_{k=1}^{S} \bar{u}_{k} \dot{\omega}_{k}+\frac{d T}{d t} \sum_{k=1}^{S} n_{k} \bar{C}_{V, k}
$$

The pressure is found from the ideal gas law,

$$
P=\left(\sum_{k=1}^{S}\left[X_{k}\right]\right) \bar{R} T
$$

The species equations are given by:

$$
\frac{d\left[X_{k}\right]}{d t}=\frac{d}{d t}\left(\frac{n_{k}}{V}\right)=\frac{1}{V} \frac{d n_{k}}{d t}-\frac{n_{k}}{V^{2}} \frac{d V}{d t}
$$

or 


$$
\frac{d\left[X_{k}\right]}{d t}=\dot{\omega}_{k}-\frac{\left[X_{k}\right]}{V} \frac{d V}{d t}
$$

Combination of the above equation results in a system of ordinary differential equations:

$$
\begin{aligned}
& \frac{d T}{d t}=\frac{\dot{Q}-\left(\sum_{k=1}^{S}\left[X_{k}\right]\right) \bar{R} T \frac{d V}{d t}-V \sum_{k=1}^{S} \bar{u}_{k} \dot{\omega}_{k}}{V \sum_{k=1}^{S}\left[X_{k}\right] \bar{C}_{V, k}} \\
& \frac{d\left[X_{k}\right]}{d t}=\dot{\omega}_{k}-\frac{\left[X_{k}\right]}{V} \frac{d V}{d t}
\end{aligned}
$$

The initial concentration and temperature must be specified. The unknowns in eq. 2.11 are the volume and derivative of volume and the heat transfer. These are accounted for differently in the single and multi zone models.

The overall volume change of the charge in the engine cylinder is a function of crank angle based on the so-called slider-crank formula, with $\mathrm{V}_{\mathrm{c}}$ the top dead center clearance volume, $\mathrm{r}_{\mathrm{c}}$ the compression ratio, and $\theta$ the instantaneous crank angle.

$$
\begin{gathered}
\frac{V}{V_{c}}=1+\frac{1}{2}\left(r_{c}-1\right)\left[R+1-\cos (\theta)-\sqrt{R^{2}-\sin ^{2} \theta}\right] \\
R=\frac{2(\text { connecting rod length })}{\text { Stroke }}
\end{gathered}
$$

The rate of change of volume is obtained by analytically differentiating eq. 2.12:

$$
\frac{1}{V_{c}} \frac{d V}{d t}=\frac{1}{2}\left(r_{c}-1\right)\left[\sin \theta+\frac{\sin \theta \cos \theta}{\sqrt{R^{2}-\sin ^{2} \theta}}\right] \frac{d \theta}{d t}
$$

Note that $\frac{d \theta}{d t}$ is simply the engine rotational speed. Within a single zone the instantaneous volume and volume rate of change will be specified by eqs. 2.12 and 2.13. 


\subsubsection{Heat transfer sub-model}

A heat transfer model is incorporated into both the single zone model and multizone model. This model is based on the Woschni correlation [50]. This is an empirical model of the heat transfer coefficient in an engine based on correlating data from a variety of engines. The rate of convective heat transfer is given by:

$$
\dot{Q}=h A_{s}\left(T-T_{w}\right)
$$

The heat transfer coefficient, $h\left(W / \mathrm{m}^{2} \mathrm{~K}\right)$, is defined by:

$$
\begin{aligned}
& h=129.8 B^{-0.2} P^{0.8} T^{-0.55} w^{0.8} \\
& w=C_{1} \bar{S}_{p}+C_{2} \frac{V_{d} T_{r}}{P_{r} V_{r}}\left(P-P_{m o t}\right) \\
& C_{1}=2.28+0.308 \cdot \text { Swirl } \\
& C_{2}=\left\{\begin{array}{cc}
0.0 & \text { for compressio } \mathrm{n} \\
3.34 \cdot 10^{-3} & \text { for combustion and expansion }
\end{array}\right.
\end{aligned}
$$

where B is the cylinder bore (m), $\mathrm{P}$ is cylinder pressure (bar), and $\mathrm{T}$ is cylinder temperature $(\mathrm{K})$. The average cylinder gas velocity $(\mathrm{w}, \mathrm{m} / \mathrm{s})$ is defined based on mean piston speed, $\left(\bar{S}_{p}, \mathrm{~m} / \mathrm{s}\right)$, displacement volume $\left(\mathrm{V}_{\mathrm{d}}, \mathrm{m}^{3}\right)$, and reference temperature $\left(\mathrm{T}_{\mathrm{r}}\right.$, $\mathrm{K})$, pressure $\left(\mathrm{P}_{\mathrm{r}}\right.$, bar), and volume $\left(\mathrm{V}_{\mathrm{r}}, \mathrm{m}^{3}\right)$. The reference conditions are typically taken at bottom dead center or intake valve closure. $\mathrm{C}_{1}$ and $\mathrm{C}_{2}$ are empirical constants, and Swirl is the swirl ratio for the engine. The swirl ratio is a measure of the initial axial rotational speed of the fluid within the cylinder relative to the engine speed and is considered constant for a particular engine. The motoring pressure $\left(\mathrm{P}_{\mathrm{mot}}\right.$, bar) is determined by solution of the $1^{\text {st }}$ law for the fixed mass non-reacting system in an engine along with the ideal gas law: 


$$
\frac{d P_{m o t}}{d t}=\left(\gamma_{m o t}-1\right) \frac{\dot{Q}_{m o t}}{V}-\gamma_{m o t} \frac{P_{m o t}}{V} \frac{d V}{d t}
$$

The heat transfer rate, $\dot{Q}$, is determined from eq. 2.15, noting that the second term of $w$ is zero because $\mathrm{P}$ is equal to $\mathrm{P}_{\mathrm{mot}}$. Note that the specific heat is not constant in the eq. 2.16, but varies with temperature.

\subsection{Single-zone modeling of HCCI combustion}

The single-zone model used for simulation of HCCI combustion is spatially zero-dimensional with chemistry handled by utilizing a high "dimension" in species so-called detailed chemical kinetic mechanisms that account for many elementary reaction steps. A premixed charge at uniform temperature and pressure is compressed and expanded at a rate that depends on the engine speed and geometry. As stated earlier, this kind of model cannot capture the multidimensional processes that occur in a real engine cylinder, but, since the heat release is a global non-propagating autoignition process, a zero-dimensional model can reasonably capture the start of combustion of the core mixture. Since the start of combustion of the central core dictates the overall process, control of this combustion timing will control performance.

Single zone simulation is performed by solving the ordinary differential equation (ODE) system in eq. 2.11 using equations 2.12 and 2.13 for the volume and volume rate of change. The Woschni heat transfer coefficient (eq. 2.15) is used to determine heat transfer throughout the cycle. Rate chemistry can be handled using a detailed kinetics code such as HCT (Hydrodynamics, Chemistry and Transport [60]) or a simulation code based on CHEMKIN chemistry and species data [61]. In this research the HCT code has been used for single-zone simulations. HCT has been used in a large number of 
investigations over the years, and in particular was used in past studies of engine knock and autoignition [36-38]. The HCT code permits the use of a variety of boundary and initial conditions for reactive systems, depending on the needs of the particular system being examined. In the single zone case, the relevant conditions are those that describe the bulk gases in the combustion chamber.

Autoignition of a homogeneous charge is virtually identical to the knock process that can occur in the Otto cycle engine. From detailed kinetic modeling of motored engines using a homogeneous charge of a variety of fuels, it is known that the controlling parameters in the initiation of this process are the fuel components (mixtures behave differently than neat fuels), and the temperature and density history that the fuelair mixture experiences. Motored engine experiments at General Motors Research Laboratories $[38,39]$ agree well with HCT simulation of this process. Thus if the precise conditions at the start of compression are known (species, temperature and pressure), the beginning of combus tion can be accurately predicted.

During an engine cycle, a number of processes occur which influence the time variation of the temperature and pressure of the bulk reactive gases in the combustion chamber. Piston motion first compresses (and heats) the bulk gases and then expands (and cools) them. During this time chemical reactions may release heat and change the overall composition of the gases. Fresh unreacted fuel and air are added to hot residual gases left over from the previous cycle. Residual gases from previous engine cycles, which consist largely of water vapor, $\mathrm{CO}_{2}$, and molecular nitrogen and oxygen are assumed fully mixed with the fresh charge. In addition, heat losses to the engine 
chamber walls, blowby, fuel trapping in crevice volumes, and other processes occur. In the current simulations only heat transfer losses are taken into account.

The computational model treats the combustion chamber as a homogeneous reactor with a variable volume. The mixed temperature of the residual gases and the fresh charge is estimated by a published procedure [62].

The present analysis considers a single zone, lumped model that ignores spatial variations in the combustion chamber, treating heat loss as a distributed heat transfer rate, proportional to the temperature difference between the average gas temperature and a time-averaged wall temperature. It is recognized that this is a great oversimplification of the actual condition within the combustion chamber. In particular, the boundary layer, which contains significant mass (5-10\%), must be at a lower temperature than the bulk gas near TDC. Due to the assumed temperature uniformity, estimates of burn duration and the heat release processes will be shorter than in experiments. That is, the boundary layer and crevices will always react last and extend the heat release rate compared to this single-zone simulation. Peak cylinder pressure and rate of pressure rise are thus overestimated with the current single-zone model, and the model cannot accurately predict $\mathrm{CO}$ and hydrocarbon emissions, which primarily depend on the boundary layer and crevices. Predictions of the start of combustion and $\mathrm{NO}_{\mathrm{x}}$ concentrations, which depend on the peak temperature of the core gases inside the cylinder, have been shown to be determined with reasonable accuracy [43]. 


\subsection{Multi-zone modeling of HCCI combustion}

\subsubsection{Formulation of the governing equations}

A multi-zone modeling methodology has been developed that allows for indirect coupling of geometry specific information from a computational fluid mechanics simulation with detailed chemistry. The computational effort required is significantly reduced with the indirect coupling relative to direct coupling. Further discussion of the indirect coupling method will be provided in the next section. The five assumptions listed in Section 2.1 apply to multi-zone modeling along with these additional assumptions:

6. Pressure is uniform in all zones

7. No heat transfer between zones, but heat transfer can occur between each zone and the surroundings

8. No mass transfer between zones

The derivation of the multi-zones model is based upon a piston-cylinder assembly model with multiple arbitrarily shaped fixed-mass reactors. The sketch below shows the idealized system used for multi-zone simulation. The mass is divided up into fixed mass zones based on the temperature distribution within the combustion chamber prior to combustion. Information from the CFD code related to spatial location of mass at specific temperatures is not used in the chemistry solution. These zones can change volume but allow no mass transfer through their boundaries. 


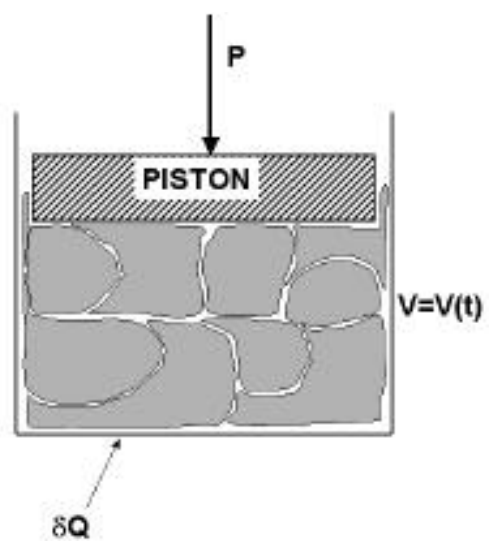

The first law of thermodynamics can be applied to the fixed mass system of zone $\mathrm{j}:$

$$
\delta Q_{j}-\delta W_{j}=d U_{j}
$$

For a simple compressible substance the work in zone $\mathrm{j}$ is defined as:

$$
\delta W_{j}=P d V_{j}
$$

The rate of change of internal energy is developed as follows:

$$
\begin{aligned}
& U_{j}=\sum_{i=1}^{S} m_{i j} u_{i j} \\
& d U_{j}=\sum_{i=1}^{S} m_{i j} d u_{i j}+\sum_{i=1}^{S} d m_{i j} u_{i j} \\
& d m_{i j}=M_{i j} d n_{i j} \\
& d n_{i j} \equiv V_{j} \dot{\omega}_{i j} d t \\
& \sum_{i=1}^{S} m_{i j} d u_{i j}=\sum_{i=1}^{S} m_{i j} c_{V i j} d T_{j}=m_{j} c_{V j} d T_{j} \\
& d U_{j}=m_{j} c_{V j} d T_{j}+\sum_{i=1}^{S} u_{i j} M_{i j} V_{j} \dot{\omega}_{i j} d t
\end{aligned}
$$

The first law of thermodynamics for this system becomes:

$$
\delta Q_{j}-P d V_{j}=m_{j} c_{V j} d T_{j}+\sum_{i=1}^{S} u_{i j} M_{i j} V_{j} \dot{\omega}_{i j} d t
$$


The ideal gas equation of state is differentiated:

$$
\begin{aligned}
& P V_{j}=\sum_{i}^{S} n_{i j} \bar{R} T_{j} \\
& V_{j} d P+P d V_{j}=\sum_{i}^{S} n_{i j} \bar{R} d T_{j}+\bar{R} T_{j} \sum_{i}^{S} d n_{i j} \\
& V_{j} d P+P d V_{j}=m_{j} \frac{\bar{R}}{M_{j}} d T_{j}+\bar{R} T_{j} V_{j} \sum_{i=1}^{S} \dot{\omega}_{i j} d t
\end{aligned}
$$

The zonal volumes and volume derivatives can be related to the total cylinder volume and volume derivative given in equations 2.12 and 2.13.

$$
\begin{aligned}
& \sum_{j=1}^{N_{\text {ZONES }}} V_{j}=V(t) \\
& \sum_{j=1}^{N_{\text {ZONES }}} \frac{d V_{j}}{d t}=\frac{d V(t)}{d t}
\end{aligned}
$$

Equations 2.17-2.20 are a complete set of equations for solution of this system. The first step is to combine equations 2.17 and 2.18 so that the $d T_{j}$ terms are eliminated. The next step is to sum all terms over $\mathrm{j}$ so that equations 2.19 and 2.20 can be used. The resulting equation is:

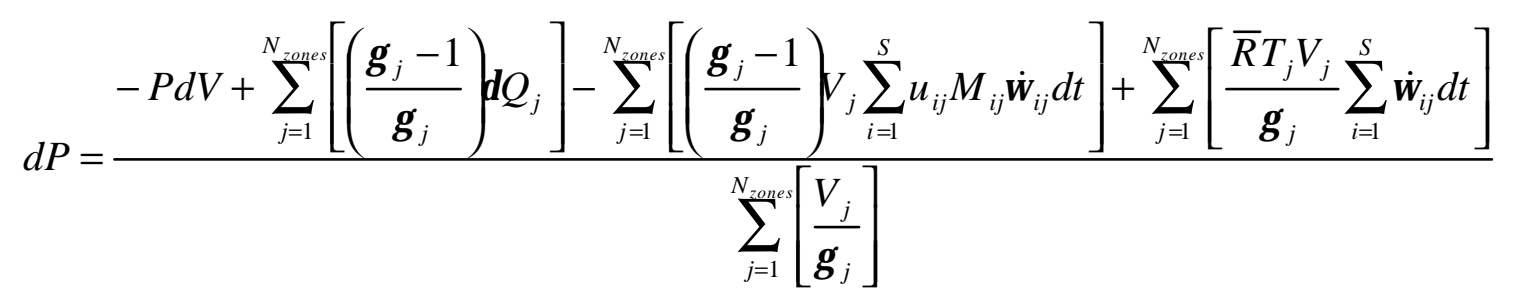

Once $d P$ is known the zonal temperature derivatives are determined by:

$$
d T_{j}=\frac{\delta Q_{j}+d P-\sum_{i=1}^{S} h_{i j} M_{i j} \dot{\omega_{i j}} d t}{\rho_{j} c_{p j}}
$$


The change in mass fraction of each species is then determined:

$$
d Y_{i j}=\frac{1}{\rho_{j}} M_{i j} \dot{\omega}_{i j} d t
$$

The heat transfer correlation given in equation 2.15 can be used along with the motored pressure determined by solution of equation 2.16. For a system with $\mathrm{N}$ zones and S species, equations $2.21-23$ and 2.16 result in an system with $2+\mathrm{N}(\mathrm{S}+1)$ ordinary differential equations. It is important to note that the main coupling of this system occurs in the pressure differential equation (2.21). The coupling of the temperature and species mass fraction between zones essentially occurs only through the pressure term.

\subsubsection{Coupling a CFD Solver with the multi-model for prediction of pre- combustion temperature histories}

The kinetics of autoignition, and therefore the ignition process in HCCI engines, has an exponential dependence on temperature [67]. Empirical heat transfer correlations, such as the one given in equation 2.15 , give inadequate information on the spatial distribution of temperature within the combustion chamber. The physics of HCCI combustion could be simulated very well by directly adding detailed kinetic chemistry to a computational fluid dynamics solver that handles turbulent flow and heat transfer. Unfortunately, for most fuels of practical interest (hydrocarbons) the number of species required to accurately simulate the chemical kinetics HCCI process is on the order of 100-1000 species. Thus each computational zone in the CFD code would be required to add 100s to 1000s of unknowns (the species). The number of zones necessary to resolve the flow sufficiently within an engine combustion chamber ranges from tens of thousands to millions. The computational resources required for the 
simulation of directly coupled flow and detailed chemistry quickly exceeds the capabilities of even the fastest computers available today.

But HCCI is different from conventional engine combustion processes because the chemical reactions are not intimately coupled to the turbulent mixing processes such as those that occur in spark ignited and diesel combustion. Turbulent flow and heat transfer mainly influence the initiation of the autoignition process by the temperature time history that is imposed on the gasses within the chamber. Prior to the main heat release the chemistry does not influence the fluid mechanics. Once heat release begins, the chemistry does have a significant influence on the flow through the pressure and temperature rise in the combustion chamber. But, the autoignition heat release process occurs so rapidly that the flow does not have sufficient time to be affected by the chemical heat release. After the main heat release, turbulent diffusion of combustion products is likely more coupled, but little heat is released. The three distinct different conditions that can be hypothesized are summarized below and in Figure 2.3.1:

- Pre-combustion: Flow dominates; relatively little change in species (mostly trace amounts of radical species formed).

- Combustion: Chemistry dominates; heat release occurs so rapidly and globally that turbulent mixing does not have time to be a significant influence.

- Post-combustion: Chemistry and turbulent mixing are likely to have some coupling, but no chemical heat release occurs 
This description of the HCCI combustion process gives a guide to simplifications that can be made to model the process using CFD with chemistry. The flow and chemistry in the pre-combustion and combustion phases are essentially decoupled. In the post combustion phase, the mixing of unreacted or partially reacted portions of the mixture with the hotter fully reacted mixture likely will result in some additional oxidation. It is assumed that the post combustion mixing effects are negligible. Neglecting the post combustion species transport could lead to some inaccuracy in prediction of hyd rocarbon and carbon monoxide emissions, but this is likely minor. The most important area of concern in the development of a predictive model is simulation of the pre-combustion and combustion processes.

A methodology has been developed that takes advantage of the decoupling of chemistry and fluid mechanics in the pre-combustion and combustion phases. The procedure, as described here, applies to a well-mixed charge, although it could be modified to run for a non-homogeneous composition. Figure 2.3.2 illus trates the overall sequence of calculations. The procedure is started by making a KIVA-3V [64] run for motored (no heat release) conditions. KIVA-3V is a finite-volume fluid mechanics and heat transfer code specially designed for engine simulations. The code uses a special grid modification strategy that deactivates elements in the direction of piston motion as the piston moves from BDC to TDC in the compression stroke and then reactivates them during expansion. Turbulence is handled using an unsteady $\mathrm{k}-\varepsilon$ model in both momentum and thermal transport equations [65]. KIVA-3V is used in its original form, with no modifications to the physical models. The resulting temperature distribution, shown in Figure 2.3.2(a), is then converted into a temperature-mass distribution. The 
temperature-mass distribution gives the fraction of the total mass in the cylinder that has a certain temperature. Figure 2.3.2(b) shows a typical temperature mass distribution at $5^{\circ}$ BTDC and a cumulative mass distribution, which indicates the fraction of the mass that is colder than a specified temperature T. The mass within the cylinder is then divided into zones. The number of zones is selected, as well as a mass distribution within the zones. Figure 2.3.2(b) also shows the distribution of zones in the temperature domain. In this example the mass within the cylinder has been divided into 10 zones. Zone average temperatures and boundaries are indicated by dots and lines. The figure indicates that zones 1-5 occupy a wider range of temperature than zones 6-10, even though they include a much smaller fraction of the total mass.

The temperature mass distributions are then used for assigning a temperature history to the ten zones. From the temperature distributions, zone 1 receives the average temperature of the coldest $1 \%$ of the mass, zone 2 has the temperature of the next coldest $1 \%$, and so on until zone 10 , which has the average temperature of the hottest $40 \%$ of the mass. This calculation is repeated for multiple crank angles to determine the temperature history for the zones. Figure 2.3.2(c) shows a temperature history for each of the 10 zones. The temperatures calculated from KIVA-3V are used only until ignition is achieved. Figure 2.3.2(c) also shows that the temperature of some zones (1-4) drops during the compression stroke due to heat transfer to the wall.

The final step consists of making a detailed chemical kinetic analysis of the process with the multi-zone model to calculate all combustion parameters, including pressure, burn duration, heat release, efficiency, emissions, radical concentration (Figure 2.3.2(d)) and all the details about the chemical kinetics of HCCI combustion. The 
temperatures of the zones for the multi-zone run are specified by the temperature histories obtained from KIVA-3V (Figure 2.3.2(c)). These temperature histories are the geometry-specific information that is handed from KIVA-3V to multi-zone model to link the two codes and yield results that fully consider the effect of both fluid mechanics and chemical kinetics.

An important issue with the multi zone run is chemical heat release. It is clear that the temperature histories calculated from KIVA-3V for a motored engine are not valid if substantial heat release occurs. For this reason, the KIVA-3V temperature distribution is followed only until a certain amount of chemical heat release has taken place. At this moment, the KIVA-3V temperature histories are abandoned, and instead temperatures determined from multi zone model with the Woschni heat transfer correlation (eq. 2.15, [50]) are used until the expansion. The transition between KIVA3V and HCT temperatures is illustrated in Figure 2.3.2(c) by a vertical line and a sudden change in slope in the temperature lines.

\subsubsection{Determining zonal mass distributions for the multi-zone solver}

The selection of zones for a multi-zone simulation are performed so that the temperature history regimes of the combustion process are accounted for. A methodology has been developed that allows for arbitrary selection of the number of zones. An example based on a simulation of the Volkswagen TDI combustion chamber geometry will be used to illustrate this methodology. Figure 2.3.3 shows results from an axis-symmetric KIVA-3V simulation of the VW TDI combustion chamber during a motoring simulation of the compression stroke. The left hand side of the figure shows the computational grid and the right hand side shows a pseudocolor plot of temperature 
throughout the chamber at $10^{\circ}$ BTDC. The simulation was performed using KIVA-3V with a relatively coarse 40,000 cell (at BDC) grid. KIVA output has been modified to write out the mass/temperature distribution within the combustion chamber at several crank angle intervals during the engine cycle.

Figure 2.3.4 shows the cumulative mass fraction within the combustion chamber for this case plotted with respect to the temperature at $10^{\circ} \mathrm{BTDC}$. The temperature shown is actually the average temperature in $0.5 \%$ mass fraction bins. The cumulative mass fraction is shown with both a linear scale (Figure 2.3.4(a)) and log scale (Figure 2.3.4(b)). This is a typical distribution found from the motoring simulation. Figure 2.3.4(b) shows that there are essentially two parts of the distributions, a flat distribution at lower temperature and a steeper distribution at the higher temperatures. A good fit to these two parts is to use a linear fit for the flatter section an exponential fit for the steeper section. The procedure that is used to fit this data works as follows:

- $\quad$ First assume the logarithmic profile holds from zone 1 to the final zone.

- Check the zone mass distributions starting with zone 1 and make sure that the mass fraction in each zone is above a certain threshold (typically $0.5-1 \%$ is used for this threshold)

- If a particular zone is specified with less mass by this logarithmic distribution, then that zone and all prior zones are assigned the threshold value - $\quad$ Repeat for all zones

Figure 2.3.5 shows this method applied for 10, 20 and 50 zones to the temperature distribution in Figure 2.3.4 for a $0.5 \%$ threshold value. The method does a very nice job of fitting the shape of the curve. The resolution on the flat part of the 
curve is essentially determined by the threshold value and the resolution on the rest of the distribution is a function of the number of zones. 


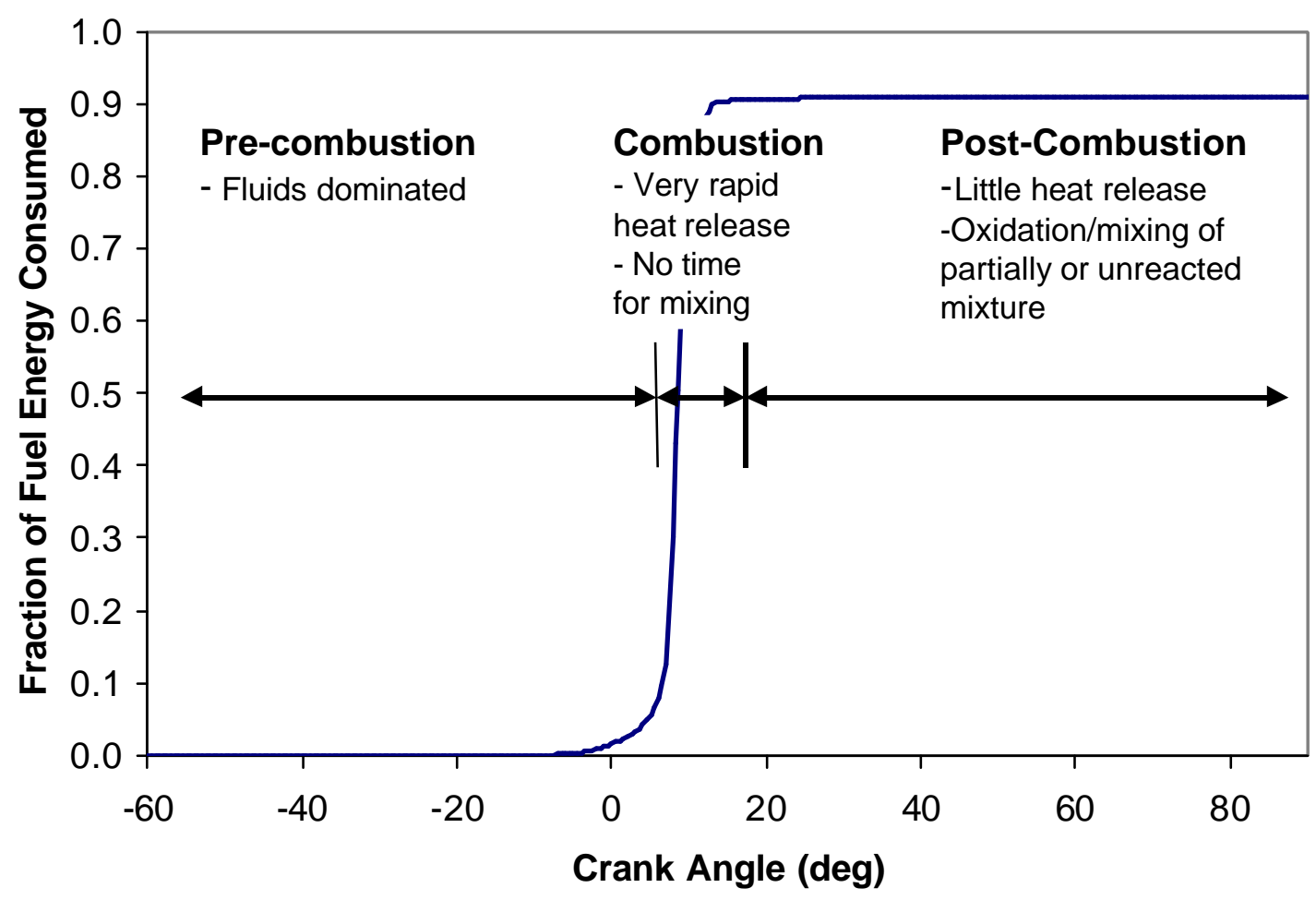

Figure 2.3.1 - Pressure versus crank angle for an HCCI engine cycle. Three regions are labeled with regard to the coupling of chemistry and fluid mechanics. 


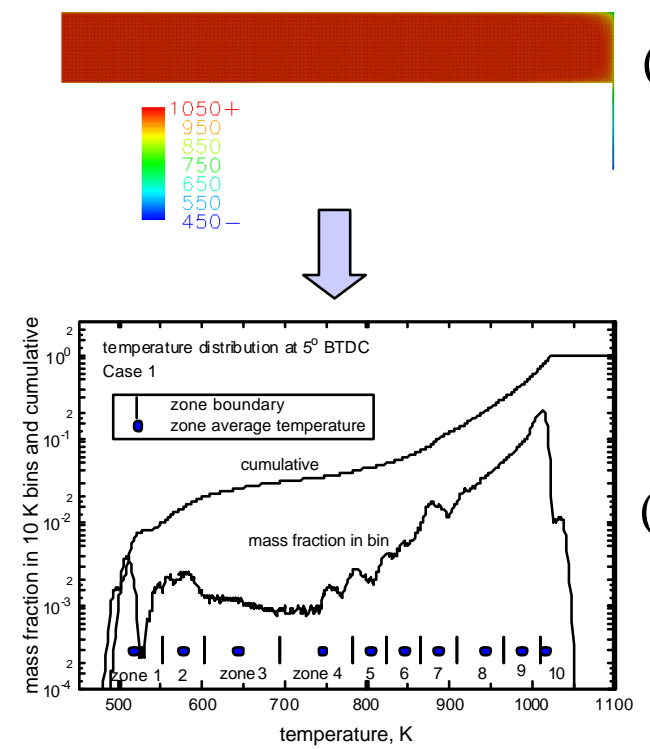

(a)

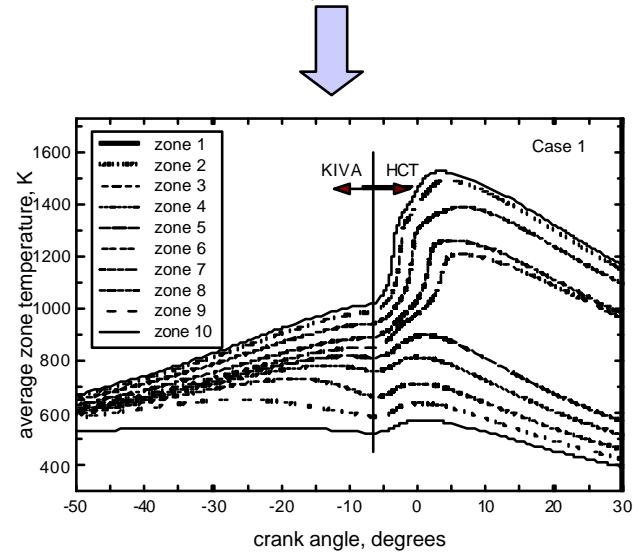

(b)

(c)
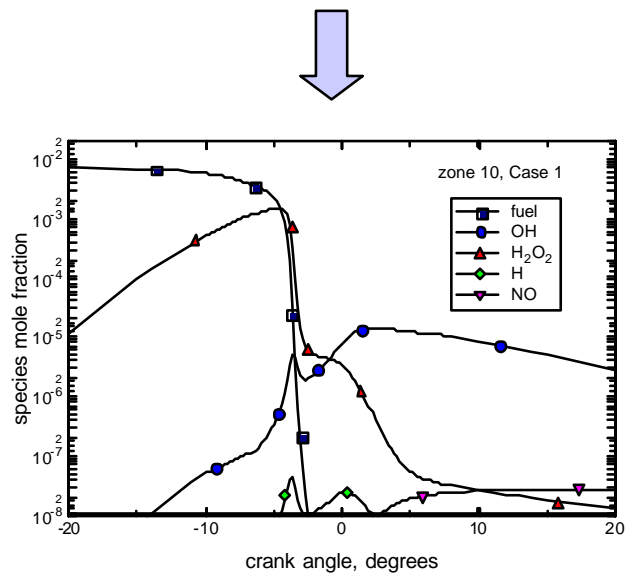

(d)

Figure 2.3.2 - The main steps in the sequential multi-zone analysis of HCCI combustion. (a) Calculation of temperatures inside the cylinder from KIVA-3V. (b) Calculation of mass distribution as a function of temperature. (c) Calculation of temperature histories for the zones. (d) Detailed chemical kinetics HCT run with temperature histories determined from KIVA-3V. 


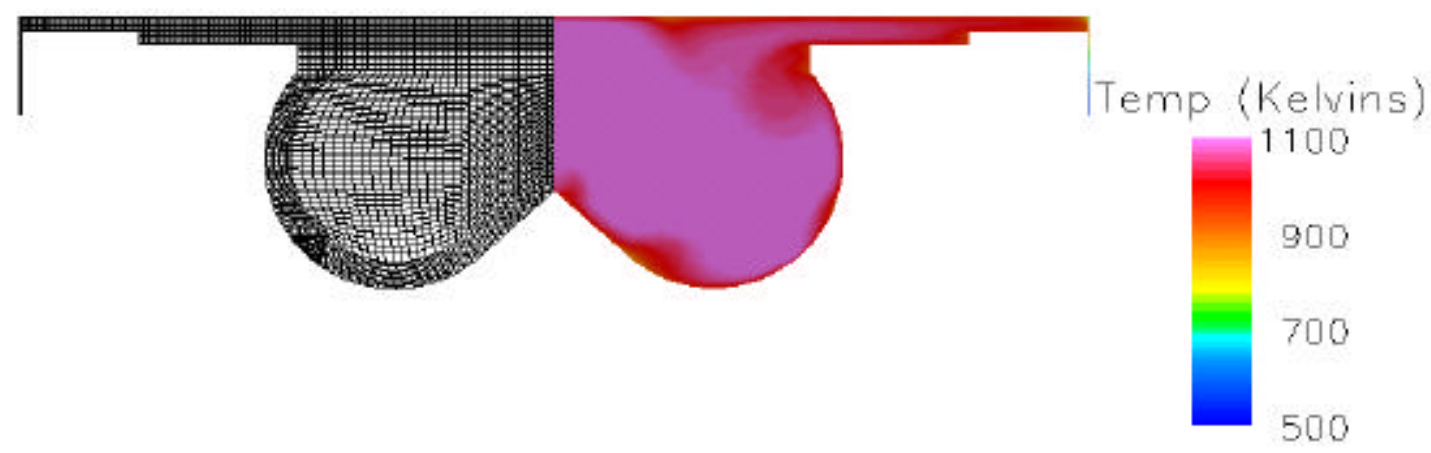

$\mathrm{CA}=10$ Deg BTDC

Figure 2.3.3 - Simulation results at $10^{\circ}$ BTDC from an axisymmetric simulation of the Volkswagen TDI under motoring conditions. The left hand side shows the computational grid and the right hand side shows psuedocolors of temperature. 


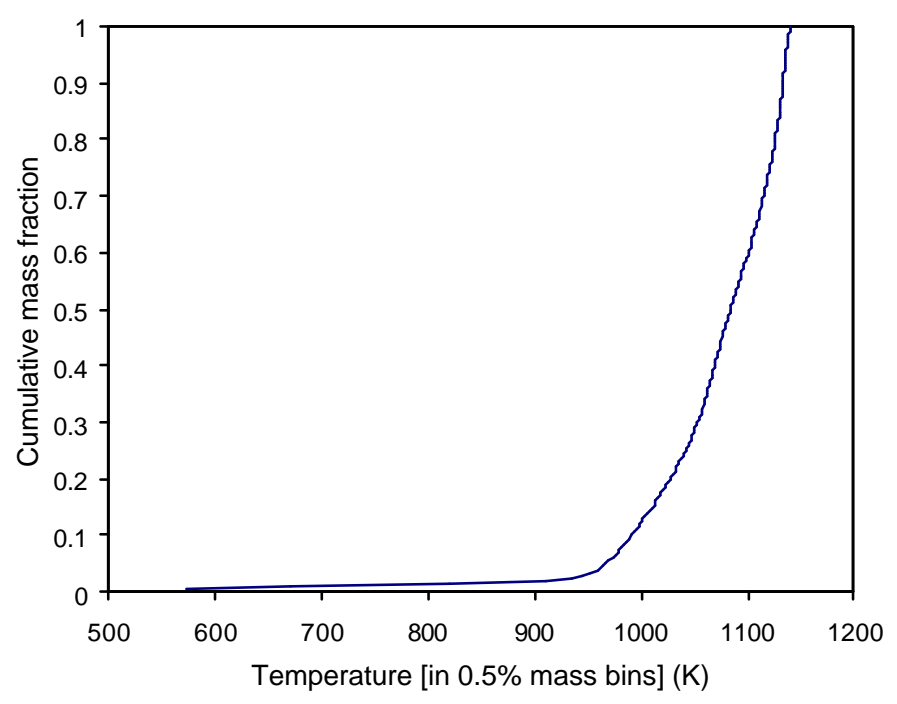

(a)

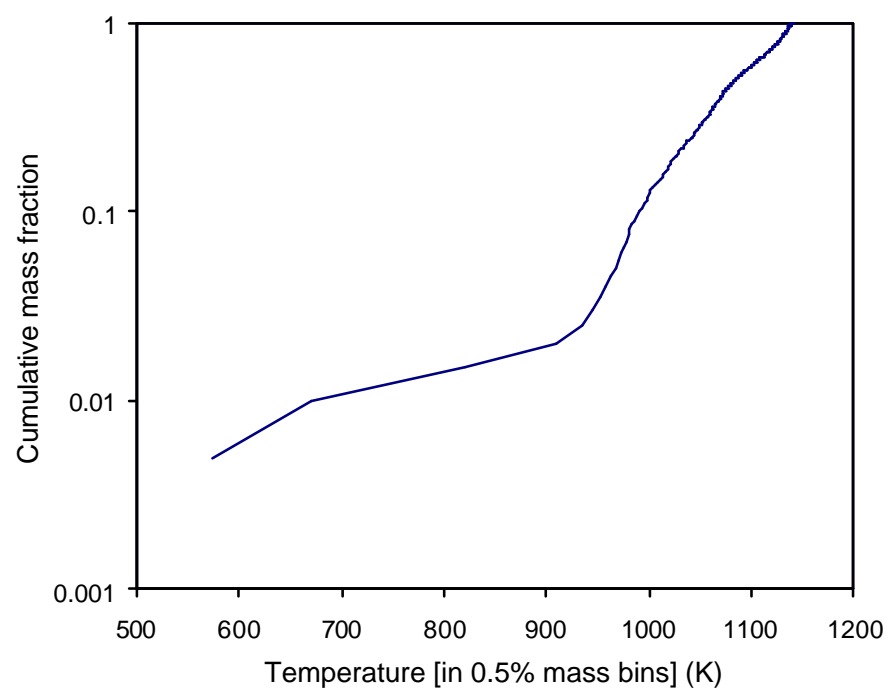

(b)

Figure 2.3.4 - Cumulative mass distributions versus temperature within the combustion chamber at $10^{\circ}$ BTDC (corresponds to Figure 2.3.3). (a) Shows linear- linear plot and (b) shows log-linear plot 


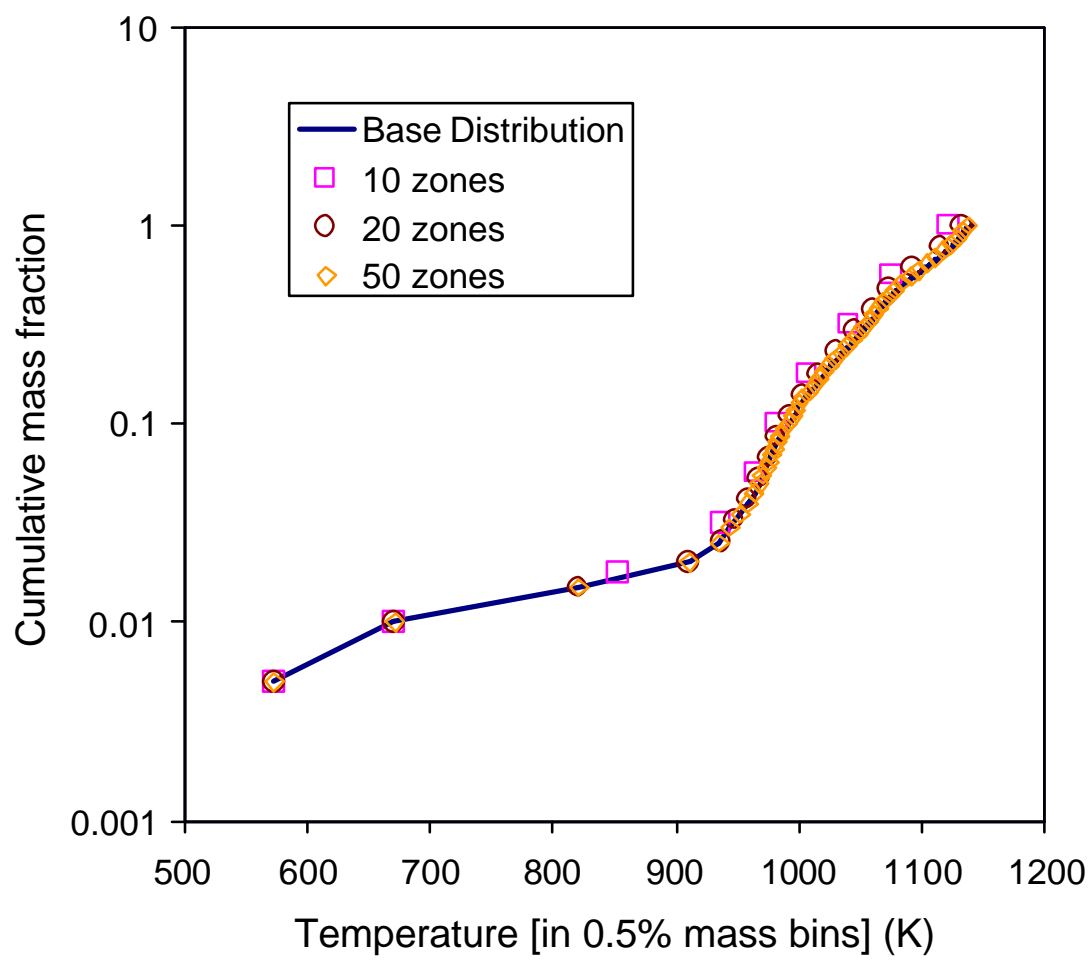

Figure 2.3.5 - Zone cutoff points versus temperature for 10, 20 and 50 zones using automated zoning procedure. A $0.5 \%$ threshold value was used for minimum zone mass. 


\section{HCCI Engine Simulations}

\subsection{Single-Zone Simulation Results}

Simulations have been performed to look at the effect of several different control parameters on HCCI combustion. A detailed natural gas chemistry model (species through $\mathrm{C}_{4}$ with $\mathrm{NO}_{\mathrm{x}}$ chemistry from [41]) is used to look at the effect of natural gas composition on the peak of heat release in an HCCI engine. A methane oxidation mechanism (based on the same mechanism but including species through $\mathrm{C}_{2}$, [41]) with a dimethyl-ether (DME) oxidation mechanism ([40]) has been used to investigate the effect of DME addition, inlet heating, and EGR to the control of combustion timing.

Two reaction mechanisms are used in this study. The first mechanism includes species through $\mathrm{C}_{4}[39,41]$, and models natural gas autoignition chemistry. The second mechanism is a reduced set with species through $\mathrm{C}_{2}$ and additionally including dimethyl ether (DME) oxidation chemistry [40]. Both mechanisms include $\mathrm{NO}_{\mathrm{x}}$ kinetics from the Gas Research Institute mechanism version 1.2 [66]. The chemical kinetic reaction mechanisms used by the model for natural gas ignition and $\mathrm{NO}_{\mathrm{x}}$ production have been extremely well established and are widely used.

The simulation is started at BDC where fresh charge at specified pressure, temperature and composition is inducted into the cylinder. If EGR is used, the appropriate amounts of major residual gas component species are added, based on the fraction of EGR specified. The cylinder wall, piston and head are all assumed to be at a uniform $430 \mathrm{~K}$. Chemical reactions are computed explicitly in the kinetics model. Thermodynamic table values of ideal gas $c_{p}$ and $c_{v}$ are explicitly calculated to account for enthalpy and pressure changes. The simulation is stopped at BDC at the end of the 
expansion stroke and the indicated efficiency is computed. The $\mathrm{NO}_{\mathrm{x}}$ values reported are taken at BDC.

\subsubsection{Effect of Fuel Composition on Combustion Timing}

In these simulations the "best" operating point for an HCCI engine is taken to correspond to the condition that gives peak heat release at TDC. This choice is debatable. Figure 3.1.1 shows experimental results of gross (based on energy conversion for expansion and compression stokes only) indicated efficiency versus combustion timing for HCCI engines, adapted from [35]. The combustion timing is specified by the peak rate of heat release. The data represent a wide variety of fuels under different operating conditions. According to these data, the highest efficiency occurs at slightly advanced combustion timing. A tradeoff occurs between $\mathrm{NO}_{\mathrm{x}}$ and $\mathrm{HC}$ emissions relative to combustion timing. As combustion timing advances, $\mathrm{NO}_{\mathrm{x}}$ emissions rapidly increase, and delayed combustion results in a rapid increase in HC emissions [35]. The best combustion timing depends on a variety of factors and likely varies depending on the operating conditions. The use of TDC combustion timing in this study seeks to address the tradeoffs in efficiency, $\mathrm{NO}_{\mathrm{x}}$, and $\mathrm{HC}$ emissions at some level. The selection of TDC combustion as "best" timing provides a baseline for comparison of different control strategies and timing effects due to fuel composition

The HCT engine code has been used to assess the effect of variations in natural gas fuel composition on the start of combustion in an HCCI operated engine. The engine selected for these simulations is a 1.9 L engine based on the Volkswagen TDI. The TDI has a bore of $79.5 \mathrm{~mm}$ and a stroke of $95.5 \mathrm{~mm}$. The model engine has a compression ratio of 18 , and the absolute intake pressure is assumed equal to 2.0 bar. 
This engine has been selected because it is an appropriate geometry for a small vehicular engine, and will be studied in future experimental research.

These fuel sensitivity simulations compare crank angle for maximum heat release of a natural gas blend relative to a baseline blend operated at the same conditions. Because methane is the major component of natural gas, pure methane is the baseline fuel. The BDC temperature is adjusted so that the peak heat release of pure methane, for a given equivalence ratio and engine speed, occurs at TDC. The simulation is run with no EGR or residual gas and the BDC temperature at the beginning of the compression stroke is specified.

Figure 3.1.2 shows the results of methane combustion with maximum heat release at TDC for three equivalence ratios with varying engine speed. The Figure shows that the BDC temperature for start of combustion must increase with increasing engine speed. The shorter reaction time available to achieve combustion at higher speeds makes it necessary to start the process at a higher temperature for obtaining peak heat release at TDC.

Natural gas is typically a mixture of methane, ethane, propane, and butane, as well as small amounts of other higher hydrocarbons and inert species (usually less than $1-2 \%$ by volume). Regional and seasonal factors play a significant role in the specific composition that a producer delivers. The Gas Research Institute studied the natural gas composition in the United States [67]. Higher hydrocarbons in the fuel cause autoignition to start earlier than for pure methane. Low temperature reactions occur due to the higher hydrocarbons that do not occur in pure methane, causing additional charge heating and production of radicals well before TDC. In order to understand the effect of 
the fuel composition on the ignition process, several compositions of natural gas were tried and the advance of maximum heat release from TDC relative to pure methane combustion was determined using HCT. Using the Gas Research Institute data, several fuel blends have been selected that define a large range in composition. The natural gas has been specified to consist only of the four primary components: methane, ethane, propane, and butane. Inert species are neglected as part of the composition because they serve only to slightly lower equivalence ratio with little effect on the results. Also neglected are hydrocarbons higher than butane, which typically are less than 0.1 mole percent of the gas composition. Table 3.1.1 presents the gas blends used for these studies.

Figure 3.1.3 shows the advance in maximum heat release time for the different natural gas blends. For a fixed equivalence ratio and engine speed, the BDC temperature that results in maximum heat release at TDC for methane is determined. Using the methane BDC temperature the crank angle at which maximum heat release occurs for the different natural gas compositions is determined. The advance is plotted as a function of a figure of merit, which was found to collapse the data into a single curve. The figure of merit is calculated by scaling the mole fraction of ethane by a factor of $1 / 6$ and adding that to the mole fraction of propane and butane. This $1 / 6$ factor for the ethane mole fraction was determined in an ad hoc manner by assessing what scaling resulted in the data falling on a single curve with the least scatter. This scaling implies that the dominant components that lead to early combustion are propane and butane. The twenty-three natural gas blends of Table 3.1.1 have been evaluated at each of the three equivalence ratio/engine speed combinations. The important trend that these 
simulations show is the high sensitivity of heat release timing that can be seen for figures of merit up to 5, a range that represents very typical blends delivered by gas suppliers.

A second study has been performed to determine what BDC temperature is required for different gas mixtures to achieve maximum heat release at TDC. Six blends from the previous twenty-three have been selected as extremes in composition of each of the components as well as the overall blends. The reduction in BDC temperature with respect to methane required to achieve maximum heat release at TDC for each of the blends is shown in Figure 3.1.4, as a function of the same figure of merit used in Figure 3.1.3. The required temperature reduction is fairly consistent for the three cases.

Figures 3.1.3 and 3.1.4 indicate that compensation will be required to account for normal variations in fuel composition across the U. S., and a closed loop control system with an indicator of the timing of heat release may be necessary to account for these variations. It should be noted that the blends with the most advance are not typical and would likely occur only during "peak shaving" when a significant amount of propane is blended into the fuel during heavy natural gas use periods [67].

\subsubsection{Control Methods for HCCI Engines}

Three different methods have been studied for their ability to control combustion timing in HCCI engines: dimethyl-ether (DME) addition, intake heating, and EGR. The engine modeled in these simulations is a Cooperative Fuels Research engine with a bore of $82.5 \mathrm{~mm}$, a stroke of $114.3 \mathrm{~mm}$, and a connecting rod length of $254 \mathrm{~mm}$. Two compression ratios are considered: $12: 1$ and 18:1, with natural aspiration and 1 bar supercharge. Engine speed is fixed at $1800 \mathrm{rpm}$. The methane/DME reaction 
mechanism is used for these calculations. The control variable is adjusted so that the peak heat release always occurs at TDC. This engine and fuel have been selected to complement experimental research currently underway at UC Berkeley. Operating conditions have been selected based on experimental parameters. These results should be taken as relative indicators of the performance of the engine with respect to the control parameters.

We constrain operation of the engine by peak cylinder pressure and $\mathrm{NO}_{\mathrm{x}}$ emissions. The maximum peak cylinder pressure is set at 250 bar. This value is higher than the existing limit in most current Diesel engines which are typically are limited to 200 bar. However, previous validation of the model has shown that single-zone HCT analysis overpredicts peak cylinder pressure by about 20\%, [43], therefore 250 bar in a single-zone simulation corresponds to 200 bar in real operation with the same intake conditions. The $\mathrm{NO}_{\mathrm{x}}$ emissions are restricted to $100 \mathrm{ppm}$. This limit would result in very low driving cycle emissions if the engine were used in an automobile. For other applications, such as stationary power, the $\mathrm{NO}_{\mathrm{x}}$ limit may need to be set at a lower level to meet regulatory standards, e.g. $9 \mathrm{ppm}$ at $15 \% \mathrm{O}_{2}$.

\subsubsection{Dimethyl-Ether Additive Control}

Autoignition timing may be controllable by blending low cetane number fuel (natural gas) with high cetane number fuel (DME). Dimethyl ether is an ideal fuel additive for natural gas HCCI because has a small ignition delay, and because DME has similar reaction chemistry to methane, and DME does not tend to promote soot formation. 
Figure 3.1.5 shows the results for the addition of DME to the engine. DME fraction in the fuel, indicated efficiency, indicated mean effective pressure, peak cylinder pressure, and $\mathrm{NO}_{\mathrm{x}}$ are plotted versus intake equivalence ratio for the four different conditions. DME concentration is always adjusted to achieve peak heat release at TDC. Residual gases are not considered in this analysis in order to isolate specific temperature effects. Thus, the charge is pure fuel and air and the intake equivalence ratio is equal to the in-cylinder equivalence ratio. The inlet temperature is fixed at 333 $\mathrm{K}$ for each case except for the naturally aspirated 12:1 compression ratio. In that case the inlet temperature is increased to $400 \mathrm{~K}$ because complete combustion could not be achieved for the range of equivalence ratio without some inlet heating. Complete combustion refers to having a significant fraction (say 80\%) of the fuel burned. In practice it is very easy to determine complete combustion in the single zone model because either very little fuel reacts or nearly all reacts. The equivalence ratio reported includes both DME and methane. Complete combustion could not be achieved for the 12:1 compression ratio cases with equivalence ratio below 0.3 , and could not be achieved for the 18:1 compression ratio cases below equivalence ratio of 0.25 .

The maximum values of the performance variables achievable during operation may be constrained by peak cylinder pressure and a specified limit on $\mathrm{NO}_{\mathrm{x}}$. As Figure 3.1.5 shows, only the supercharged 18:1 compression ratio case approaches the 250 bar peak pressure limit. In all the cases analyzed, the $\mathrm{NO}_{\mathrm{x}}$ threshold is the governing constraint. If greater intake boost is used the pressure limit will likely play a stronger role. The $\mathrm{NO}_{\mathrm{x}}$ constraint limits both naturally aspirated cases and the supercharged 18:1 compression ratio case to an equivalence ratio of 0.4 , while the maximum equivalence 
ratio of the supercharged 12:1 compression ratio case is roughly 0.43 . The DME fraction required for the 12:1 cases ranges from slightly over 50\% at low load to $30-35 \%$ at high load. For 18:1 compression ratio, the naturally aspirated engine requires 50\% DME at low load to $30 \%$ at high load, and the supercharged engine requires $25 \%$ at low load to $15 \%$ at high load.

The gross indicated efficiencies range from $58 \%$ to $60 \%$ for $18: 1$ compression ratio, and from $52 \%$ to $54 \%$ for the $12: 1$ compression ratio cases. The indicated efficiency decreases with increasing equivalence ratio due to decreasing specific heat ratio and increasing heat transfer as the equivalence ratio increases. These efficiency results indicate the potential for high efficiency operation of HCCI engines.

The imep, in the allowable range of operation, ranges from 10 to 15 bar for the 18:1 compression ratio supercharged case, and from 11 to 15 bar for the 12:1 compression ratio supercharged case. For the 18:1 compression ratio naturally aspirated case, the imep ranges from 5 to 7.5 bar, and ranges from 5 to 6 bar for the 12:1 compression ratio naturally aspirated case. The naturally aspirated maximum imep results are fairly low, and indicate that supercharging is necessary to increase the power density. Because the lowest calculated imep achievable in this control method is 5 bar, throttling may be required for idle operation, to balance a typical 1-2 bar frictional loss at these conditions [62].

\subsubsection{Inlet heating Control}

HCCI control by inlet heating involves adjusting the mixture temperature so that conditions are appropriate for autoignition of the charge to occur at the desired crank angle, TDC in this case. A heat source, such as an electric heater or air-to-air heat 
exchanger with hot exhaust gases would be required in an operating engine. Figure 3.1.6 shows inlet temperature, indicated efficiency, imep, peak pressure, and $\mathrm{NO}_{\mathrm{x}}$ plotted versus equivalence ratio for the numerical model of the CFR engine operated with inlet heating to obtain maximum heat release at TDC. The mixture at the start of the cycle is fuel and air only with no residual gases considered. The inlet temperature is the temperature specified in the cylinder at beginning of the compression stroke.

The 250 bar pressure constraint is not approached in any of the simulations. The $100 \mathrm{ppm} \mathrm{NO}_{\mathrm{x}}$ constraint is reached at equivalence ratios of 0.31 to 0.32 for all cases. This $\mathrm{NO}_{\mathrm{x}}$ limit could probably be extended with some EGR, at the expense of efficiency. Supercharging and increasing the compression ratio decreases the required inlet heating and this appears to also reduce the peak temperature at a fixed equivalence ratio, leading to lower $\mathrm{NO}_{\mathrm{x}}$ for these cases. For the 12:1 compression ratio naturally aspirated engine the simulation results indicate inlet temperatures of about $550 \mathrm{~K}$ to obtain combustion at TDC. Supercharging a 12:1 compression ratio engine reduces the required inlet temperature down to the range of 525 to $540 \mathrm{~K}$. For the 18:1 compression ratio naturally aspirated case the inlet temperature required for TDC combustion is in the range of 465 to $470 \mathrm{~K}$, and for the $18: 1$ supercharged case the inlet temperature range is 435 to $450 \mathrm{~K}$. With inlet heating, autoignition can be achieved even at very low equivalence ratio. Supercharging heats the intake air, so that little additional heating may be required under some supercharged conditions. It should also be noted that, in some cases as equivalence ratio is increased, higher intake temperatures are required to achieve TDC peak heat release, due to decreasing specific heat ratio and chemistry effects, such as the negative temperature coefficient effect of methane [67]. 
The indicated efficiency ranges from $55 \%$ to $60 \%$ for the $18: 1$ compression ratio cases and from $49 \%$ to $54 \%$ for the $12: 1$ compression ratio cases, with the two supercharged cases having slightly higher efficiency over most of the range than the respective naturally aspirated cases. Again, these efficiency results demonstrate the potential for very high efficiency in an HCCI engine.

For the constrained range of operation, the imep ranges from 3 to 8 bar for the supercharged 18:1 compression ratio, 1.3 to 4 bar for the naturally aspirated 18:1 compression ratio, 2 to 6 bar for the supercharged 12:1 compression ratio, and 1 to 3 bar for the naturally aspirated 12:1 compression ratio. The peak numbers suggest that even more supercharging may be required to achieve reasonable power density out of an HCCI engine relative to a spark-ignited or diesel engine. This could lead to the peak cylinder pressure being the dominant constraint. The low-load imep results show that frictional work can be balanced by the combustion work without throttling.

\subsubsection{EGR Control}

Blending the intake fuelair mixture with hot residual gases has several effects. First, the residual gases will raise the charge temperature. Second, the specific heat ratio of the mixture will decrease, resulting in lower TDC temperature and pressure, relative to the TDC temperature for a pure fuel/air mixture. In a lean burn engine, the intake fuel-air ratio, based on the mixture of fuel and air before addition of residual gasses, will be different than the in-cylinder fuel-air ratio when residual gas has been blended with the intake charge. The relation below accounts for the air present in the cylinder due to addition of residual gas in a lean combustion system. 


$$
\phi_{a c t}=\frac{1-E G R}{1-E G R \cdot \phi_{\text {in }}} \phi_{\text {in }}
$$

In equation (1) EGR is the fraction of residual gas in the cylinder relative to the inducted fresh fuel and air, $\phi_{\text {in }}$ is the intake equivalence ratio, and $\phi_{\text {act }}$ is the in-cylinder equivalence ratio. See Appendix A for a more discussion of this definition of EGR. In an operating engine, hot residual gases can be introduced into the cylinder in several ways. For example, an insulated line could be run from the exhaust and blended with the intake air or the engine exhaust valve could be closed early with variable valve timing control. The EGR must be effectively mixed with the incoming charge to prevent the possibility of issues such as increased $\mathrm{NO}_{\mathrm{x}}$ emissions or cycle-to-cycle variations.

Figure 3.1.7 shows the EGR fraction, indicated efficiency, imep, peak cylinder pressure, and $\mathrm{NO}_{\mathrm{x}}$ plotted versus the in-cylinder equivalence ratio. The maximum cylinder pressure constraint is not met in any of these cases. The $\mathrm{NO}_{\mathrm{x}}$ limit governs the operation range. The maximum equivalence ratio allowable based on the $\mathrm{NO}_{\mathrm{x}}$ constraint ranges between 0.5 for the naturally aspirated $12: 1$ compression ratio and 0.39 for the supercharged 18:1 compression ratio. The lower $\mathrm{NO}_{\mathrm{x}}$ emissions for a given equivalence ratio compared with the results for preheated intake (Figure 3.1.6) are due to the lower specific heat of the residual gases, which reduces the peak cylinder temperature in the EGR case. The EGR fraction required for TDC peak heat release decreases with supercharging and increased compression ratio. The EGR fraction ranges from $60 \%$ for low load in the naturally aspirated $12: 1$ case to $26 \%$ in the $18: 1$ case at high load. The left-hand end of each curve on the EGR fraction versus equivalence ratio plot is the 
lowest equivalence ratio at which complete combustion at TDC could be achieved. Supercharging and increased compression ratio both have the affect to extend the operating limit to leaner mixtures.

Gross indicated efficiency is higher than $49 \%$ in all cases, and reaches $58 \%$ for the supercharged 18:1 case. The imep ranges from 2 to 2.5 bar for the naturally aspirated 12:1 compression ratio, from 5 to 6 bar for the supercharged 12:1 compression ratio, from 3 to 3.7 bar for the naturally aspirated 18:1 compression ratio, and from 6 to 8 bar for the supercharged 18:1 compression ratio. Further supercharging or relaxation of the $\mathrm{NO}_{\mathrm{x}}$ limit at peak load may be necessary to achieve power density comparable to current engines. The low-load imep results indicate that some throttling may be necessary for idle operation.

\subsubsection{Overall Discussion of Control Methods}

Each of the control methods presented has the potential to control combustion timing in an HCCI engine. Some general observations can be made about how these methods can be applied to HCCI engine control. Supercharging will be required to achieve reasonable power density. Intake air compression, either with a mechanical supercharger or turbocharger, will need to be able to accommodate a wide range of boost pressure, possibly up to 2 bar of pressure boost. The mechanical pressure limits of the engine will become a constraint with higher levels of supercharging. The constraint on peak $\mathrm{NO}_{\mathrm{x}}$ also affects power density. Boosting the intake pressure and increasing the compression ratio decreases the quantity of a particular control variable necessary to achieve TDC combustion, i.e. less DME additive, less inlet heating, or less EGR is required. Higher compression ratio engines appear to be the best choice for an HCCI 
engine, particularly due to the inherent higher efficiency, although the lower compression ratio engines may better handle very low loads. Lower compression ratio engines would probably yield higher imep, considering peak pressure and $\mathrm{NO}_{\mathrm{x}}$ limits. Previous experimental work has shown that late combustion timing allows for reducing $\mathrm{NO}_{\mathrm{x}}$ emissions at higher equivalence ratio at the expense of lower combustion efficiency and greater $\mathrm{HC}$ and $\mathrm{CO}$ emissions [34]. The peak cylinder pressure may also be reduced for a given operating condition by going to later combustion timing. The tradeoff between lower $\mathrm{NO}_{\mathrm{x}}$ and increased $\mathrm{HC}$ and $\mathrm{CO}$ emissions as timing occurs later may be worthwhile to extend the operating range. As will be shown in the experimental section, the $\mathrm{HC}$ and $\mathrm{CO}$ can rise to 1000s of ppm at late combustion timing. Because of these high levels of $\mathrm{HC}$ and $\mathrm{CO}$, it is likely that the tailpipe emissions of $\mathrm{CO}$ and $\mathrm{HC}$ would still be very high - even when an oxidation catalyst is employed. The compression ratio for an HCCI engine will likely be limited by peak cylinder pressure and heat transfer. A variable compression ratio engine could allow for a wide range of loads without throttling. A fixed compression ratio machine with inlet valve timing control could be used to effectively vary the compression ratio, and with inlet and exhaust valve timing control the intake and exhaust could be effectively throttled without pumping losses.

Inlet heating allows for the greatest control of the operating range particularly at low load. Extremely lean mixtures can be ignited and very low power output can be produced. However, $\mathrm{NO}_{\mathrm{x}}$ rises very rapidly at relatively low equivalence ratio, limiting the low emission operating range. Implementation of inlet heating could require additional energy cost to power an external heater, particularly for startup. In an automotive application requiring the operator to wait for the intake air to heat up could 
be an unacceptable inconvenience. A DME additive scheme has potential for rapid startup because the fuel composition could be adjusted rapidly to create conditions necessary for startup. Using DME additive control may not be practical for vehicle applications because it would require large quantities of both natural gas and DME to be stored. Also the DME results showed a significant amount of throttling required for idle. If used only for startup, only a small storage volume would be required and it could be sized for refill at a maintenance interval. An EGR-controlled engine could probably achieve reasonable peak power with the advantage that the exhaust gas is readily available in a warmed up engine, but, as with inlet heating, a startup scheme is necessary. 
Table 3.1.1 - Fuel blends used for sensitivity analysis study

\begin{tabular}{|c|c|c|c|c|}
\hline $\mathrm{mol}_{4} \mathrm{CH}_{4}$ & $\mathrm{~mol}_{2} \mathrm{C}_{2} \mathrm{H}_{6}$ & $\mathrm{~mol}_{2} \mathrm{C}_{3} \mathrm{H}_{8}$ & $\mathrm{~mol}_{0} \mathrm{C}_{4} \mathrm{H}_{10}$ & Notes \\
\hline 100.00 & 0.00 & 0.00 & 0.00 & \\
\hline 96.50 & 3.50 & 0.00 & 0.00 & Methane/Ethane Blend \\
\hline 93.00 & 7.00 & 0.00 & 0.00 & Methane/Ethane Blend \\
\hline 86.00 & 14.00 & 0.00 & 0.00 & Methane/Ethane Blend \\
\hline 98.30 & 0.00 & 1.70 & 0.00 & Methane/Propane Blend \\
\hline 96.60 & 0.00 & 3.40 & 0.00 & Methane/Propane Blend \\
\hline 93.20 & 0.00 & 6.80 & 0.00 & Methane/Propane Blend \\
\hline 99.30 & 0.00 & 0.00 & 0.70 & Methane/Butane Blend \\
\hline 98.60 & 0.00 & 0.00 & 1.40 & Methane/Butane Blend \\
\hline 97.20 & 0.00 & 0.00 & 2.80 & Methane/Butane Blend \\
\hline 94.10 & 3.50 & 1.70 & 0.70 & \\
\hline 88.20 & 7.00 & 3.40 & 1.40 & \\
\hline 76.40 & 14.00 & 6.80 & 2.80 & \\
\hline 87.15 & 7.63 & 3.70 & 1.53 & \\
\hline 84.18 & 14.59 & 0.90 & 0.34 & \\
\hline 60.43 & 2.01 & 37.30 & 0.26 & Extreme Peakshaving Blend \\
\hline 93.14 & 4.61 & 2.05 & 0.20 & Massachusettes City 2 \\
\hline 83.43 & 1.94 & 14.40 & 0.23 & Maryland Propane-Air Peakshaving \\
\hline 95.85 & 3.44 & 0.51 & 0.20 & Virginia Station A \\
\hline 93.53 & 4.69 & 1.36 & 0.42 & Ohio \\
\hline 92.92 & 4.72 & 1.64 & 0.72 & Texas City \#1 \\
\hline 91.06 & 7.62 & 1.10 & 0.22 & Colorado Station A \\
\hline 94.21 & 4.24 & 1.14 & 0.41 & California City \#1 Gate Station A \\
\hline
\end{tabular}




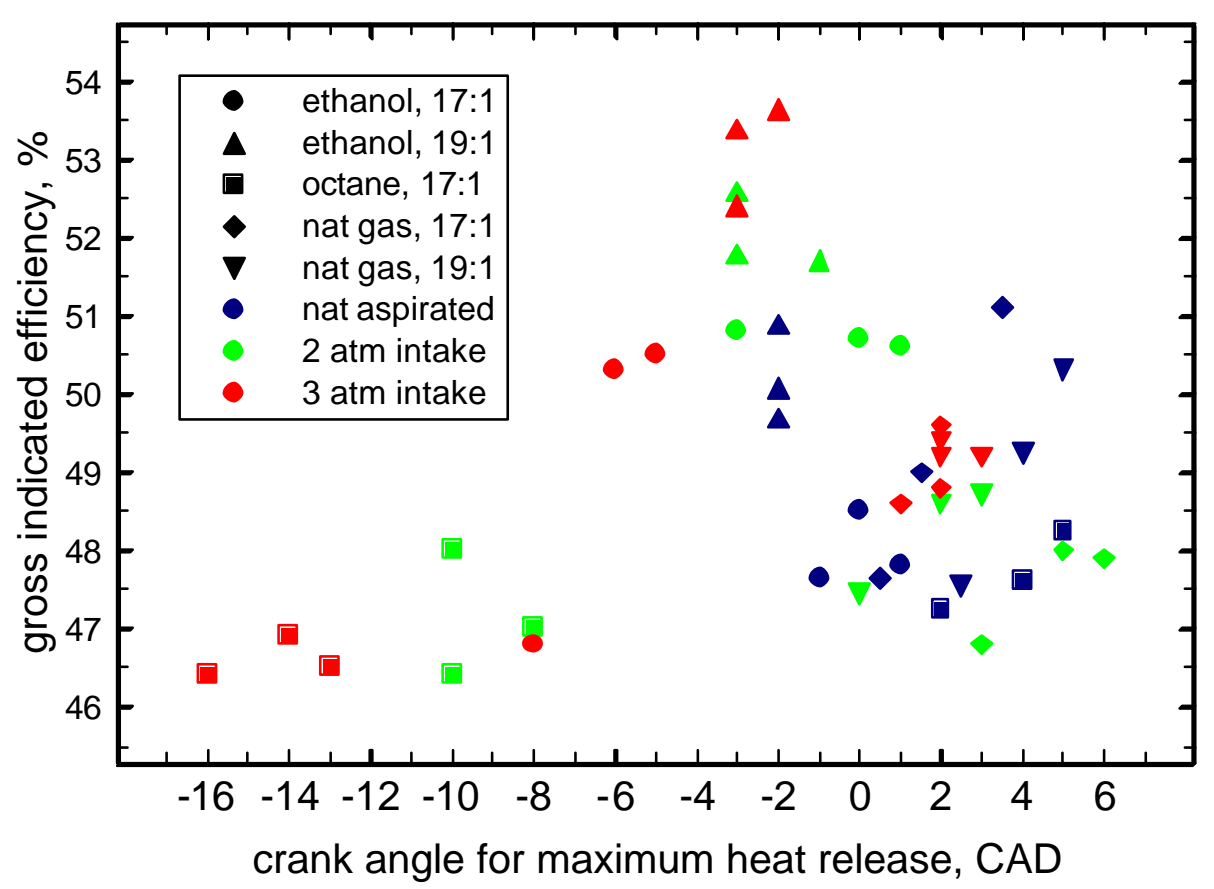

Figure 3.1.1- Gross indicated thermal efficiency versus timing for peak heat release adapted from Lund Institute data [35]. 


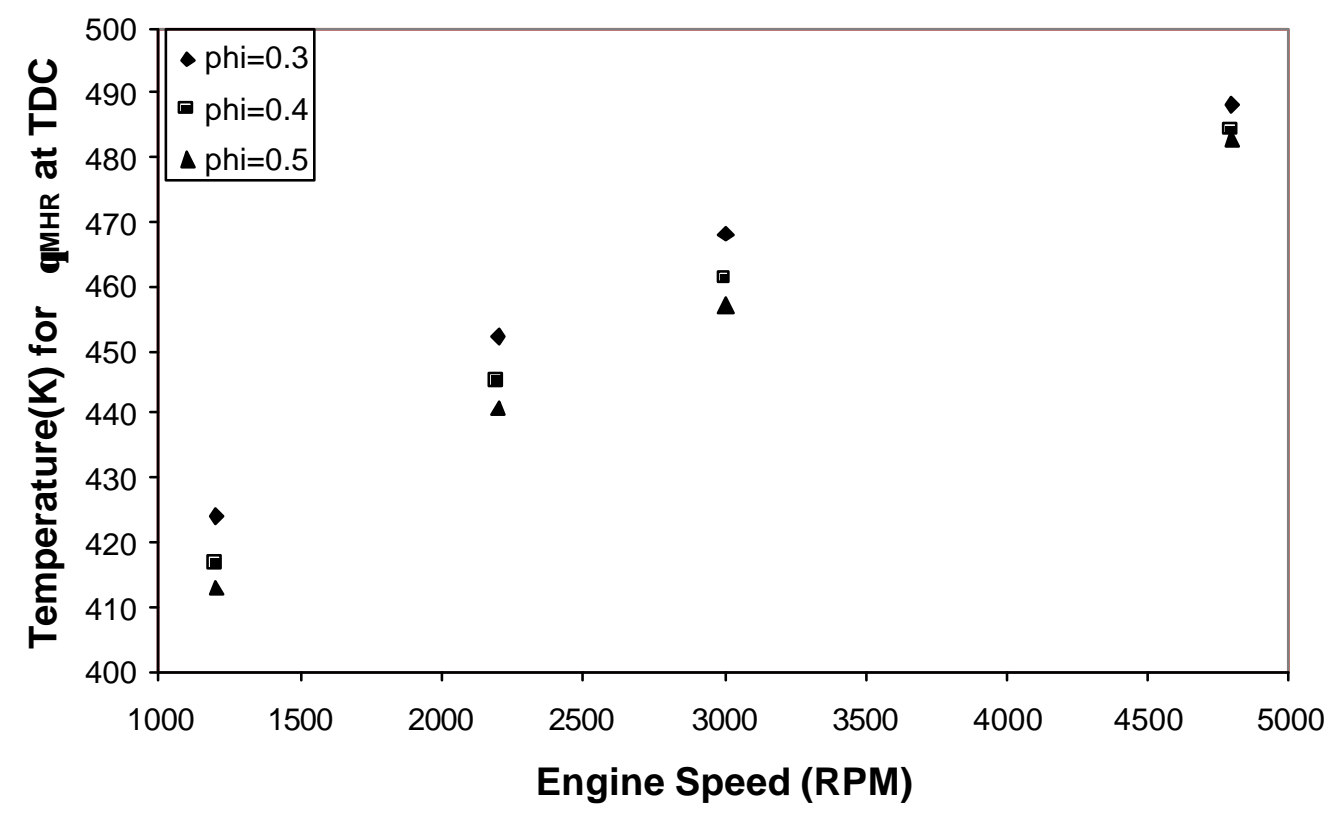

Figure 3.1.2 - Temperature for TDC peak heat release of pure methane versus engine speed. 


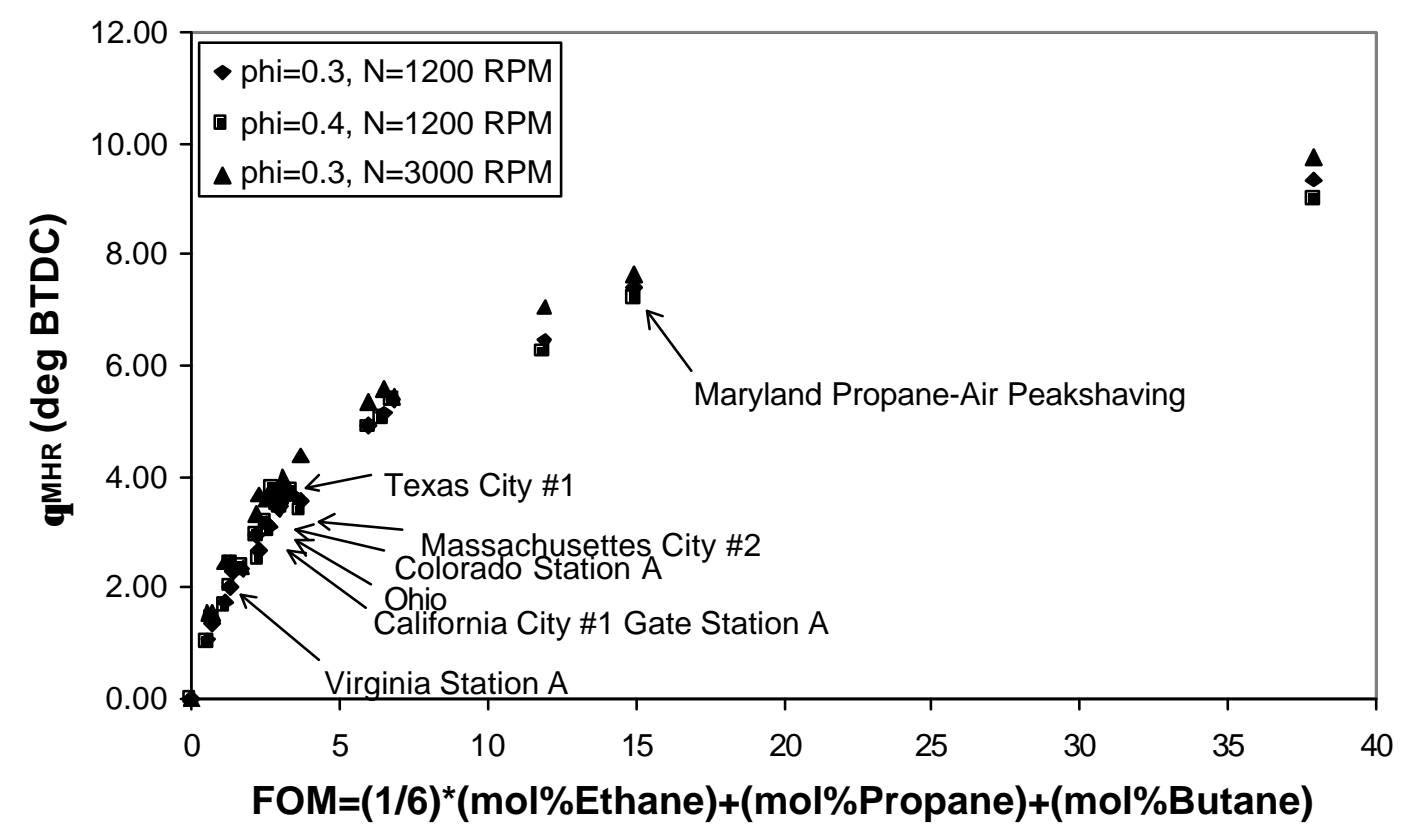

Figure 3.1.3 - Crank angle advance of peak heat release versus fuel composition figure of merit for fuel blends. 


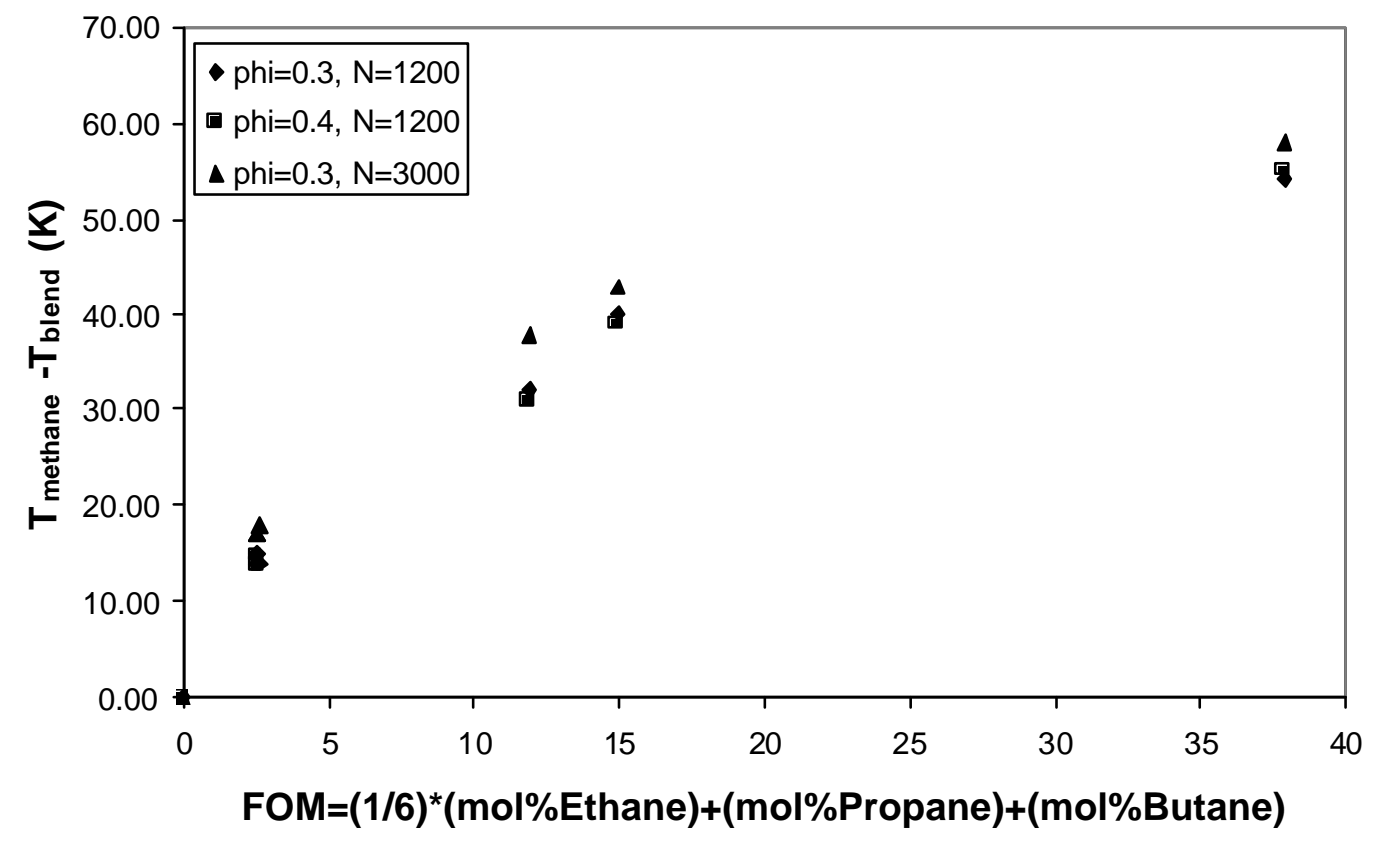

Figure 3.1.4 - Temperature for TDC peak heat release versus figure of merit for various fuel blends. 


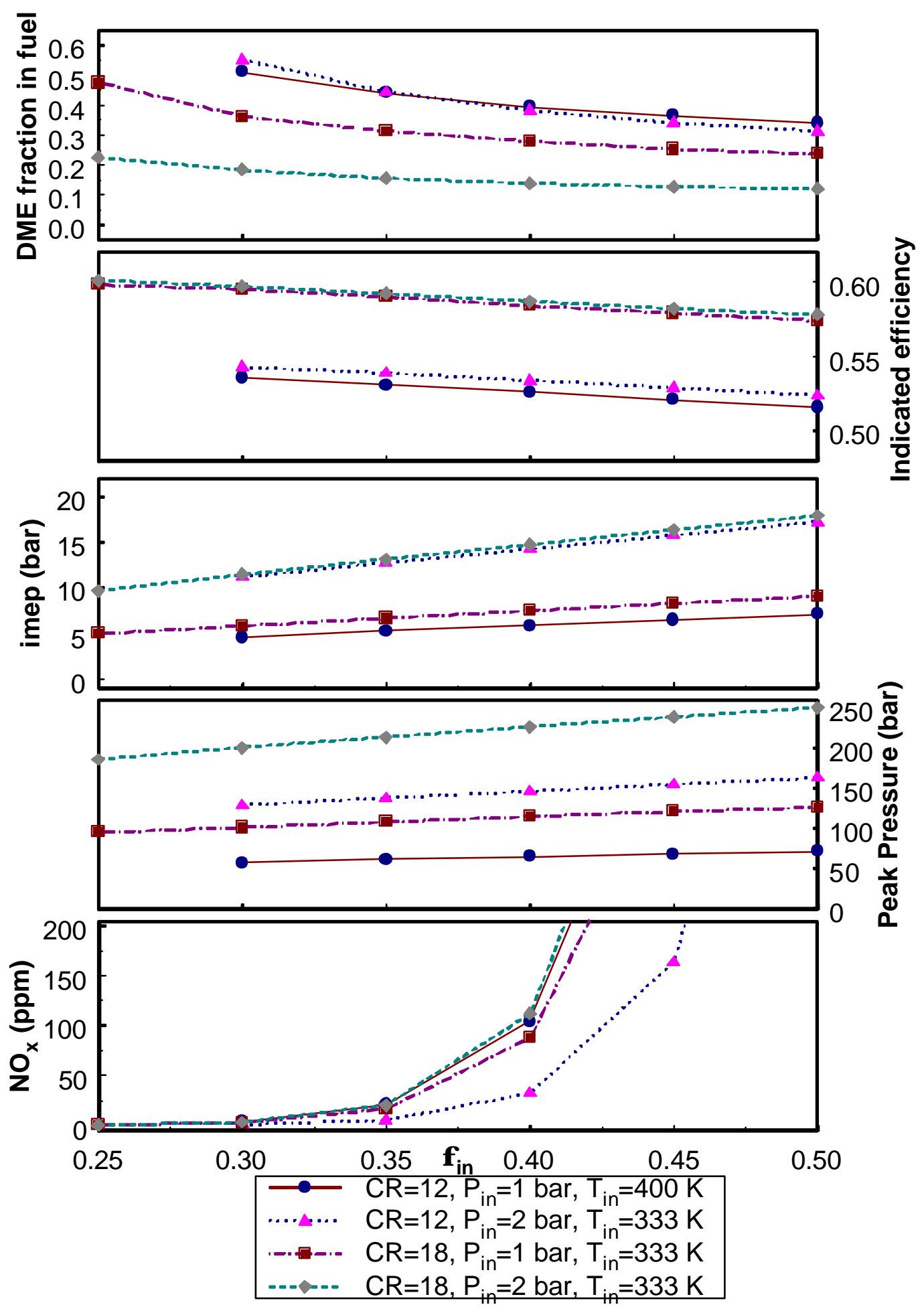

Figure 3.1.5 - Simulation results for HCCI control by DME addition. 

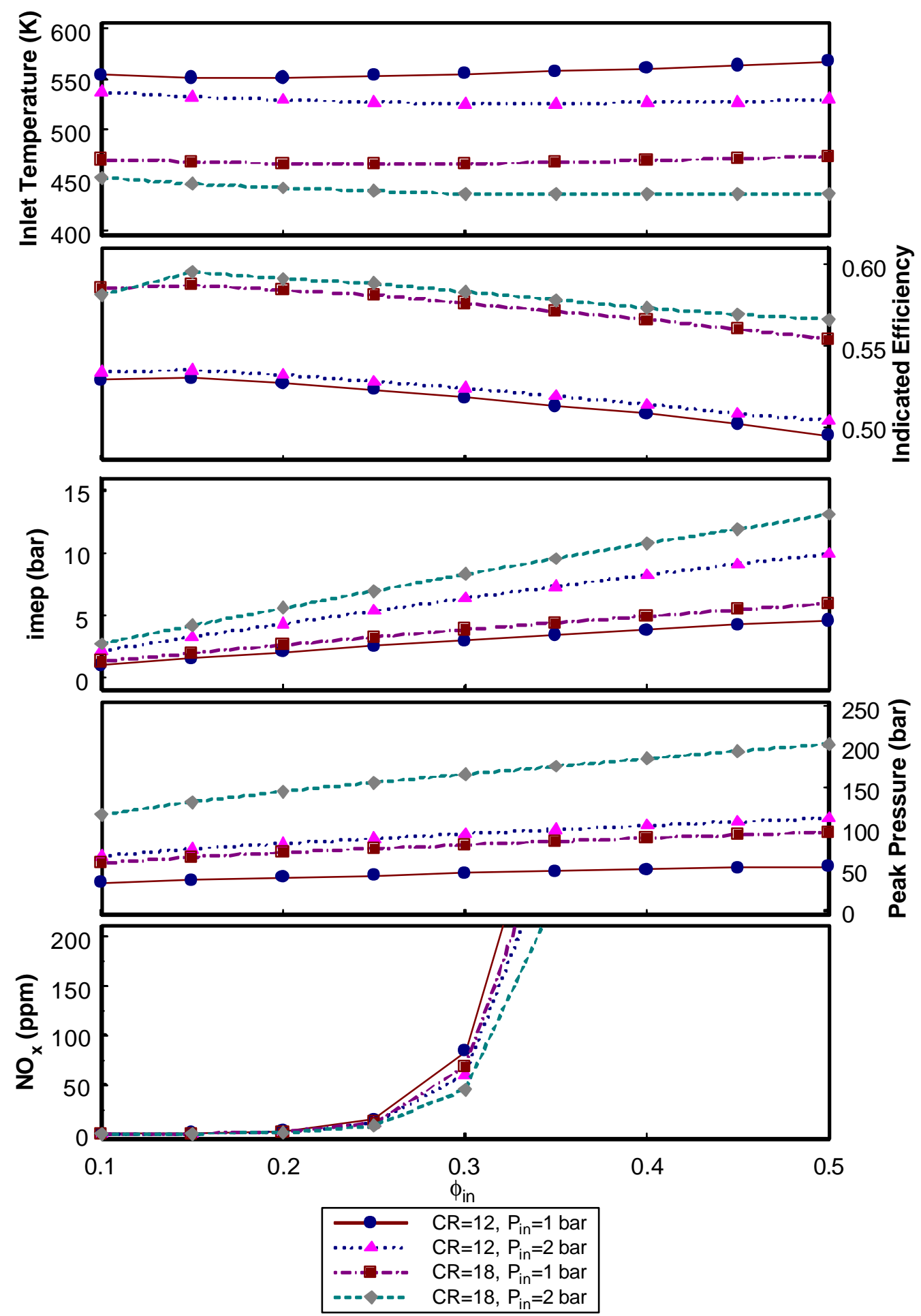

Figure 3.1.6 - Simulation results for HCCI control by intake heating. 

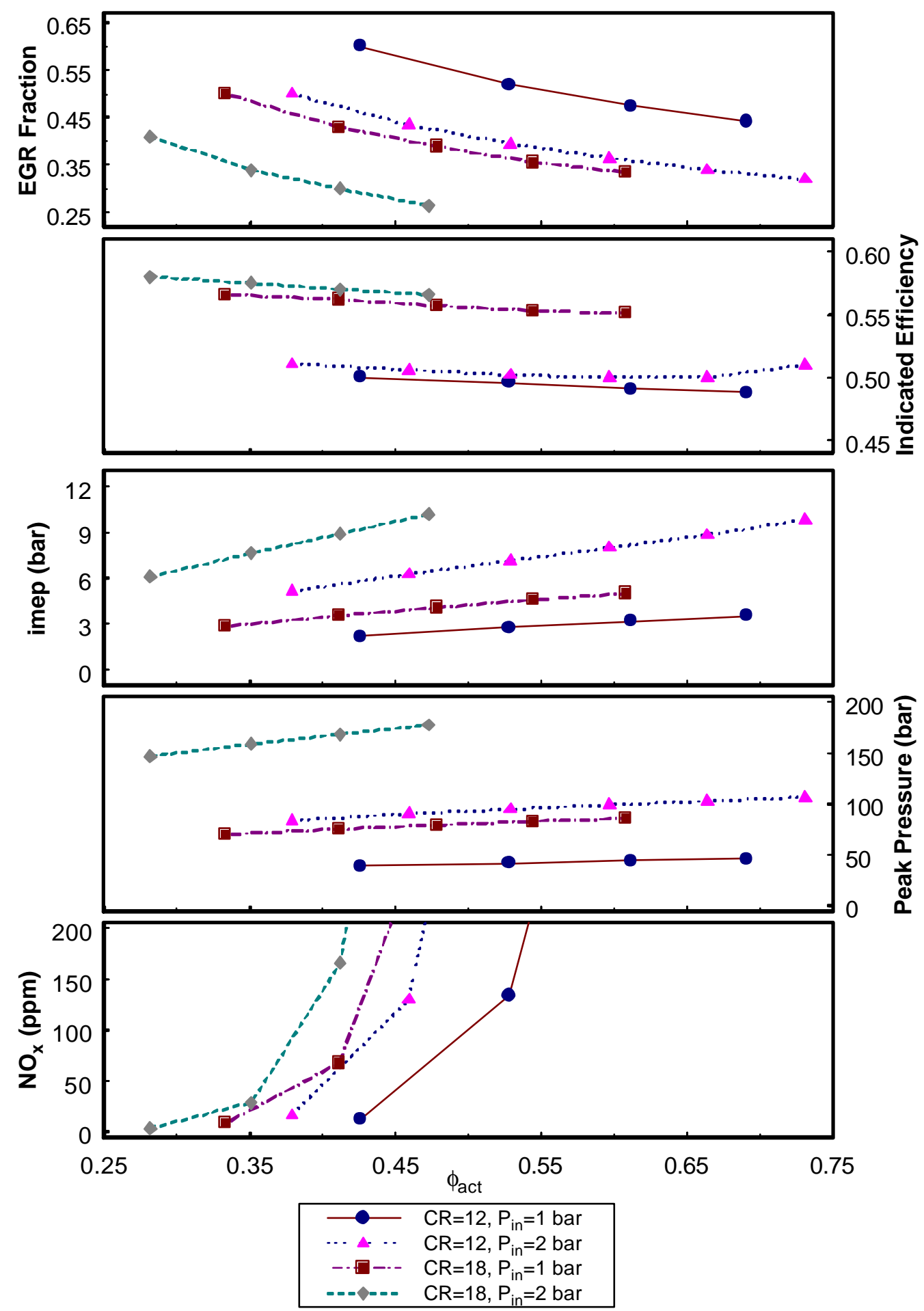

Figure 3.1.7 - Simulation results for HCCI control by EGR. 


\subsection{Multi-zone Modeling of HCCI in VW TDI Engine Geometry}

Simulations of HCCI combustion in the Volkswagen TDI combustion chamber have been performed using the multi- zone modeling technique. These simulations utilize KIVA-3V to predict the temperature time history for the combustion gasses in the precombustion phase as described in Chapter 2. The system of equations outlined in Section 2.3.1 is solved using the CHEMKIN II library for handling the thermo-chemical data [61]. The chemical kinetic data used for this analysis is a CHEMKIN II version of 179 species mechanism used for the fuel sensitivity analysis studies in Section 3.1.1.

Simulations are performed to validate the multi-zone method with experimental data for propane HCCI combustion in the TDI engine (as reported in Section 4.2). The as-tested configuration of the engine has a bowl-in-piston combustion chamber geometry. This geometry is likely not ideal for an HCCI engine, because of high surface to volume ratio and large effective crevice volume, so the multi-zone results for the bowl-in-piston combustion cha mber are compared to another design option, a "pancake" (flat-top piston) combustion chamber design. The effect of swirl on the performance and emissions was also investigated.

The baseline computational grid for the bowl-in-piston geometry is shown in Figure 3.2.1. This grid was developed with two assumptions that deviate from the actual geometry for the TDI combustion chamber. First, the bowl is assumed to be centered in the combustion chamber. In the actual combustion chamber the bowl is slightly offs et from the centerline of the combustion chamber to enhance mixing of direct injected Diesel fuel. The second assumption involves the valve pocket in the TDI combustion 
chamber. On the actual piston the valve pocket is an asymmetrical cutout of roughly $1 \mathrm{~mm}$ depth over the piston crown. For the grid, a right circular cylinder of equal depth and volume represents the valve pocket. These assumptions allow for the simulations to be axisymmetric, which greatly reduces running time over simulations using a full threedimensional grid. The axisymmetric grid contains roughly 140,000 computational zones, and has a run-time of approximately 48 hours on a 64 bit, $300 \mathrm{MHz}$, SGI Origin 2000 workstation. To retain the same wall resolution for a full three-dimensional grid at least two orders of magnitude more elements would be required, and the run time would increase by several orders of magnitude. If the simulations were investigating mixing of injected fuel for diesel like combustion then these geometric details would be more important to resolve. But for the simulation of compression of a premixed charge in an HCCI engine these assumptions likely have little impact on the prediction of the temperature time histories that are taken from the CFD code.

Figure 3.2.2 shows the mass-temperature distribution within the combustion chamber as a function of grid resolution. As the figure shows the intermediate grid resolution chosen for this study is sufficient to capture the temperature time histories correctly.

\subsubsection{Comparison to Experimental Combustion Data}

Simulations of HCCI using the TDI geometry are compared to experimental pressure versus crank angle data from the TDI combustion chamber. The operating point selected is detailed in Table 3.2.1. A ten-zone chemical kinetic model is used in these simulations, with the zoning determined by the procedure specified in Section 
2.3.3. The zonal mass fractions for the 10-zone model are given in Table 3.2.2. The same zoning has been used for all of the multi-zone simulations in this chapter. Figure 3.2.3 shows the zone distribution on the mass-temperature distribution at TDC in the base case combustion chamber.

Figure 3.2.4 shows a comparison between an experimental pressure trace and the pressure trace determined by the multi-zone method. Two computational input parameters were adjusted to match the data, these are temperature and pressure at BDC. The pressure is adjusted so that the pressure in the cycle prior to start of combustion matches well with the experimental pressure trace. The BDC temperature is adjusted to match the combustion timing with the experiment. The experimental and simulated pressure traces match well during the heat release process. The "spikey" nature of the simulated pressure trace is due to the use of the multi-zone methodology. Heat release in each zone occurs more rapidly than would actually occur in the experiments because of the temperature-mass averaging that is used. But the integrated effect captures the distributed nature of the combustion process. A larger number of zones would smooth the pressure distribution during the heat release process - at the expense of a significant increase in computational time required.

Figure 3.2.5 shows ratios of simulation results to experimental results. The parameters that are readily comparable for these simulations are those that can be extracted from the pressure data during the combustion process: gross IMEP, burn duration, and peak cylinder pressure. Emissions data is unavailable because it is taken globally for all four cylinders on this four-cylinder engine and thus the cylinder-bycylinder distribution in emissions is unknown. As will be discussed in Chapter 4, the 
imbalance of combustion timing between cylinders in this engine results in wide variation in emissions from each cylinder.

Figure 3.2.5 shows the simulation overpredicts the IMEP. This suggests that the heat transfer during the cycle is not captured sufficiently well. The likely reason for the underprediction of heat transfer is that the Woschni coefficient poorly captures the heat transfer during combustion and expansion. KIVA may also need to be tuned further to better match heat transfer prior combustion. The combustion process itself is matched nicely, as demonstrated by the good agreement in the pressure trace and burn duration. The spikey nature of the simulations results gives a slight overprediction in peak pressure. Again, using to a larger number of zones may reduce this.

\subsubsection{Effect of Geometry}

The bowl-in-piston geometry that is appropriate for a diesel engine is likely not ideal for an HCCI engine. This study looks at comparing the current bowl in-piston geometry to a (lower heat transfer) flat-top piston ("pancake") combustion chamber geometry. A flat-top grid, shown in Figure 3.2.6, has been created that is a flat-top analogy to the bowl in-piston grid. The total volume, bore, stroke, and crevice volume were made identical for the flat-top design to the original design. Figure 3.2.7 shows pressure traces shows pressure traces for simulations of bowlin-piston and flat-top geometry. Two different flat-top cases were simulated. The first case used identical BDC temperature and pressure as the bowl in-piston case. Because the flat-top geometry results in lower heat transfer, the temperature-time history for this flat-top case results in more advanced timing. A second simulation was performed using a slightly 
lower intake temperature so that the combustion timing for the flat-top case was similar to that of the bowl-in-piston case. The total mass of the gasses within the cylinder was kept constant for both cases.

The mass versus temperature distribution at TDC from KIVA for the each of the cases is shown in Figure 3.2.8. The two flat top cases are very similar, with the same timing case having slightly lower temperatures over the higher temperature portion of the mass distribution. The flat top geometry has more of the mass concentrated at higher temperatures than the base bowl in-piston case and greater temperature uniformity than the base case.

Figure 3.2.9 shows a comparison between results for the flat-top cases relative to the base case. The IMEP for both flat top cases is higher than for the base case, due to lower heat transfer. The burn duration for the flat top geometry is $25 \%-30 \%$ more rapid than the base case. The greater uniformity in temperature of the flat-top geometry results in the heat release being more rapid. The shifting of the temperature distribution towards higher temperatures results in more of the reacting gasses being at higher temperature and therefore higher combustion efficiency for the flat-top cases. The peak cylinder pressure is higher for the same BDC temperature case as a result of earlier timing.

The hydrocarbon (HC) emissions are dramatically reduced by $30-50 \%$ for the flat-top cases compared to the base case. The carbon monoxide (CO) emissions are comparable or higher than the base case. The $\mathrm{CO}$ emissions are due to intermediate temperature regions within the combustion chamber and so the flat-top case apparently 
has more volume of the combustion gasses in which incomplete oxidation occurs. As $\mathrm{CO}$ formation and destruction rates are very sensitive to temperature, multi-zone simulations with a larger number of zones could provide more insight into the spatial regions where $\mathrm{CO}$ is produced.

\subsubsection{Effect of Swirl}

Swirl, axially centered fluid rotation within the cylinder, is often a major consideration in engine combustion chamber design. Swirl is usually characterized by the swirl ratio, which is defined as the initial axial rotational speed of the fluid within the cylinder relative to the engine speed, where the axial direction is normal to the piston face. Moderate to high levels of swirl (swirl ratio of 2-5) have been found to enhance the Diesel combustion process. But, because of the increased level of fluid motion, swirl will tend to increase convective heat transfer from the combustion chamber. In an HCCI engine, the level of swirl could improve performance if it resulted in lower engine heat transfer. Since the temperature distribution in the cylinder has strong influence on the combustion efficiency and emissions, changing the swirl could affect combustion performance. A reduction in swirl could be hypothesized to increase the fraction of charge volume at increased temperature, thus resulting in higher combustion efficiency and lower hydrocarbon emissions. The TDI combustion chamber has a moderate swirl ratio of 2.0. This study looks at the effect of reducing the swirl ratio on performance and emissions in the engine. The comparison is between cases with bowl in-piston geometry. The base case has the 2.0 swirl ratio and the low swirl cases have swirl ratios of 0.2. Swirl of 0.2 was chosen instead of zero to give better definition to the velocity field as an initial condition for KIVA. Two low swirl cases are used: one with the same 
$\mathrm{BDC}$ temperature and pressure, and one with the same combustion timing. Lower swirl reduces heat transfer and causes the timing of combustion to advance relative to the base case when intake conditions are the same.

Figure 3.2.10 shows pressure traces for the base and low-swirl cases. The lowswirl case with the same initial conditions at BDC has advanced timing relative to the base case. Figure 3.2.11 shows the TDC mass-temperature distribution within the combustion chamber. The temperature distribution within the combustion chamber for the low swirl cases is shifted to slightly higher temperatures, although not as dramatically as in the flat-top cases (Figure 3.2.7).

Figure 3.2.12 shows the comparison between performance and emissions parameters for the low swirl cases and the base case. For the case with the same intake temperature, the reduction in swirl yields improvement in IMEP, combustion efficiency, $\mathrm{HC}$ and $\mathrm{CO}$ emissions when compared to the base case. In addition, the peak cylinder pressure is higher and the burn duration slightly shorter. For the case with the same timing, almost no difference is found between the two cases in IMEP, peak cylinder pressure, and combustion efficiency. Slight reduction in burn duration and HC emissions are seen. The most dramatic change is a near doubling of $\mathrm{CO}$ emissions. This may be somewhat exaggerated result, as prediction $\mathrm{CO}$ emissions are very sensitive to slight changes in the modeling parameters. Nevertheless, any improvement in performance due to swirl appears to be primarily due to the timing advance that occurs because of slightly reduced heat transfer. Reducing swirl from the moderate to low level may have relatively little effect on engine performance, and could be detrimental with 
respect to emissions. These results are consistent with previous multi-zone HCCI simulations [45]. 
Table 3.2.1 - Engine data and operating parameters for comparison point

\begin{tabular}{|l|c|}
\hline Equivalence ratio & 0.44 \\
\hline Gross IMEP (bar) & 3.6 \\
\hline Peak cylinder pressure (bar) & 60.1 \\
\hline Burn duration (CAD) & 7.4 \\
\hline Engine speed (RPM) & 1800 \\
\hline Intake manifold pressure (bar) & 0.91 \\
\hline Cylinder Displacement (L) & 0.474 \\
\hline Bore (cm) & 7.95 \\
\hline Stroke (cm) & 9.55 \\
\hline Connecting rod length (cm) & 14.4 \\
\hline Swirl Ratio & 2.0 \\
\hline
\end{tabular}


Table 3.2.2 - Mass fractions in each zone used for 10-zone simulations. Zone 1 corresponds to lowest temperature zone and zone 10 corresponds to highest average temperature zone.

\begin{tabular}{|c|c|}
\hline Zone & Zonal mass fraction \\
\hline 1 & 0.0100 \\
\hline 2 & 0.0100 \\
\hline 3 & 0.0126 \\
\hline 4 & 0.0205 \\
\hline 5 & 0.0335 \\
\hline 6 & 0.0547 \\
\hline 7 & 0.0892 \\
\hline 8 & 0.145 \\
\hline 9 & 0.237 \\
\hline 10 & 0.387 \\
\hline
\end{tabular}




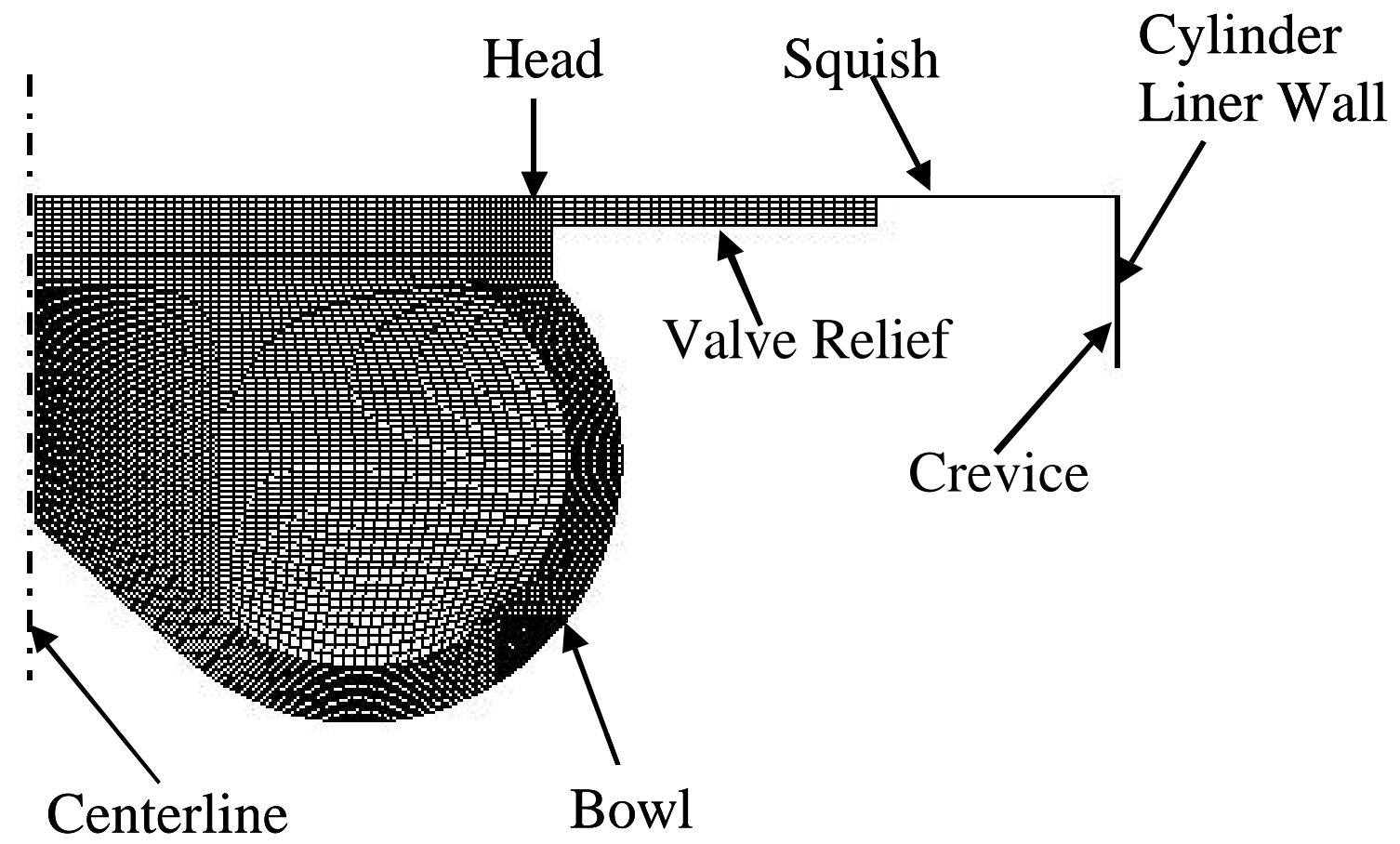

Figure 3.2.1 - Axisymmetric grid at TDC for baseline bowlin-piston geometry in the TDI combustion chamber. 


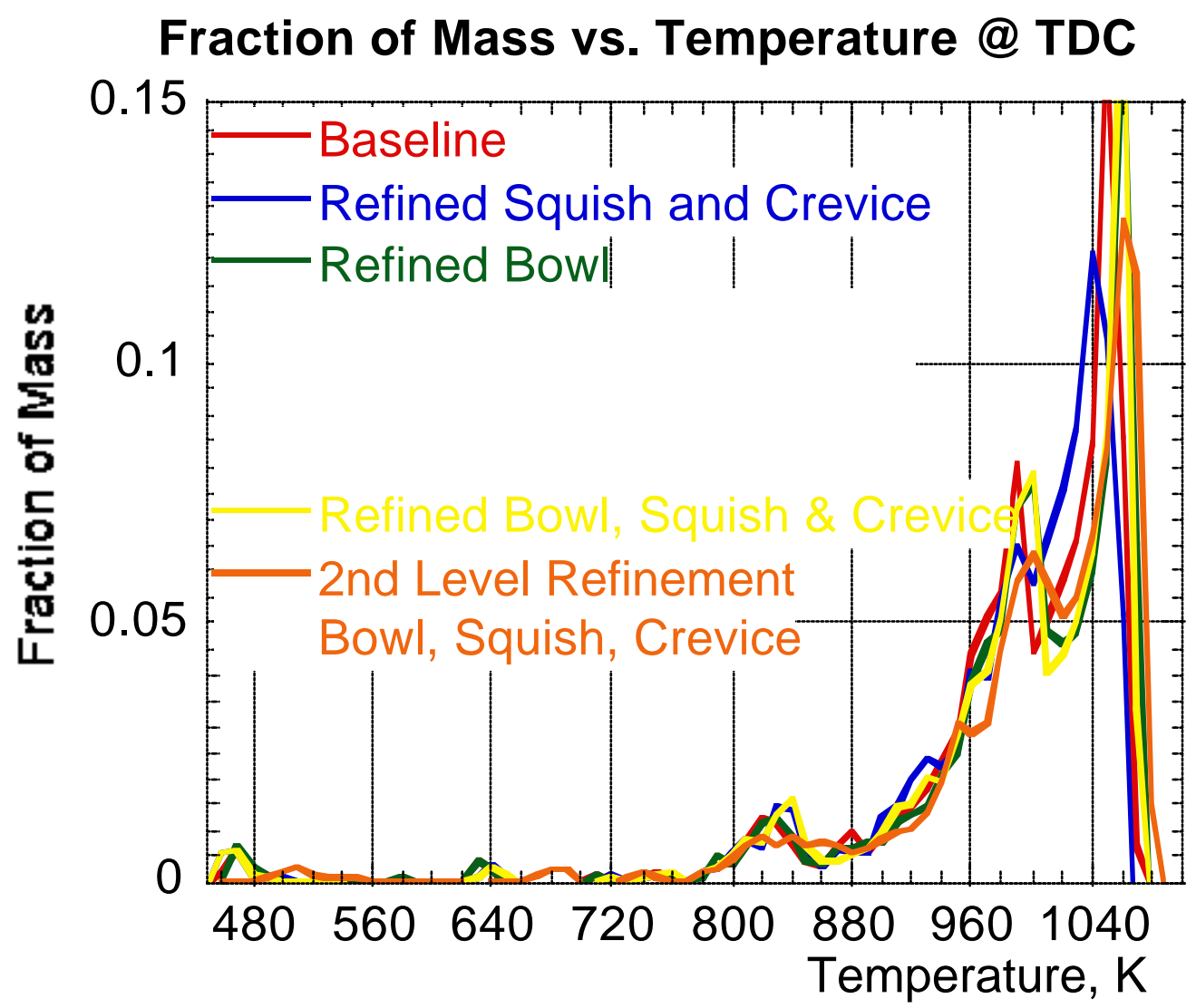

Figure 3.2.2 - Comparison of TDC mass-temperature distributions for different levels of grid refinements for the base TDI combustion chamber geometry. 


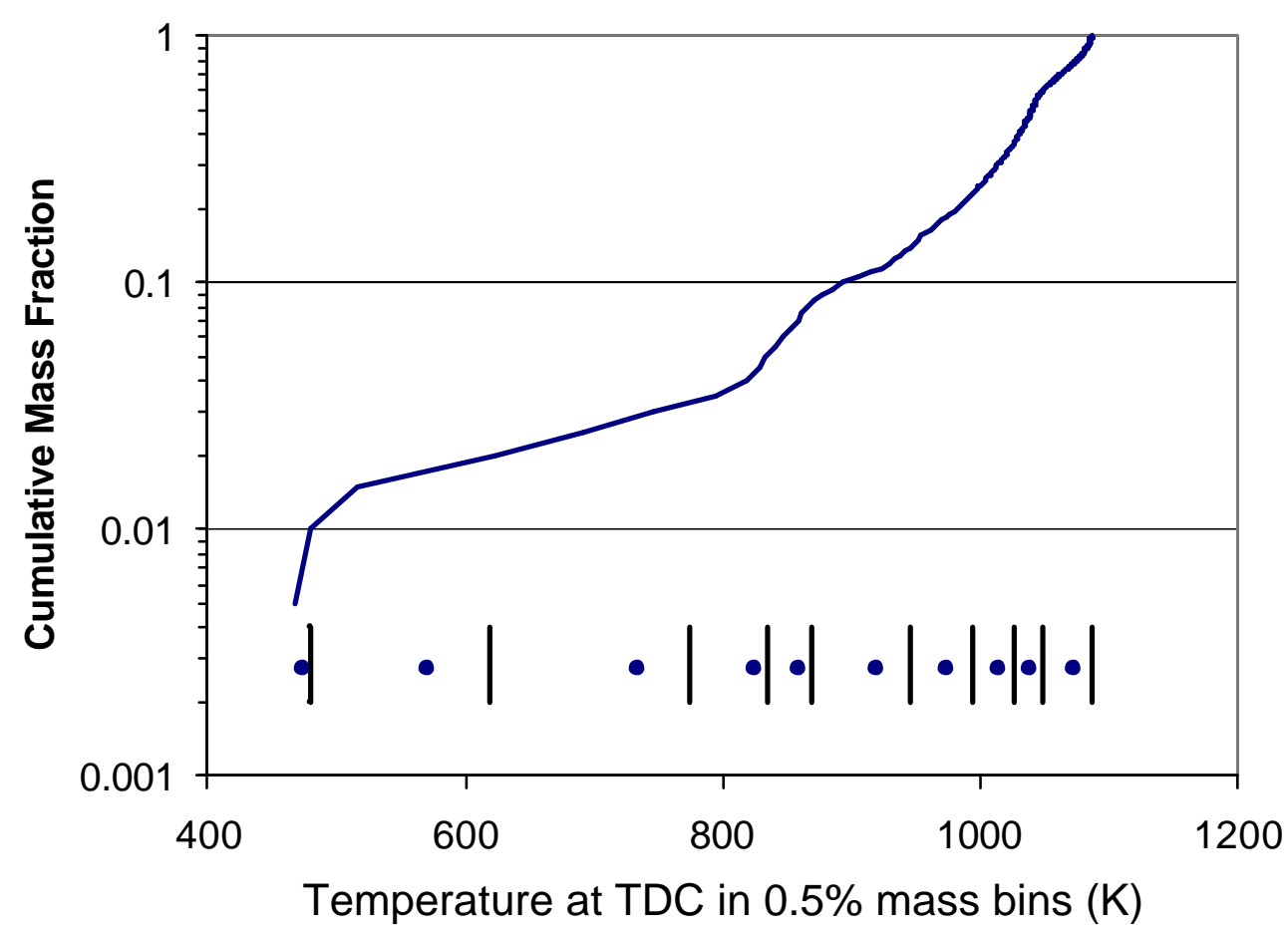

Figure 3.2.3 - Cumulative mass fraction and associated temperature for the base case TDI combustion chamber at TDC. Vertical bars on the chart show zone boundaries as defined by the masses in table 3.2.2. Dots represent the average zone temperature within the zone at TDC. 


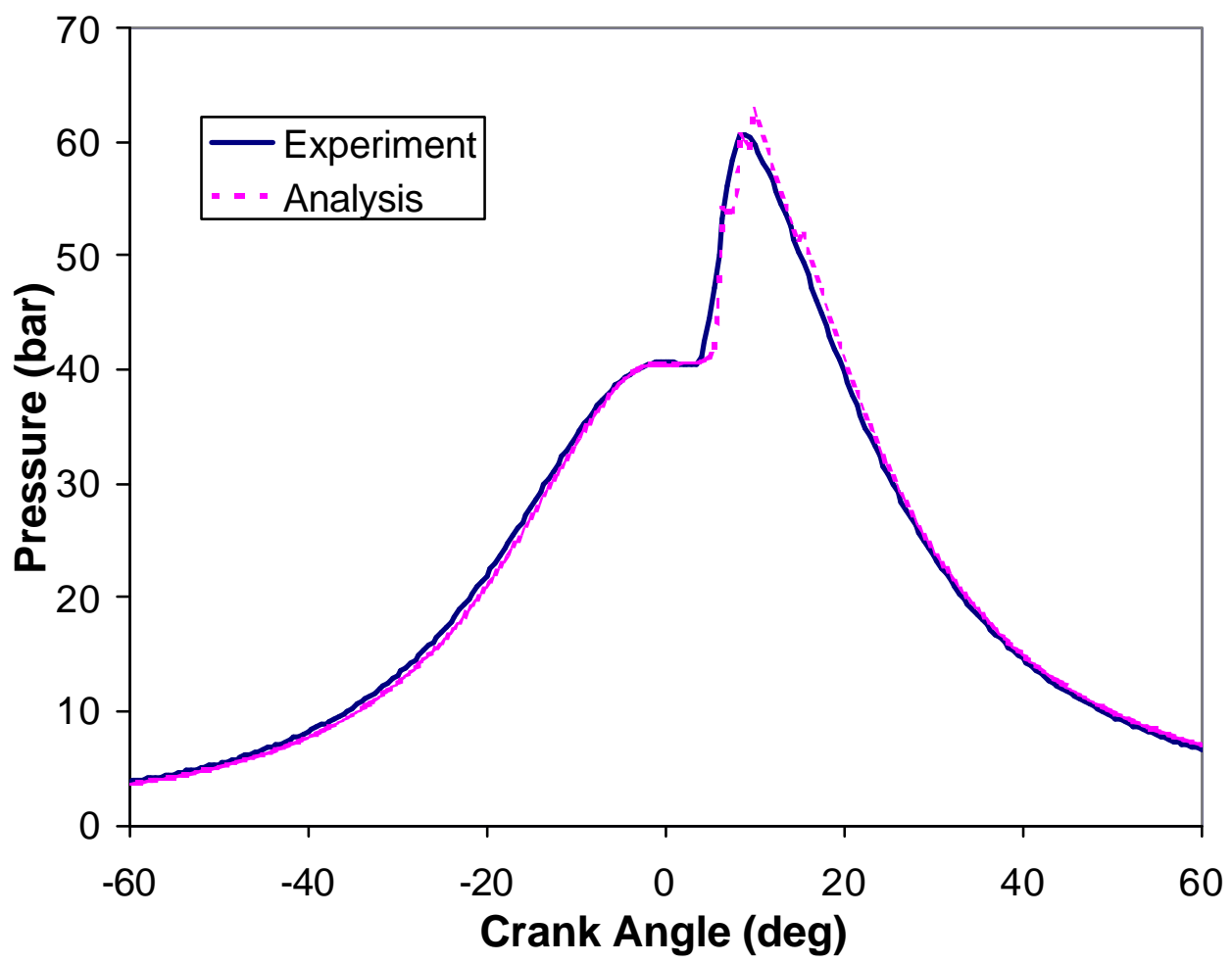

Figure 3.2.4 - Comparison of simulated and experimental pressure traces for base case. Solid line is experimental data, dashed line is ten-zone simulation. 


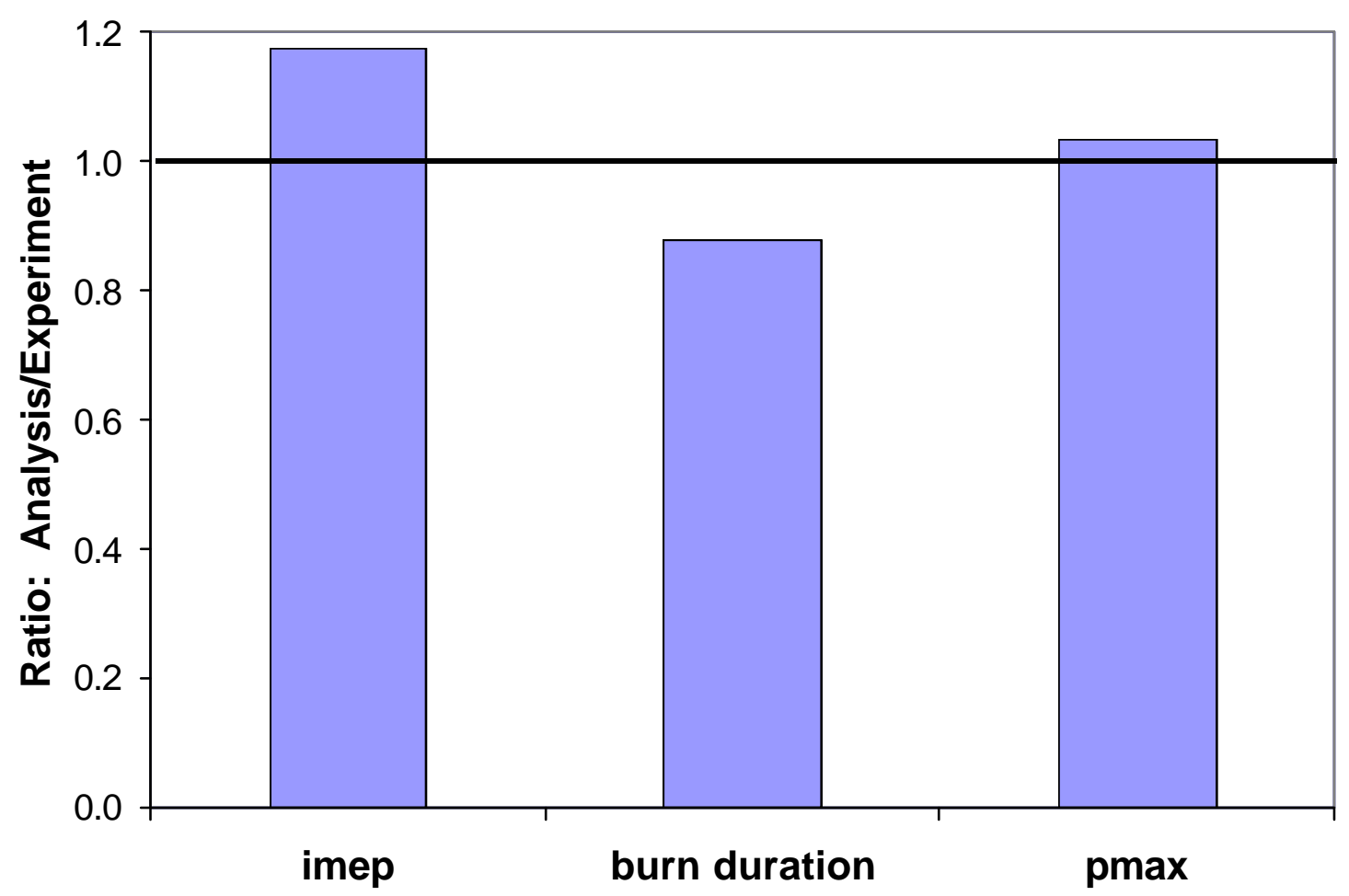

Figure 3.2.5 - Ratio of simulated to experimental operating parameters for base case. 


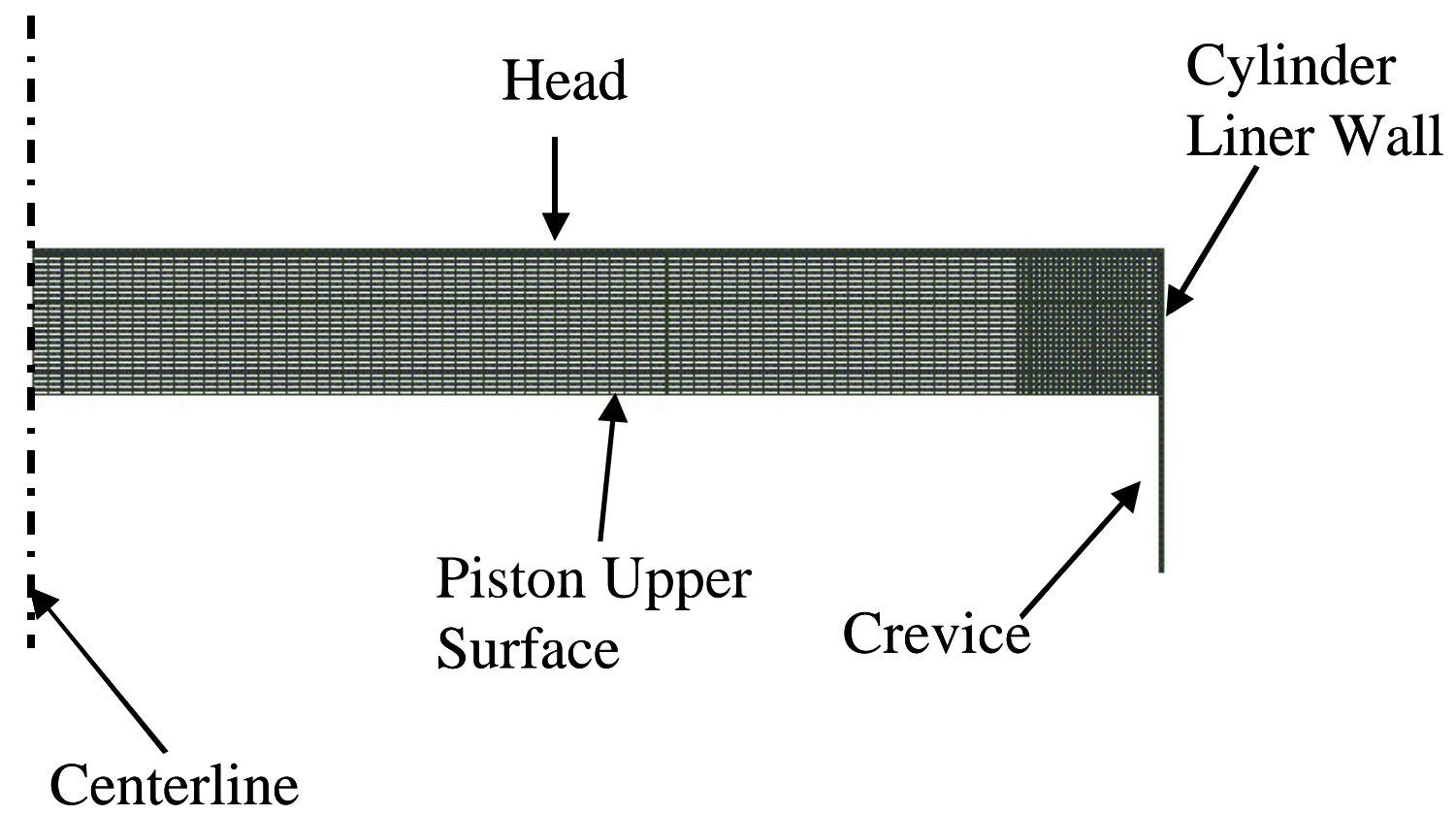

Figure 3.2.6 - Axisymmetric at TDC grid for flat-top geometry in the TDI combustion chamber. Total volume, bore, stroke, and crevice dimensions, are identical to baseline geometry. 


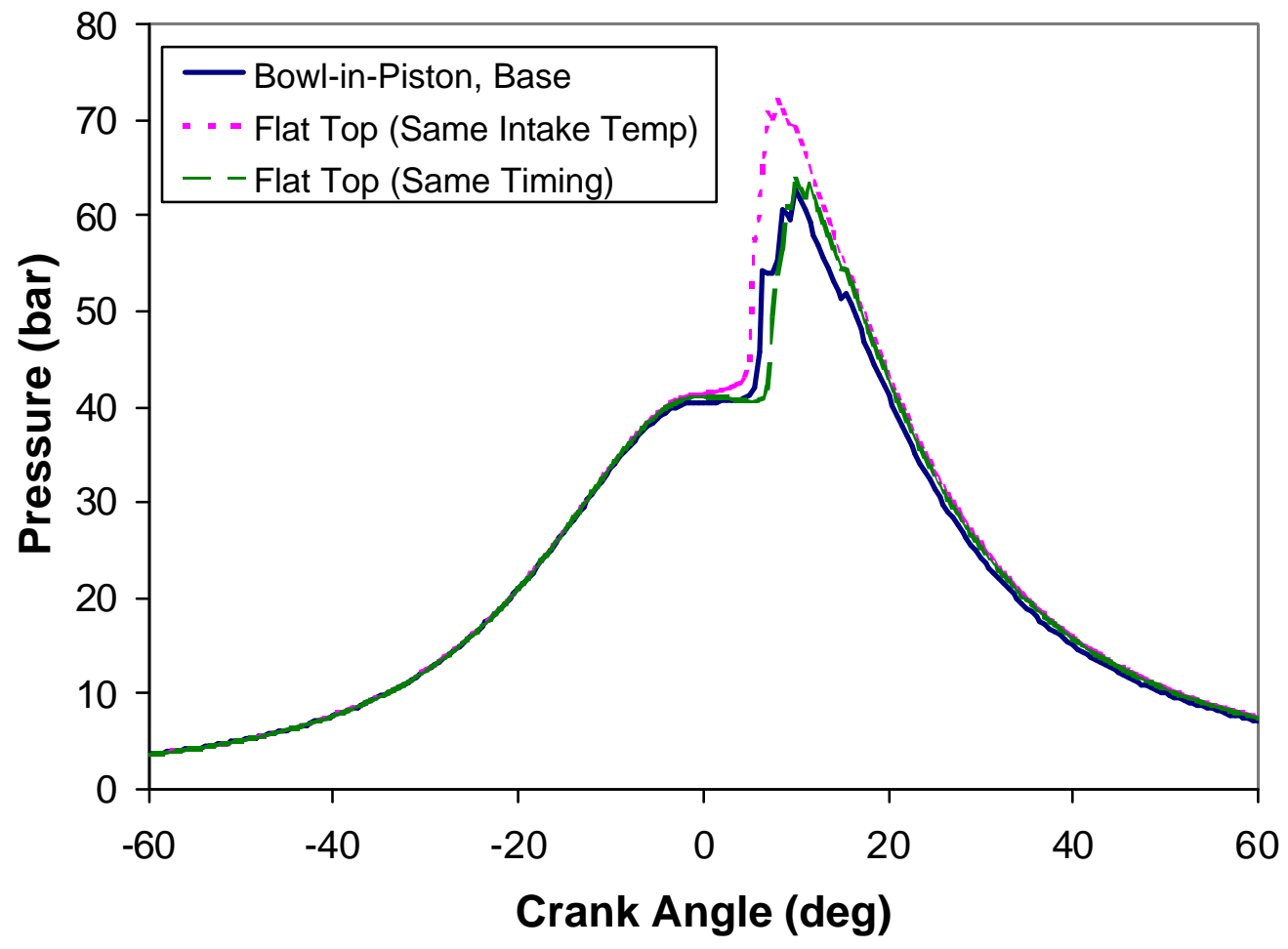

Figure 3.2.7 - Pressure traces from simulations of the base bowlin-piston case and the two flat-top combustion chamber cases. 


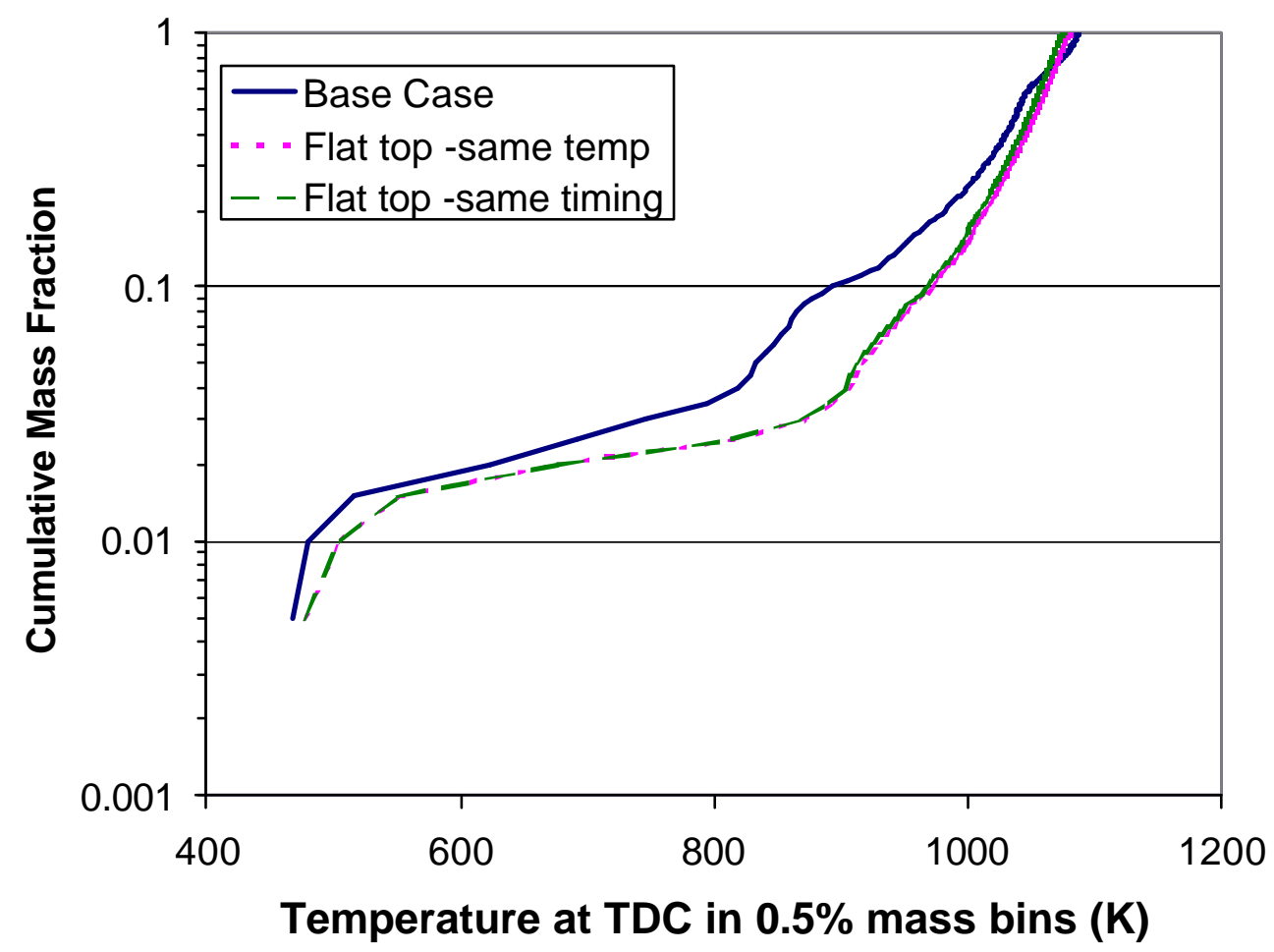

Figure 3.2.8 - TDC mass-temperature distributions for base case and flat-top cases. 


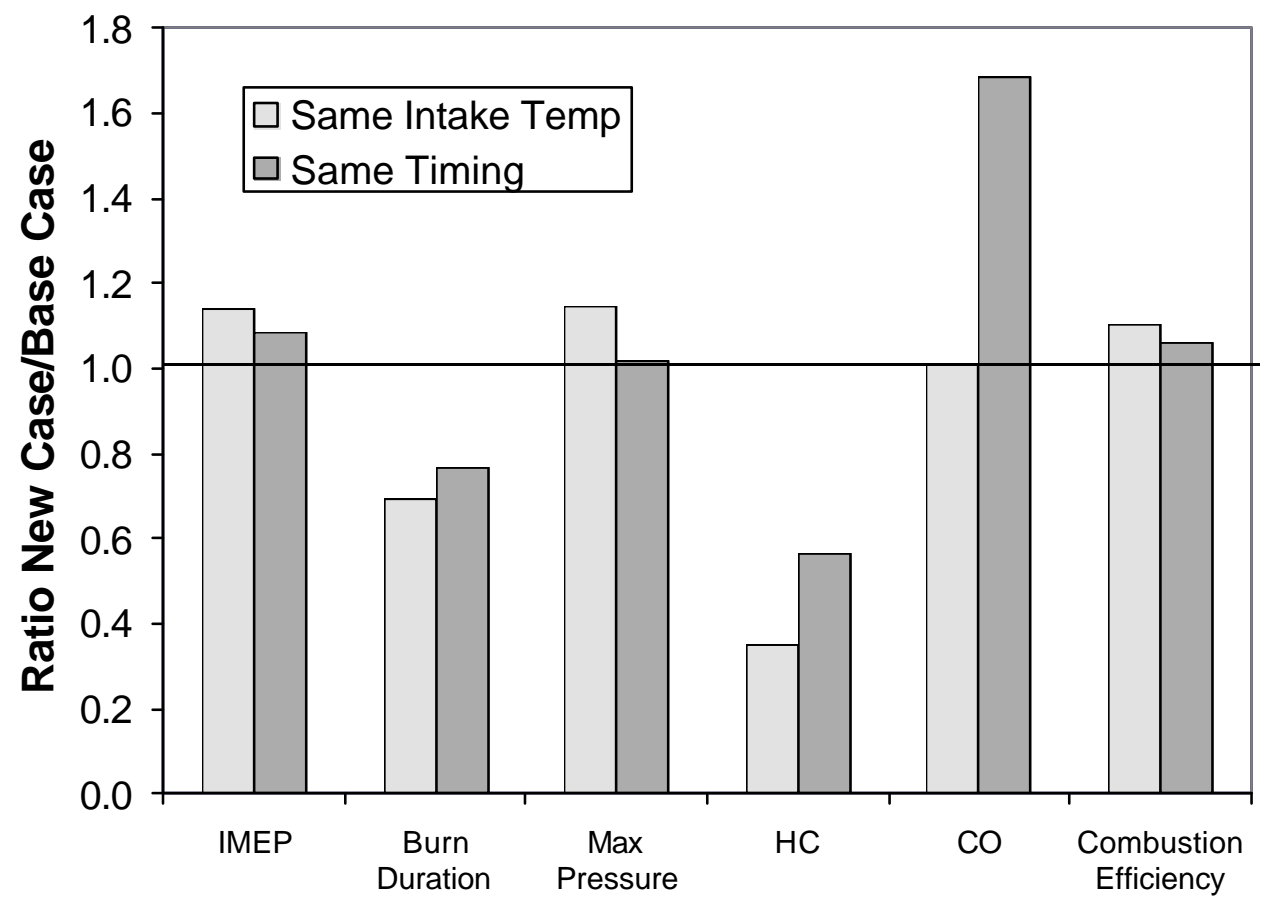

Figure 3.2.9 - Ratio of simulation results of performance and emissions for two flat-top cases to the base case. 


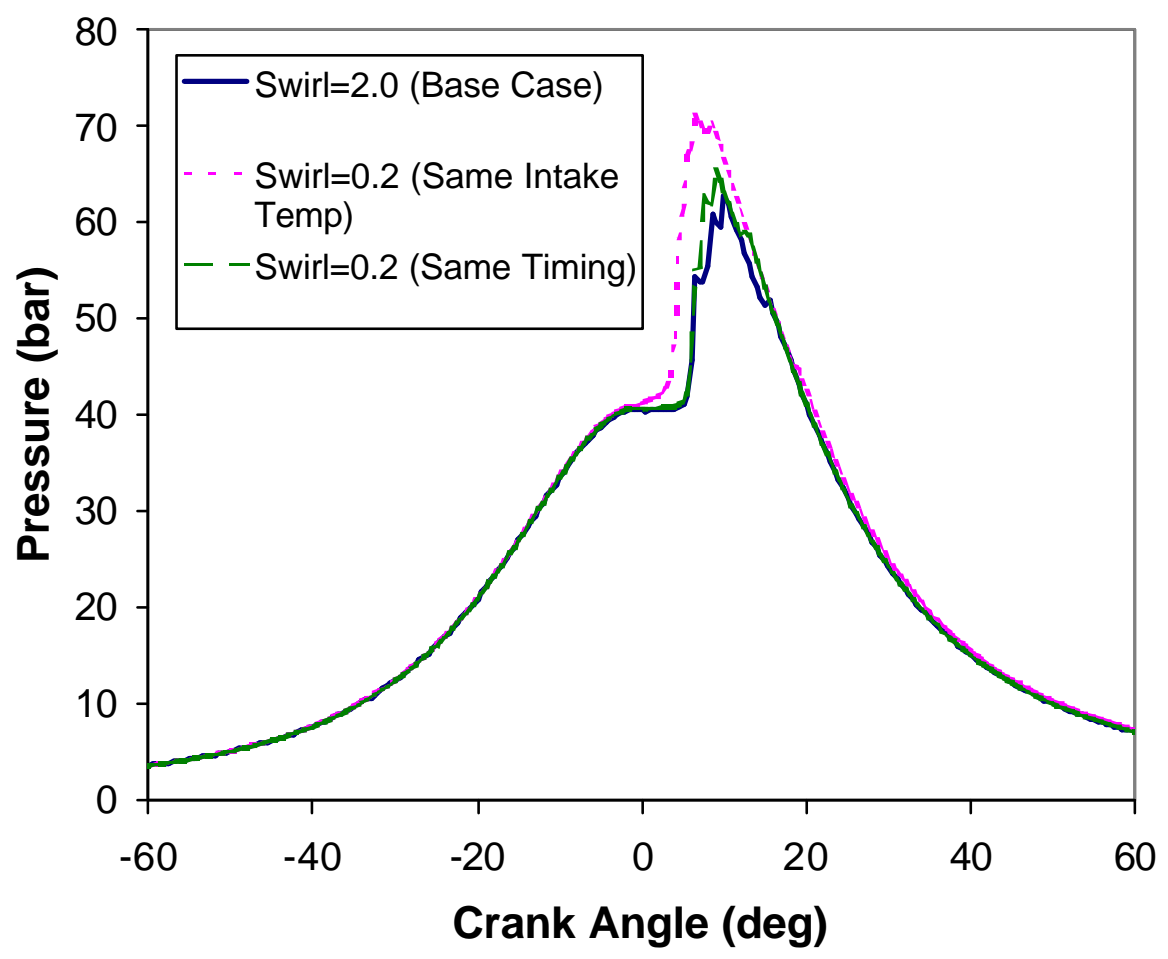

Figure 3.2.10 - Pressure traces from simulations of the base case and the two low-swirl cases. 


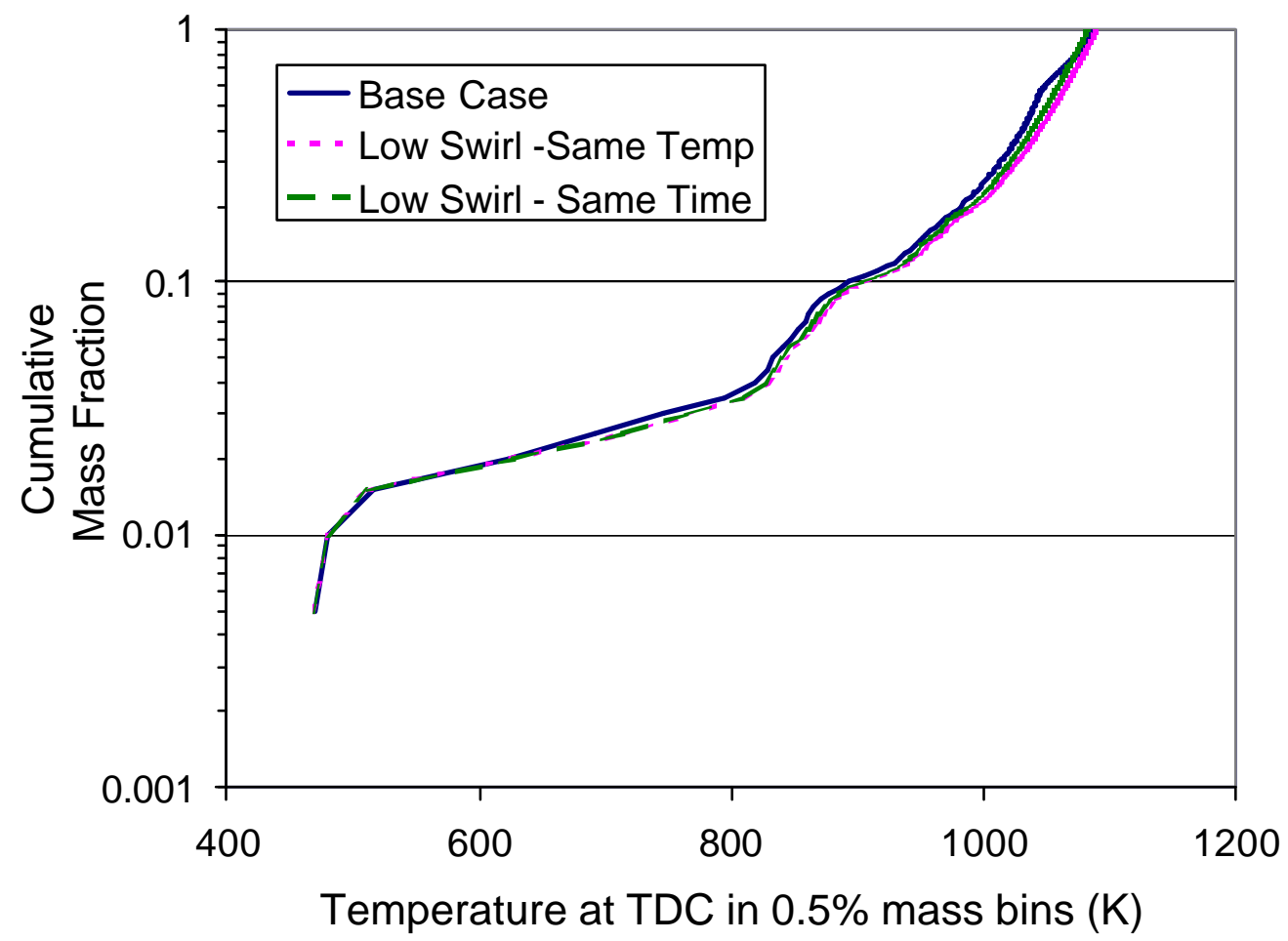

Figure 3.2.11 - TDC mass-temperature distributions for base case and low-swirl cases. 


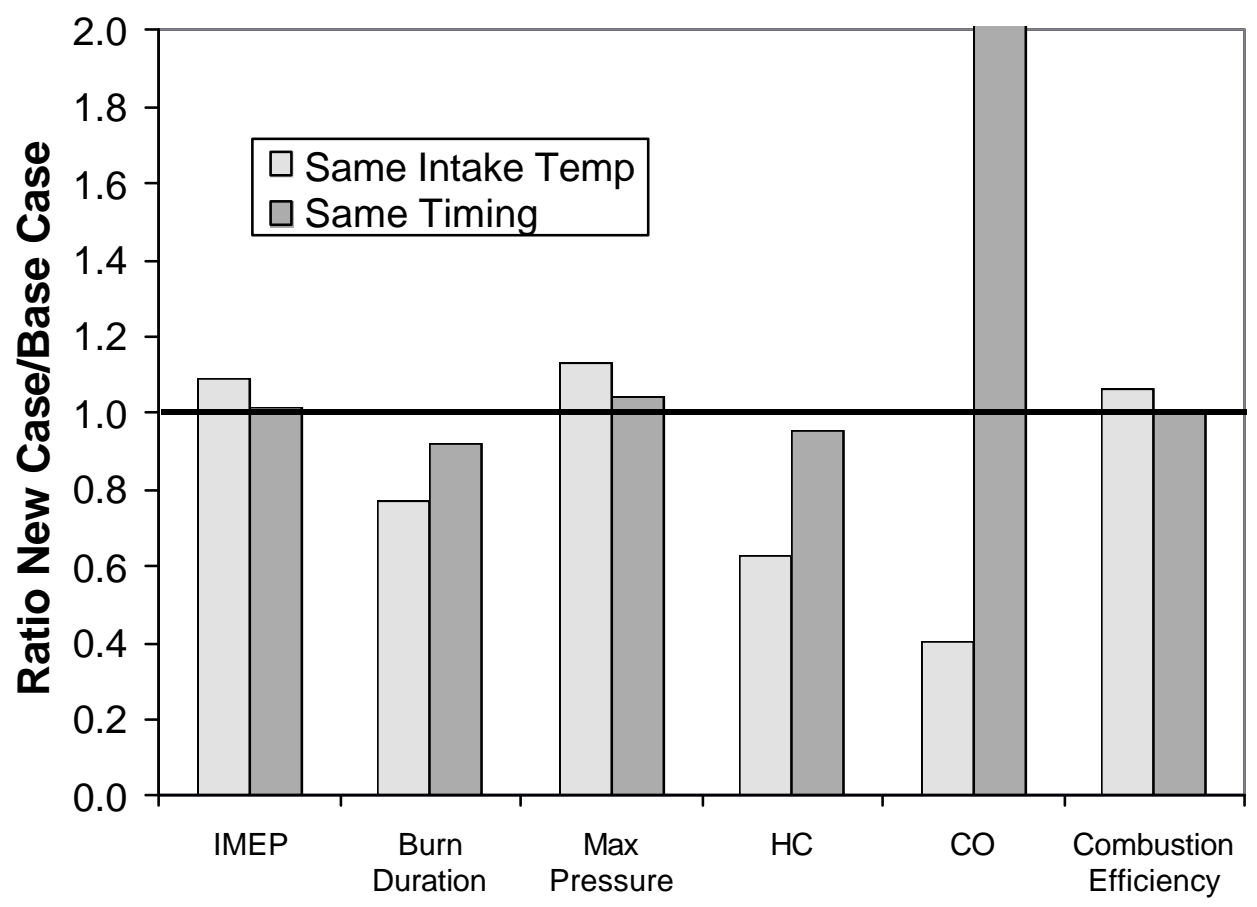

Figure 3.2.12 - Ratio of simulation results of performance and emissions for two lowswirl cases to the base case. 


\section{HCCI Combustion Experiments}

Implementation of HCCI combustion requires understanding fundamental parameters that affect combustion timing. Experiments have been conducted in a singlecylinder and multi-cylinder engine to investigate fundamental performance characteristics of HCCI engines. The single-cylinder engine operates as an isolated system while the individual cylinders in the multi-cylinder engine interact with each other during operation. The two engines are similar in individual cylinder displacement and thus provide a good framework for comparison.

\subsection{Single-Cylinder HCCI Experiments}

A key to practical implementation of the HCCI concept in an engine lies in the development of methods to control combustion timing. Control methods need to be designed to adjust the heat release process to occur at the appropriate time in the engine cycle. Single cylinder engine experiments and chemical kinetic simulations are applied to study the effect of variation in fuel, equivalence ratio, and intake temperature on ignition timing. The intent of these single cylinder tests is to provide some basic insight into the control of HCCI combustion. In addition to the experiments, single-zone simulations have been performed to give further insight into the combustion process and the ability of single zone modeling to predict operational trends. The data demonstrate some of the operational issues that need to be addressed. Single cylinder experiments provide unambiguous emissions data compared to multi-cylinder experiments. 


\subsubsection{Experimental Setup}

Experiments have been performed on a single cylinder Cooperative Fuels Research (CFR) engine modified for HCCI operation. The engine is naturally aspirated and an intake manifold heater has been installed to allow for preheating the intake air. The engine characteristics and operating parameters used in these experiments are listed in Table 4.1.1. Pure propane and a blend of 15\% (by volume) dimethyl-ether (DME) in methane were the fuels tested. These tests have been designed to characterize the operating parameters that influence HCCI engine emissions and performance. The fuel, intake-air temperature, and equivalence ratio were varied in these experiments.

Testing was also conducted with pure methane fuel, but stable HCCI operation was only achieved for one operating point at the upper limit of preheating capacity and compression ratio. Operation in HCCI mode with pure methane was achieved initially using blend of methane and DME. The flow rate of each fuel was independently controlled and once stable operation was achieved, the DME flow rate was gradually reduced to zero.

The CFR engine has been fitted with an Optrand AutoPSI-S (200 bar full-scale range) combustion pressure sensor. The signal is acquired with a National Instruments PCI-6110E data acquisition (four input channels with a 5 mega-sample per second per channel maximum acquisition rate) board in a Windows NT computer system. The pressure is acquired at every 0.1 crank angle degrees (CAD) using a 3600/rev crankshaft encoder. Significant noise was present in the pressure data, despite extensive efforts to suppress it. An eighth-order Butterworth digital low pass filter has been used to filter the 
raw pressure data, in post-processing. The raw pressure signal is filtered forward and backward to eliminate any phase shift. The pressure data is filtered, and then averaged. The rate of heat release was calculated from the average pressure trace using the method described in the Heywood text [62].

Propane and the DME-in-methane blend have similar reaction characteristics in an HCCI engine cycle, exhibiting cool flame heat release [40, 41]. These lowtemperature reactions increase charge temperature (and generate a radical pool initiating further chemical reactions) as the charge is compressed. Pure methane has very little cool flame chemistry causing the greater difficulty achieving conditions for autoignition in an engine cycle relative to the other fuels [63].

Figure 4.1.1 shows typical pressure traces for HCCI operation of the CFR. The figure also shows several overlaid pressure traces that demonstrate the low cycle-tocycle variation in HCCI operation. These data are filtered at a cutoff frequency of around $3 \mathrm{kHz}$. This cutoff frequency was selected because it minimized the noise in the calculation of the rate of heat release without compromising the pressure trace. The analyses of all of the experimental pressure traces were performed on data filtered with this cutoff frequency. This cutoff frequency does eliminate the acoustic "knock" signal from the pressure trace, but allowing higher frequencies led to a significant contribution of noise into the calculation of heat release rate.

An acoustic wave phenomenon is generally present in the pressure traces. This knock- like pressure wave is fairly low amplitude, but Fourier analysis of the instantaneous pressure data shows that the frequency is consistent from cycle-to-cycle. 
Figure 4.1.2 shows a few instantaneous pressure traces at crank angles near the combustion event. These pressure data are low pass filtered at a $10 \mathrm{kHz}$ cutoff so that the knock frequency could be resolved. The frequency of roughly $5 \mathrm{kHz}$ near TDC corresponds to the expected knock frequency for this engine bore, $f=a /(2 B)$, where $f$ is frequency, a is sound speed and B is the engine bore. While the frequency of the wave is consistent the phasing of the pressure wave varies from cycle-to-cycle.

Figure 4.1.3 shows the rate of chemical heat release that has been estimated from the pressure trace for a typical cycle. The Woschni heat transfer correlation is used to estimate the wall heat transfer and thus to more accurately estimate chemical heat release [50]. Acoustic and electronic noise present in the pressure data propagates significant noise into the heat release calculation. Numerical differentiation, used to determine the heat release, significantly amplifies the noise, but the main release of heat is sufficiently intense to be well characterized, despite the noise. In a practical engine a marker for the combustion timing is necessary for closed loop control. The peak value of the rate of heat release has been taken here to be the marker for the timing of the heat release event. This marker essentially corresponds to the peak of the pressure rate of change and is easily identified. The performance data have been presented with respect to this peak of the heat release rate.

\subsubsection{Single-Cylinder Experimental Results}

Figures 4.1.4 and 4.1.5 show the intake equivalence ratio plotted against the peak of heat release for propane and the DME-in-methane blend. The intake equivalence ratio is determined using the measured flow rates of fuel and intake air. Each fuel has 
been operated at three different intake temperatures. The intake temperature is measured upstream of the intake valve, the charge temperature at intake valve closure is not known. Heat transfer and hot residuals affect the in-cylinder temperature. The measured intake temperature should be considered only as a relative indicator of the charge air temperature at valve closure, because the true temperature could be higher or lower than this measured temperature. The relationship between equivalence ratio and crank angle for peak of heat release for these fuels is essentially monotonic. As equivalence ratio is increased, the walls and residual gas become hotter, resulting in an earlier appearance of the main autoignition event. Ignition temperature is reached earlier in the cycle. For an individual fuel, the curves appear to be consistent for each inlet temperature and shifted to lower equivalence ratio as temperature increases. This indicates that the ignition temperature is reached earlier in the cycle for the same equivalence ratio, as would be expected. The propane curves are much steeper than the DME-in-methane curves. This is likely due to the difference in chemistry between the fuels. One can speculate the following: This difference in slope could be due to the decrease in the negative partial pressure coefficient of methane, which causes reduced reactivity as the partial pressure of methane increases. Also methane can tend to be a sink for radicals which could also reduce the slope of the equivalence ratio versus timing. For each intake temperature the lower limit of equivalence ratio is the lowest level at which stable operation could be achieved.

Figures 4.1.6 and 4.1.7 show the peak cylinder pressure as a function of combustion timing. The trends shown for both fuels are consistent in that the peak pressure is relatively flat at peak of heat release near TDC and then decreases as the 
peak of heat release occurs later in the cycle. The peak pressure increases with decreasing temperature due to the higher volumetric efficiency at lower intake temperature.

Figures 4.1.8 and 4.1.9 show burn duration versus timing for both fuels. The burn duration is defined as the crank angle difference between the occurrence of $10 \%$ of the peak value of rate of heat release on the rise and fall of the heat release curve (i.e. the crank angle width of the heat release rate curve). For propane, the burn duration increases smoothly as the timing moves later, ranging from roughly 7 to 9 crank angle degrees (CAD). Lower inlet temperature seems to reduce the burn duration for propane. For the same heat release timing, the equivalence ratio will be higher for lower inlet temperature. The higher equivalence ratio results in hotter walls and hotter residuals. The DME-in- methane blend follows a similar trend in burn duration until the peak of heat release occurs at 7 CAD ATDC. As combustion becomes later than this the burn duration jumps to 13-14 CAD. This discontinuity is likely due to the kinetics of the dual fuel mixture. The heat release rate has a dual mode nature for this fuel blend. Chemical kinetic modeling shows that as the timing occurs later in the cycle the DME is almost entirely consumed before the methane begins to react. This lag in reactivity of the two components coupled with the expansion cooling could result in significant extens ion of the heat release. This will be further discussed in the modeling section.

Figures 4.1.10 and 4.1.11 show the indicated mean effective pressure (imep) versus crank angle for peak rate of heat release. The imep follows a fairly smooth trend with timing. The peak imep shifts with different intake conditions. For increasing intake temperature the timing of the peak imep can be seen to advance. With lower intake 
temperatures, the equivalence ratio, required to achieve earlier combustion, increases. A tradeoff between equivalence ratio and the timing of the pressure rise determine the peak imep. The reduction in overall imep with elevated intake temperature is due to reduction in volumetric efficiency. It should be noted that in this naturally aspirated, unthrottled engine, the imep at the lower limit of stable operation is 3-3.5 bar, depending on the fuel. In order to idle the engine, the available chemical energy in the cylinder must be reduced either by addition of residual gas or by throttling. The earlier singlezone simulation of HCCI engine operation (3.1.2) has demonstrated that residual gas addition may be an effective way of reducing output power for idle operation.

Figures 4.1.12 and 4.1.13 show the gross indicated thermal efficiency versus timing of the peak of rate of heat release. The efficiency increases uniformly with later combustion timing. This is likely due to decreasing heat transfer with the lower temperatures occurring in later timed, higher equivalence ratio combustion. The efficiency varies significantly (from 32-45\%) with a relatively small change in the timing (12 CAD). This change in efficiency suggests that heat transfer becomes much greater as the equivalence ratio increases, resulting in lower efficiency.

Figures 4.1.14 and 4.1.15 show the hydrocarbon emissions versus timing of peak heat release rate. The hydrocarbon emissions essentially increase linearly with later timing. The lower hydrocarbon emissions as combustion advances, despite the presence of more fuel, may be due to a variety of factors. The higher equivalence ratio mixture causes more rapid pressure rise during the autoignition process, resulting in a more of the charge reaching temperatures that allow ignition. The hydrocarbon reduction at higher equivalence ratio also may result from late hydrocarbon oxidation during the 
expansion stroke, also due to the higher overall temperature due to greater heat release at higher temperature. The energy released due to late hydrocarbon oxidation would do little additional work on the piston.

Figure 4.1.16 shows the carbon monoxide (CO) in exhaust for the DME-inmethane tests. $\mathrm{CO}$ measurements were not available during the propane tests. The trend in the carbon monoxide is initially to decrease as peak heat release occurs later, and then to increase after a minimum value. One may speculate that exhaust $\mathrm{CO}$ is a result of incomplete combustion in intermediate temperature regions where the $\mathrm{OH}$ radical concentration becomes significantly diminished, resulting in less conversion of CO to $\mathrm{CO}_{2}$. For earlier combustion the charge is hotter overall and the mass in the intermediate temperature regions may be less, but more carbon is available because of increased equivalence ratio. As the combustion occurs later, the charge is cooler overall and the mass in the intermediate temperature regions is greater, resulting in a greater concentration of $\mathrm{CO}$.

Figures 4.1.17 and 4.1.18 show oxides of nitrogen $\left(\mathrm{NO}_{\mathrm{x}}\right)$ emission versus timing of peak of heat release rate. The results indicate the increase in emissions as the heat release advances due to higher peak temperatures due to higher equivalence ratio. For lower intake temperature, higher equivalence ratio is needed to achieve the same combustion timing, resulting in higher $\mathrm{NO}_{\mathrm{x}}$ at the same timing as the intake temperature is reduced. $\mathrm{NO}_{\mathrm{x}}$ levels of less than 1 to $10 \mathrm{ppm}$ can be achieved with late combustion. 


\subsubsection{Single-Zone Simulation of CFR Operating Conditions}

The single zone model has been used to simulate the HCCI combustion process in the CFR engine. The 102 species mechanism is used to model the chemistry for the DME-in-methane blend and the 179 species mechanism has been used to model the propane chemistry. The operating parameters used in the simulation are the same as specified in Table 1 . For each operating point the simulation requires roughly 45 seconds of CPU time for the 102 species mechanism and roughly 3 minutes of CPU time for the 179 species mechanism on a single processor of a Compaq AlphaServer 4100 $5 / 533$.

Residual gas, with a fraction corresponding to the clearance volume of the cylinder, is mixed with the displaced volume of fresh charge. The heat transfer correlation requires specification of the wall temperature. The wall temperature must be specified for the heat transfer correlation and is set at a constant value of $157^{\circ} \mathrm{C}$.

The results for equivalence ratio, imep, indicated efficiency, maximum cylinder pressure, and $\mathrm{NO}_{\mathrm{x}}$ emissions versus the timing for peak rate of heat release are shown in Figures 4.1.19 through 4.1.28. For both fuels, the propane and the DME-in-methane blend, the results for HCCI operation has been simulated for intake temperatures of $150^{\circ} \mathrm{C}, 160^{\circ} \mathrm{C}$, and $170^{\circ} \mathrm{C}$. These simulations are not designed to be a direct validation of the experimental data, because the initial conditions in the engine are not well established here. These results show trends consistent with the experimental data in the general trends with respect to intake temperature. The predicted efficiency shows an overall increase as the peak of heat release occurs later. The imep shows a decline with 
later timing that is consistent with only part of the trend of imep shown in the experiments. As mentioned previously, this inconsistency can be explained as being due to increased heat transfer in higher equivalence ratio. The $\mathrm{NO}_{\mathrm{x}}$ trend is very consistent as it depends principally on the peak temperature during the cycle. Accurately modeling engine heat transfer characteristics is very important in modeling the HCCI combustion process correctly.

The experimental results show that the burn duration can become significantly longer as the combustion timing occurs later and later in the cycle. Single zone modeling has been performed to further investigate this phenomenon. The 102 species methane and DME reaction mechanism has been used in this HCT simulation of the CFR engine. The $15 \%$ DME-in-methane blend is studied for equivalence ratio ranging from 0.25 to 0.4 . Figure 4.1.29 shows the rate of heat release versus crank angle for four different equivalence ratios. This mixture is very extreme with a very high cetane number fuel (DME), and very low cetane number (methane). The heat release is clearly bimodal, and as the equivalence ratio decreases and the timing moves later and later, the separation between the primary heat release and the secondary heat release becomes increasingly larger. It is also apparent that the burn duration becomes increasingly longer as ignition occurs later in the cycle.

Figure 4.1.30 shows the fraction of each species consumed for the four different equivalence ratios. This figure shows that with decreasing equivalence ratio, the timing for the consumption of the DME delays gradually, while the timing for the consumption of methane becomes significantly later as the equivalence ratio is reduced. The response of individual components in multi-component fuels can significantly affect the heat 
release process. As most practical fuels contain several components (gasoline, commercial propane, natural gas) variations in the ignition and heat release process due to component chemistry should be considered.

The experimental and simulation results provide fundamental information related to control of HCCI engine combustion timing. In practical operation, selection of the operating points may require considering tradeoffs between efficiency and output power. Efficiency typically will increase with delayed timing, while output power is maximized near TDC. The compensation variable that is most related to engine control in this case is intake temperature. For a thermally controlled engine the load and efficiency should be considered with respect to intake temperature, and then the temperature and equivalence ratio would be selected to meet the load requirement with highest efficiency. Emission constraints would also be incorporated into the operating point selection process. 
Table 4.1.1 - CFR engine geometry and operating parameters

\begin{tabular}{|l|r|}
\hline Displacement & $0.612 \mathrm{~L}$ \\
\hline Bore & $8.25 \mathrm{~cm}$ \\
\hline Stroke & $11.4 \mathrm{~cm}$ \\
\hline $\begin{array}{l}\text { Connecting Rod } \\
\text { Length }\end{array}$ & $25.4 \mathrm{~cm}$ \\
\hline Compression Ratio & $16: 1$ \\
\hline Engine Speed & $1800 \mathrm{RPM}$ \\
\hline
\end{tabular}




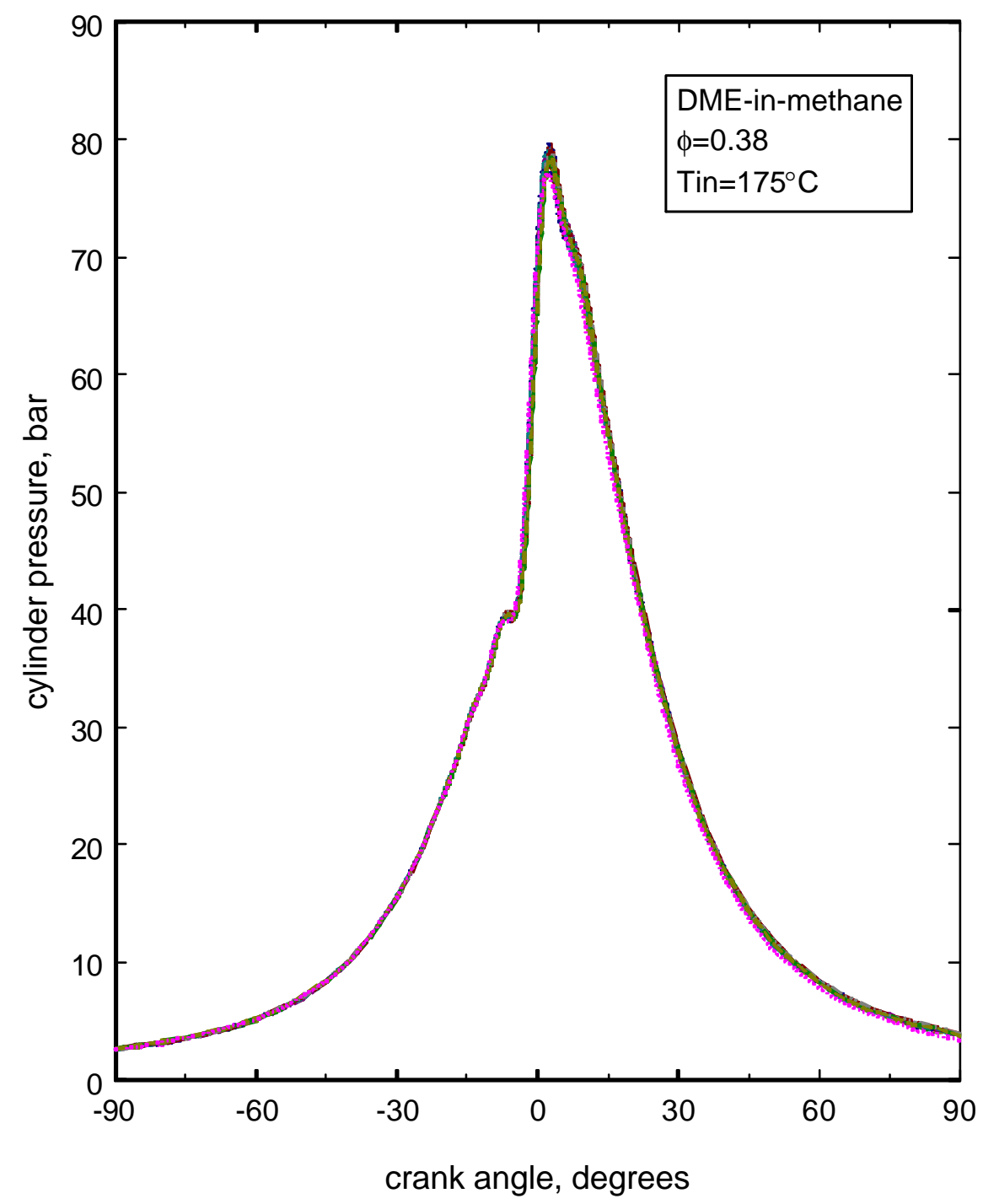

Figure 4.1.1 - Multiple instantaneous pressure versus crank angle traces for a typical experimental HCCI operating point on propane 


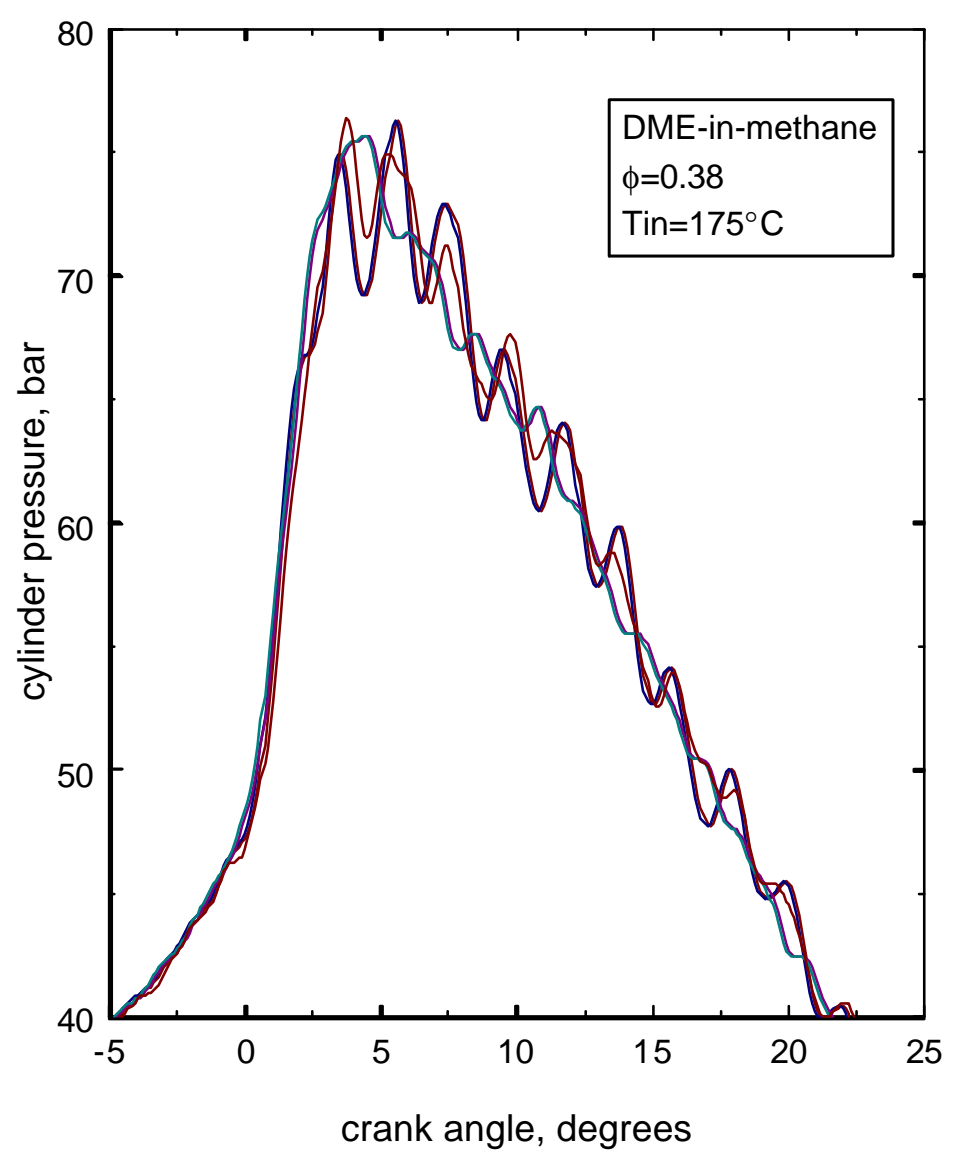

Figure 4.1.2 - Overlay of several instantaneous pressure versus crank angle traces showing acoustic wave response 


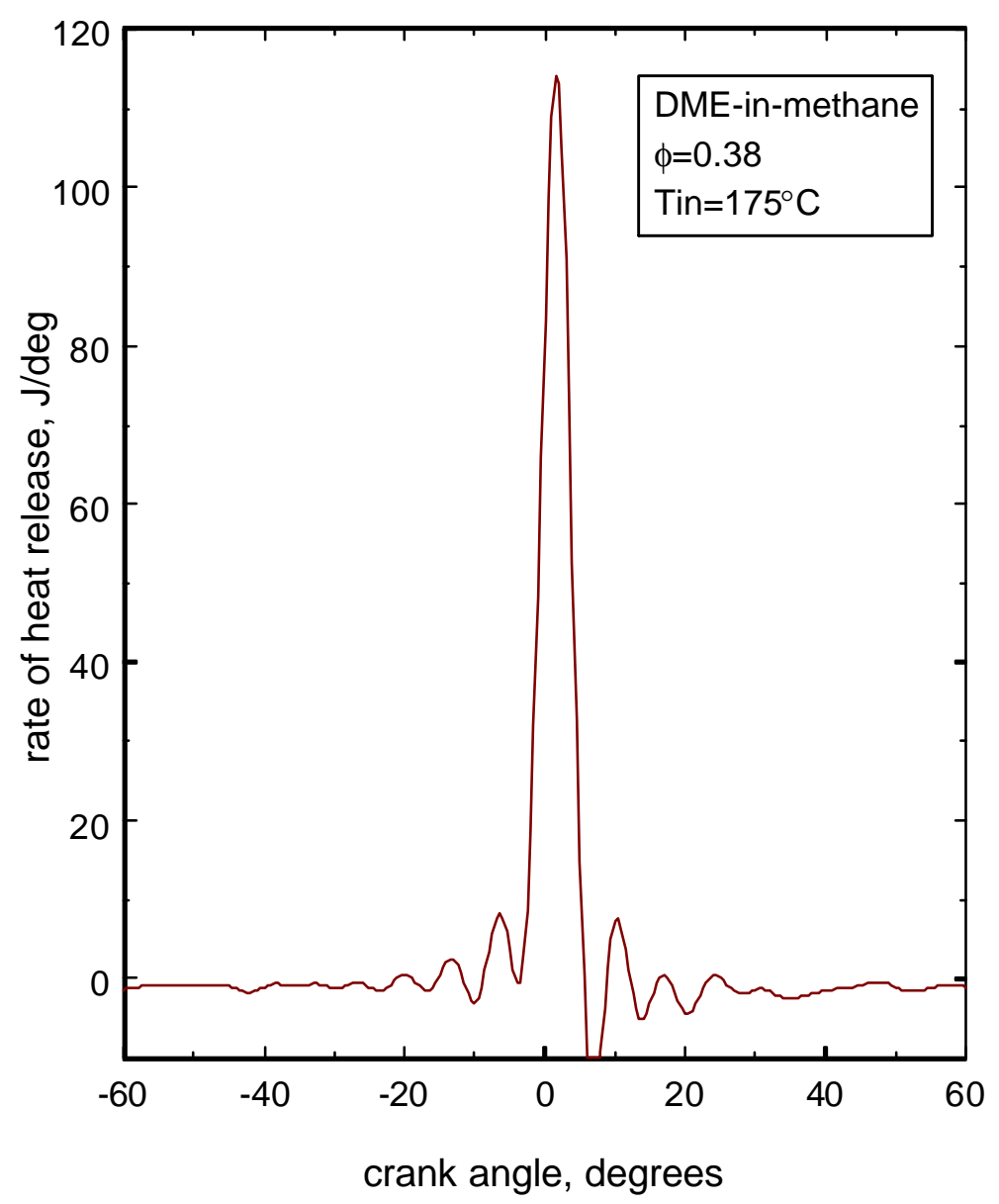

Figure 4.1.3 - Rate of heat release versus crank angle 


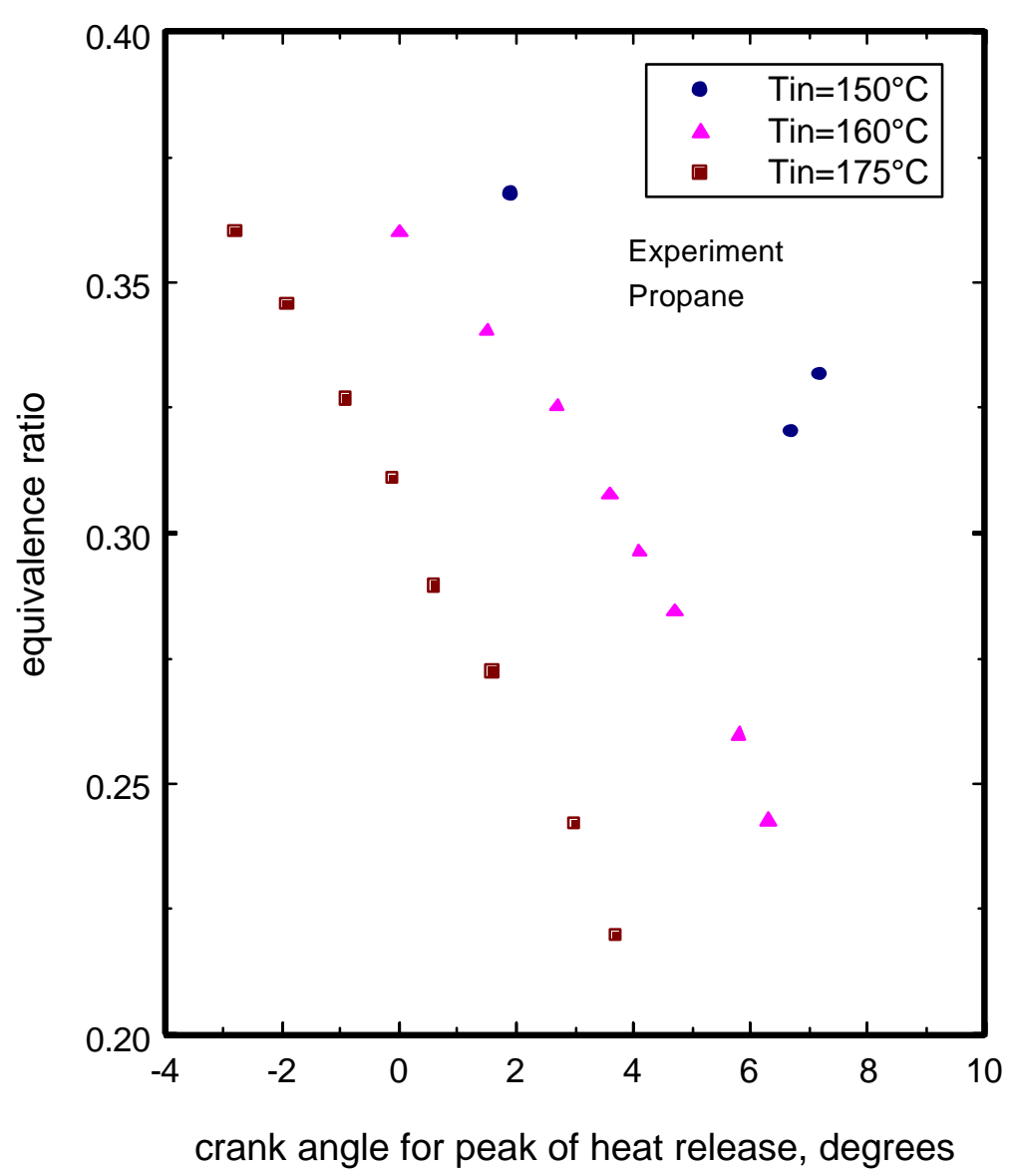

Figure 4.1.4 - Experimental results of equivalence ratio versus timing for peak rate of heat release for propane 


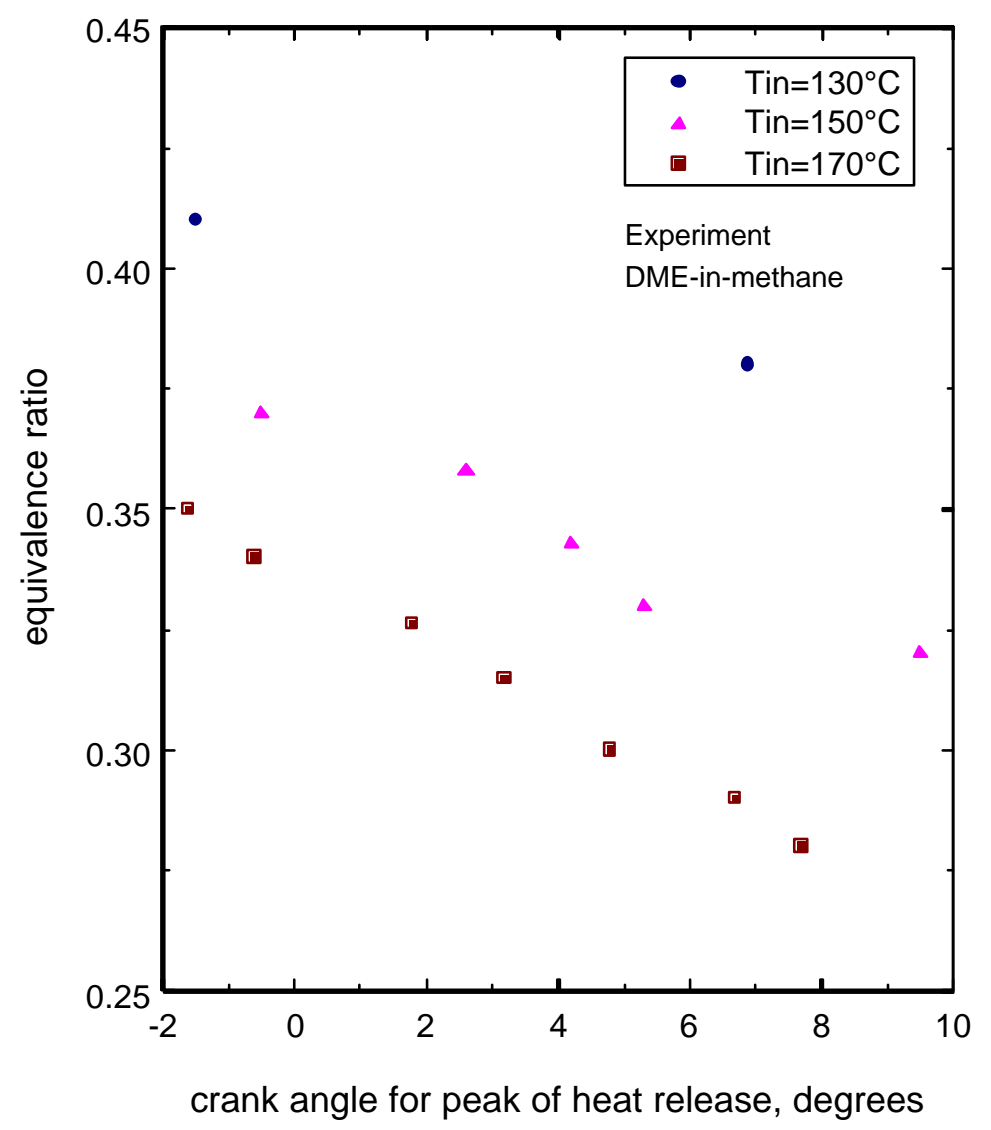

Figure 4.1.5 - Experimental results of equivalence ratio versus timing for peak rate of heat release for DME-in-methane 


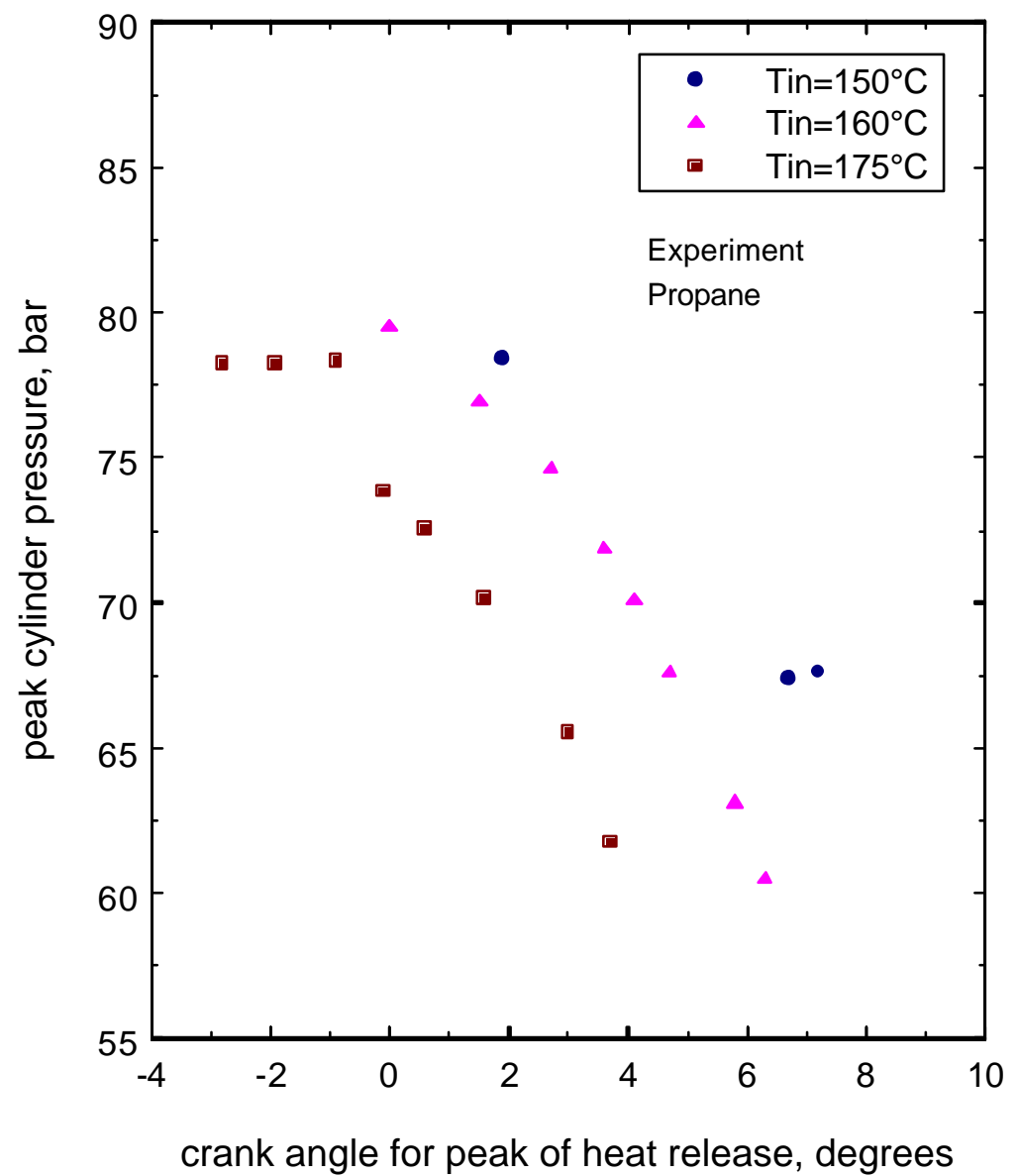

Figure 4.1.6 - Experimental results of peak cylinder pressure versus peak rate of heat release for propane 


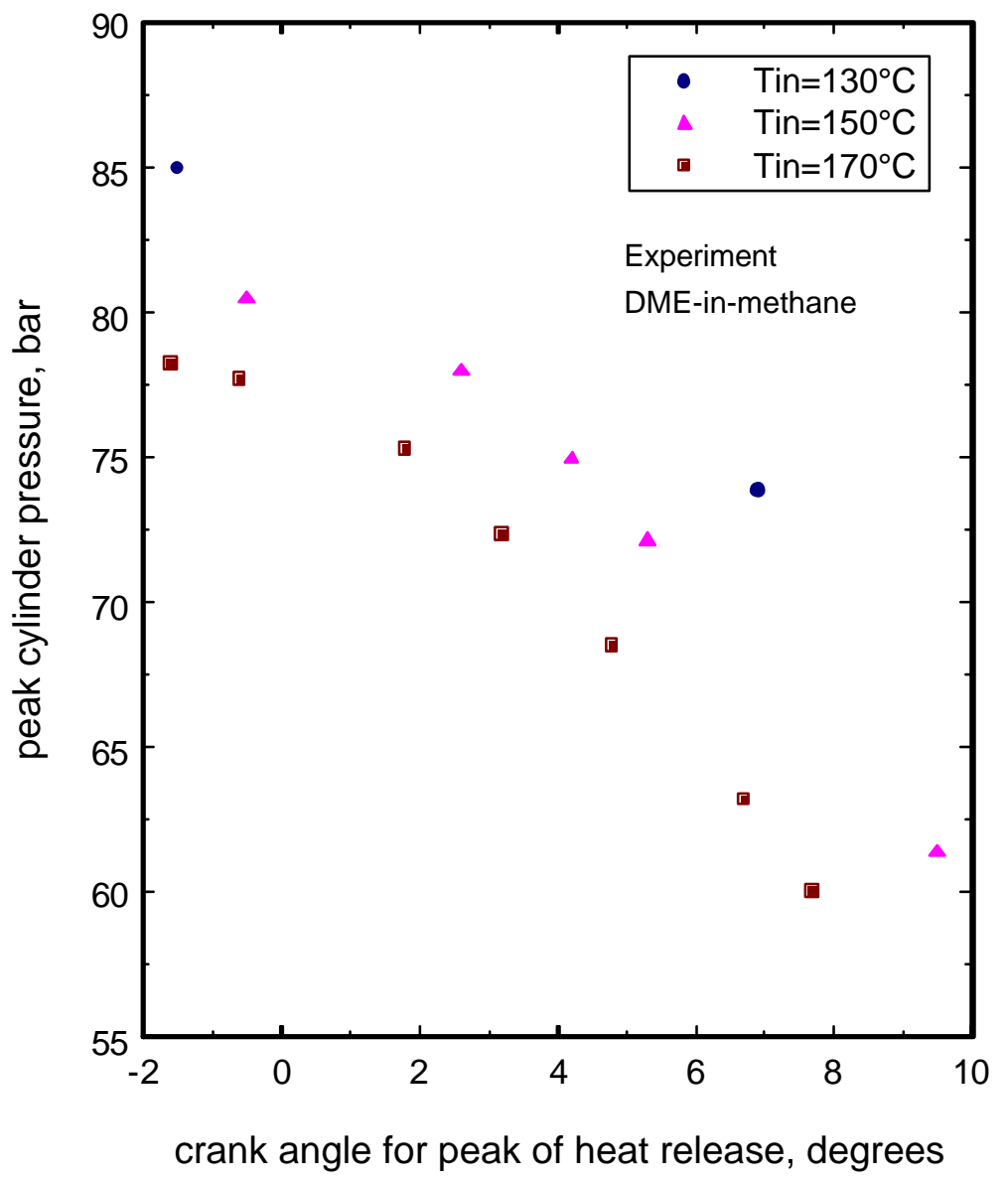

Figure 4.1.7 - Experimental results of peak cylinder pressure versus peak rate of heat release for DME-in-methane 


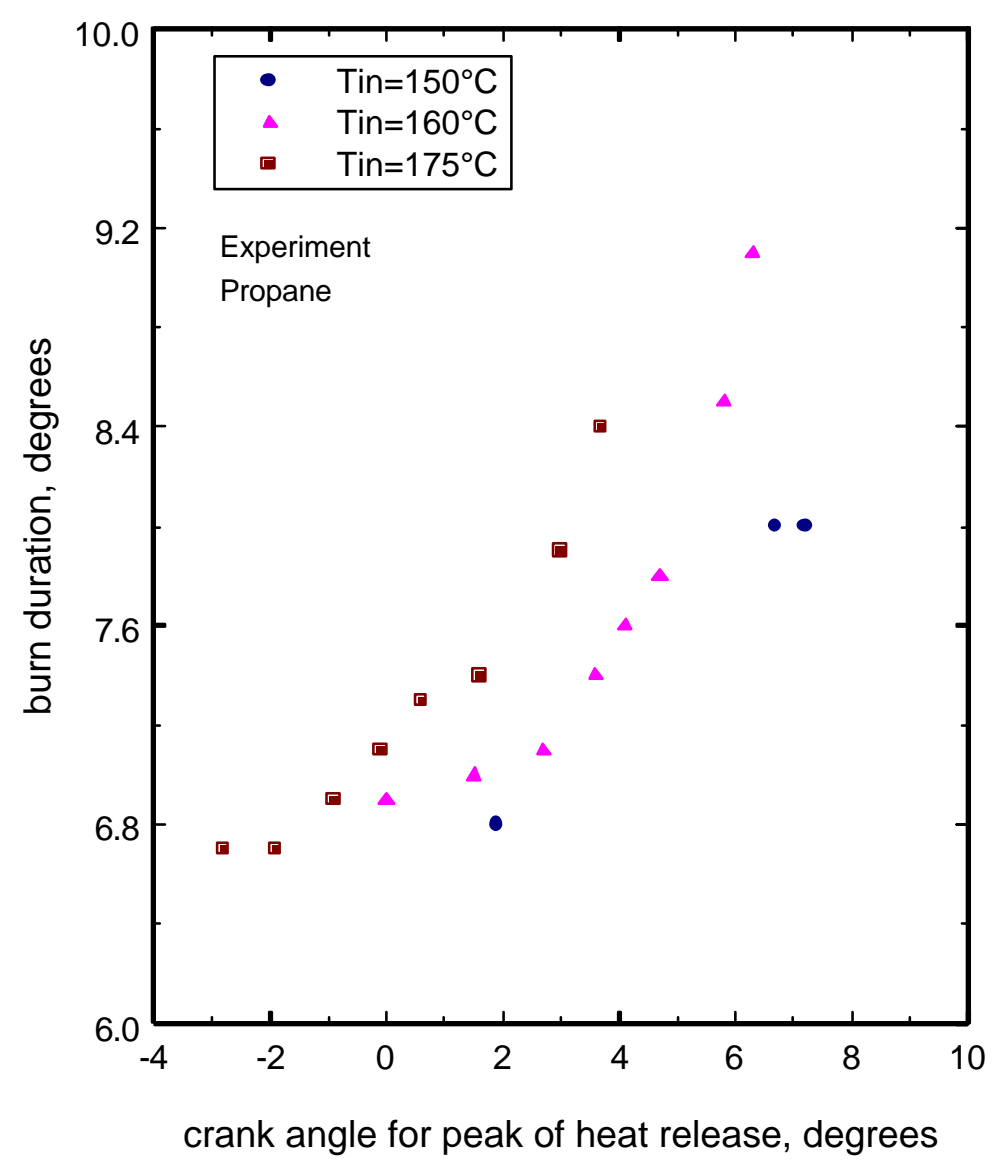

Figure 4.1.8 - Experimental results of burn duration versus timing for peak rate of heat release for propane 


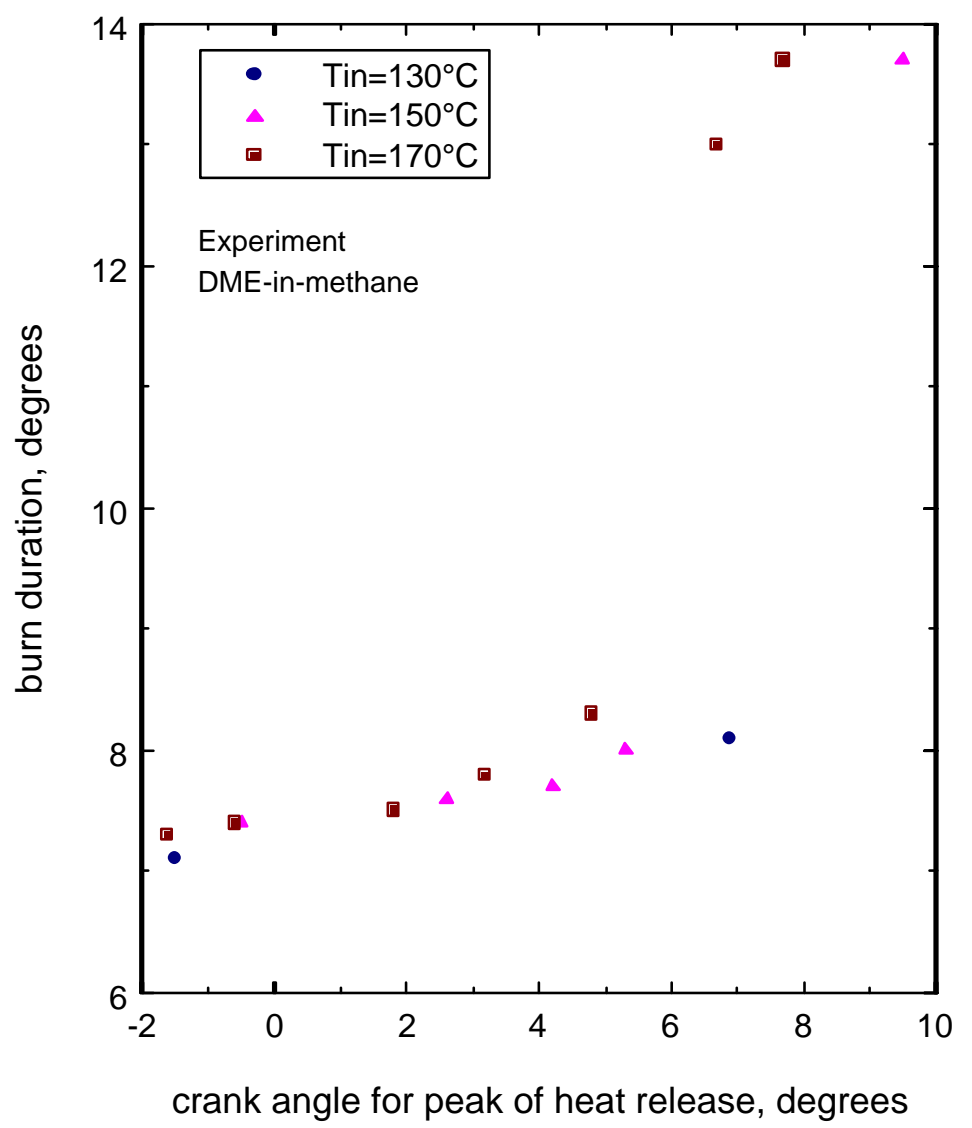

Figure 4.1.9 - Experimental results of burn duration versus timing for peak rate of heat release for DME-in-methane 


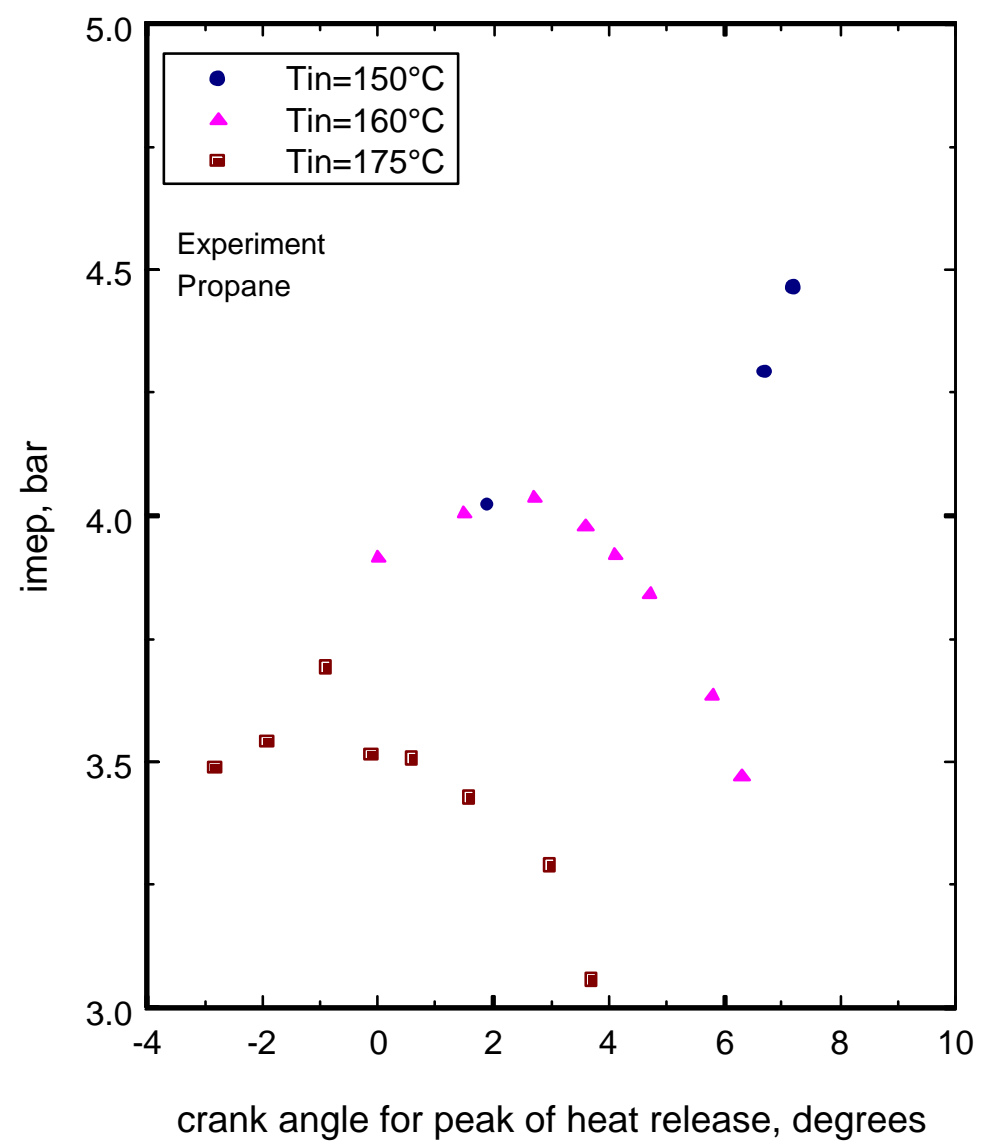

Figure 4.1.10 - Experimental results of imep versus timing for peak rate of heat release for propane 


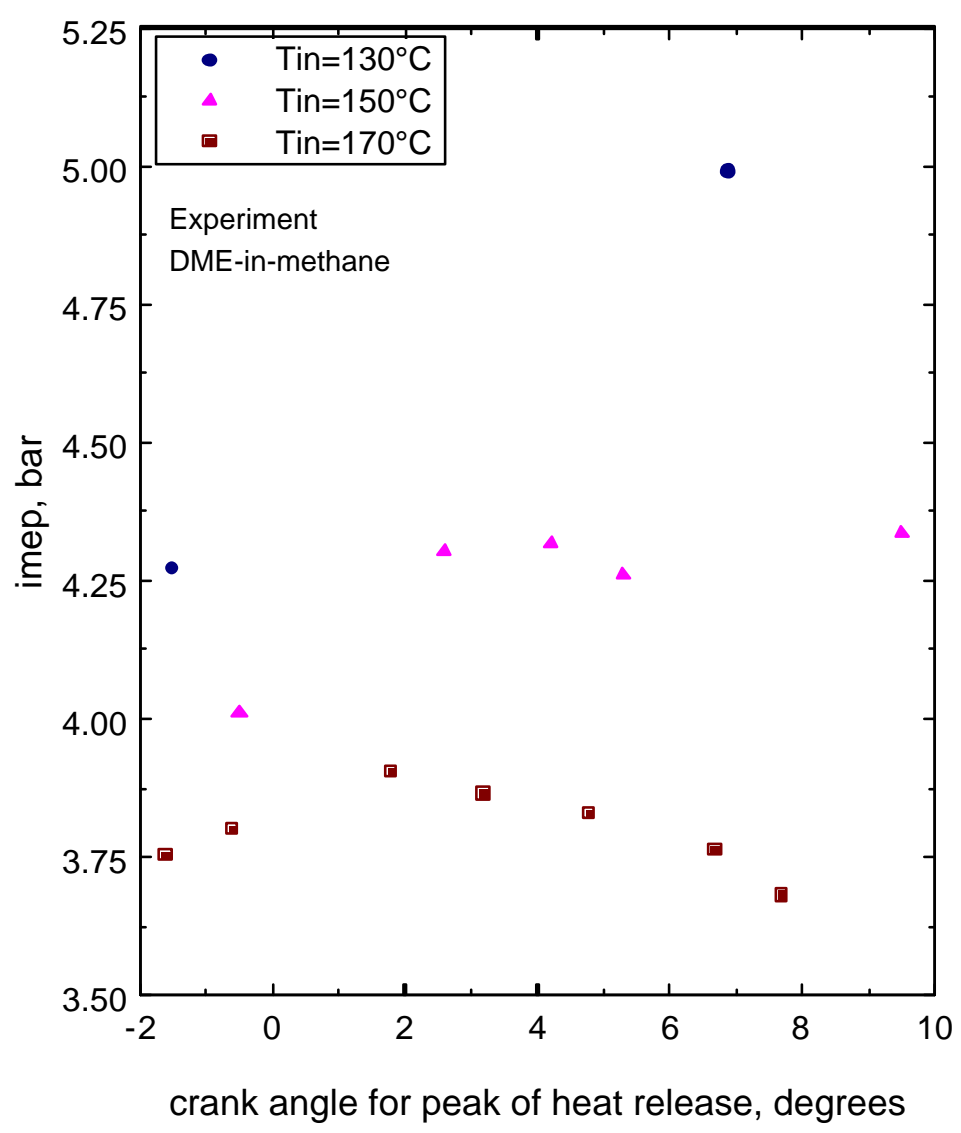

Figure 4.1.11 - Experimental results of imep versus timing for peak rate of heat release for DME-in-methane 


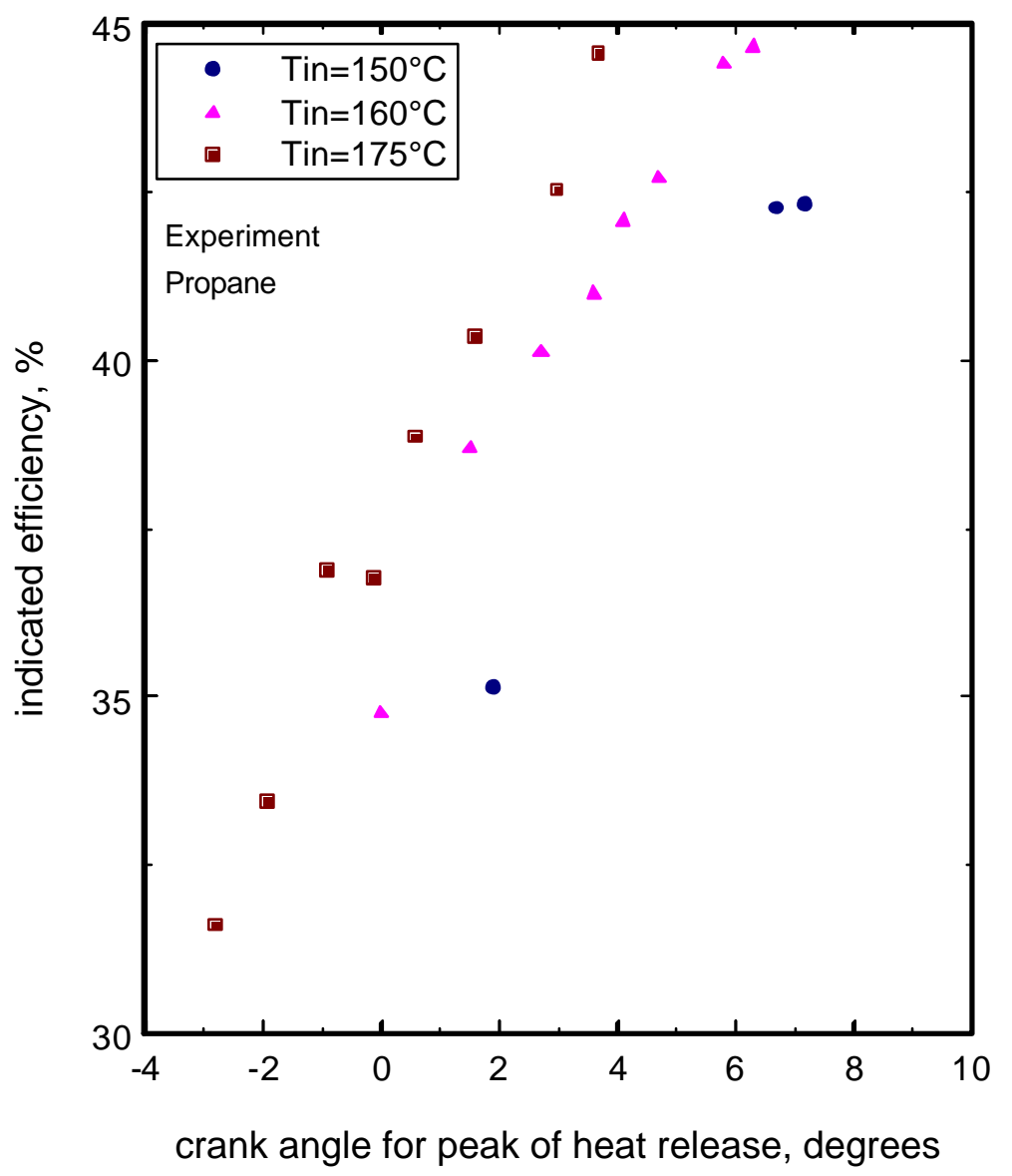

Figure 4.1.12 - Experimental results of indicated efficiency versus timing for peak rate of heat release for propane 


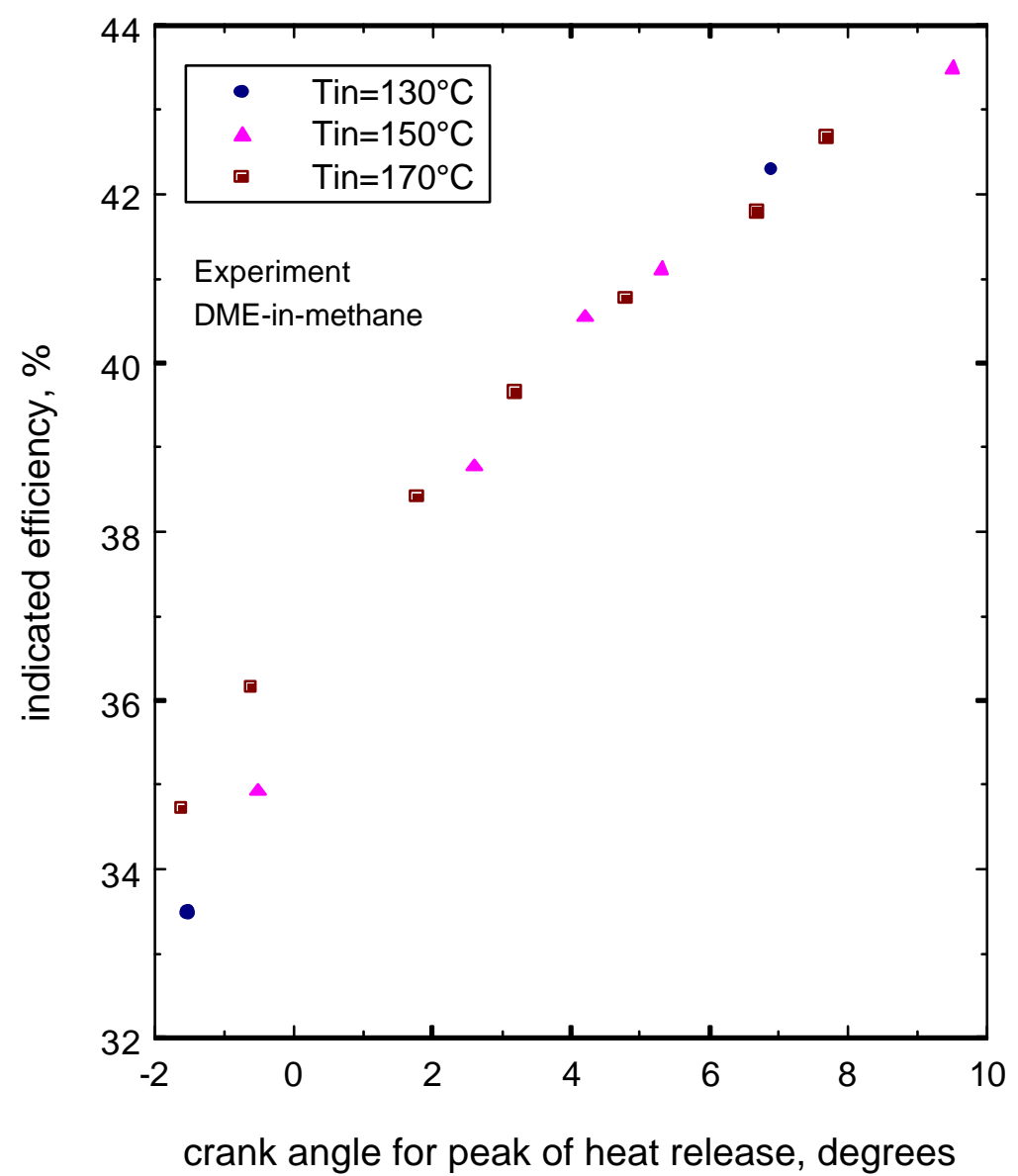

Figure 4.1.13 - Experimental results of indicated efficiency versus timing for peak rate of heat release for DME-in-methane 


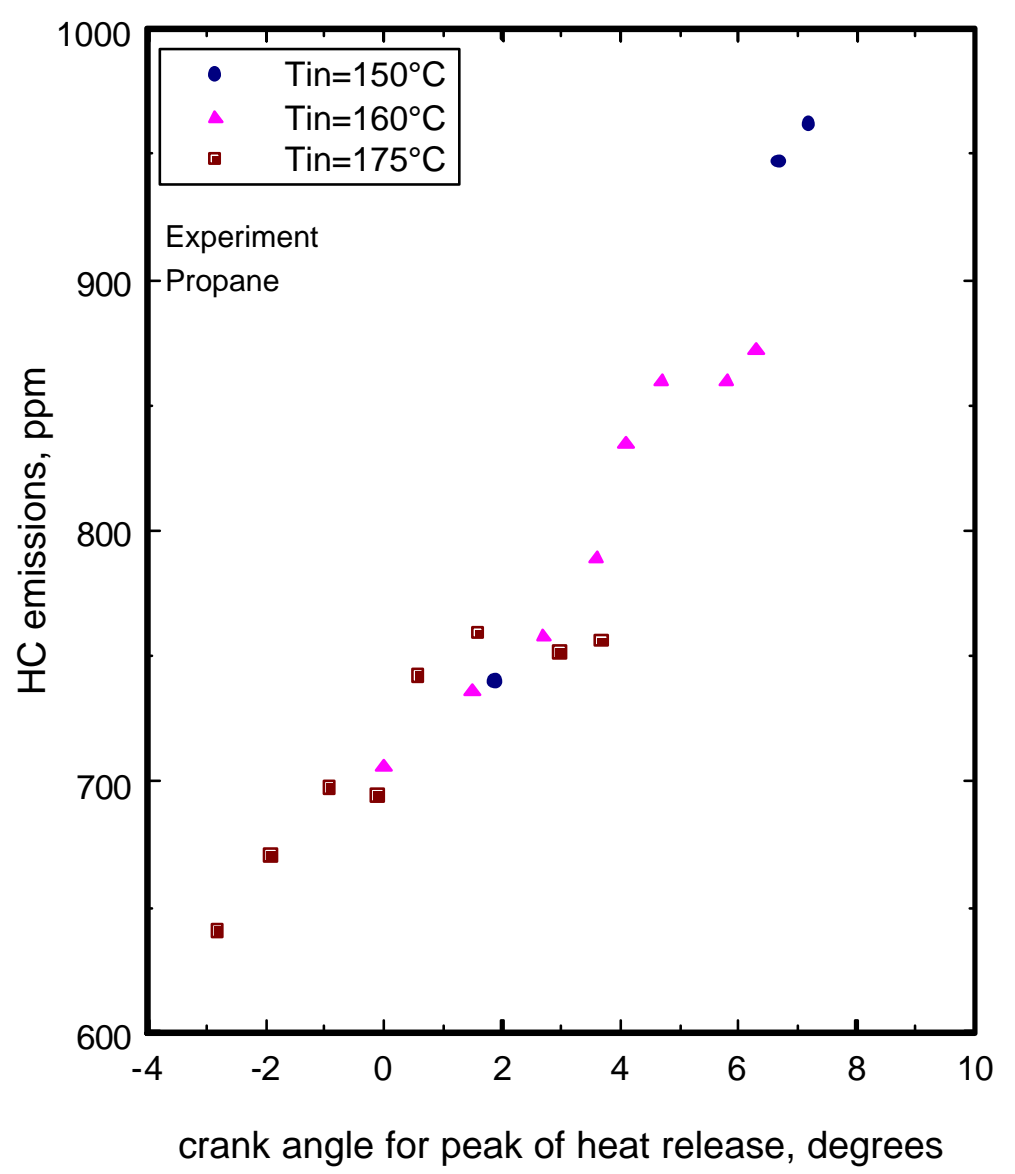

Figure 4.1.14 - Experimental results of hydrocarbon emission versus timing for peak rate of heat release for propane 


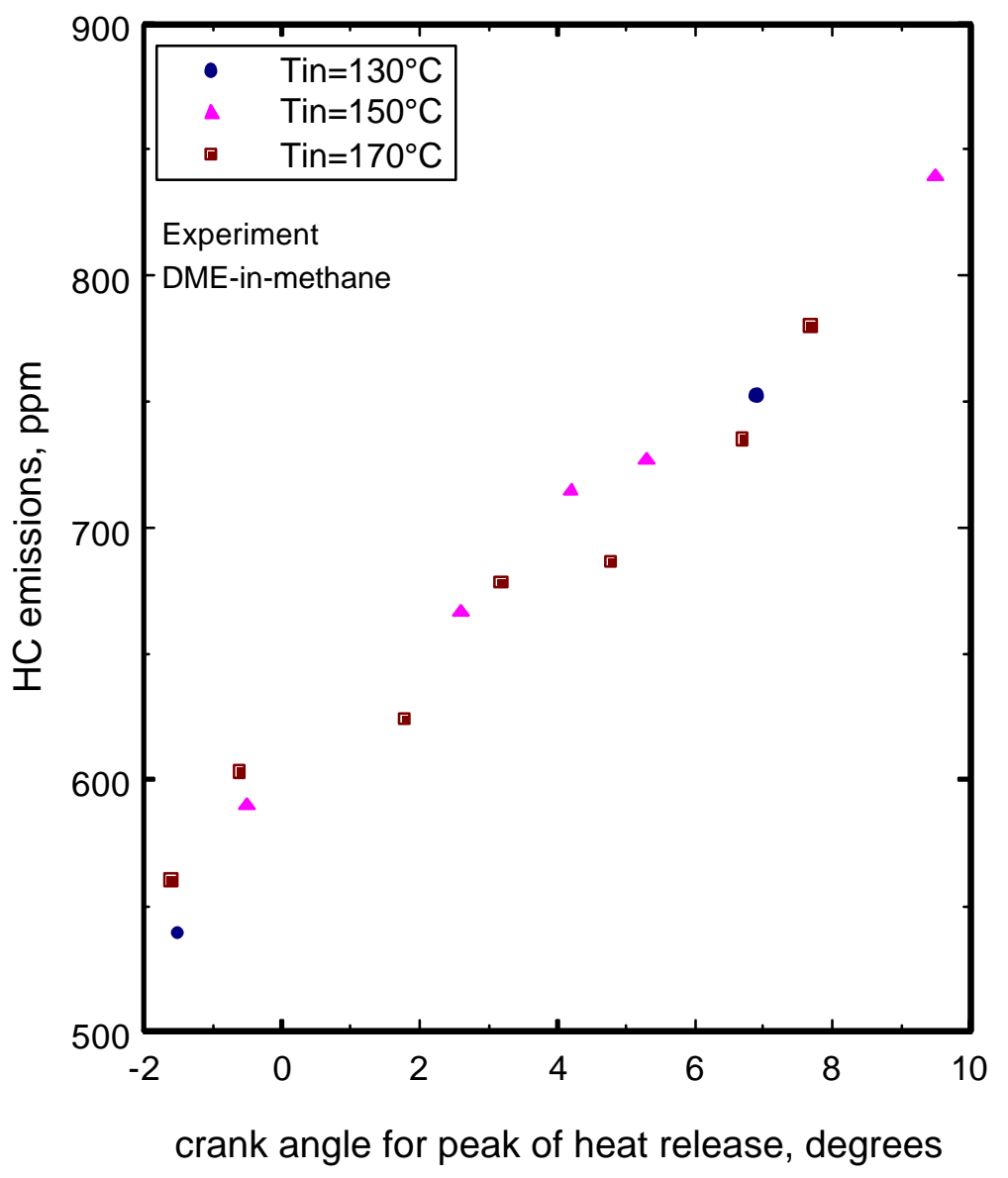

Figure 4.1.15 - Experimental results of hydrocarbon emission versus timing for peak rate of heat release for DME-in-methane 


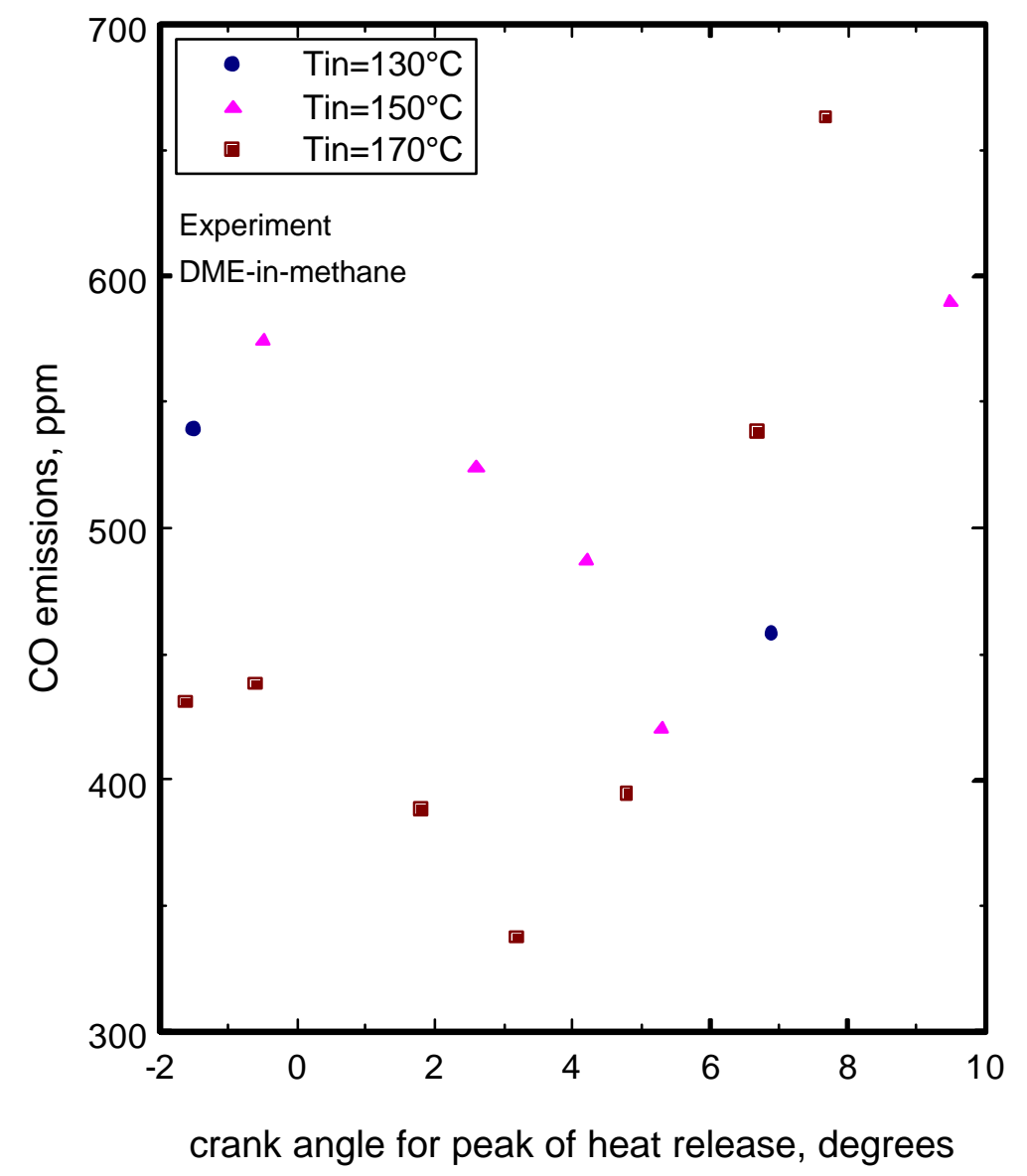

Figure 4.1.16-Experimental results of $\mathrm{CO}$ emissions versus timing for peak rate of heat release for DME-in-methane 


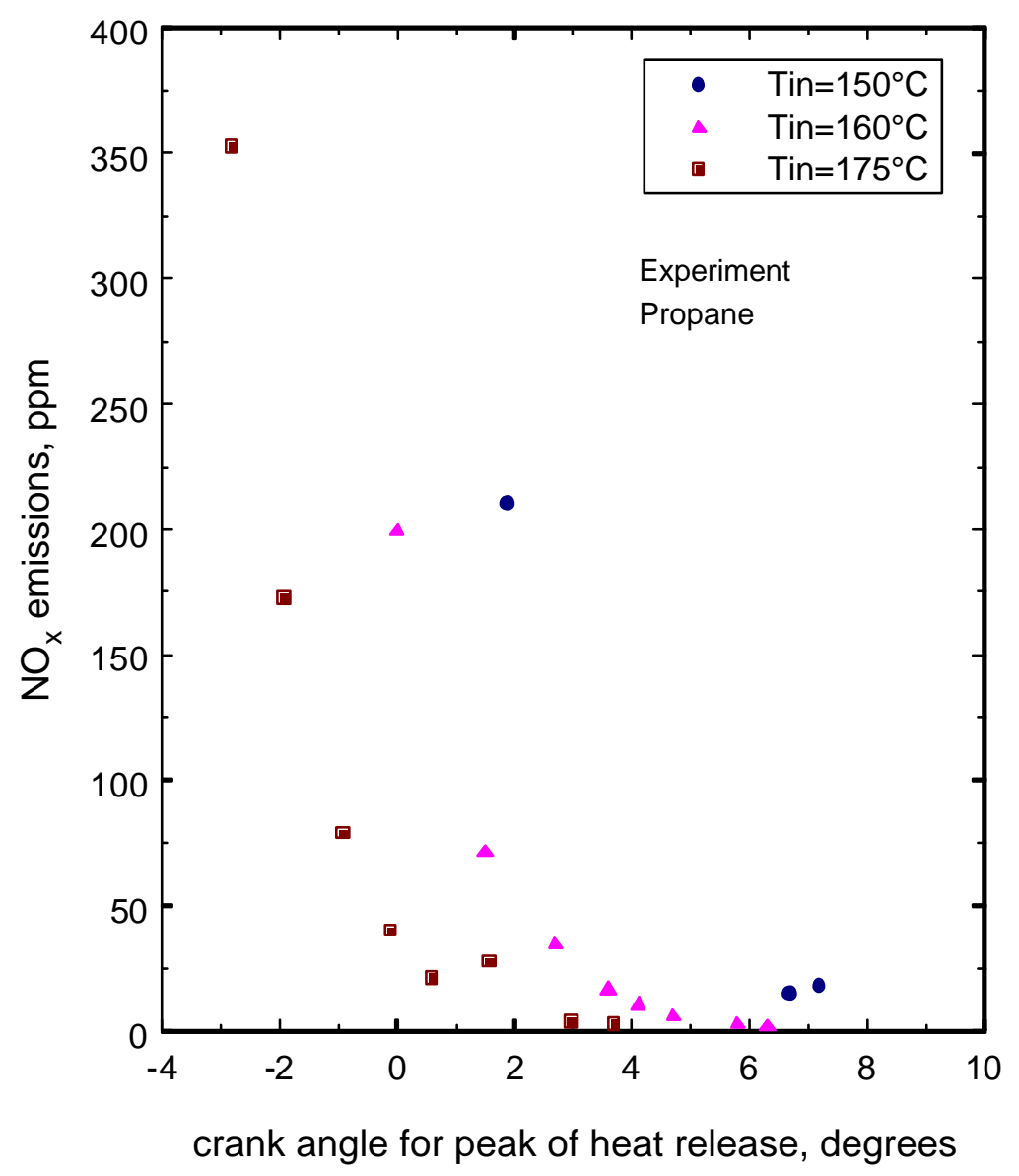

Figure 4.1.17 - Experimental results of $\mathrm{NO}_{\mathrm{x}}$ emissions versus timing of peak rate of heat release for propane 


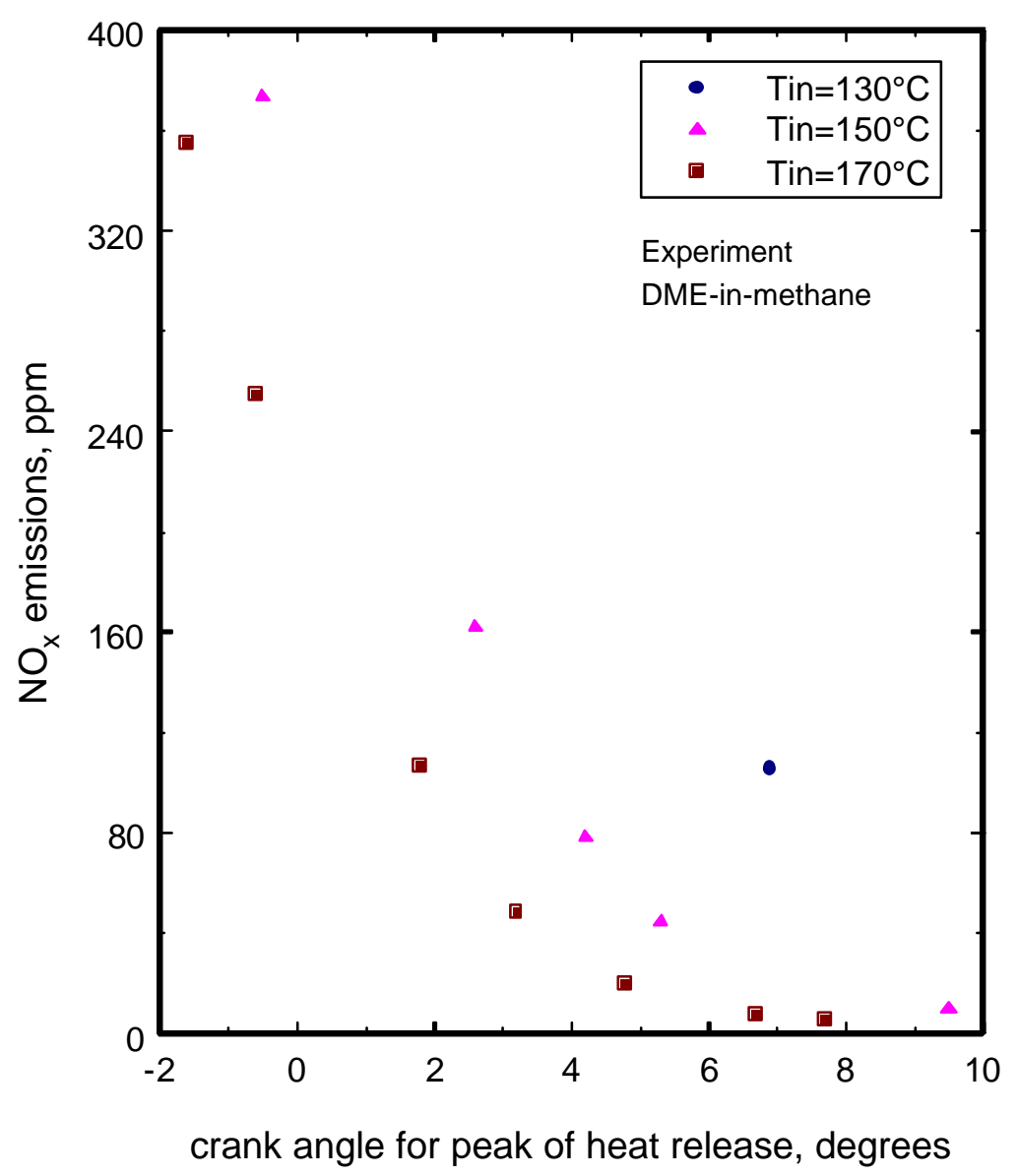

Figure 4.1.18 - Experimental results of $\mathrm{NO}_{\mathrm{x}}$ emissions versus timing of peak rate of heat release for DME-in-methane 


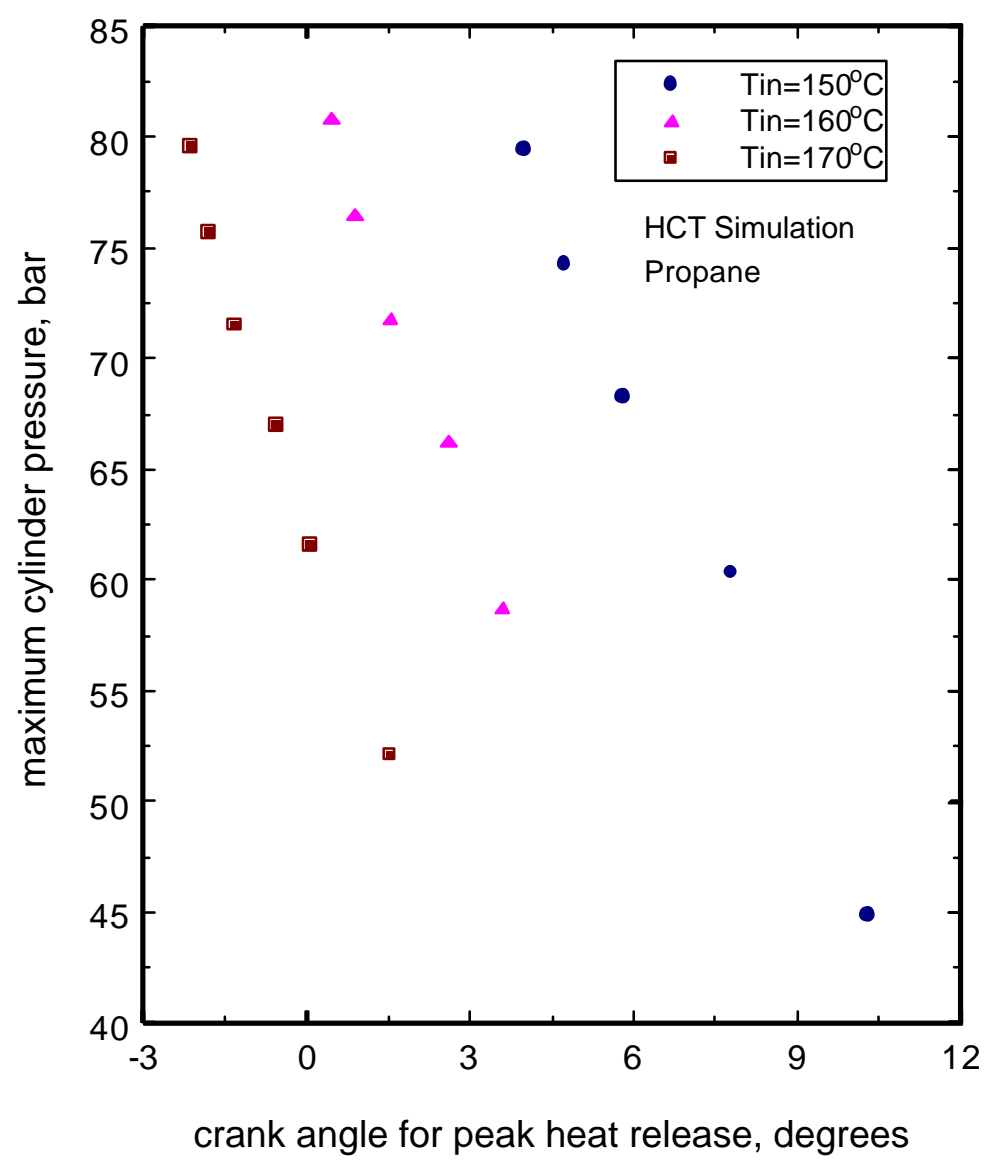

Figure 4.1.21 - Simulation results of peak pressure versus peak of heat release for propane 


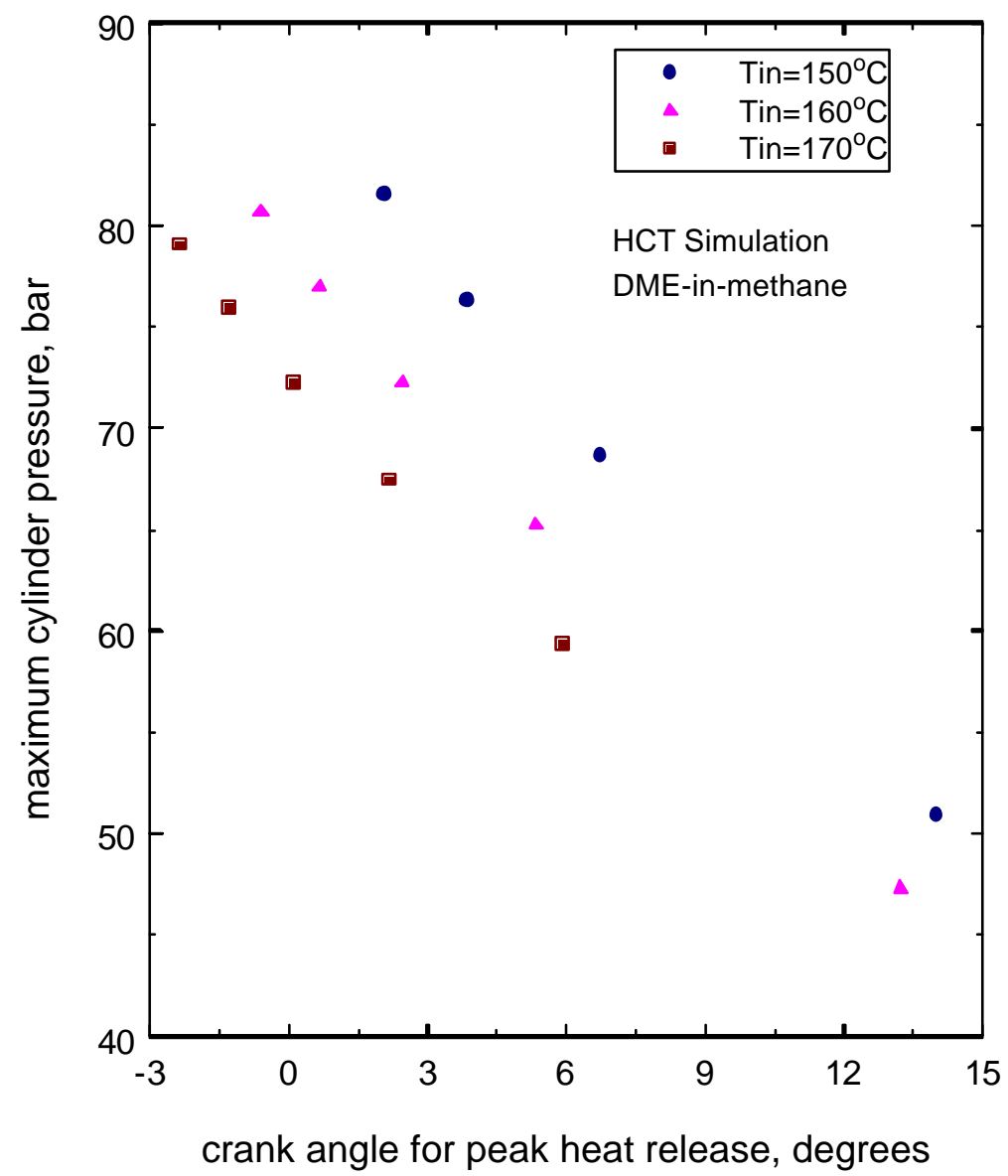

Figure 4.1.22 - Simulation results of peak pressure versus peak of heat release for DMEin-methane 


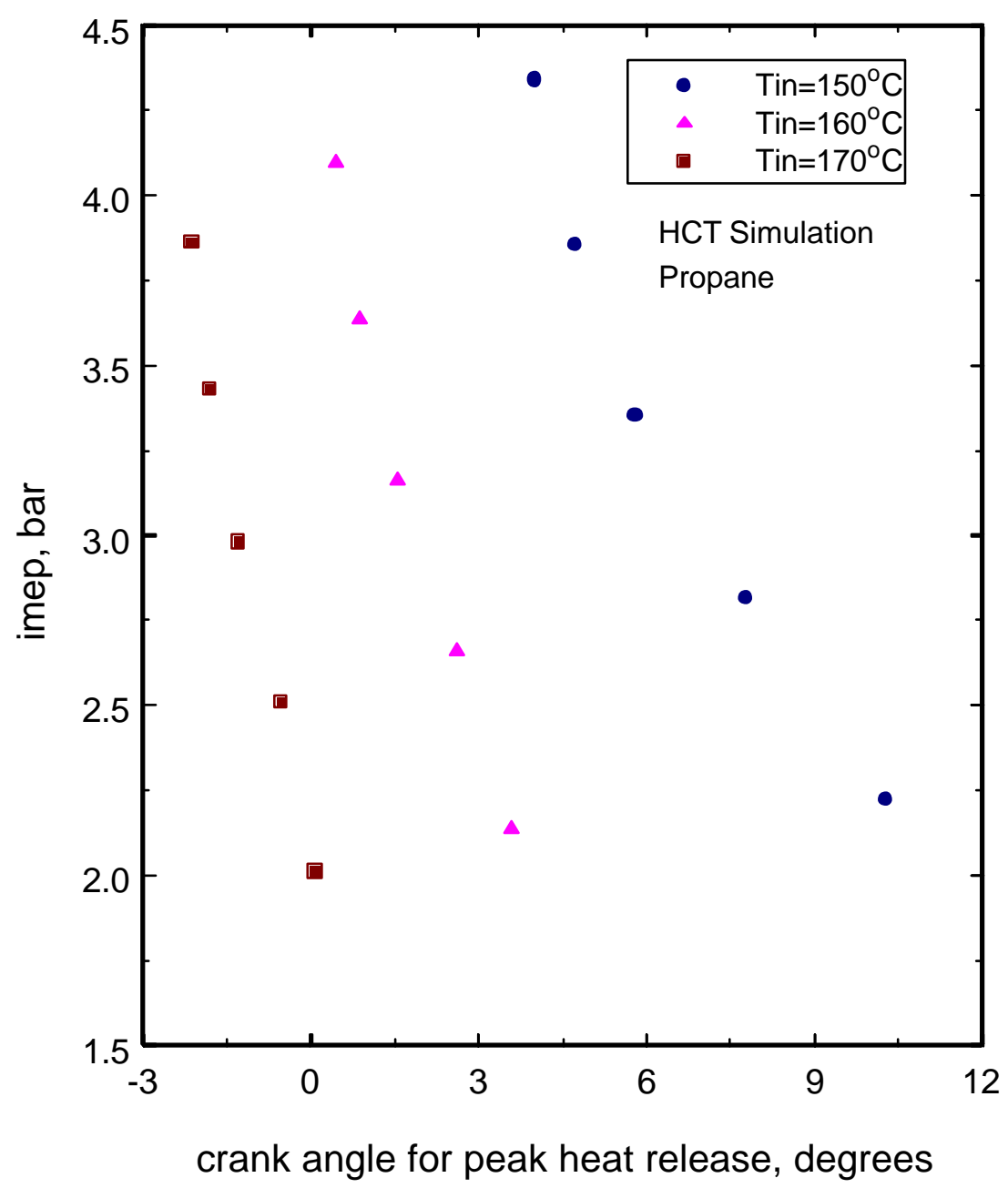

Figure 4.1.23 - Simulation results of imep versus peak of heat release for propane 


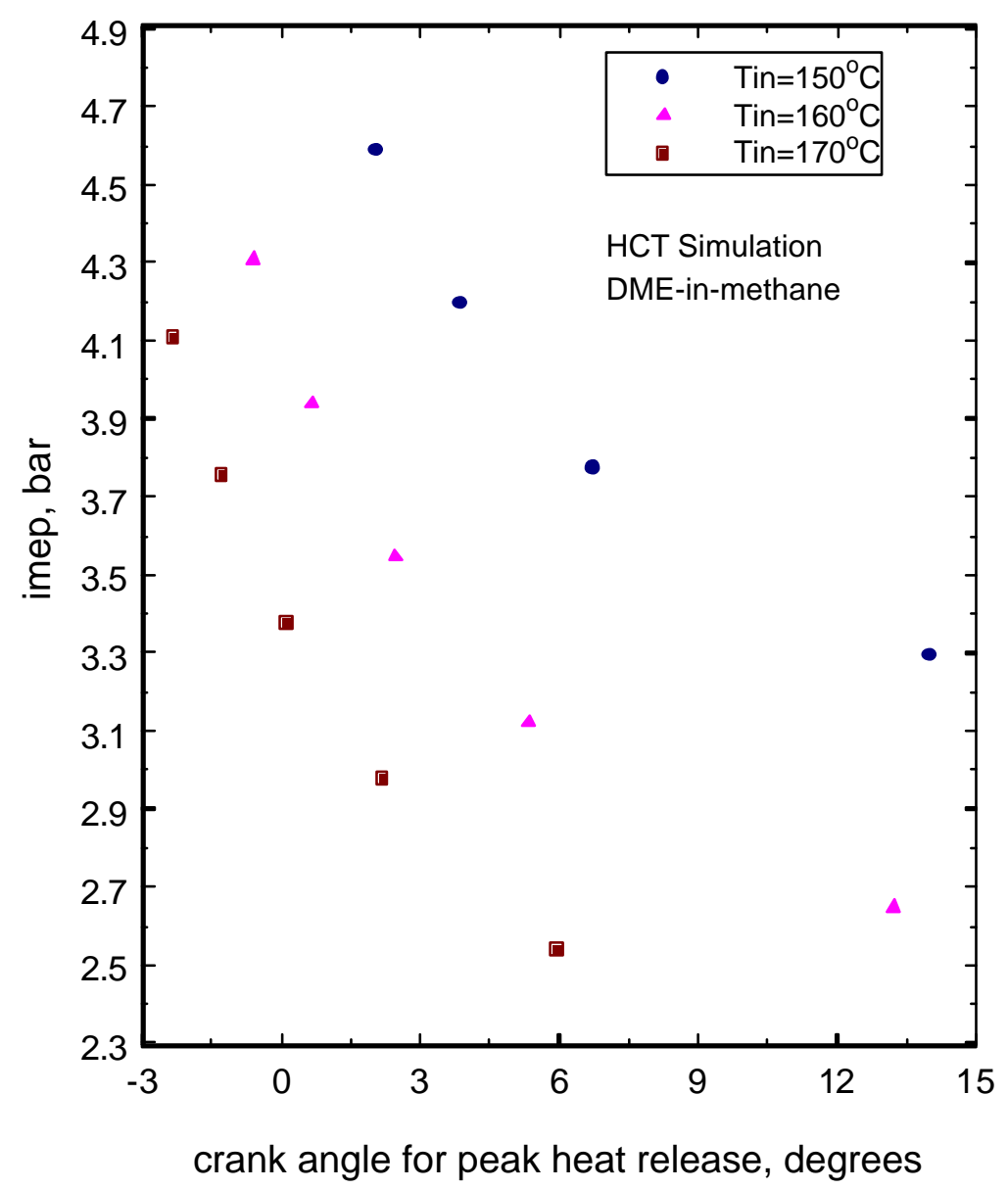

Figure 4.1.24 - Simulation results of imep versus peak of heat release for DME-inmethane 


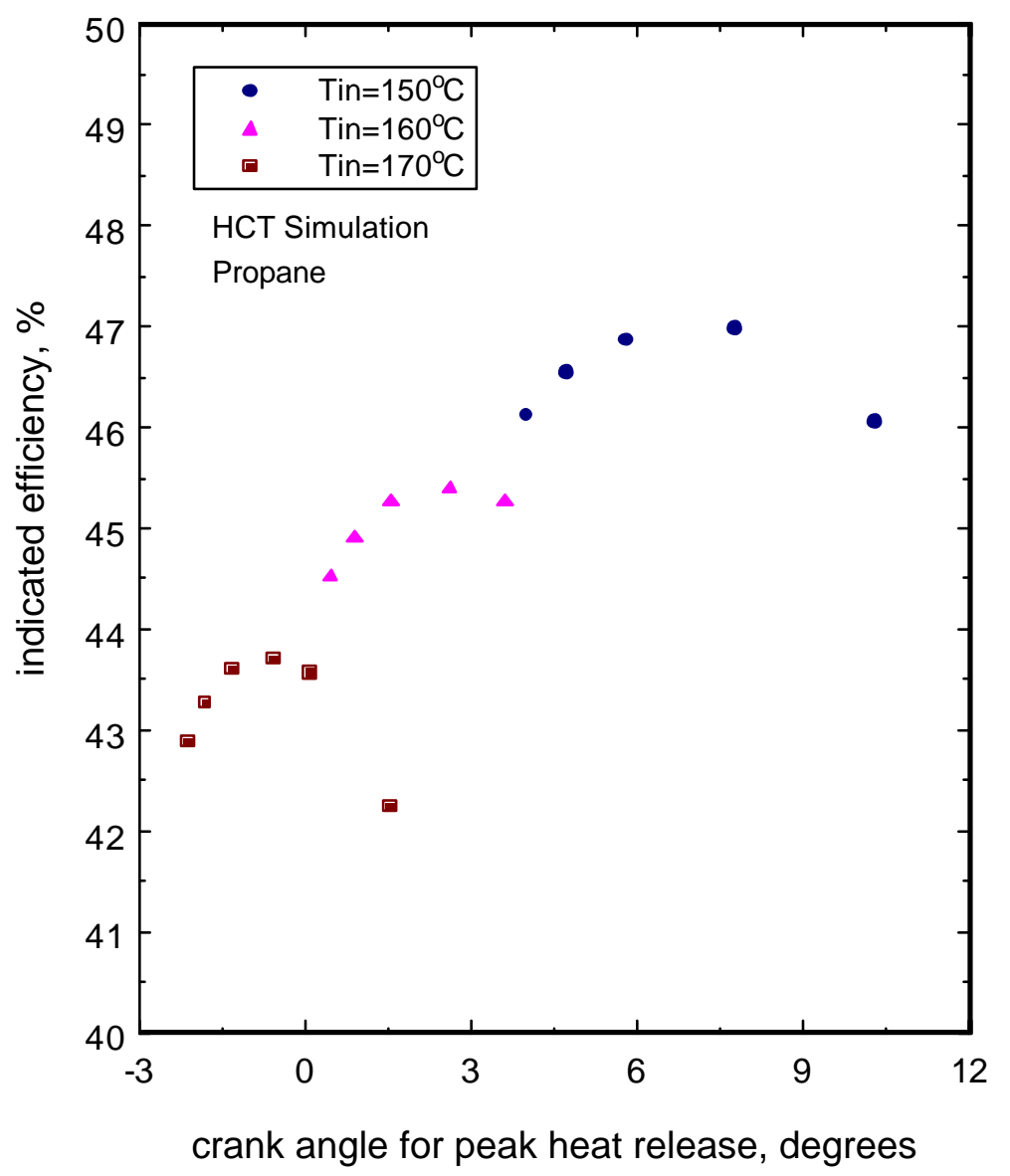

Figure 4.1.25 - Simulation results of efficiency versus peak of heat release for propane 


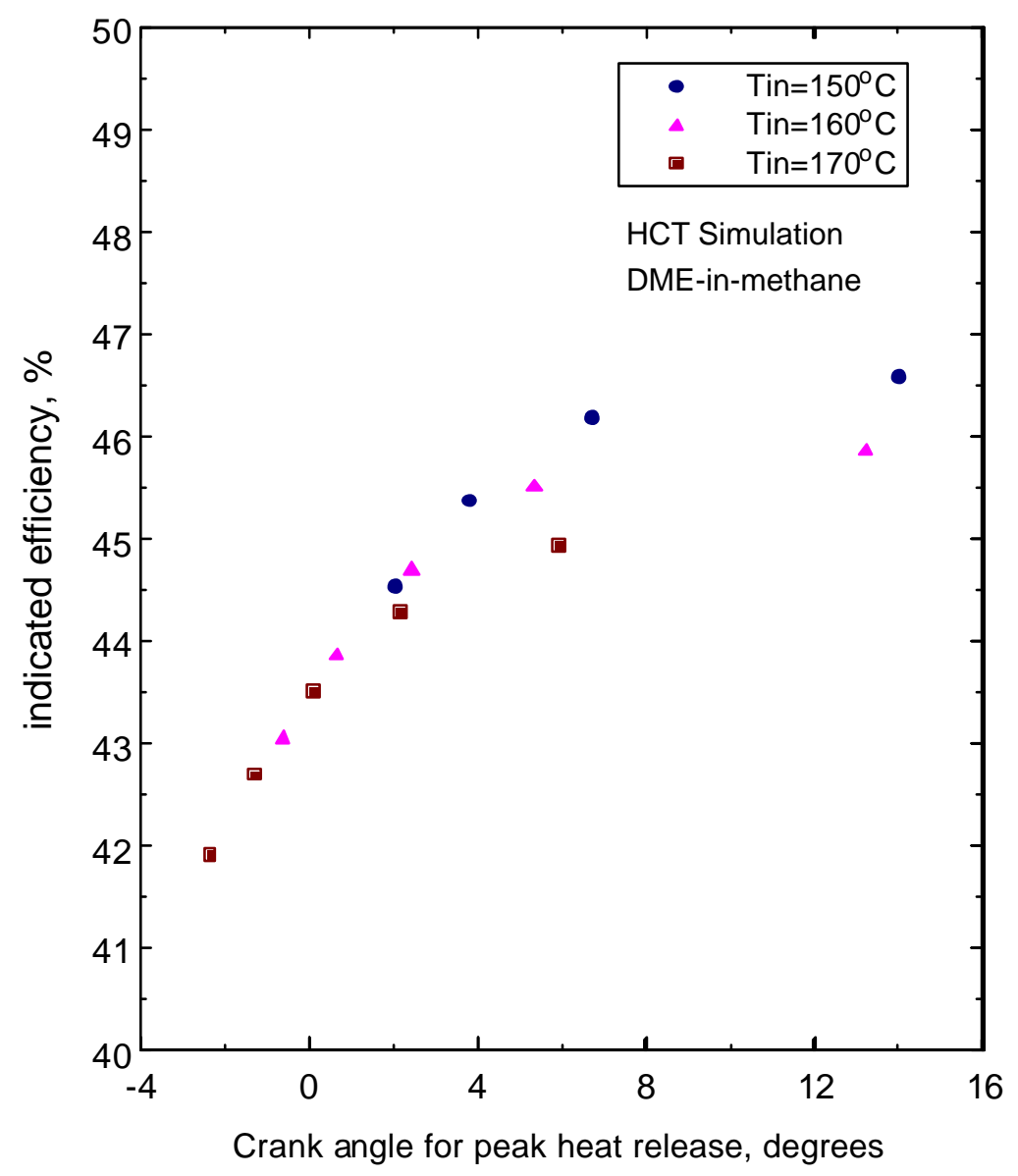

Figure 4.1.26 - Simulation results of efficiency versus peak of heat release for DME-inmethane 


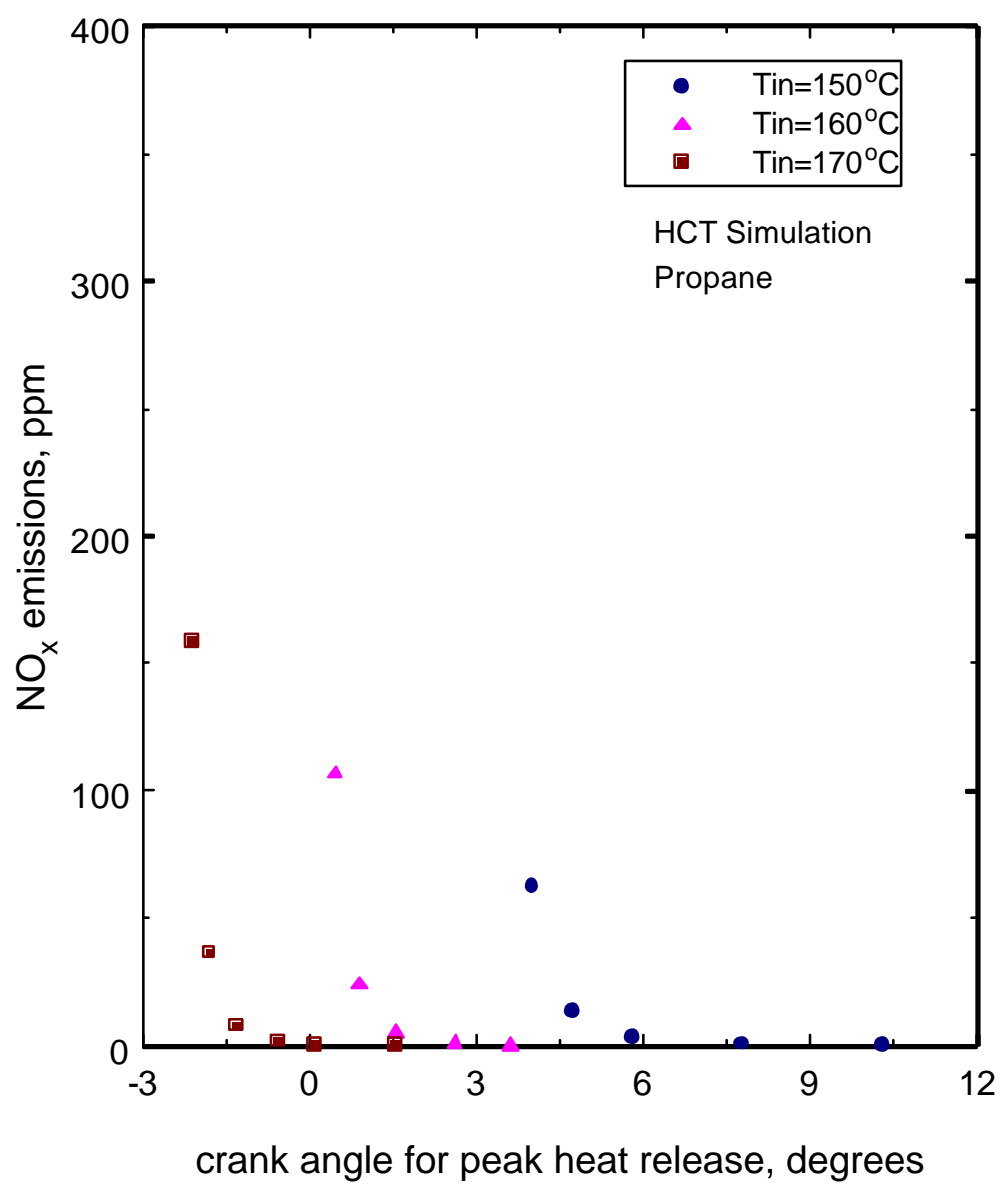

Figure 4.1.27 - Simulation results of $\mathrm{NO}_{\mathrm{x}}$ emissions versus peak of heat release for propane 


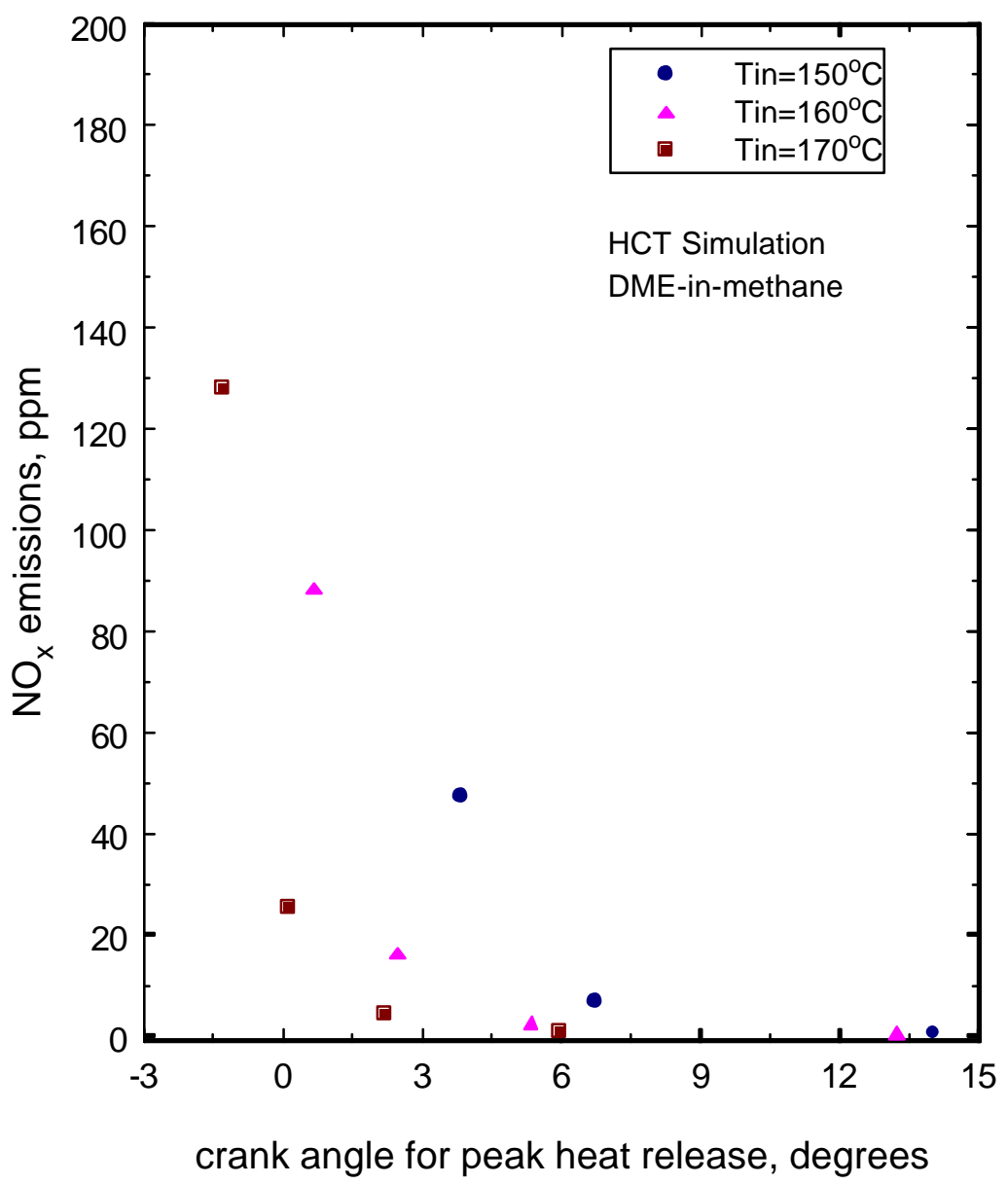

Figure 4.1.28 - Simulation results of $\mathrm{NO}_{\mathrm{x}}$ emissions versus peak of heat release for DME-in-methane 


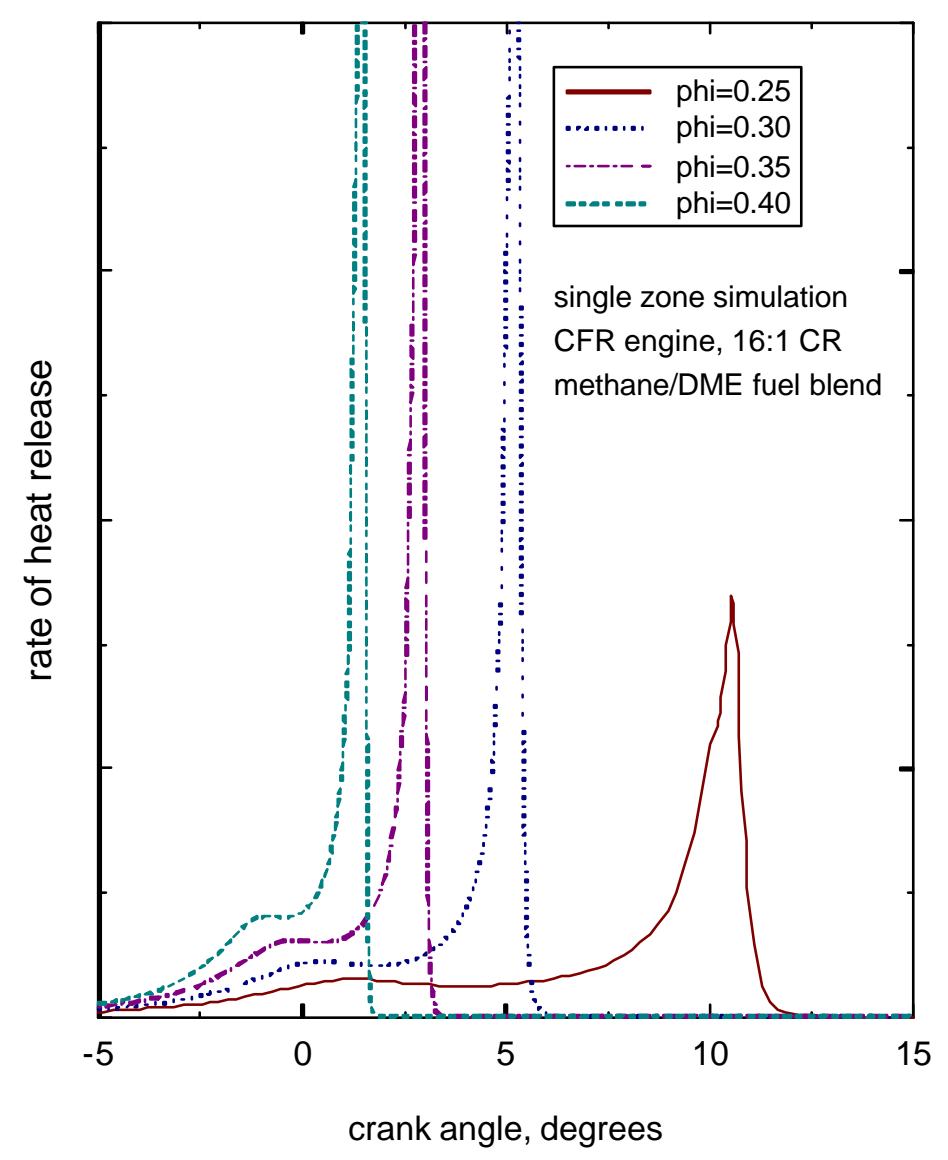

Figure 4.1.29 - Simulation results of heat release versus crank angle for several equivalence ratios with a DME-in-methane fuel blend 


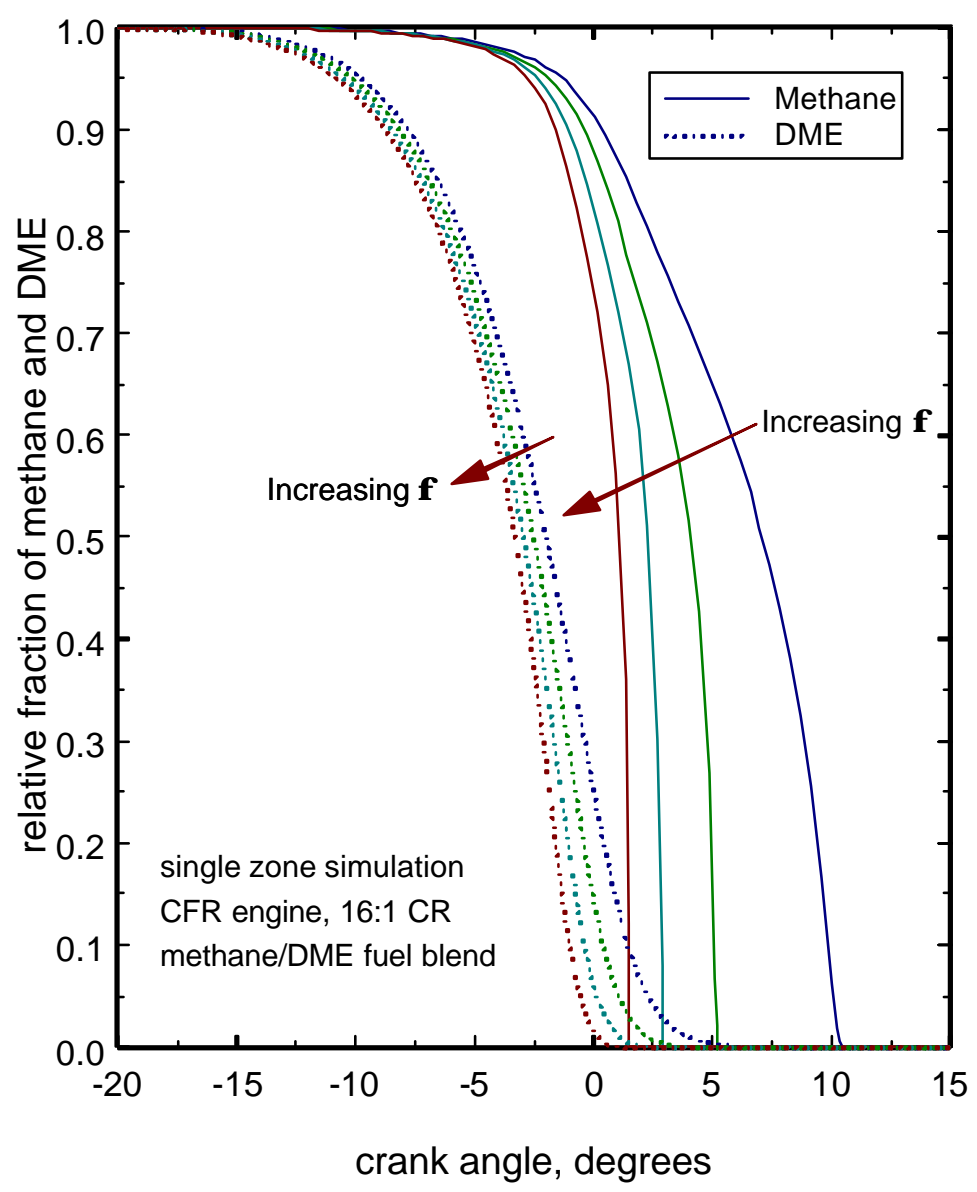

Figure 4.1.30 - Simulation results of component fuel consumption versus crank angle for several equivalence ratios with a DME-in-methane fuel blend 


\subsection{Multi-Cylinder Experiments}

\subsubsection{Experimental Setup}

A Volkswagen TDI engine has been selected as the base engine for development and testing of an automotive-class HCCI engine applicable to conventional or hybrid power trains. The TDI engine is a four-cylinder turbocharged direct injection diesel engine. This engine has attributes appropriate for an automotive HCCI engine: 1.9L displacement, high compression ratio, and ability to withstand high peak pressure. Table 4.2.1 lists engine specifications. The in-cylinder fuel injectors have been removed from the combustion chamber and have been replaced with inserts containing water-cooled quartz pressure transducers. The combustion chamber has not been modified otherwise the stock pistons containing the reentrant bowl, shown in Figure 4.2.1, have been retained for this research. Figure 4.2.1 also shows the head and the block. The piston crown sits slightly above the level of the block at TDC, so the head gasket provides all the clearance height. Figure 4.2.2 shows the motoring pressure traces for the four cylinders operating at $1800 \mathrm{rpm}$. The engine BMEP is reported along with net IMEP for each cylinder. These IMEPs indicate significant heat transfer during motoring, suggesting heat transfer will be significant during firing operation. The differences in the motoring peak pressure between cylinders during motoring could be due to variations in compression ratio or heat transfer.

Figure 4.2.3 shows a schematic of the experimental setup. The inducted air flow rate is measured with an orifice plate. Fuel flow is measured using an electronic mass flow meter. Uncertainty in the fuel flow rate measurement contributes \pm 0.02 maximum 
absolute error in equivalence ratio. The air is then heated with an electric heater, followed by fuel addition upstream of the intake manifold. The intake and exhaust have been modified by removal of the turbocharger, but the intake and exhaust manifolds have been retained. The fuel-air mixture is inducted into the engine and the combustion process is monitored with the four in-cylinder pressure transducers. A 3600/rev shaft encoder is used to trigger the pressure acquisition. A small amount of the exhaust is diverted to the emissions analyzer for measurement of $\mathrm{THC}, \mathrm{CO}$, and $\mathrm{NO}_{\mathrm{x}}$ emissions.

A $30 \mathrm{~kW}$ (40 hp) AC induction motor/generator is coupled to the engine. The electric motor/generator operates at a nominal speed of $1800 \mathrm{rpm}$ with $60 \mathrm{~Hz}$ excitation. The motor is direct coupled to the engine so the ability to operate at other motor speeds is not currently available. Because of the asynchronous operation of induction motors, the engine rotational speed is slightly lower or higher than $1800 \mathrm{rpm}$ when acting as a motor or generator, respectively. This variation from nominal operating speed typically is \pm 5 rpm. The engine output torque is measured with an inline torque transducer, inline between the engine and generator motor.

In this research, variation in intake mixture temperature and fuel flow rate on the engine operation is studied. For several fixed fuel flow rates the intake manifold temperature is varied. For a given fuel flow rate the lower limit of operation is specified by the temperature at which at least one cylinder misfires. Because HCCI combustion is so sensitive to temperature, slight variations in the conditions of each cylinder can result in one cylinder firing very well while at the same time, another cylinder misfires. As the intake temperature is further raised, the combustion timing becomes increasingly advanced relative to TDC and severe pressure oscillations ("knock") occur. In these 
cases, heat transfer to the water and oil becomes very large, causing the water temperature to rise rapidly and the oil pressure to drop precariously. Operation in these regimes could be damaging to the engine and is therefore avoided.

\subsubsection{Multi-Cylinder Engine Test Results}

Experiments have been conducted for naturally aspirated operation with propane fuel. The engine performance, combustion process, and emissions are monitored for variations in intake temperature and fuel flow rate. The intake temperature ranges from roughly $105^{\circ} \mathrm{C}$ to $145^{\circ} \mathrm{C}$. Five different fuel flow rates have been studied: $0.34 \mathrm{~g} / \mathrm{s}, 0.50$ $\mathrm{g} / \mathrm{s}, 0.65 \mathrm{~g} / \mathrm{s}, 0.72 \mathrm{~g} / \mathrm{s}$, and $0.83 \mathrm{~g} / \mathrm{s}$. The next sections will discuss the performance of the overall engine and individual cylinders.

\subsubsection{Overall Performance}

Figure 4.2.4 shows intake equivalence ratio versus intake manifold temperature for the conditions tested. The equivalence ratio is determined from the measured intake air and fuel flow rates. The equivalence ratio ranges from 0.2 to 0.55 for these conditions, $( \pm 0.02)$.

The combustion efficiency, based on fraction of fuel converted to $\mathrm{CO}, \mathrm{CO}_{2}$, and $\mathrm{H}_{2} \mathrm{O}$, has been determined from the exhaust emissions using the textbook procedure of Heywood [62] that accounts for conversion and partial conversion of the inducted fuel. Figure 4.2.5 shows combustion efficiency versus intake temperature. The combustion efficiency tends to increase as fuel flow rate increases at constant inlet temperature or as inlet temperature is increased at constant fuel flow rate. For the lowest fuel flow rate case, the combustion efficiency is very poor, yielding less than $60 \%$ efficiency at the 
lowest temperature. In this extreme case (lowest intake temperature, lowest fuel flow rate) all cylinders are firing with relative consistency, as seen in Figure 4.2.6, but this is a very poor operating point because the combustion efficiency in each cylinder is consistently low. In contrast to this, the lowest temperature operating point at $0.65 \mathrm{~g} / \mathrm{s}$ fuel flow rate shows significant differences in the operation of each cylinder, as seen in Figure 4.2.7. These results will be discussed in more detail in a later section, but are presented for preliminary explanation and to demonstrate some of the challenges of multi-cylinder HCCI engine operation.

Total hydrocarbon emissions (THC), carbon monoxide (CO) and $\mathrm{NO}_{\mathrm{x}}$ emissions are shown in Figures 4.2.8, 4.2.9, and 4.2.10 respectively. All emissions are normalized by the fuel mass flow in order to have a common basis for comparison between operating conditions. The hydrocarbon emissions are very closely related to the combustion efficiency, albeit inversely. The trends show that as the fuel flow rate or intake temperature increase the hydrocarbon emissions decrease. The $\mathrm{CO}$ emissions follow the same pattern. The trend in $\mathrm{NO}_{\mathrm{x}}$ emissions is to increase with increasing fuel flow rate at constant intake temperature or increasing temperature at constant fuel flow rate. At the lowest fuel flow rates $(0.34 \mathrm{~g} / \mathrm{s}$ and $0.50 \mathrm{~g} / \mathrm{s})$ the $\mathrm{NO}_{\mathrm{x}}$ is very low (less than $5 \mathrm{ppm} \mathrm{NO}_{\mathrm{x}}$ ), so the crossover seen may be due to the precision of the $\mathrm{NO}_{\mathrm{x}}$ analyzer.

Figure 4.2.11 shows the brake mean effective pressure (BMEP) versus intake manifold temperature. The BMEP ranges from -0.8 bar to 3.3 bar for this operating range. The idle ( 0 bar BMEP) operating point occurs at $0.34 \mathrm{~g} / \mathrm{s}$ fuel flow rate and an intake temperature of roughly $130{ }^{\circ} \mathrm{C}$. Referring back to Figure 4.2 .5 , the combustion efficiency at this idle operating point is around $75 \%$. The THC and CO emissions for this 
point may be unacceptably high. It may be possible to improve combustion efficiency by going to a lower fuel flow rate and a higher intake temperature. For the high load operating points, the trend is that lower intake temperature results in higher BMEP. Ignoring the lowest temperature operating point for $0.65 \mathrm{~g} / \mathrm{s}$ fuel flow rate (which is relatively unstable), the three highest fuel flow rates, $0.65,0.72$, and $0.83 \mathrm{~g} / \mathrm{s}$ have the same trend. The brake thermal efficiency, average net indicated efficiency, and average gross indicated efficiency are shown in Figures 4.2.12-4.2.14, respectively, for all fuel flow rates. These indicated efficiencies are calculated based on the average of the work per cycle for all four cylinders. The brake thermal efficiency ranges from less than zero (negative efficiency meaning that work must be added to the engine by the electric motor to sustain operation) to $25 \%$. The maximum gross indicated thermal efficiency is $32 \%$. The indicated efficiency is low despite the high compression ratio, likely due to a combustion chamber design (high swirl, very little clearance between the piston top and head at TDC) that results in significant heat transfer. Figure 4.2.15 shows the brake, average net indicated, and average gross indicated mean effective pressure for $0.65 \mathrm{~g} / \mathrm{s}$ fuel flow rate. For all operating points the difference between the net IMEP and BMEP ranges from 0.85 to 0.9 bar.

In multi-cylinder $\mathrm{HCCI}$ engines variation in performance between cylinders can limit efficiency and BMEP. For instance, Figures 4.2.16 and 4.2.17 show the gross IMEP for each cylinder versus intake temperature for 0.34 and $0.83 \mathrm{~g} / \mathrm{s}$ fuel flow rates, respectively. The IMEP of each cylinder varies considerably between the cylinders. The trends are not completely consistent (i.e. the IMEP for cylinder 2 is not always higher than cylinder 1), suggesting that multiple factors play a role: non-uniformity in the intake 
manifold temperature, small variations in compression ratio between the cylinders, variations in combustion chamber wall temperatures, exhaust gas residuals, etc. As will be shown in the next section, the combustion phasing is different between the cylinders for the same intake manifold temperature. This can lead to a situation where some cylinders can be in stable operation and others misfire. Balancing the cylinders, so that all cylinders have optimum combustion timing for a specific load, will allow for better overall engine performance. The cylinder balancing process would likely require a feedback control mechanism for each cylinder.

\subsubsection{Cylinder-by-Cylinder Operation}

At each operating condition the performance of each cylinder can vary significantly. Results for the $0.65 \mathrm{~g} / \mathrm{s}$ fuel flow rate case to illustrate cylinder by cylinder operation will be used. The individual cylinder data are plotted versus intake temperature or combustion timing. Figure 4.2.18 shows a sample plot of rate of heat release versus crank angle for propane HCCI combustion. The rate of heat release presented is chemical heat release determined by analysis of the pressure trace [62].

Again, the combustion timing and burn duration are defined from the heat release curve. The crank angle corresponding to the peak of the rate of heat release (POHR) is used as the marker of combustion timing. The crank angle that corresponds to $10 \%$ of the peak rate of heat release on the rising edge of the rate of heat release curve is specified as the start of combustion (SOC). Similarly the "end" of combustion is specified as the crank angle corresponding to $10 \%$ of the peak heat release rate on the falling edge of the curve. The difference in crank angle between the start of combustion 
and the end of combustion is the burn duration. The falling edge of the heat release curve can be very noisy due to acoustic phenomena in the cylinder (knock-like pressure oscillations). To compensate for this, a Gaussian exponential function is fitted to the falling edge and is used to average these oscillations. The smoothed curve is used for determining burn duration.

Figures 4.2.19 and 4.2.20 show pressure traces and rate of heat release (ROHR) traces for each cylinder at four different intake manifold temperatures at $0.65 \mathrm{~g} / \mathrm{s}$ fuel flow rate. The pressure traces are an average of 332 instantaneous traces and ROHR is determined from this average. The lowest temperature operating point, $108^{\circ} \mathrm{C}$ intake temperature, operation can be seen to be inconsistent between the cylinders. Operation around the lower limits is tenuous, and the difference between stable operation and misfire requires only a small change in the control parameters [43]. Slight variations in cooling water temperature, oil temperature, compression ratio of each cylinder, intake manifold temperature inhomogeneities could result in significant variations in the combustion process. For example, in the VW TDI engine the cooling water runs longitudinally through the engine entering near cylinder 1 and exiting near cylinder 4 . This could result in a higher water temperature gradient along the engine, resulting in variations in heat transfer throughout the engine. The $108^{\circ} \mathrm{C}$ operating point may be near the lower limit of operation, and the slight differences in the parameters mentioned above could explain this inconsistent operation.

Figures 4.2.19 and 4.2.20 show that as the intake temperature is increased the combustion process becomes more consistent among the cylinders. Figure 4.2.21 shows the combustion timing defined as the peak rate of heat release (POHR) plotted against 
intake manifold temperature for each of the four cylinders. At the lowest temperature the spread in timing between cylinders is 7 CAD (Crank Angle Degrees), but for the higher intake temperatures operating points the spread is consistently about $2 \mathrm{CAD}$. As expected, the timing advances for each cylinder as intake temperature increases. The trend in POHR between cylinders is not particularly consistent. For instance, cylinder 2 fires latest in the lowest temperature case, but cylinder 1 fires latest in the other cases. These results show that controlling individual cylinders requires a strategy strong enough to overcome a variety of operating factors.

Figure 4.2.22 shows burn duration for each cylinder plotted versus intake manifold temperature. The difference in burn duration between cylinders is large at the low temperature operating point $(10 \mathrm{CAD})$ and reduces to 2.5 degrees for the other temperatures. As intake temperature increases in the two highest temperature cases, the variation in burn duration decreases. The combustion timing in Figure 4.2.21 also decreases for these cases. Figure 4.2.23 shows the burn duration versus the POHR combustion timing. The correlation of burn duration relative to combustion timing is good for early timed cases and poor for later timed cases. The late timing case for each cylinder corresponds to the lowest temperature operating point where inconsistent combustion occurs in the four cylinders.

Figure 4.2.24 shows the gross IMEP versus POHR combustion timing for each of the four cylinders. The main conclusion that can be drawn from this figure is that the IMEP has a somewhat consistent trend with respect to peak of heat release between cylinders although there is a great deal of spread. Figure 4.2.25 shows peak cylinder pressure 
versus POHR timing and the trend shown is that later timing reduces peak cylinder pressure in all cylinders. 
Table 4.2.1 - TDI Engine parameters

\begin{tabular}{|l|l|}
\hline Displacement (all 4 cylinders) & $1.896 \mathrm{~L}$ \\
\hline Bore & $79.5 \mathrm{~mm}$ \\
\hline Stroke & $95.5 \mathrm{~mm}$ \\
\hline Connecting Rod & $144 \mathrm{~mm}$ \\
\hline Compression Ratio & $19: 1$ \\
\hline Intake Valve Open $(1 \mathrm{~mm} \mathrm{lift})$ & $16^{\circ}$ ATDC \\
\hline Intake Valve Close $(1 \mathrm{~mm}$ lift $)$ & $25^{\circ}$ ABDC \\
\hline Exhaust Valve Open $(1 \mathrm{~mm}$ lift) & $28^{\circ}$ BBDC \\
\hline Exhaust Valve Close $(1 \mathrm{~mm} \mathrm{lift})$ & $19^{\circ}$ BTDC \\
\hline
\end{tabular}



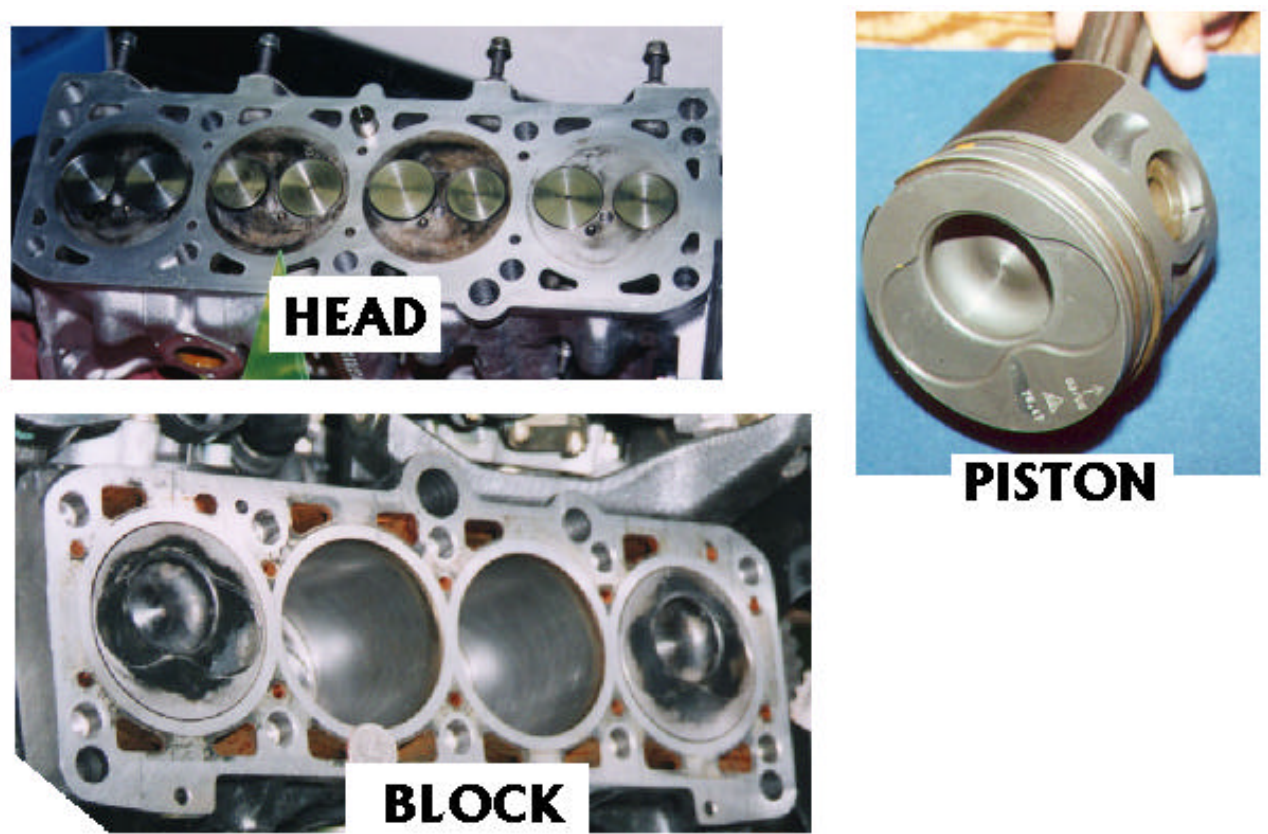

Figure 4.2.1 - Head, block (pistons at 1 and 4 at TDC, 2 and 3 at BDC), and a piston for VW TDI used for these tests. 


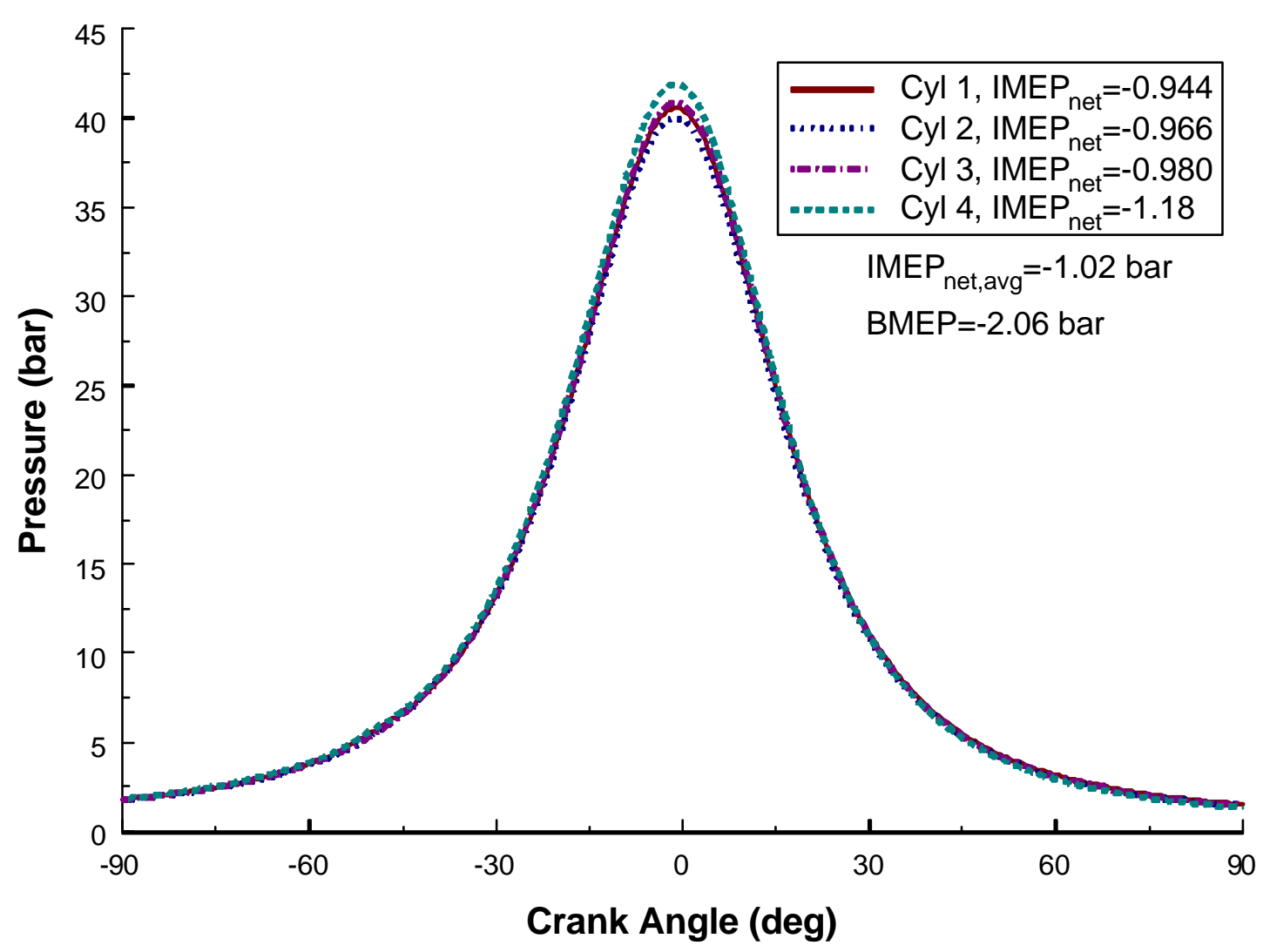

Figure 4.2.2 - Motoring pressure traces for individual cylinders in TDI engine. Net IMEP is reported for each cylinder, along with the average net IMEP of the four cylinders and BMEP 


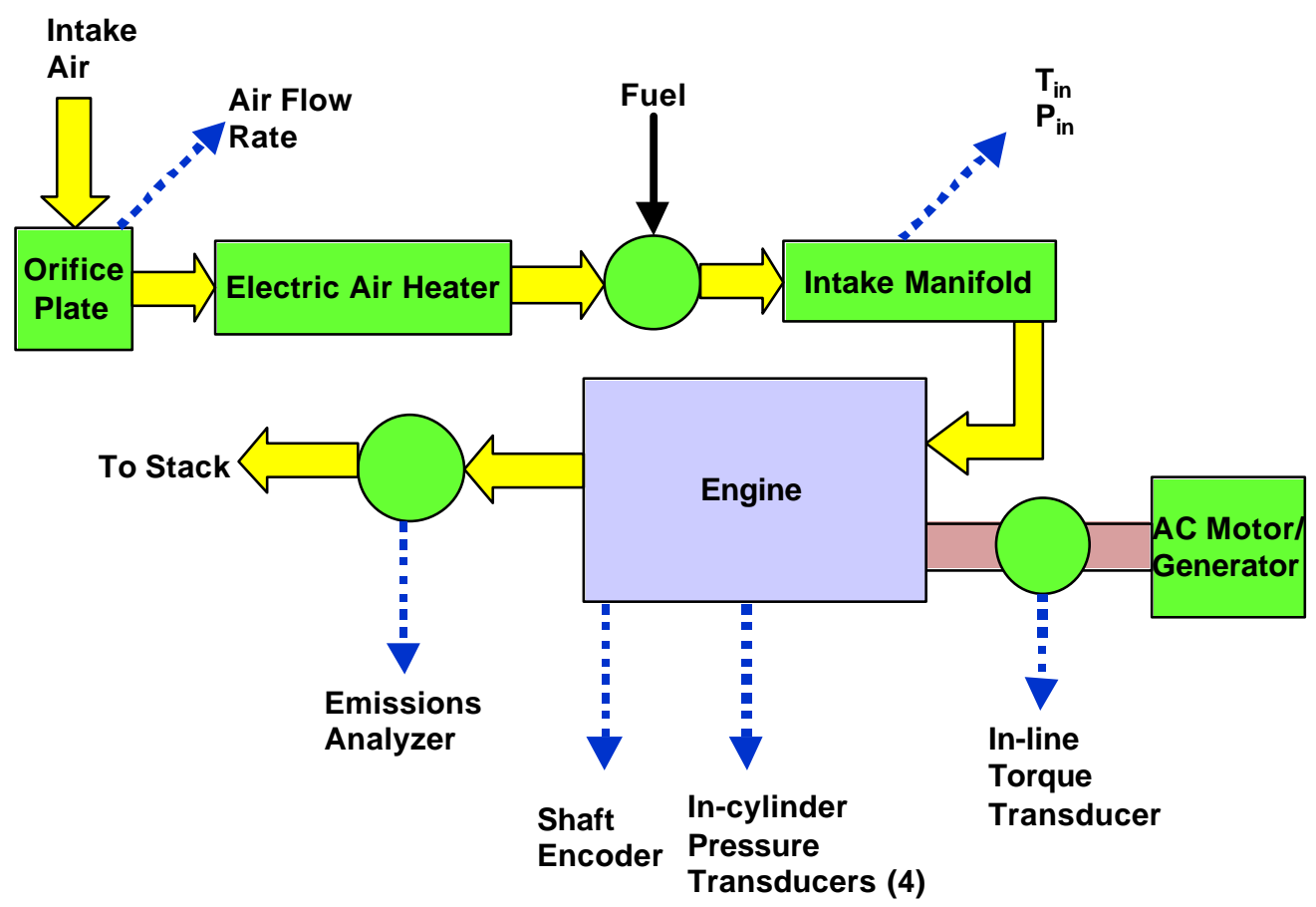

Figure 4.2.3 - Schematic of experimental setup 


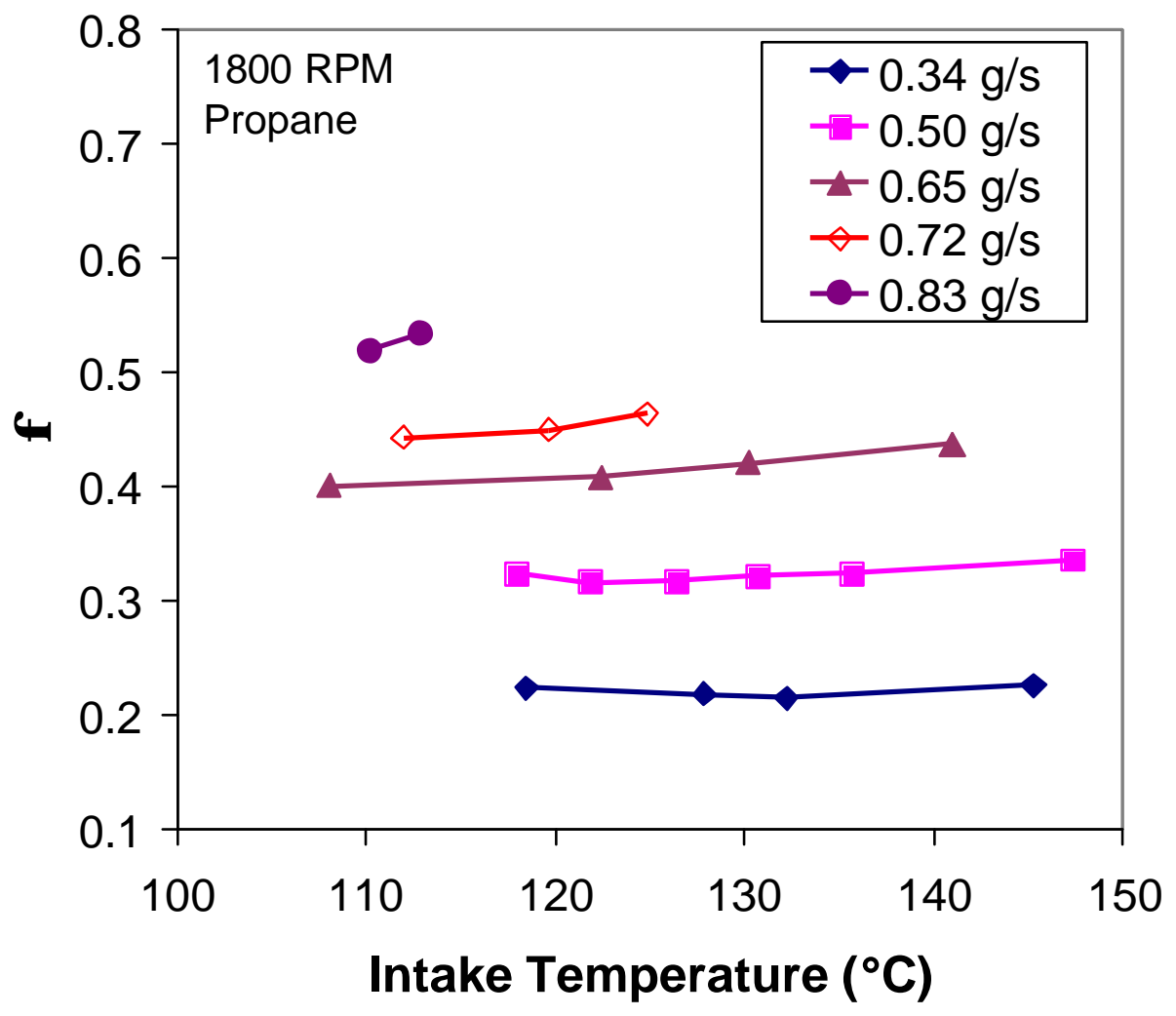

Figure 4.2.4 - Intake equivalence ratio versus intake manifold temperature, for several fuel flow rates. 


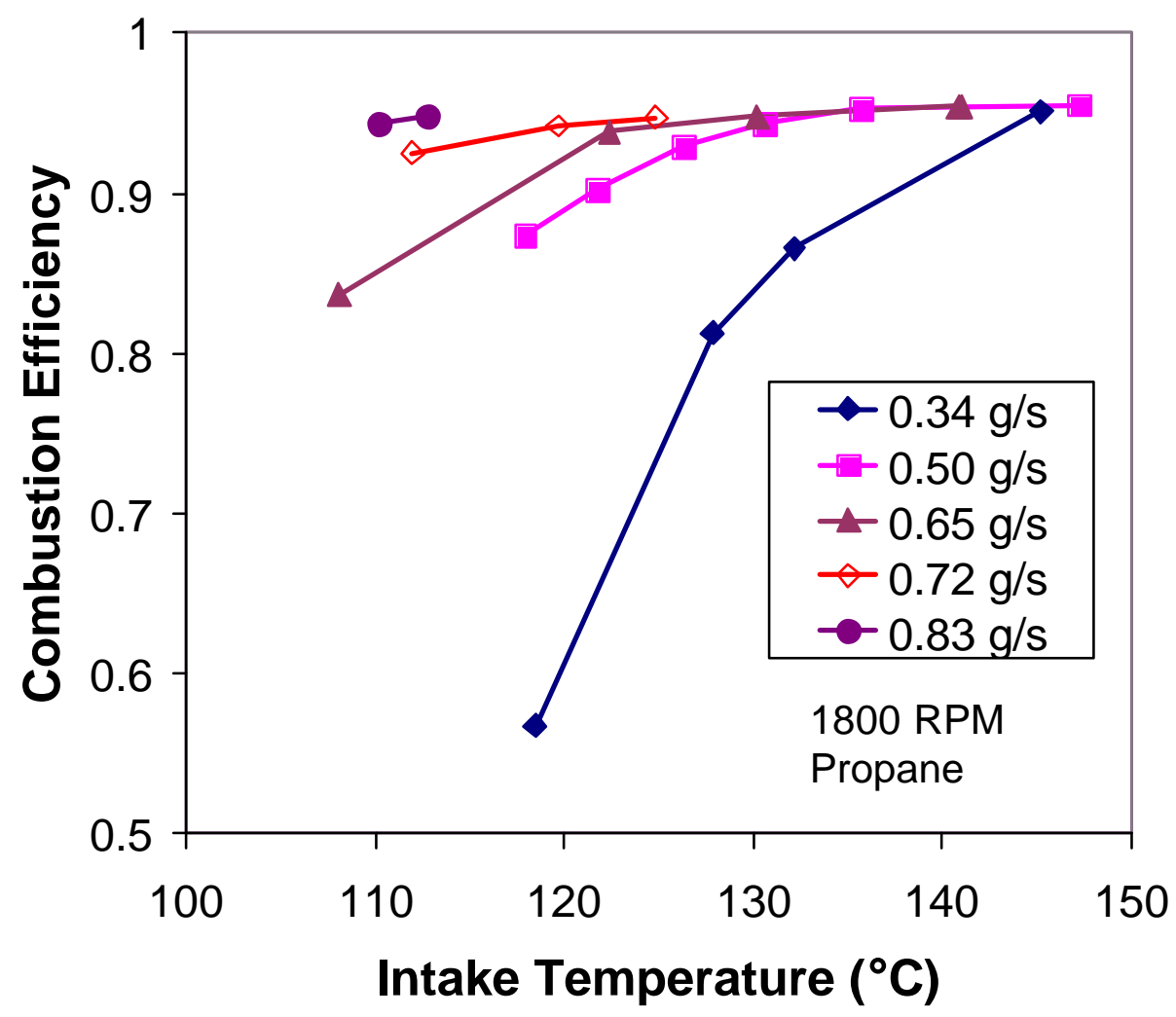

Figure 4.2.5 - Combustion efficiency based on exhaust emissions versus intake manifold temperature 

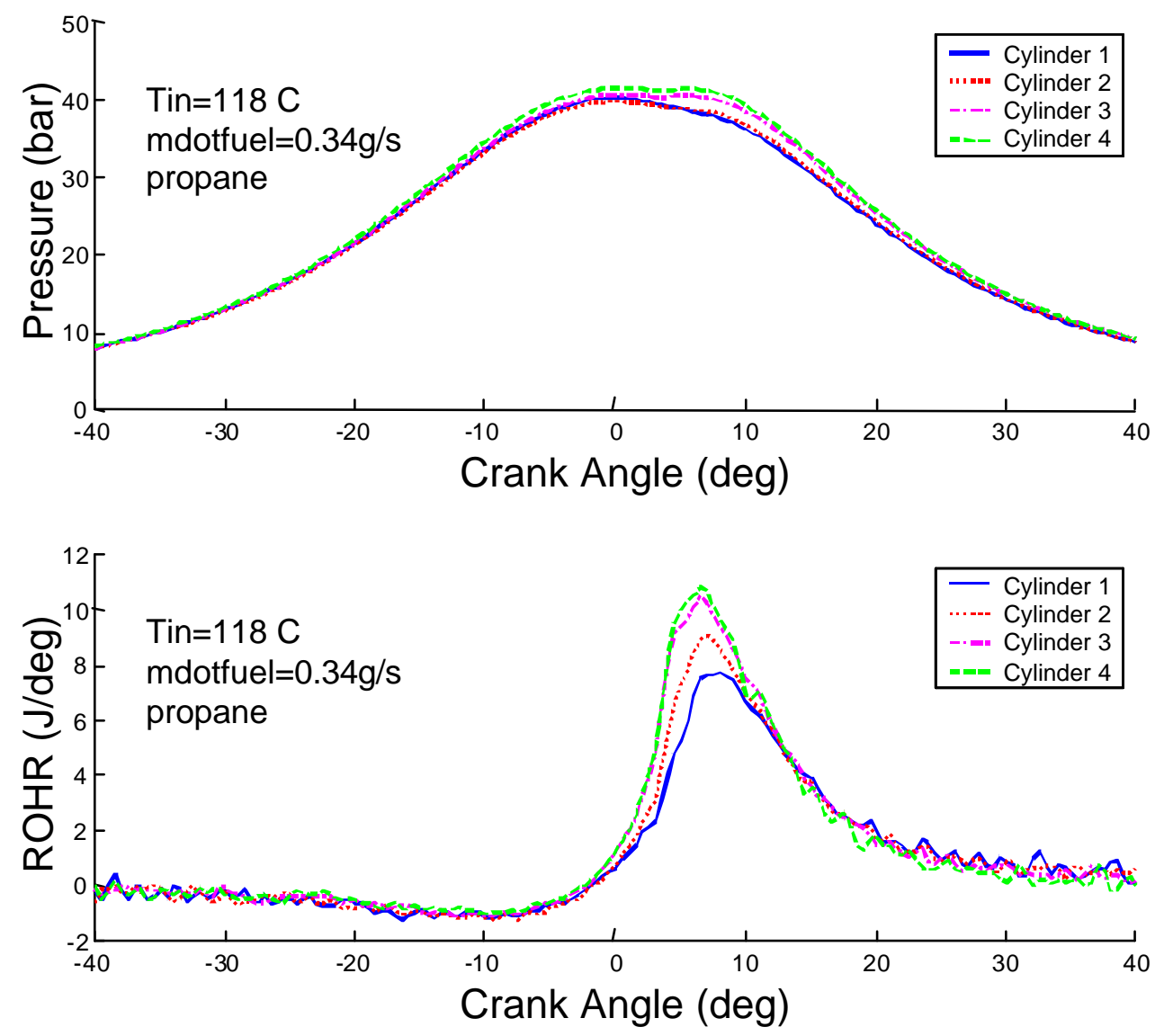

Figure 4.2.6 - Pressure trace and calculated rate of heat release for the lowest fuel flow rate, $0.34 \mathrm{~g} / \mathrm{s}$, and lowest intake temperature 

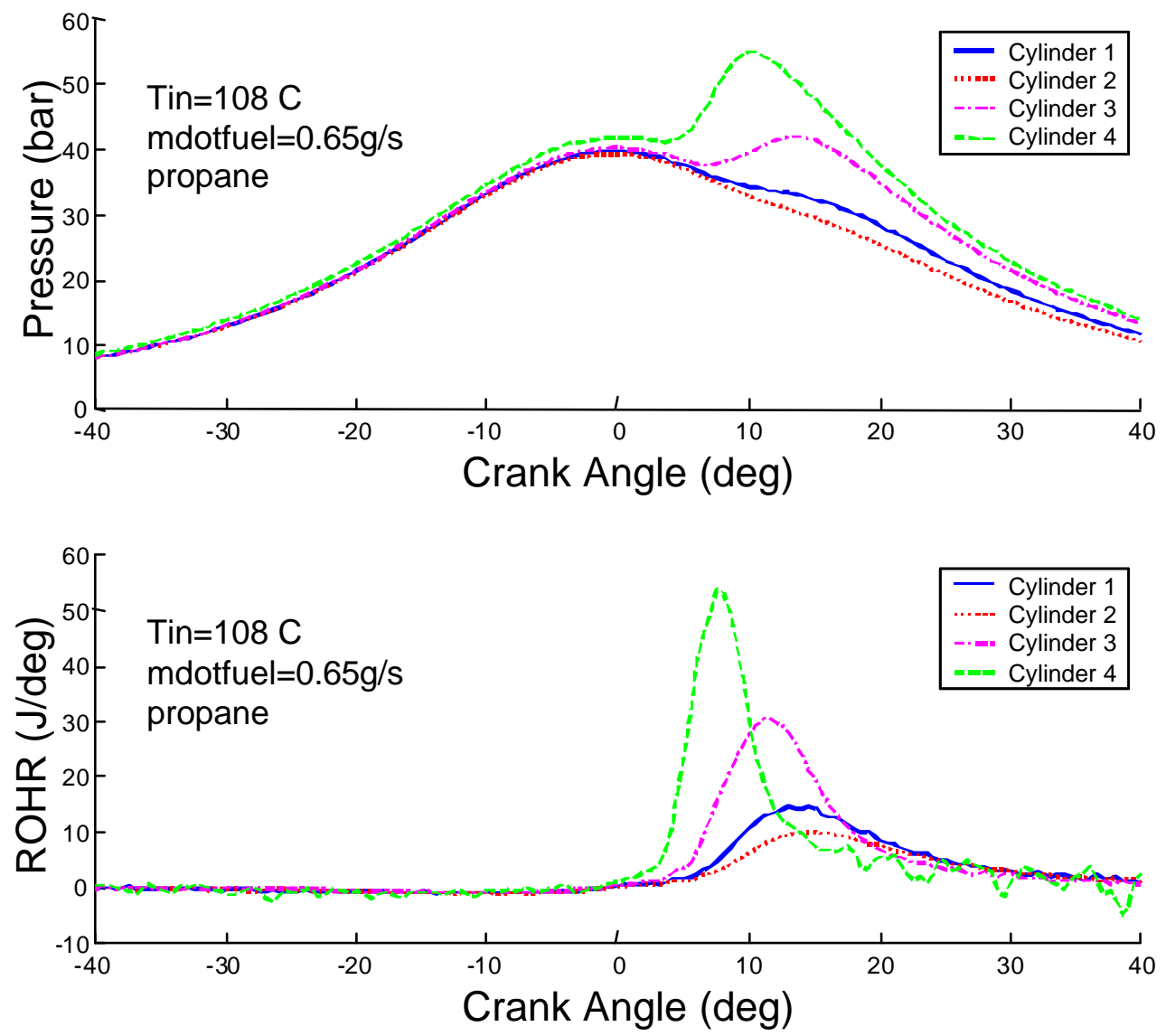

Figure 4.2.7 - Pressure trace and calculated rate of heat release for a fuel flow rate of 0.65 $\mathrm{g} / \mathrm{s}$ and the lowest intake temperature. 


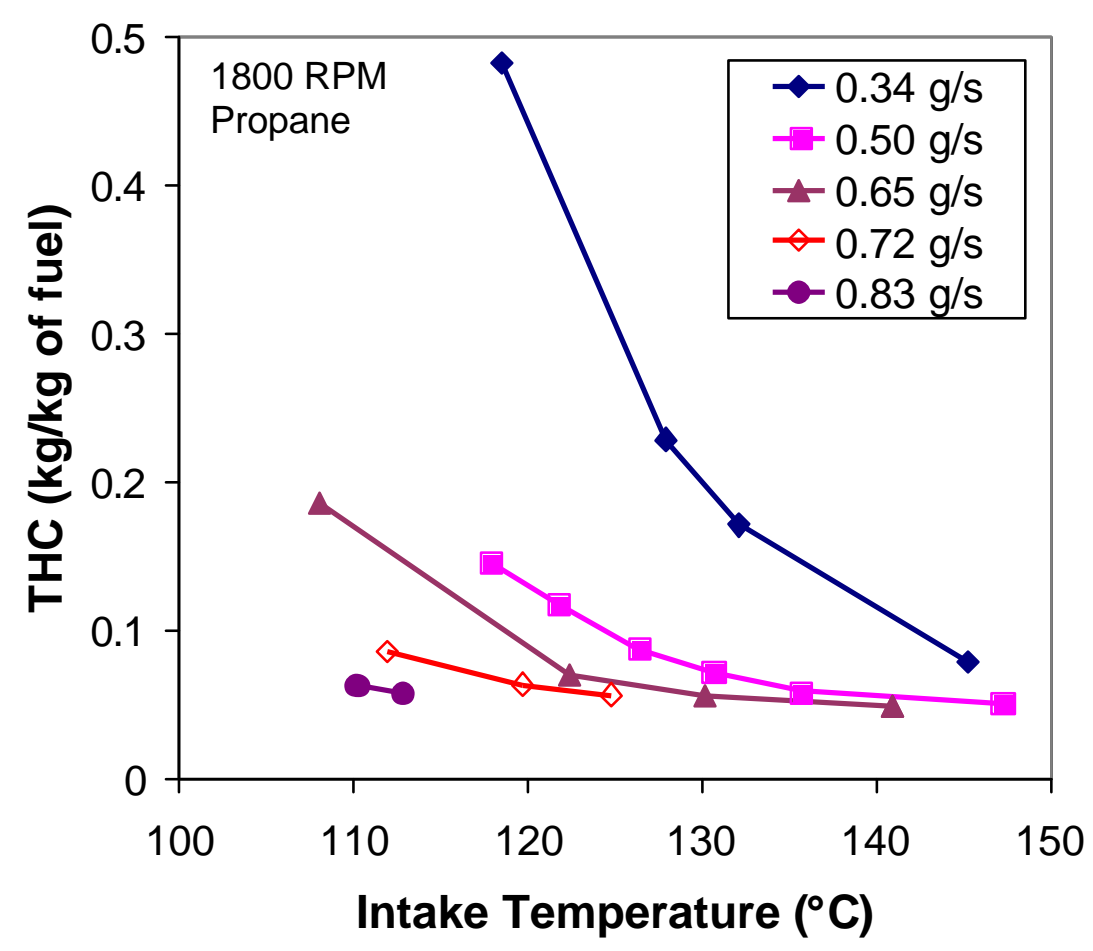

Figure 4.2.8 - Total hydrocarbon emissions versus intake manifold temperauture 


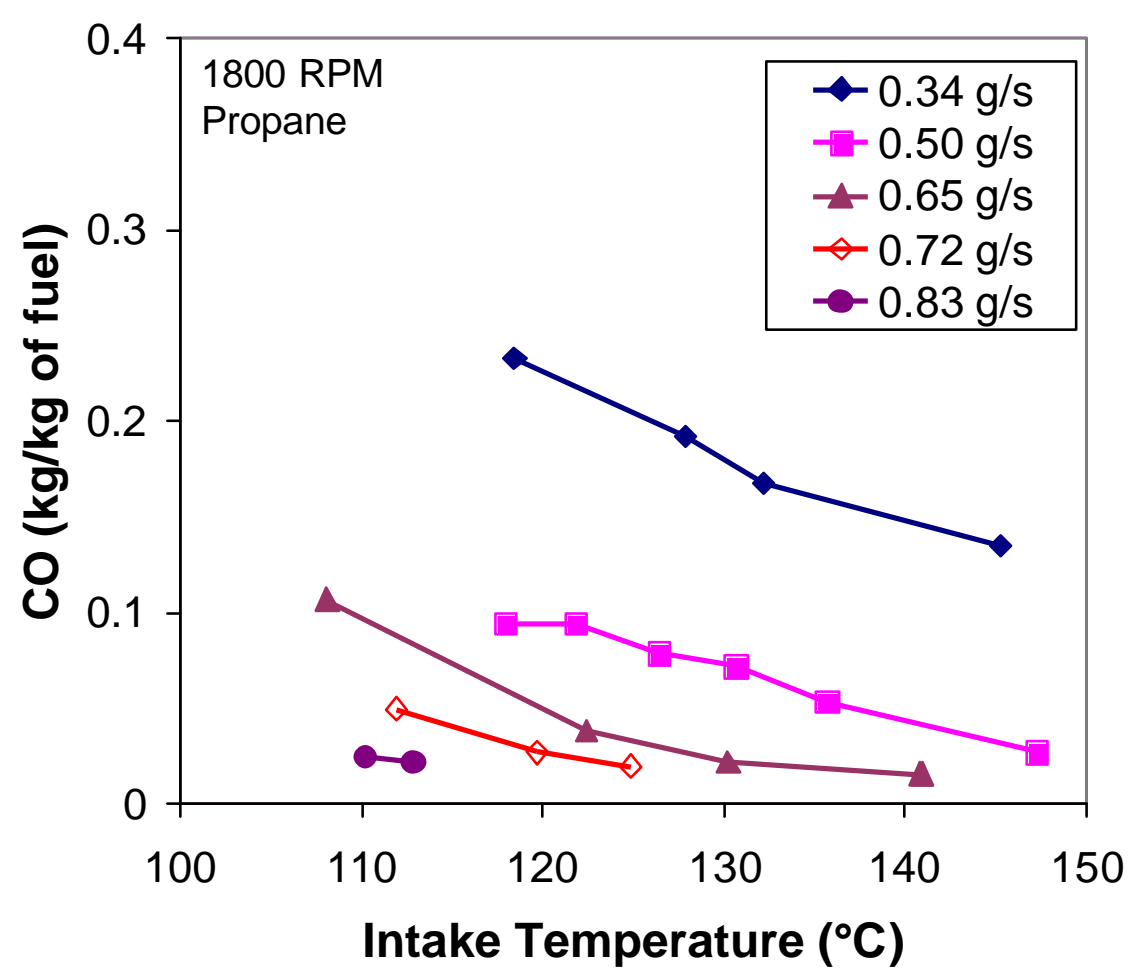

Figure 4.2.9 - Carbon monoxide emissions versus intake manifold temperature 


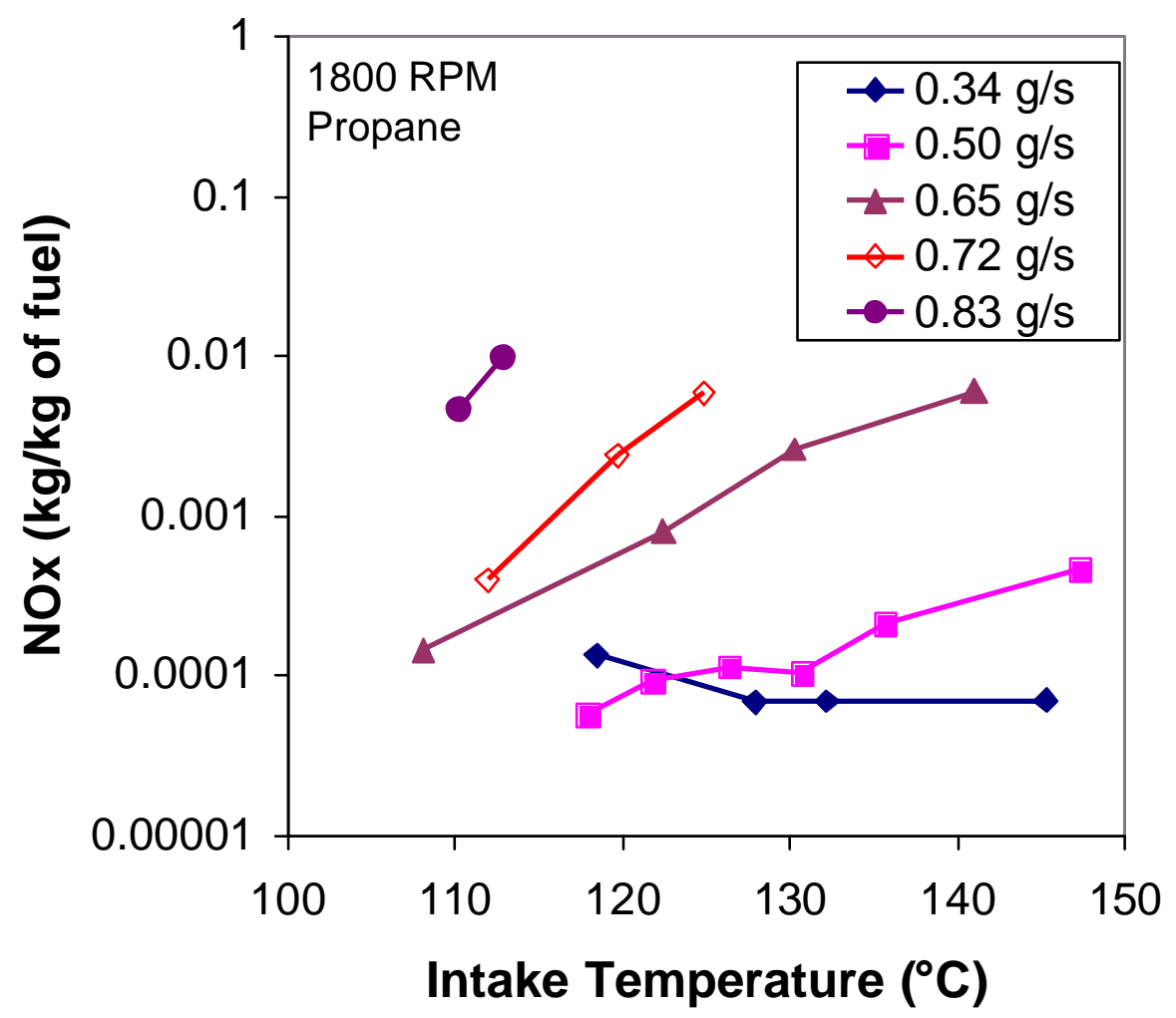

Figure 4.2.10 - Oxides of nitrogen emission versus intake manifold temperature 


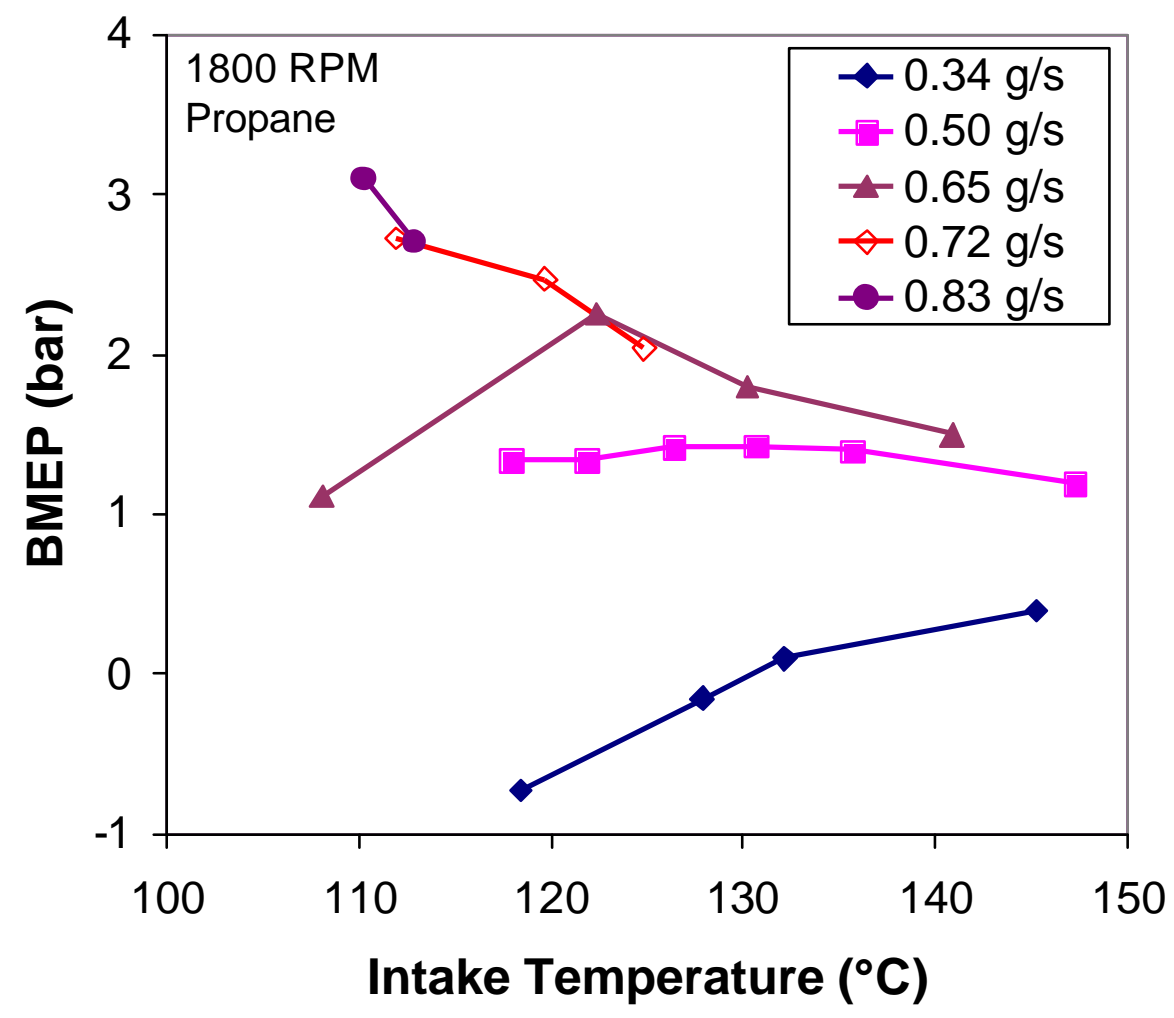

Figure 4.2.11 - BMEP versus intake manifold temperature 


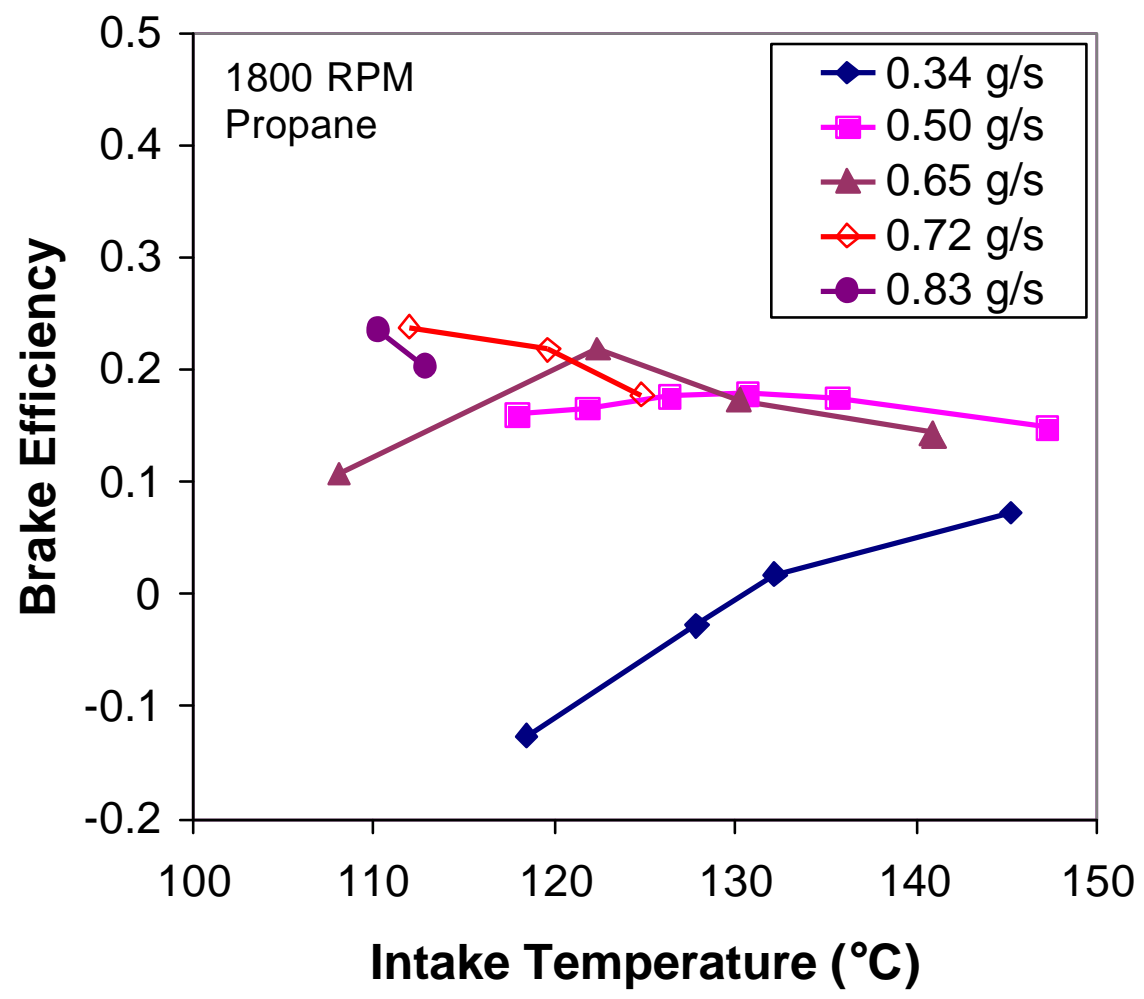

Figure 4.2.12 - Brake efficiency versus intake manifold temperature 


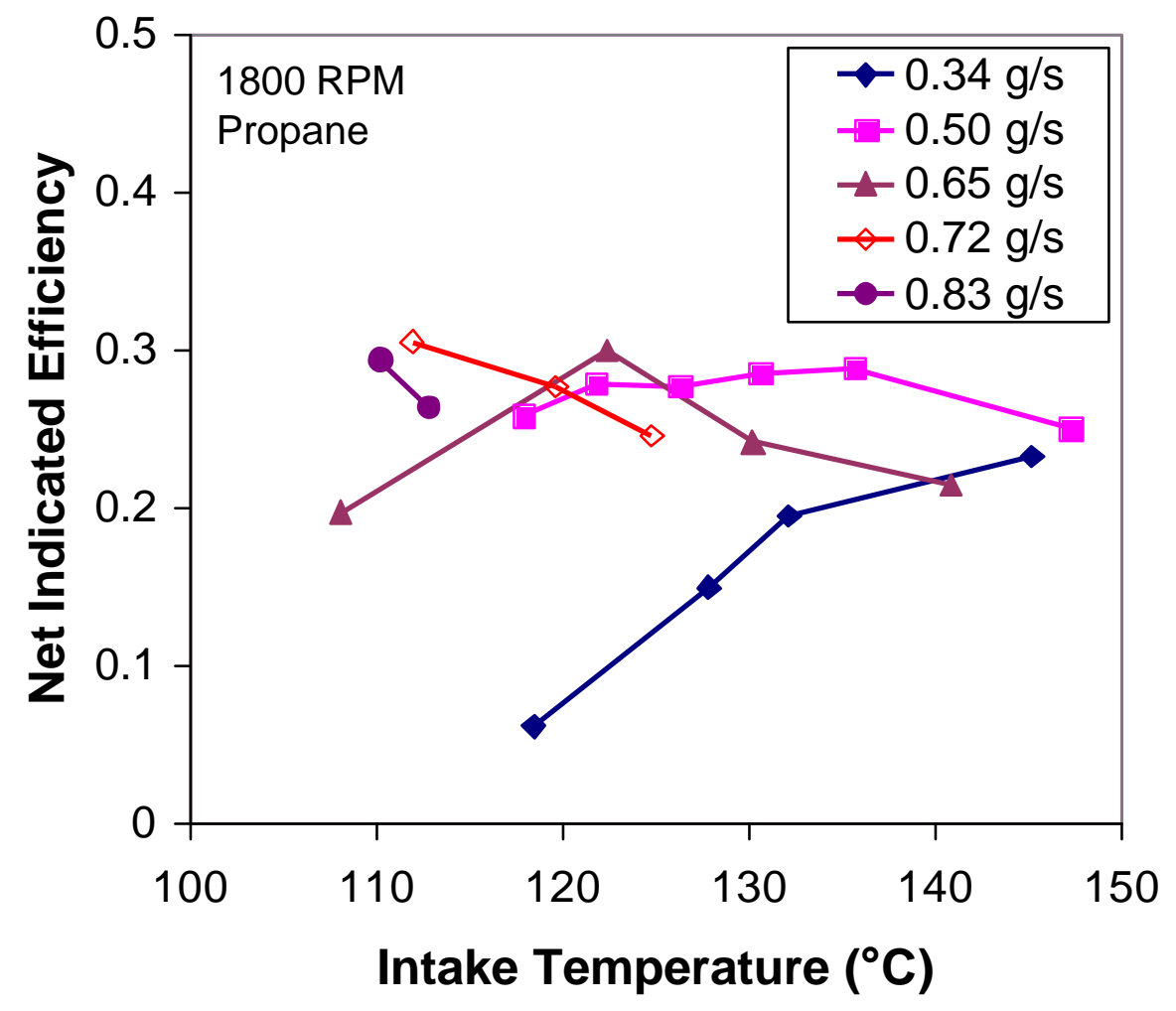

Figure 4.2.13 - Net indicated efficiency (average of the four cylinders) versus intake manifold temperature. 


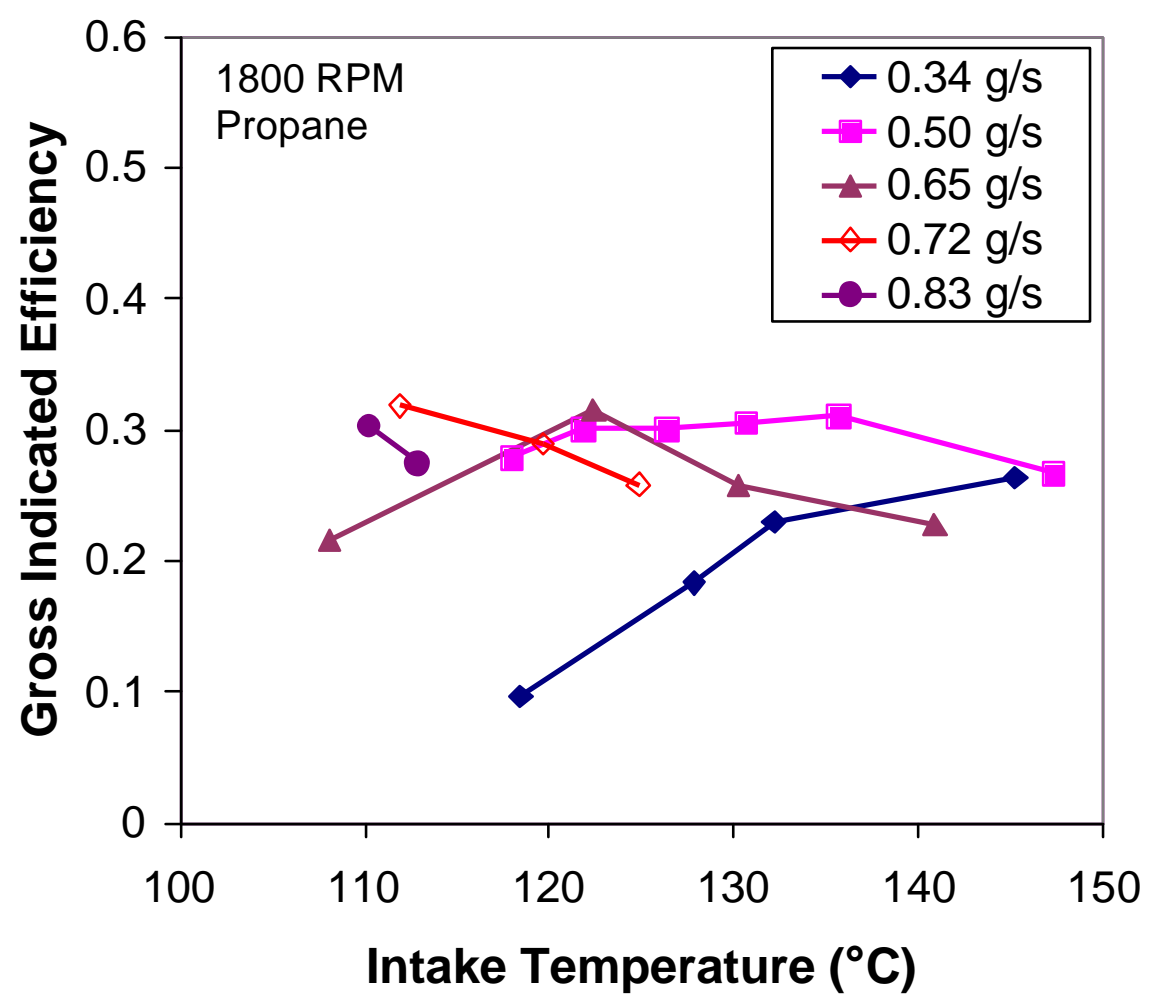

Figure 4.2.14 - Gross indicated efficiency (average of the four cylinders) versus intake manifold temperature. 


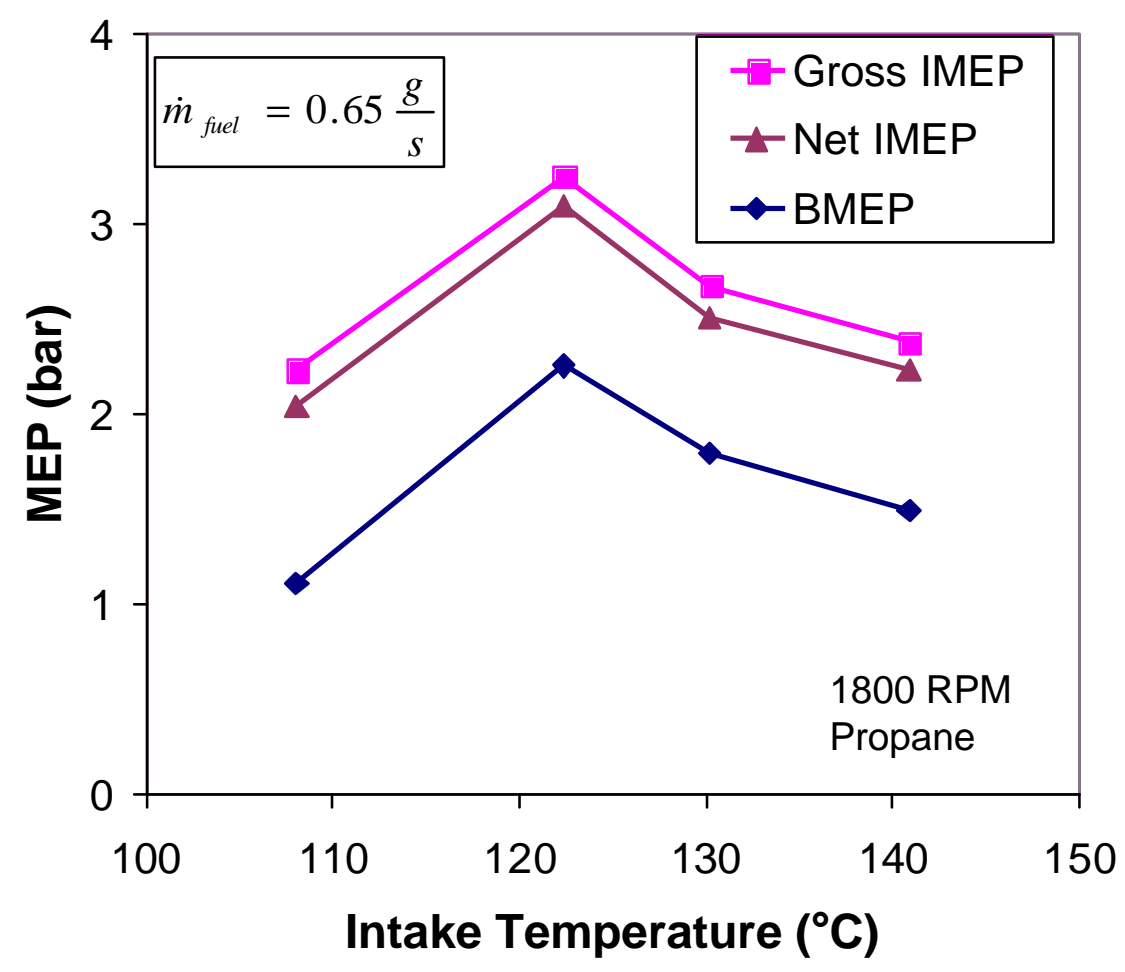

Figure 4.2.15 - Brake, net indicated, and gross indicated thermal efficiency versus intake temperature for $0.65 \mathrm{~g} / \mathrm{s}$ fuel flow rate. Indicated efficiencies are averages from all four cylinders. 


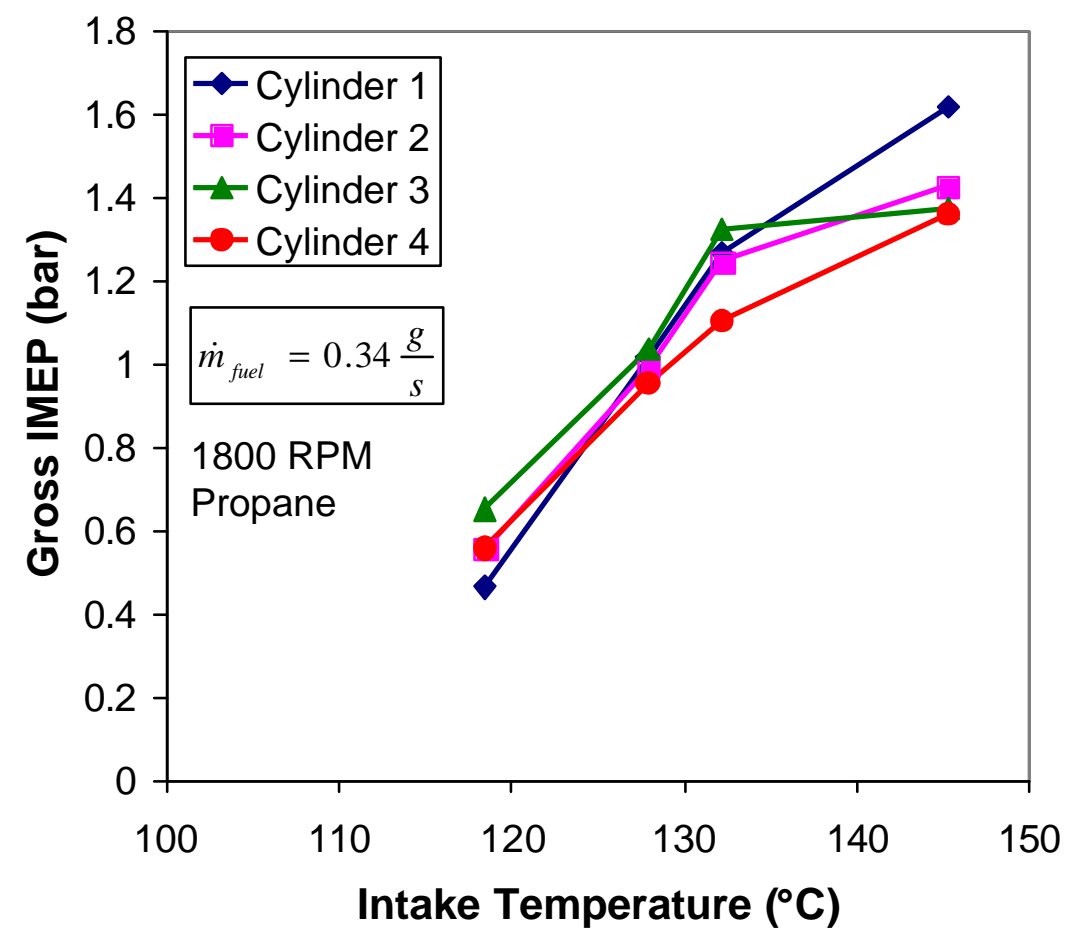

Figure 4.2.16- Gross IMEP for each cylinder versus intake manifold temperature for 0.34 $\mathrm{g} / \mathrm{s}$ fuel flow rate 


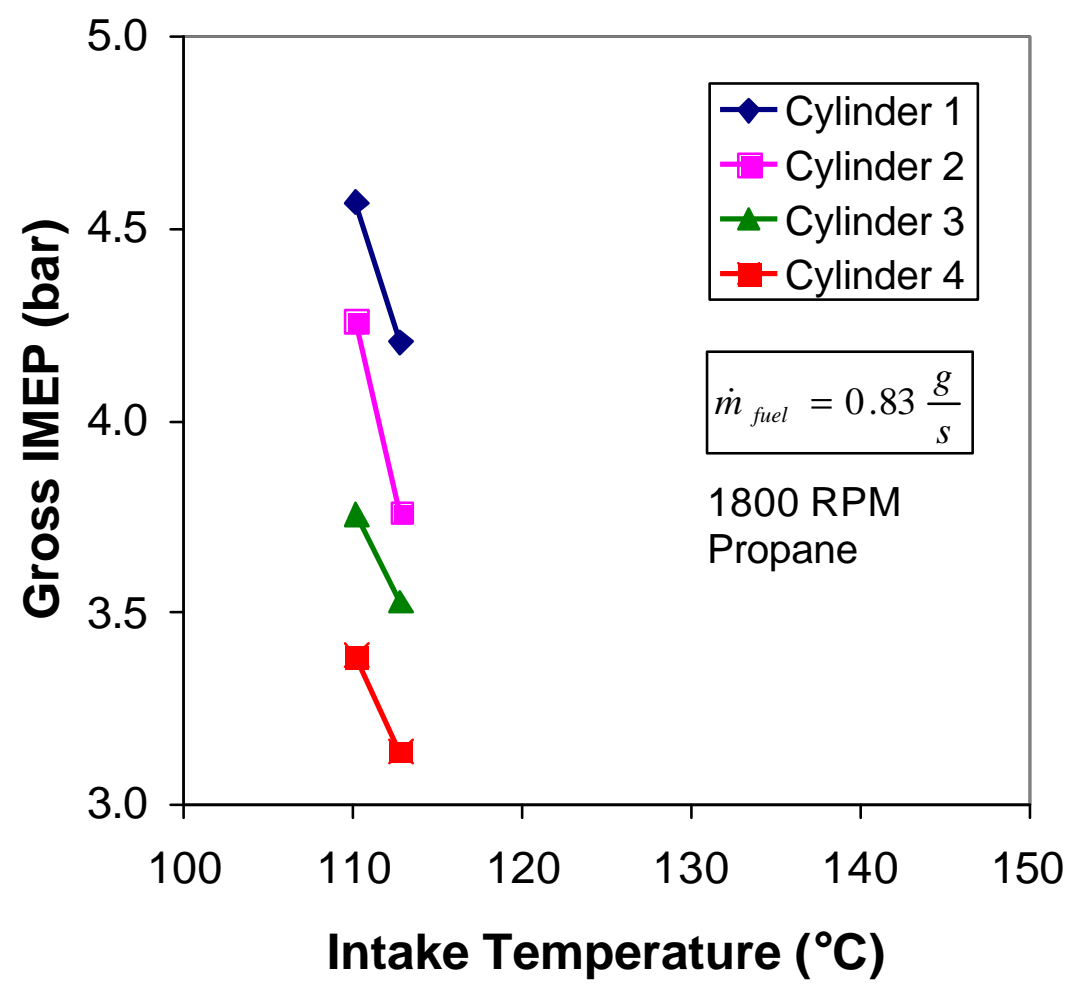

Figure 4.2.17 - Gross IMEP for each cylinder versus intake manifold temperature for $0.83 \mathrm{~g} / \mathrm{s}$ fuel flow rate 


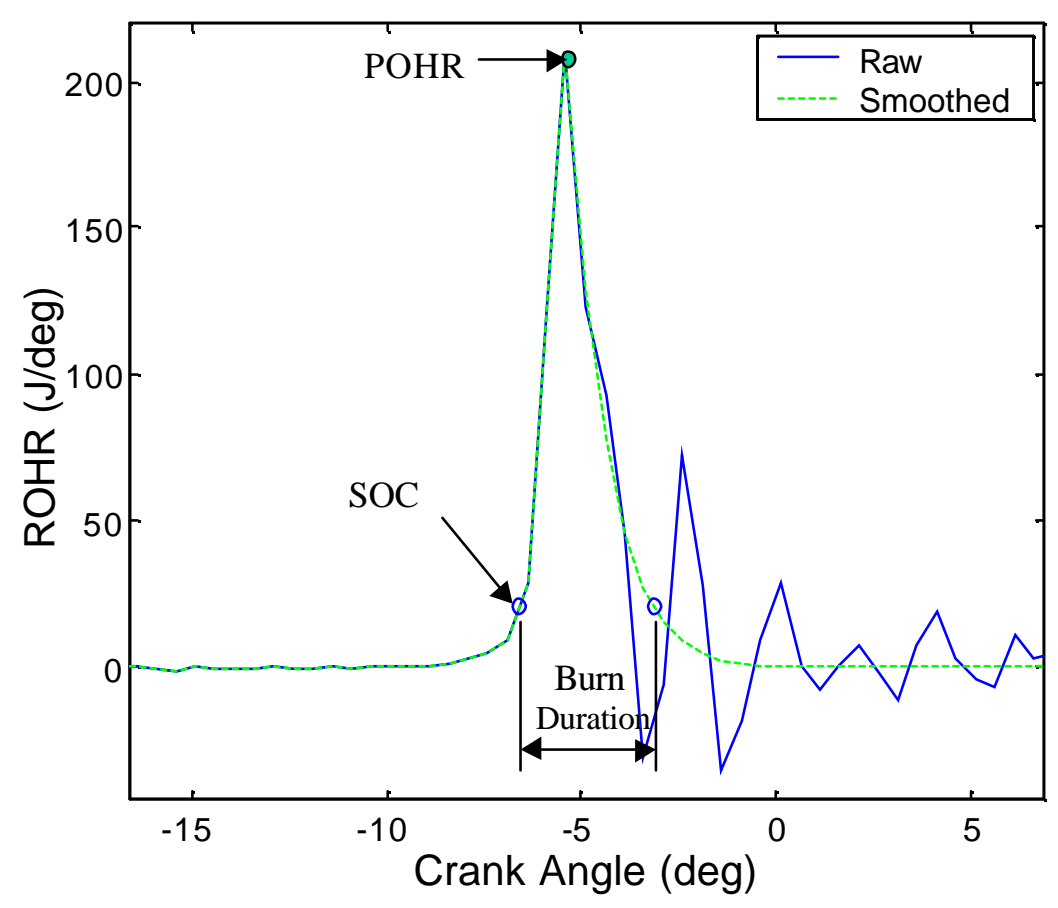

Figure 4.2.18 - Rate of heat release versus crank angle. The falling side of the curve is smoothed by Gaussian fitting. Start of combustion (SOC) is specified crank angle corresponding to $10 \%$ of the magnitude of peak of heat release (POHR) on the rising side of the curve. Burn duration is the distance between the SOC crank angle and the crank angle coressponding to $10 \%$ of the peak of heat release on the falling side of the curve, using the smoothed curve. 

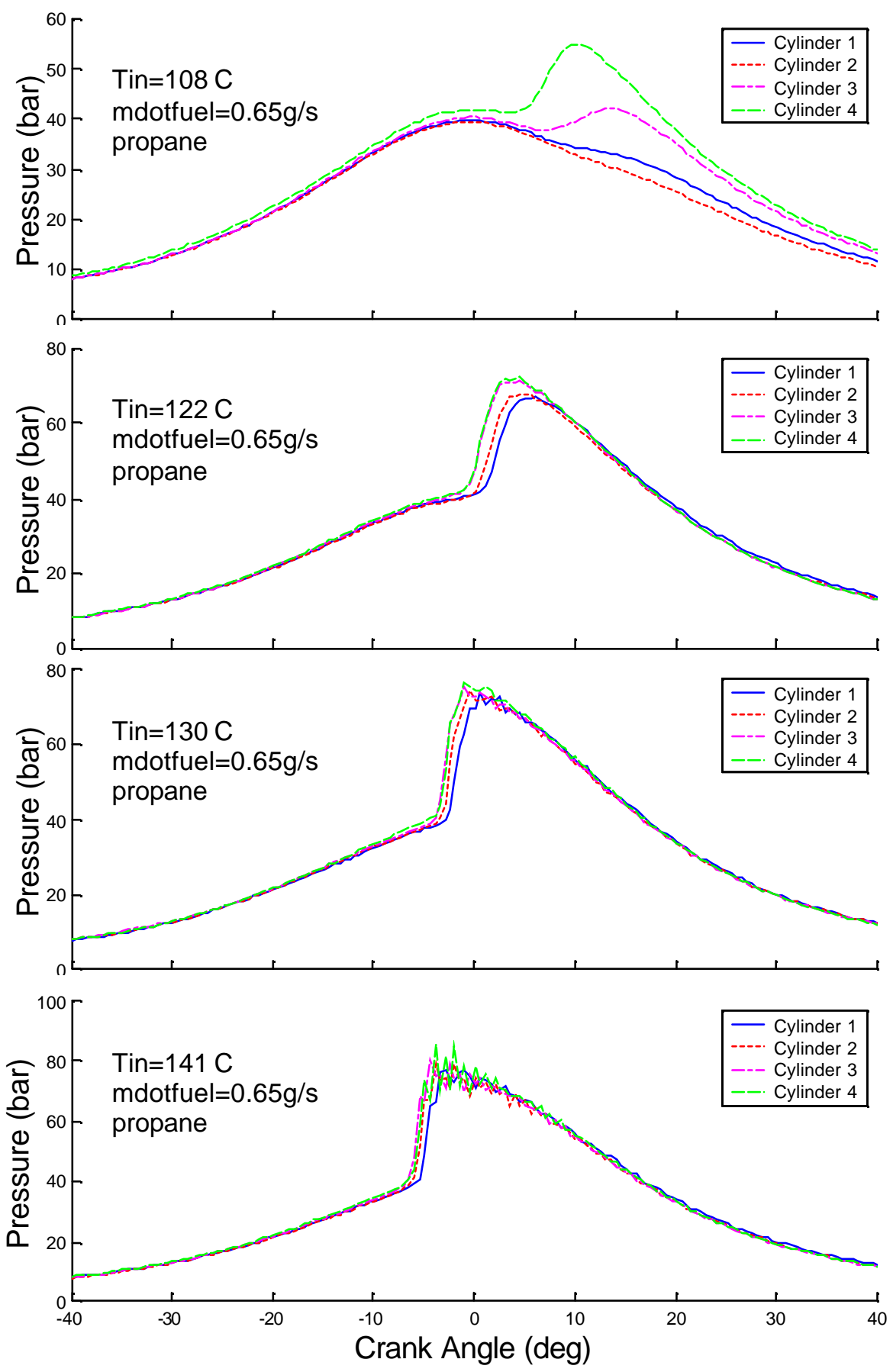

Figure 4.2.19 - Pressure traces for four different intake manifold temperatures at $0.65 \mathrm{~g} / \mathrm{s}$ fuel flow rate (average of 332 instantaneous traces). 

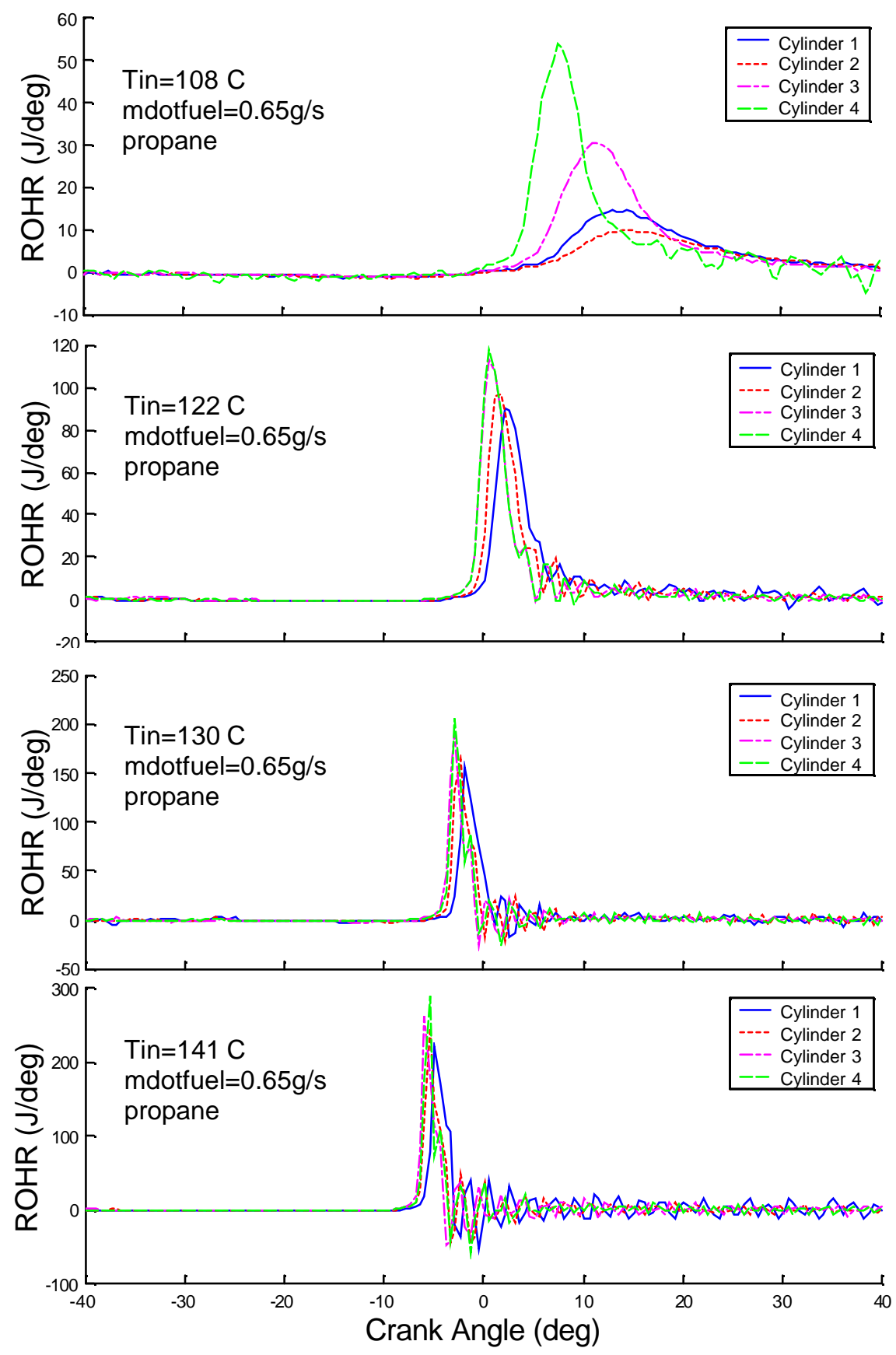

Figure 4.2.20 - Rate of heat release traces for four different intake manifold temperatures at $0.65 \mathrm{~g} / \mathrm{s}$ fuel flow rate. 


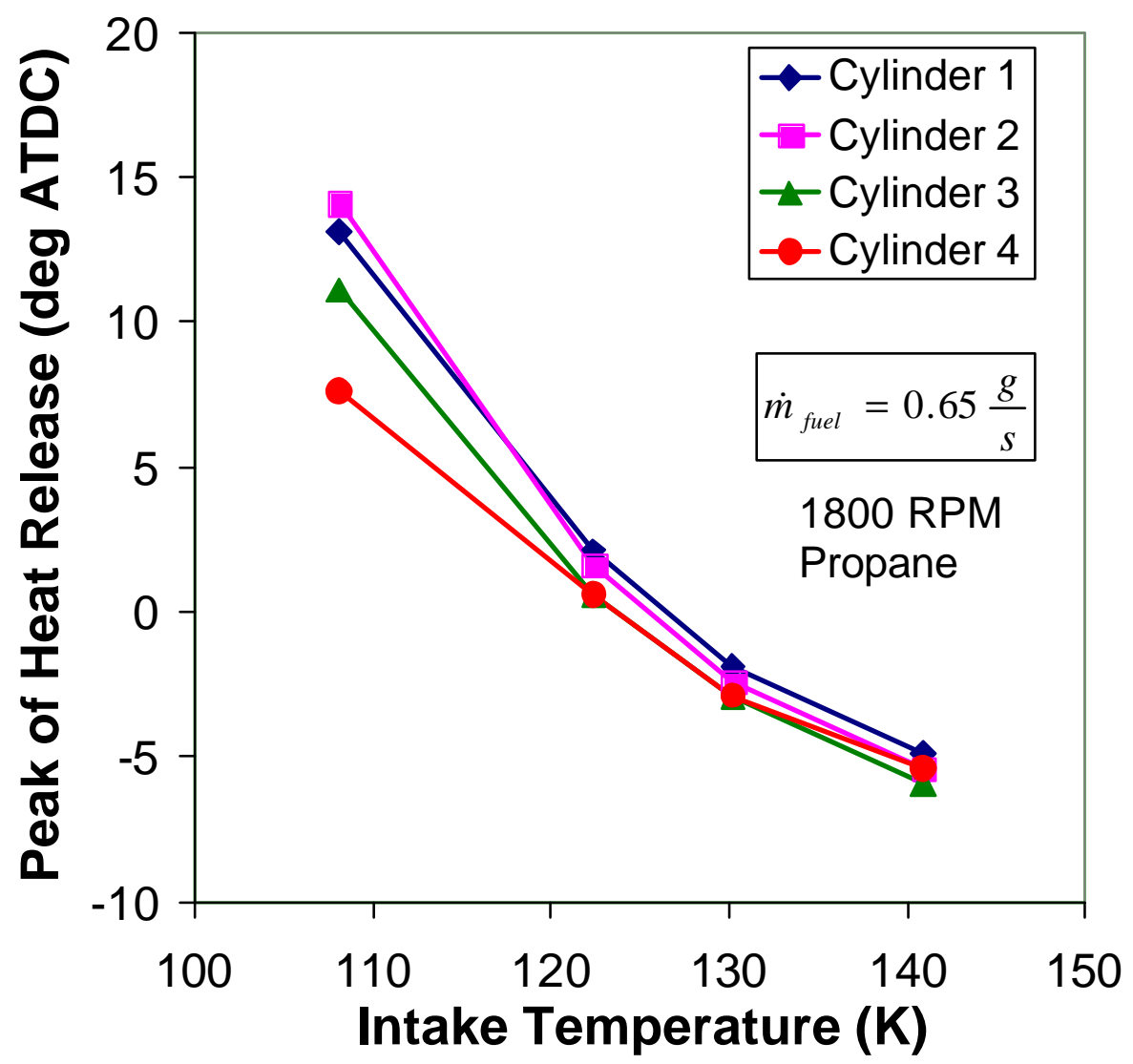

Figure 4.2.21 - Timing of peak of heat release rate versus intake temperature for $0.65 \mathrm{~g} / \mathrm{s}$ fuel flow rate. 


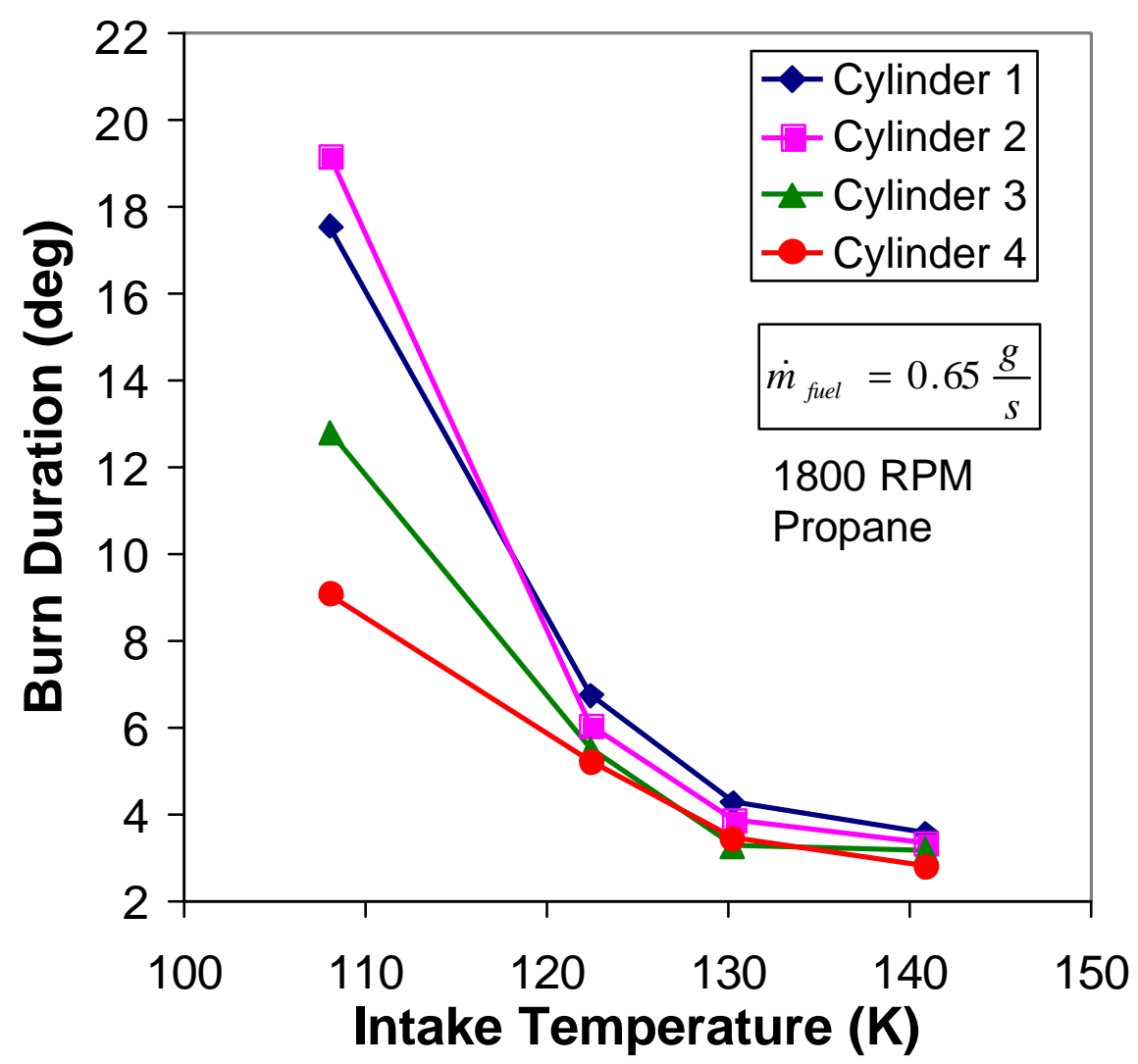

Figure 4.2.22 - Burn duration versus intake manifold temperature for each cylinder at $0.65 \mathrm{~g} / \mathrm{s}$ fuel flow rate. 


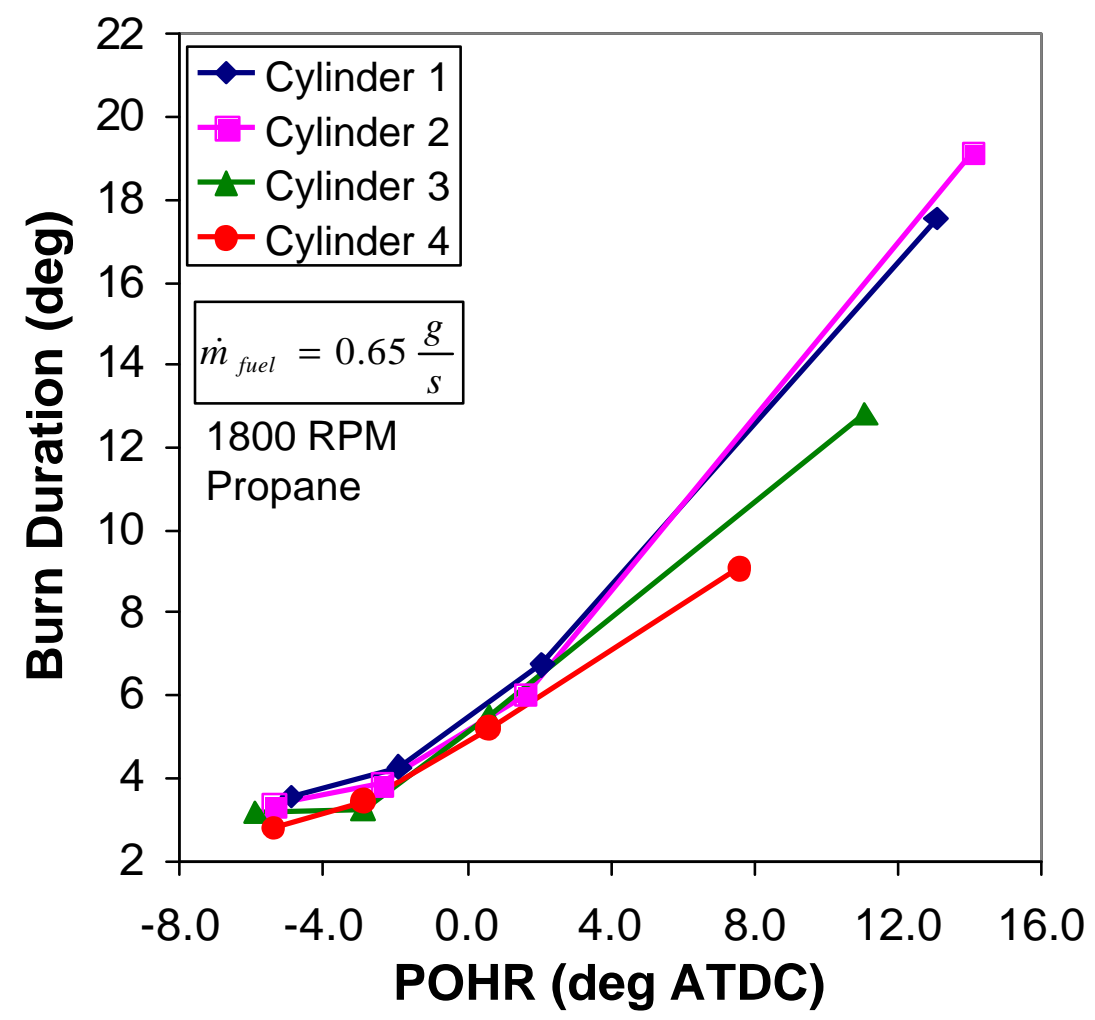

Figure 4.2.23 - Burn duration versus peak of heat release rate combustion timing for each cylinder at $0.65 \mathrm{~g} / \mathrm{s}$ fuel flow rate. 


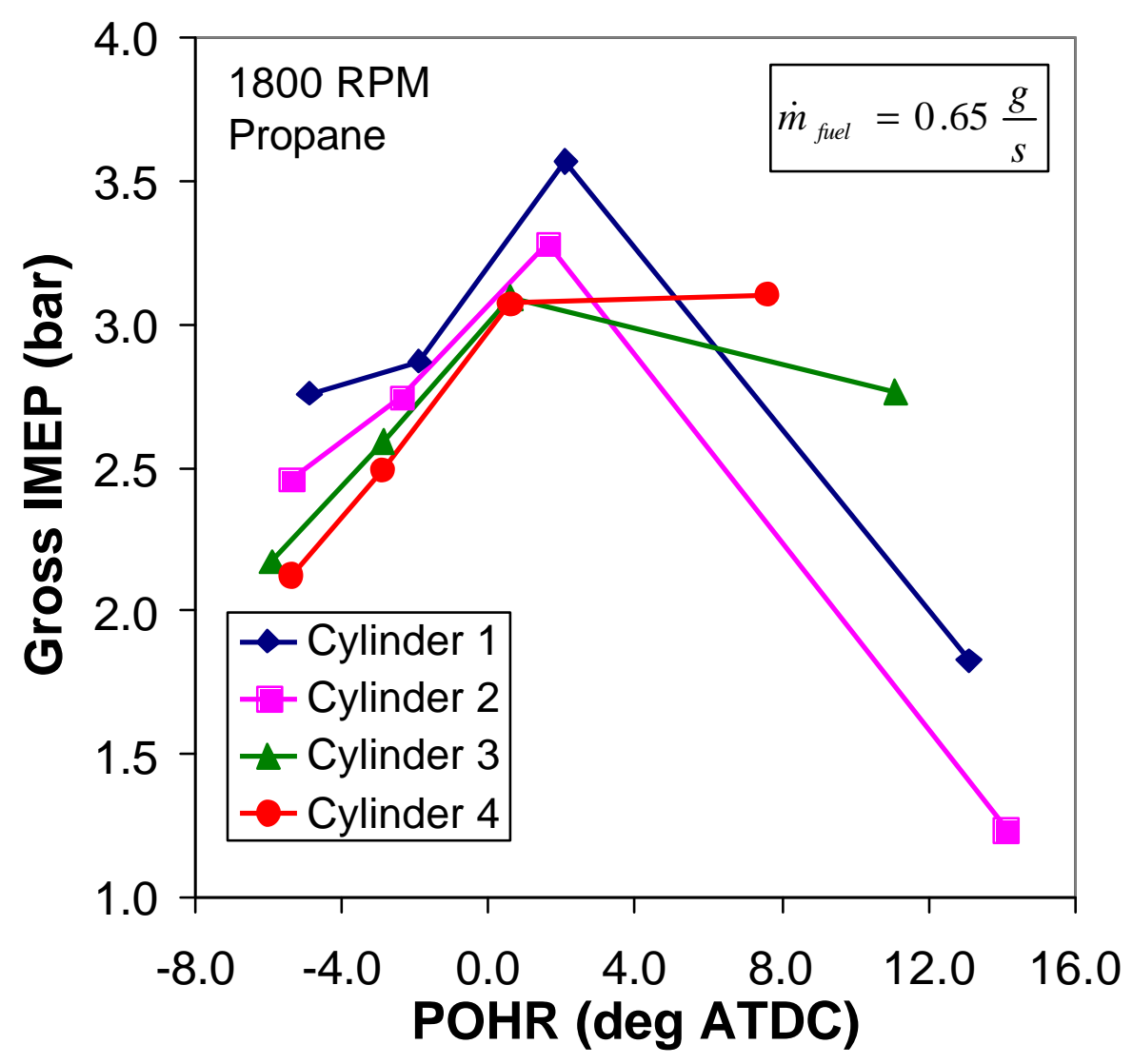

Figure 4.2.24 - Gross Indicated Mean Effective Pressure versus peak of heat release rate combustion timing for each cylinder at $0.65 \mathrm{~g} / \mathrm{s}$ fuel flow rate. 


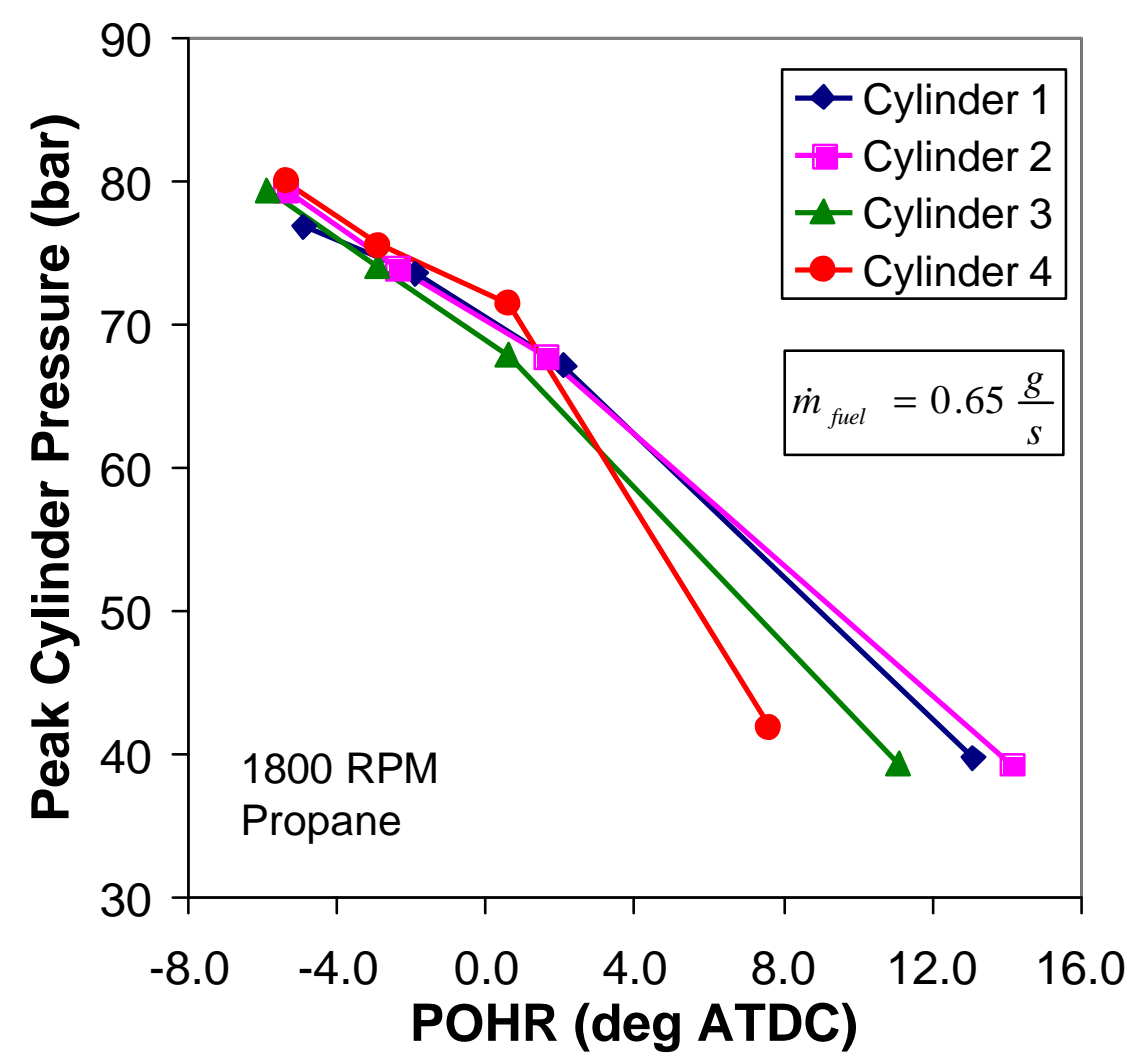

Figure 4.2.25 - Gross Indicated Mean Effective Pressure versus peak of heat release rate combustion timing for each cylinder at $0.65 \mathrm{~g} / \mathrm{s}$ fuel flow rate. 


\section{Conclusions and Discussion}

The focus of this research has been to characterize fundamental operational and design characteristics of HCCI engines. The methodology of applying both experiments and simulations to the HCCI combustion process has identified technical barriers and given insight into means to overcome these barriers.

Natural gas HCCI combustion was analyzed using a single-zone detailed chemical kinetics code adapted to simulate engine conditions. Two main issues were analyzed: the effect of natural gas composition on HCCI combustion; and the use of three control methodologies for obtaining satisfactory and reliable HCCI combustion. The three control methodologies studied were: addition of DME, intake gas preheat, and mixing with hot EGR. From these analyses the following conclusions can be drawn:

- HCCI combustion is sensitive to natural gas composition, and an active control will be required to compensate for possible changes in composition. Changes in natural gas composition may shift the peak heat release timing by as much as 10 crank angle degrees. This change would have a significant effect on emissions, peak cylinder pressure, and efficiency.

- A figure of merit has been obtained that represents to a good approximation the effect of higher hydrocarbons on HCCI combustion. The figure of merit is dominated by the mole fraction of propane and butane. 
- The three control strategies considered have a great effect in changing the combustion parameters for the engine, and should be able to control HCCI combustion. Optimum HCCI combustion (defined as combustion that results in maximum indicated efficiency) can be maintained over a wide range of operating conditions with these control strategies.

- The results indicate low peak power output per unit displacement. Supercharging beyond current typical values (beyond 2 bar absolute intake pressure) may be necessary to achieve values comparable to those obtained with naturally aspirated spark-ignited engines.

Multi-zone simulations were applied to investigate potential design changes for the multi-cylinder engine. These simulations results suggest:

- Lower surface-to-volume ratio geometry, like a pancake combustion chamber, may improve overall performance and emissions of HCCI engines relative to higher surface to volume ratio designs.

- Swirl has a relatively modest effect on performance that is due primarily to slightly reduced heat transfer.

- Multi-zone model predictions of HCCI engine could be improved by utilizing a larger number of zones. This would give a smoother heat release curve and could better resolve the formation of carbon monoxide. Current computational limitations make 
going to more than 10 zones difficult, but an improved solver (possibly a parallel solver) could relax this limitation.

- Improving the heat transfer model during expansion would improve the predictive capability of the multi-zone HCCI model, particularly in high heat transfer geometries like the TDI combustion chamber.

Single cylinder experiments have been performed on a CFR engine to study the effects of combustion timing on the HCCI combustion process for an isolated combustion chamber. Complimentary single zone simulations of the CFR experiments were performed to provide further clarify experimental results and to evaluate the consistency of the trends seen in modeling and experiments.

- The indicated efficiency increases as the combustion timing is delayed, while the IMEP tends to decrease as the timing is delayed.

- Hydrocarbon emissions increase with later combustion timing, but $\mathrm{NO}_{\mathrm{x}}$ emissions become very low with later combustion.

- HCT single zone chemical kinetics model shows trends similar to the experimental results in looking the relationship between combustion timing, equivalence ratio, efficiency, IMEP, and $\mathrm{NO}_{\mathrm{x}}$ emissions. 
- The single zone model was used to evaluate the bimodal nature of heat release in a two-component fuel. The kinetics of the mixture of a very high cetane number fuel and a low cetane number fuel show a two-stage heat release, particularly as the combustion timing moves later.

Operation of a multi-cylinder engine in HCCI mode has been investigated to characterize the operational characteristics and limits of operations.

- Operation from idle conditions to slightly over 3 bar BMEP has been achieved. The highest power output operating point tends to be approached as intake temperature is lowered and fuel flow rate is increased. A difference in combustion timing between the cylinders may be responsible for the inability to achieve higher BMEP. It is suspected that the current Diesel combustion chamber design promotes significant heat transfer (high swirl, unfavorable surface to volume ratio, very small clearance between much of the piston top and the head at TDC). High heat transfer could explain the relatively low peak indicated efficiency (32\%) for this engine.

- Specific emissions of hydrocarbons and carbon monoxide (mass flow of emissions relative to mass flow of fuel inducted) tend to decrease with increasing intake temperature or increasing fuel flow rate.

- At a specific intake manifold temperature the combustion timing for each cylinder can vary widely. At the lowest temperatures one cylinder can be firing very well while another may be not firing at all due to variations between the cylinders. When looking at a constant fuel flow rate the trend in combustion timing is not necessarily 
consistent (i.e. cylinder 4 will not always be the most advanced in timing as intake temperature increases).

- When viewing the data with respect to combustion timing, the trends in burn duration, and peak cylinder pressure appear to correlate well. The overall trend in IMEP seems relatively consistent between the cylinders, but the spread in values at particular combustion timing is large. Variations between the cylinders such as individual cylinder intake temperature, compression ratio, wall temperature, etc. are proposed as possible factors that could contribute to the variation in IMEP.

- Key to further improving performance of the engine is controlling individual cylinder combustion timing. Minimizing phasing differences between the cylinders is likely necessary to achieve higher BMEP.

It is still unclear whether the potential of HCCI engines will be realized. A robust control method must be developed that can handle the necessary duty cycle, variations in fuel composition, variations in ambient temperature and pressure, as well as engine wear and life issues. An HCCI engine for a conventional automotive powertrain may be the most difficult to implement because of the wide operating range required. Stationary power applications or series hybrid applications may require less sophisticated control systems. Engines for series hybrid automotive powertrains have similar operating requirements to stationary powerplants in that the engine is operated at a few (typically one or two) speed-load points. The energy generated by the engine is stored in batteries that are used to drive electric motors that drive the wheels. The most practical means of control is likely to utilize hot residual gas to control combustion timing, likely at the 
expense of power per displacement volume. Control systems that require additives or multiple fuels are likely to be too cumbersome for widespread use. The intake charge could be heated through direct mixing of residual gas or by passing hot residual gas and intake charge through a heat exchanger. A direct mixing approach likely has the best time response.

The low power per displacement volume in HCCI engines must be addressed. Turbocharging or supercharging to high levels should be explored, as should operating in an HCCI mode under certain conditions and transitioning to spark-ignited or Diesel mode as needed. High boost engines may have durability and cost issues associated with them. Engines operating in multiple modes (HCCI/SI or HCCI/Diesel) are subject to limitations of current engines, such as knock (SI engines) and high particulate and $\mathrm{NO}_{\mathrm{x}}$ emissions (Diesel Engines). Multi-mode operation could also be a practical solution to startup.

Despite its challenges, HCCI has the potential to be a viable alternative for improving efficiency and reducing emissions in piston engines. The understanding of the physical processes occurring, along with the ability to simulate these processes with high fidelity, should provide greater leverage towards the advancement of this technology than was ever available in the development of previous engine technologies. 


\section{References}

1. Hallworth, K., From Our Archive, in The Classic Motorcycle, July 2000, p. 12-16.

2. Hiltner, J., Agama, R., Mauss, F., Christensen, M. and Johansson, B. 2000, " HCCI Operation with Natural Gas: Fuel Composition Implications," in ASME 2000 ICE Fall Technical Conference, Paper 2000-ICE-317.

3. Noguchi, M., Tanaka, Y., Tanaka, T. and Takeuchi, Y., 1979, "A Study on Gasoline Engine Combustion by Observation of Intermediate Reactive Products During Combustion," SAE Paper 790840.

4. Onishi, S., Jo, S.H., Shoda, K., Jo, P.D. and Kato, S., 1979, "Active ThermoAtmosphere Combustion (ATAC) - A New Combustion Process for Internal Combustion Engines," SAE Paper 790501.

5. Iida, N., 1994, "Combustion Analysis of Methanol-Fueled Active ThermoAtmosphere Combustion (ATAC) Engine Using a Spectroscopic Observation," SAE Paper 940684.

6. Richhter, M., Alden, M., Hultqvist, A. and Johansson, B., 1999, "Optical Diagnostics Applied to a Naturally Aspirated Homogeneous Charge Compression Ignition Engine," SAE Paper 1999-01-3649.

7. Hultqvist, A., Christensen, M., Johansson, B., Franke, A., Richhter, M. and Alden, M., 1999, "A Study of the Homogeneous Charge Compression Ignition Combustion Process by Chemiluminescence Imaging," SAE Paper 1999-01-3680.

8. Ishibashi, Y. and Asai, M., 1996, "Improving the Exhaust Emissions of TwoStroke Engines by Applying the Activated Radical Concept," SAE Paper 960742.

9. Honda Readies Activated Radical Combustion Two-Stroke Engine for Production Motorcycle, in Automotive Engineering, December 1997, p. 101-102.

10. Ishibashi, Y. and Asai, M., 1998, "A Low Pressure Pneumatic Direct Injection Two-Stroke Engine by Activated Radical Combustion Concept," SAE Paper 980757.

11. Najt, P.M. and Foster, D.E., 1983, "Compression-Ignited Homogeneous Charge Combustion," SAE Paper 830264.

12. Thring, R.H., 1989, "Homogeneous Charge Compression Ignition (HCCI) Engines," SAE Paper 892068.

13. Ryan, T.W. and Callahan, T.J., 1996, "Homogeneous Charge Compression Ignition of Diesel Fuel," SAE Paper 961160. 
14. Suzuki, H., Koike, N., Ishii, H. and Odaka, M., 1997, "Exhaust Purification of Diesel Engines by Homogeneous Charge with Compression Ignition Part 1: Experimental Investigation of Combustion and Exhaust Emission Behavior Under Pre-Mixed Homogeneous Charge Compression Ignition Method," SAE Paper 970313.

15. Yanagihara, H., Sato, Y. and Mizuta, J., 1996, "A simultaneous reduction of NOx and Soot in Diesel Engines Under a New Combustion System (Uniform Bulky Combustion System - UNIBUS)," Proceedings of the 17th Vienna Motor Symposium (1996).

16. Tekada, Y., Nakagome, K. and Niimura, N., 1996, "Emission Characteristics of Premixed Lean Diesel Combustion with Extremely Early Staged Fuel Injection," SAE Paper 961163.

17. Nakagome, K., Naoki, S., Niimura, N. and Kobayashi, S., 1997, "Combustion and Emission Characteristics of Premixed Lean Diesel Combustion Engine," SAE Paper 970898.

18. Suzuki, H., Koike, N. and Odaka, M., 1998, "Combustion Control Method of Homogeneous Charge Diesel Engines," SAE Paper 980509.

19. Harada, A., Shimazaki, N., Sasaki, S., Miyamoto, T., Akagawa, H. and Tsujimura, K., 1998, "The Effects of Mixture Formation on Premixed Lean Diesel Combustion," SAE Paper 980533.

20. Hashizume, T., Miyamoto, T., Akagawa, H. and Tsujimura, K., 1998, "Combustion and Emission Characteristics of Multiple Stage Diesel Combustion," SAE Paper 980505.

21. Shimazaki, N., Akagawa, H. and Tsujimura, K., 1999, "An Experimental Study of Premixed Lean Diesel Combustion," SAE Paper 1999-01-0181.

22. Odaka, M., Suzuki, H., Noriyuki, K. and Hajime, I., 1999, "Search for Optimizing Control Method of Homogeneous Charge Diesel Combustion," SAE Paper 199901-0184.

23. Iwabuchi, Y., Kawai, K., Takeshi, S. and Takeda, Y., 1999, "Trial of New Concept Diesel Combustion System - Premixed Compression-Ignited Combustion," SAE Paper 1999-01-0185.

24. Miyamoto, T., Hayashi, A.K., Harada, A., Sasaki, S., Hisashi, A. and Tujimura, K., 1999, "A Computational Investigation of Premixed Lean Diesel Combustion," SAE Paper 1999-01-0229.

25. Kimura, S., Aoki, O., Ogawa, H., Muranaka, S. and Enomoto, Y., 1999, "New Combustion Concept for Ultra-Clean and High-Efficiency Small DI Diesel Engines," SAE Paper 1999-01-3681. 
26. Kimura, S., Osamu, A., Kitahara, Y. and Aiyoshizawa, E., 2001, "Ultra-Clean Combustion Technology Combining a Low-Temperature and Premixed Combustion Concept for Meeting Future Emission Standards," SAE 2001-010200 .

27. Iida, N., 1997, "Alternative Fuels and Homogeneous Charge Compression Ignition," SAE Paper 972071 (JSAE 9734043).

28. Thring, R.H. and Leet, J.A., 1991, "The Stratified Charge Glowplug Ignition (SCGI) Engine with Natural Gas Fuel," SAE Paper 911767.

29. Hultqvist, A., Christensen, M. and Johansson, B., 2000, "The Application of Ceramic and Catalytic Coatings to Reduce the Unburned HC Emissions from HCCI Engines," SAE Paper 2000-01-1833.

30. Richhter, M., Engström, J., Franke, A., Alden, M., Hultqvist, A. and Johansson, B., 2000, "The Influence of Charge Inhomogeneity on the HCCI Combustion Process," SAE Paper 2000-01-2868.

31. Olsonn, J.-O., Erlandsson, O. and Johansson, B., 2000, "Experiments and Simulation of a Six-Cylinder Homogeneous Charge Compression Ignition (HCCI) Engine," SAE Paper 2000-01-2867.

32. Christensen, M. and Johansson, B., 1999, "Homogeneous Charge Compression Ignition with Water Injection," SAE Paper 1999-01-0182.

33. Christensen, M., Hultqvist, A. and Johansson, B., 1999, "Demonstrating Multi Fuel Capability of a Homogeneous Charge Compression Ignition Engine with Variable Compression Ratio," SAE Paper 1999-01-3679.

34. Christensen, M. and Johansson, B., 1998, "Influence of Mixture Quality on Homogeneous Charge Compression Ignition," SAE Paper 982454.

35. Christensen, M., Johansson, B., Amneus, P. and Mauss, F., 1998, "Supercharged Homogeneous Charge Compression Ignition," SAE Paper 980787.

36. Westbrook, C.K., Warnatz, J. and Pitz, W.J. 1988, " A Detailed Chemical Kinetic Reaction Mechanism for the Oxidation of iso-Octane and n-Heptane over an Extended Temperature Range and its Application to Analysis of Engine Knock," in Twenty-Second Symposium (International) on Combustion, p. 893, The Combustion Institute, Pittsburgh.

37. Westbrook, C.K., Pitz, W.J. and Leppard, W.R., 1991, "The Autoignition Chemistry of Paraffinic Fuels and Pro-Knock and Anti-Knock Additives: A Detailed Chemical Kinetic Study," SAE Paper 912314. 
38. Pitz, W.J., Westbrook, C.K. and Leppard, W.R., 1991, "Autoignition Chemistry of C4 Olefins Under Motored Engine Conditions: A Comparison of Experimental and Modeling Results," SAE Paper 912315.

39. Curran, H.J., Gaffuri, P., Pitz, W.J., Westbrook, C.K. and Leppard, W.R., 1995, "Autoignition Chemistry of the Hexane Isomers: An Experimental and Kinetic Modeling Study," SAE Paper 952406.

40. Curran, H.J., Pitz, W.J., Westbrook, C.K., Dagaut, P., Boettner, J.-C. and Cathonnet, M., 1998, " A Wide Ranging Study of Dimethyl Ether Oxidation," International Journal of Chemical Kinetics, Vol 30, No. 3, p. 229-241.

41. Curran, H.J., Gaffuri, P., Pitz, W.J. and Westbrook, C.K., 1998, " A Comprehensive Modeling Study of n-Heptane Oxidation," Combustion and Flame, Vol 114, p. 114-177, see also: http://wwwcms.llnl.gov/combustion/combustion_home.html.

42. Smith, J.R., Aceves, S.M., Westbrook, C.K. and Pitz, W.J., 1997, "Modeling of Homogeneous Charge Compression Ignition (HCCI) of Methane," Proceedings of the 1997 ASME Internal Combustion Engine Fall Technical Conference, ICEVol. 29-3, Paper 97-ICE-68, pp. 85-90.

43. Aceves, S.M., Smith, J.R., Westbrook, C.K. and Pitz, W.J., 1999, " Compression Ratio Effect on Methane HCCI Combustion," Journal of Engineering for Gas Turbines and Power, Vol 121, No. 3.

44. Aceves, S.M., Flowers, D.L., Westbrook, C.K., Smith, J.R., Dibble, R.W., Pitz, W.J., Christensen, M. and Johansson, B., 2000, "A Multizone Simulation for Prediction of HCCI combustion and Emissions," SAE paper 2000-01-0327.

45. Aceves, S.M., Flowers, D.L., Martinez-Frias, J., Smith, J.R., Westbrook, C.K., Pitz, W.J. and Dibble, R.W., 2001, "Multi-Zone Analysis of Propane HCCI Combustion," SAE Paper 2001-01-1027.

46. Maigaard, P., Mauss, F. and Kraft, M. 2000, " Homogeneous Charge Compression Ignition Engine: A Simulation Study on the Effects of Inhomogeneities," in ASME 2000 ICE Spring Technical Conference, Paper 2000-ICE-275.

47. Fiveland, S.B. and Assanis, D.N., 2001, "Development of a Two-Zone HCCI Combustion Model Accounting for Boundary Layer Effects," SAE Paper 200101-1028.

48. Easley, W.L., Agarwal, A. and Lavoie, G., 2001, "Modeling HCCI Combustion and Emissions Using Detailed Chemistry," SAE Paper 2001-01-1029. 
49. Noda, T. and Foster, D.E., 2001, "A Numerical Study to Control Combustion Duration of Hydrogen-fueled HCCI by Using Multi-zone Chemical Kinetics Simulation," SAE Paper 2001-01-0250.

50. Woschni, G., 1967, "Universally Applicable Equation for the Instantaneous Heat Transfer Coefficient in the Internal Combustion Engine," SAE Paper 670931.

51. Kong, S.-C., Marriott, C.D., Reitz, R.D. and Christensen, M., 2001, "Modeling and Experiments of HCCI Engine Combustion Using Detailed Chemical Kinetics with Multidimensional CFD," SAE Paper 2001-01-1026.

52. Kong, S.-C. and Reitz, R.D. 2000, " Use of Detailed Chemical Kinetics to Study HCCI Engine Combustion With Consideration of Turbulent Mixing Effects," ASME 2000 ICE Fall Technical Conference, Paper 2000-ICE-306.

53. Tsurushima, T., Miyamoto, T., Akagawa, H., Aoyagi, Y., Lee, J.-H., Lee, D., Goto, S., Wakisaka, T., Ishiyama, T. and Kawanabe, H., 2000, "Effects of Initial In-Cylinder Flow Field on Mixture Formation in a Premixed Compression Ignition Engine," SAE Paper 2000-01-0331.

54. Fiveland, S.B. and Assanis, D.N., 2000, "A Four-Stroke Homogeneous Charge Compression Ignition Engine Simulation for Combustion and Performance Studies," SAE Paper 2000-01-0332.

55. Martinez-Frias, J., Aceves, S.M., Flowers, D.L., Smith, J.R. and Dibble, R.W., 2000, "HCCI Engine Control By Thermal Management," SAE Paper 2000-012869.

56. Law, D., Kemp, D., Allen., J., Kirkpatrick, G. and Copland, T., 2001, "Controlled Combustion in and IC-Engine with a Fully Variable Valve Train," SAE Paper 2001-01-0251.

57. Kontarakis, G., Collings, N. and Ma, T., 2000, "Demonstration of HCCI Using a Single Cylinder Four-stroke SI Engine with Modified Valve Timing," SAE Paper 2000-01-2870.

58. Stanglmaier, R.H., Ryan, T.W. and Souder, J.S., 2001, "HCCI Operation of a Dual-Fuel Natural Gas Engine For Improved Fuel Efficiency and Ultra-Low NOx Emissions at Low and Moderate Loads," SAE Paper 2001-01-1897.

59. Olsonn, J.-O., Tunestal, P. and Johansson, B., 2001, "Closed-Loop Control of an HCCI Engine," SAE Paper 2001-01-1031.

60. Lund, C.M., 1978, "HCT - A General Computer Program for Calculating TimeDependent Phenomena Involving One-Dimensional Hydrodynamics, Transport, and Detailed Chemical Kinetics," Lawrence Livermore National Laboratory report UCRL-52504. 
61. Kee, R.J., Rupley, F.M., Meeks, E. and Miller, J.A., 1996, "CHEMKIN-III: A FORTRAN Chemical Kinetics Package for the Analysis of Gas-Phase Chemical and Plasma Kinetics," Sandia National Laboratory Report SAND96-8216.

62. Heywood, J.B., 1988, Internal Combustion Engine Fundamentals, McGraw-Hill Inc., New York, NY.

63. Amsden, A.A., 1997, "KIVA-3V: A Block-Structured KIVA Program for Engines with Vertical or Canted Valves," Los Alamos National Laboratory Report LA13313-MS.

64. Amsden, A.A., 1993, "KIVA-3: A KIVA Program with Block-Structured Mesh for Complex Geometries," Los Alamos National Laboratory Report LA-12503MS.

65. Frenklach, M., Wang, H., Goldenberg, M., Smith, G.P., Golden, D.M., Bowman, C.T., Hanson, R.K., Gardiner, W.C. and Lissianski, V., 1995, "GRI-Mech - An Optimized Detailed Chemical Reaction Mechanism for Methane Combustion," GRI Topical Report No. GRI-95/0058.

66. Liss, W.E., Thrasher, W.H., Steinmetz, G.F., Chowdiah, P. and Attari, A., 1992, "Variability of Natural Gas Composition in Select Major Metropolitan Areas of the United States," Gas Research Institute Report No. GRI-92/0123.

67. Warnatz, J., Maas, U. and Dibble, R.W., 2000, Combustion: Physical and Chemical Fundamentals, Modeling and Simulation, Experiments, Pollutant Formation, Vol. 2, Springer-Verlag. 


\section{Appendix A Definition and Calculation of Residual Gas Fraction}

For a general oxygenated fuel a fraction of recycled exhaust gas, EGR, is defined by the expression below:

$$
\begin{gathered}
(1-E G R)\left[\phi_{i n} C_{x} H_{y} O_{z}+\left(x+\frac{y}{4}-\frac{z}{2}\right)\left(O_{2}+3.76 N_{2}\right)\right] \\
+E G R\left[x \phi_{i n} C O_{2}+\frac{y}{2} \phi_{i n} H_{2} O+\left(x+\frac{y}{4}-\frac{z}{2}\right)\left(1-\phi_{i n}\right) O_{2}+3.76\left(x+\frac{y}{4}-\frac{z}{2}\right) N_{2}\right] \\
\longrightarrow\left[x \phi_{i n} C O_{2}+\frac{y}{2} \phi_{i n} H_{2} O+\left(x+\frac{y}{4}-\frac{z}{2}\right)\left(1-\phi_{i n}\right) O_{2}+3.76 N_{2}\right]
\end{gathered}
$$

The intake equivalence ratio, $\phi_{\text {in }}$, is defined based upon the ratio of fuel to fresh $\mathrm{O}_{2}$ inducted before the addition of EGR to the stoichiometric ratio of fuel to $\mathrm{O}_{2}$. For the general fuel $\mathrm{C}_{\mathrm{x}} \mathrm{H}_{\mathrm{y}} \mathrm{O}_{z}$, the stoichiometric fuel-Oxygen ratio ratio is:

$$
\left(\frac{\text { Fuel }}{\mathrm{O}_{2}}\right)_{\text {stoich }}=\frac{1}{\left(x+\frac{y}{4}-\frac{z}{2}\right)}
$$

Assuming $(1-E G R) \phi_{\text {in }}$ moles of fuel are added to the engine, the molar quantities of the intake charge (fresh charge + recycled exhaust gas) are:

$$
\begin{aligned}
& n_{\text {fuel }}=\phi_{\text {in }}(1-E G R) \\
& n_{O_{2}}=\left(x+\frac{y}{4}-\frac{z}{2}\right)(1-E G R)+\left(x+\frac{y}{4}-\frac{z}{2}\right) E G R\left(1-\phi_{\text {in }}\right)=\left(x+\frac{y}{4}-\frac{z}{2}\right)\left(1-E G R \cdot \phi_{\text {in }}\right)
\end{aligned}
$$

The ratio of fuel to Oxygen in the engine is: 


$$
\frac{\text { Fuel }}{O_{2}}=\frac{\phi_{\text {in }}(1-E G R)}{\left(x+\frac{y}{4}-\frac{z}{2}\right)\left(1-E G R \cdot \phi_{\text {in }}\right)}
$$

The in-cylinder equivalence ratio, defined as the ratio of fuel to oxygen in the cylinder relative to the stoichiometric fuel to oxygen ratio is:

$$
\phi_{\text {in }-c y l}=\frac{\left(\frac{F u e l}{O_{2}}\right)}{\left(\frac{F u e l}{O_{2}}\right)_{\text {stoich }}}=\left[\frac{\phi_{\text {in }}(1-E G R)}{\left(x+\frac{y}{4}-\frac{z}{2}\right)\left(1-E G R \cdot \phi_{i n}\right)}\right] /\left[\frac{1}{\left(x+\frac{y}{4}-\frac{z}{2}\right)}\right]
$$

or:

$$
\phi_{i n-c y l}=\frac{\phi_{i n}(1-E G R)}{1-E G R \cdot \phi_{i n}}
$$

The above expression for in cylinder equivalence ratio applies to any fuel. It is important to note that in general the parameter $E G R$ is not equal to the mole fraction of residual gas, $X_{\text {resid }}$, added to the cylinder, although they are very close. The relationship between $E G R$ and $X_{\text {resid }}$ is shown below. Again, based on $(1-E G R) \phi_{\text {in }}$ moles of fuel, the mole fractions of residual gas in the intake flow and the total moles in the intake stream can be determined. 


$$
\begin{aligned}
n_{\text {resid }} & =E G R\left[x \phi_{\text {in }}+\frac{y}{2} \phi_{\text {in }}+\left(x+\frac{y}{4}-\frac{z}{2}\right)\left(1-\phi_{\text {in }}\right)+3.76\left(x+\frac{y}{4}-\frac{z}{2}\right)\right] \\
& =E G R\left[x \phi_{\text {in }}+\frac{y}{2} \phi_{\text {in }}-\left(x+\frac{y}{4}-\frac{z}{2}\right) \phi_{\text {in }}+4.76\left(x+\frac{y}{4}-\frac{z}{2}\right)\right] \\
& =E G R\left[\left(\frac{y}{4}+\frac{z}{2}\right) \phi_{\text {in }}+4.76\left(x+\frac{y}{4}-\frac{z}{2}\right)\right] \\
n_{\text {total }} & =(1-E G R)\left[\phi_{\text {in }}+\left(x+\frac{y}{4}-\frac{z}{2}\right)(4.76)\right]+E G R\left[x \phi_{\text {in }}+\frac{y}{2} \phi_{\text {in }}+\left(x+\frac{y}{4}-\frac{z}{2}\right)\left(1-\phi_{\text {in }}\right)+3.76\left(x+\frac{y}{4}-\frac{z}{2}\right)\right] \\
& =(1-E G R)\left[\phi_{\text {in }}+\left(x+\frac{y}{4}-\frac{z}{2}\right)(4.76)\right]+E G R\left[\left(\frac{y}{4}+\frac{z}{2}\right) \phi_{\text {in }}+4.76\left(x+\frac{y}{4}-\frac{z}{2}\right)\right] \\
& =(1-E G R) \phi_{\text {in }}+E G R\left(\frac{y}{4}+\frac{z}{2}\right) \phi_{\text {in }}+4.76\left(x+\frac{y}{4}-\frac{z}{2}\right) \\
& =\phi_{\text {in }}+E G R\left(\frac{y}{4}+\frac{z}{2}-1 \phi_{\text {in }}+4.76\left(x+\frac{y}{4}-\frac{z}{2}\right)\right.
\end{aligned}
$$

Thus the mole fraction of residual gas is:

$$
X_{\text {resid }}=\frac{E G R\left[\left(\frac{y}{4}+\frac{z}{2}\right) \phi_{i n}+4.76\left(x+\frac{y}{4}-\frac{z}{2}\right)\right]}{\phi_{\text {in }}+E G R\left(\frac{y}{4}+\frac{z}{2}-1\right) \phi_{\text {in }}+4.76\left(x+\frac{y}{4}-\frac{z}{2}\right)}
$$

\section{Examples}

For methane $\left(\mathrm{CH}_{4}, \mathrm{x}=1, \mathrm{y}=4, \mathrm{z}=0\right)$ : 


$$
\begin{aligned}
X_{\text {resid }}= & \frac{E G R\left[\left(\frac{(4)}{4}+\frac{(0)}{2}\right) \phi_{i n}+4.76\left((1)+\frac{(4)}{4}-\frac{(0)}{2}\right)\right]}{\phi_{\text {in }}+E G R\left(\frac{(4)}{4}+\frac{(0)}{2}-1\right) \phi_{i n}+4.76\left((1)+\frac{(4)}{4}-\frac{(0)}{2}\right)} \\
= & \frac{E G R\left[\phi_{\text {in }}+4.76(2)\right]}{\phi_{\text {in }}+4.76(2)} \\
= & E G R
\end{aligned}
$$

Thus the residual gas fraction, $X_{\text {resid }}$, is identically equal to $E G R$ for methane.

This applies to any fuel where $(y / 4+z / 2)=1$, such as dimethyl-ether $\left(\mathrm{C}_{2} \mathrm{H}_{6} \mathrm{O}\right)$ or Ethylene $\left(\mathrm{C}_{2} \mathrm{H}_{4}\right)$

For Propane $\left(\mathrm{C}_{3} \mathrm{H}_{8}, \mathrm{x}=3, \mathrm{y}=8, \mathrm{z}=0\right)$ :

$$
\begin{aligned}
X_{\text {resid }} & =\frac{E G R\left[\left(\frac{(8)}{4}+\frac{(0)}{2}\right) \phi_{i n}+4.76\left((3)+\frac{(8)}{4}-\frac{(0)}{2}\right)\right]}{(1-E G R) \phi_{i n}+E G R\left(\frac{(8)}{4}+\frac{(0)}{2}\right) \phi_{i n}+4.76\left((3)+\frac{(8)}{4}-\frac{(0)}{2}\right)} \\
& =\frac{E G R\left[2 \phi_{i n}+4.76(5)\right]}{(1-E G R) \phi_{i n}+E G R(2) \phi_{i n}+4.76(5)} \\
= & \frac{E G R\left[2 \phi_{i n}+4.76(5)\right]}{\phi_{\text {in }}+E G R \phi_{i n}+4.76(5)}
\end{aligned}
$$

The residual gas fraction, $X_{\text {resid }}$, is not identically equal to $E G R$ in this case.

Figure A.1 shows the deviation of the residual gas fraction for various intake equivalence ratios $\left(\phi_{\text {in }}\right.$, or phi-in in the figure). The maximum deviation is $5 \%$ at very low values of $E G R$, which may be within the accuracy of experimental measurement. 


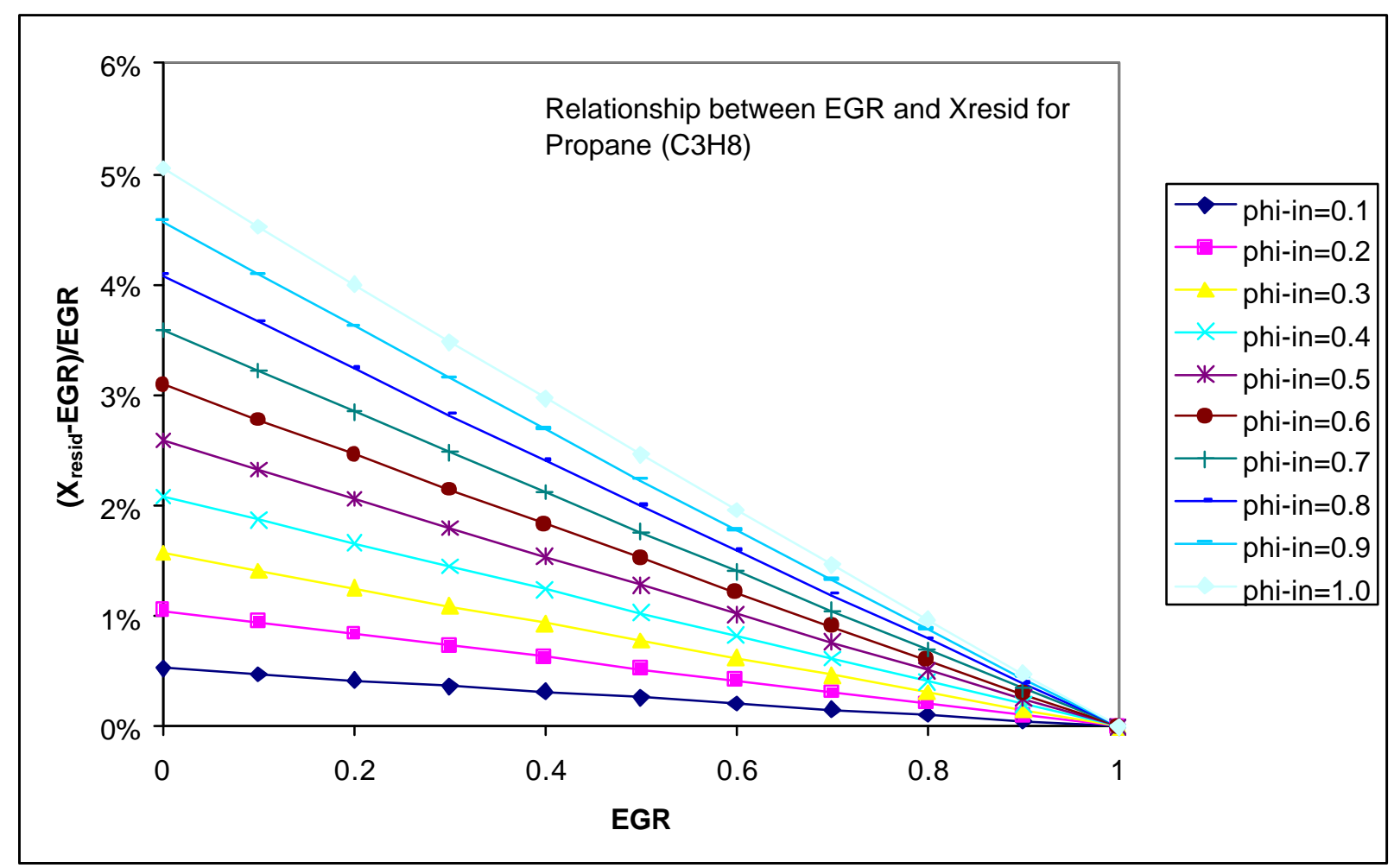

Figure A.1 - Percentage difference between $X_{\text {resid }}$ and $E G R$ for propane fuel for the range of equivalence ratio from 0.1 to 1.0 . 


